\title{
A Critical Age: Single Motherhood, Male Continuity, And the Making OF FAMILY AND NATION IN ISRAEL
}

\author{
Jennie Carmel Doberne \\ Los Angeles, CA
}

M.A. Anthropology, University of Virginia, 2009

B.A. Religion, Wesleyan University, 2001

A Dissertation presented to the Graduate Faculty of the University of Virginia in Candidacy for the Degree of

Doctor of Philosophy

Department of Anthropology

University of Virginia

May 2014 
For my family 


\section{TABLE OF CONTENTS}

$\begin{array}{ll}\text { Introduction } & 4\end{array}$

PART ONE: MAKING FAMILY

1. A Single Mother Family? $\quad 48$

2. "Revaka + 2": Single Mothers and the Multiple Meanings of Children 89

3. "A Syringe and a Cup": Making Families through Shared Parenting 135

PART TWO: MAKING NATION

4. Establishing a Loyal House: The "National Problem" of Older Single Women 180

5. "Let Israel Remember": National Sacrifice and the Logic of Male Continuity 228

The Single-Mother Family and Male Continuity 276

$\begin{array}{ll}\text { Acknowledgments } & 286\end{array}$

$\begin{array}{ll}\text { Notes } & 287\end{array}$

$\begin{array}{ll}\text { Bibliography } & 293\end{array}$ 


\section{INTRODUCTION}

"What do you mean by later motherhood?" asked Dorit, the head nurse at an in vitro fertilization (IVF) unit south of Tel Aviv. "I want to learn about the experiences of Israeli women in their late 30s and beyond who are trying to become mothers" I said. I had come to Israel to study technologically-assisted later motherhood. Not only does this small country of seven million people have more fertility clinics per capita and more annual cycles of treatment than anywhere else in the world, it also has one of the most lenient health care policies when it comes to older women: any Israeli woman can receive subsidized treatment up to the age of 54 . "Ok, but what do you mean, exactly? Because there are two situations: there is the older couple (zug), but they are a couple and there is an older woman. There is parenthood at an older age (horut b'gil mevugar) and single motherhood (horut yehidanit). But those are two different situations entirely! Here in Israel you have to separate them into two groups."

The phone rang and Dorit extended her hand forward, drawing together her thumb into a cradle formed by her fingers, gesturing hold on. I was confused by Dorit's distinction. When it came to the medical dimensions of fertility treatment, presumably married and single women of the same age shared much in common.

"What do you mean by two different situations?" I asked Dorit after she hung up. "The couple, they started young. They started on time, from the moment that they discovered a fertility problem. They weren't lazy, they were always in treatments, and only after many years did they, without a choice, enter the category of being older parents. The single woman, she never did treatments when she was younger. She started older, because she hasn't found a male partner (ben zug)....But it's not like a married couple. The coping [in her situation] is entirely different....What will you say to the child?" 
Regardless of marital status, all Israeli women have access to state-subsidized assisted reproductive technologies until the birth of two children or age 54. Over the last decade, the number of women becoming mothers on their own has steadily grown. The number of "never before married" single mothers (ravakot) grew from 8,400 in 2000 to 13,500 in 2011 —an increase of 60 percent (CBS 2011). There were 2,600 children born to never before married single mothers in 2000 and 5,050 children born in 2011 (CBS 2011). ${ }^{1}$ In fertility clinics I visited between 2009-2011, health care professionals estimated that 25-30 percent of their patients were ravakot. Everywhere I went, Israelis told me that, today, single motherhood is "accepted" (mekubal) for women of a certain age. For this reason, Dorit's insistence that later single motherhood was entirely different than later parenthood struck me. She continued:

Today we don't look at [single mothers] and say, "Oy a mother alone (levad), raising a child alone, there's no husband." It's not a couple that something happened to the father in war or in an accident or something. It's suddenly (pitom) a 40-year-old woman who decides to bring a child into the world. It's not strange today. The family cell ( $\mathrm{ta}$ mishpahti) is changing today. There is what I call "different parenthood" (horut aheret). Two mothers, two fathers, divorcees and single women (ravakot)...

Now Dorit seemed to be saying the opposite, acknowledging that Israeli society and the very idea of family (or in her words, "family cell”) are undergoing significant changes. Gay parenthood has become more prevalent, as has single motherhood, particularly through anonymous donor insemination. Israelis sometimes refer to these new family forms with the expression "different parenthood." Insofar as single motherhood is no longer strange (particularly in the IVF clinic) then what troubled this veteran nurse about a woman who "suddenly" decides to have a child on her own?

Somehow the older, single woman disrupted a sense of timing, of doing things in the right order, of "starting on time." In Dorit's account, the revaka arrives at the clinic after she decides to have a child; in contrast, the married couple begins treatment without a choice. Did 
they, too, not "choose" to have a child? Choice seemed to be at the heart of the veteran nurse's thinking about assisted reproduction and the resulting families. Similarly, her categories differentiated between becoming "a mother alone" as the consequence of loss and deciding to become a single mother. Without relationships to known men, families made through women's choices alone were unsettling.

A nurse in aqua scrubs opened the door and thrust a chart into Dorit's hands, explaining that the patient wanted to talk about the prescribed hormone protocol. "Look," Dorit said to me as she flipped through the top pages of the chart_- "here is a classic case... a lone woman, age 40 (isha bodedet, bat 40)." She picked up the receiver, pressed the flashing red button, and asked the woman on the other end, "How can I help you?"

\section{$1+$ Child?}

A Critical Age is my journey to understand the seeming contradictions that emerged out of my conversations with Israelis when I asked them about "motherhood at a later age" or "later motherhood" (imahut b'gil mitkadem, imahut meuheret) - terms that I came to learn meant many things at once. Dorit, like others with whom I shared my initial research plans, insisted that later motherhood among single Israeli women was an entirely different situation from that of later motherhood among Israeli women with male partners. For this reason, she balked at my proposal to study "later motherhood in Israel." As I later came to realize, our categories privileged entirely different dimensions: I concentrated on the aging female body, while Dorit focused on a woman's relations with those around her. What seemed to matter most to Dorit, like other Israelis I met, was a mother's situatedness within family and her connection to a known man, whether living or deceased. 
As the possibility of becoming a single mother has expanded, so have the ways Israelis of different backgrounds conceive of both the potential and the uncertainty of the "single-mother family." Across Israeli communities, the "phenomenon" of older, unmarried single women becoming mothers through anonymous sperm donation invites all kinds of solutions. These range from the mundane (matchmaking services) to the emergent (partnering with gay men, egg freezing) to the truly unusual (polygamous marriage, posthumous sperm donation). Found in abundance in popular discourses, these "solutions" to the so-called problem of later singlehood draw on technological interventions, Jewish religious tradition, Israeli modernity, and national sacrifice. What this overlapping conceptual territory appears to hold in common is the enduring salience of men's contribution to procreation and the making of Israeli family.

Motherhood, as many scholars have demonstrated, is conceived of as a national obligation in Israel, an "entrance card to participation in the collective" (e.g., Berkovitch 1999:278; Kahn 2000; Remennick 2000; Teman 2010). As one interviewee who had a child when she was 40 told me, "Here [motherhood] is part of your identity entirely. [It's how] people introduce themselves, you'll see. And women, even managers say 'Shalom, I'm so-and-so, married with three children.'” Bank tellers, receptionists, and government clerks hang photographs of children and family members in their cubicles. Business magazines feature articles about successful female entrepreneurs and leaders - here too, I noticed that these stories always highlighted information about their children. This personal information accompanies one everywhere. For example, when friends gave me input on revising my CV, they insisted, in spite of my objections, that I add my personal information to the first lines: date of birth, number of children and marital status. 
The extensive state-supported program of assisted conception and its inclusion of both older and single women encourages motherhood. Since Jewishness is passed matrilineally (from mother to child), then in terms of religious law the absence of men should not matter when it comes to "reproducing Jews" (see Kahn 2000). And given the demographic struggle between Jews and Palestinians within Israel's borders and beyond (Kanaaneh 2002; Yuval-Davis 1997), presumably making more Jews, however accomplished, is a contribution to Jewish-Israeli society, still referred to by many as the "collective" (hakolectiv). Yet despite their increasing numbers, single-mother families are not included in the same way as families with a father, mother and children. Israeli women who become mothers without getting married inhabit a “deeply ambivalent social identity” (Sa'ar 2009:454). If motherhood was supposedly the “entrance card" to Israeli society, why didn't single-mother families_- "one + child"_-gain full admission?

With those around me insisting that I was setting out to study "two different things," I became interested in the question: what is the difference between later parenthood and single (later) motherhood? As I listened to my informants' objections, interjections, questions and frustrations, I reframed the focus of my research from "technologically-assisted later motherhood" to the creation of families by single mothers. Even as constellations of Israeli family are becoming more heterogeneous, why does the presence of a known father matter to making families that count? And what does the emphasis on men's contribution to procreation and family reveal about Jewish-Israeli kinship ideologies that inform familial and national continuity?

Answering these questions entails confronting several assumptions in the anthropology of assisted reproduction and social scientific approaches to nationalism. Namely, in Euro- 
American contexts, the individual is the privileged actor and individual choice is the taken-forgranted mode of social interaction - family is conceived of as separate and subordinate. In the next section, I consider the ways these cultural presuppositions about individual choice and the place of family have shaped research in these areas, while juxtaposing these presuppositions with the Israeli context. First, I consider assisted reproductive technologies, single motherhood and their intersection in recent studies. This brief review shows how "choice" is a middle-class ideology that serves to construct some practices of motherhood as respectable while excluding women of color. In Israel, however, "choice" in relation to motherhood suggests a different set of meanings and produces different categories of exclusion, which derive from a particular narrative about family, modernity and nation. Second, I contrast the Euro-American social scientific evolutionary narrative about the emergence of the modern family and nation-state with an Israeli version of this narrative that is related, yet differs in significant ways: rather than imagining a shift from the family to the individual, the Israeli version draws upon an alternative evolutionary narrative to configure the modern family as the basic unit of citizenship in the modern, Jewish nation. It is through exploring these salient differences that we can begin to make sense of why, in Israel, the single-mother family $-1+$ child — is an entirely different situation.

\section{Single-Mother FAMILIES IN THE ERA OF ASSISTEd REPRODUCTION}

\section{Extending Reproductive Choice}

Feminist anthropologists have theorized how the advent of assisted conception fundamentally altered ideas about kinship and relatedness by defamiliarizing the natural or given order of things (Carsten 2004; Dolgin 1997; Edwards et al. 1993; Franklin 1997; Franklin and McKinnon 2000; Strathern 1992; Thompson 2005). ${ }^{2}$ Whereas kinship was once considered part 
of the domain of nature and stood for "the facts of life" and immutable relations in EuroAmerican societies, assisted reproductive technologies introduced the possibility of thinking about procreation as a choice: "However one looks at it, procreation can now be thought about as subject to personal preference and choice in a way that has never before been conceivable" (Strathern 1992:34). Like other human activity in neo-liberal contexts, the notion of reproduction as a choice has become the "privileged vantage" to think about having children (Strathern 1992:36).

The extension of choice, however, creates a paradox for would-be-parents who, as consumers of assisted reproductive technologies, have "no choice but to consume" (Strathern 1992:37). Ethnographic accounts of assisted reproduction and these "technologies of hope" (Franklin 1997) have consistently demonstrated that patients with prolonged infertility experience "no choice" but to continue treatment (Becker 2000; Cussins 1998; Franklin 1997; Thompson 2005). Indeed, by opening the door to an ever-increasing realm of choice, these technologies displace the finality that was once imposed by a diagnosis of infertility (Becker 2000; Franklin 1997; Thompson 2005). In its association with hope, progress and expanding choice, technologically-assisted reproduction cannot fail, "the whole point of ARTs...is to gain greater control over the reproductive process and by doing so to increase reproductive choice" (Cussins 1998:108). Nowhere is the failure of assisted reproduction to control physiological processes more apparent than with the dismal success rates of in vitro fertilization (IVF) for women in their 40s. Nevertheless, as success rates with a woman's own eggs dwindle, donation from younger women enables some peri- and post-menopausal women to have children.

Although many women seeking fertility treatment are of "advanced maternal age," few studies on assisted reproduction have attended to the intersection of gender and age (Becker 
2000) or the relationship between the aging female body and the construction of medical risk (Campbell 2011). ${ }^{3}$ In their review of the anthropology of assisted reproduction, Marcia Inhorn and Daphna Birenbaum-Carmeli identify several key areas for future research including postmenopausal pregnancy and the relationship between age, multiple embryo transfer and highrisk pregnancy (2008:186-187). ${ }^{4}$ With changing attitudes toward this patient population, technologically-assisted later motherhood in the United States and other countries may grow as a reproductive route among middle class women. In August 2013, the ethics committee of the American Society for Reproductive Medicine (ASRM) revised an earlier (and more cautious) position on egg donation to older women:

The reported success of oocyte donation to women in their 50s and early 60s suggests that pregnancy may be possible in virtually any woman with a normal uterus, regardless of age or the absence of ovaries and ovarian function. A woman's reproductive age, once a dictate of nature, now can be artificially extended. (Zoll 2013)

As yet another "dictate of nature" is overcome by assisted reproductive technologies, Marilyn Strathern's (1992) observation about the collapse between the categories of nature and culture in Euro-American contexts entails a reconfiguring not only of kinship relations but also of lifecourse trajectories and gendered temporalities.

Egg freezing is the latest chapter in the expansion of assisted reproduction and choice. American discourses about egg freezing technology (oocyte preservation) bring together the narrative of hope in assisted reproduction and faith in biomedical progress (Franklin 1997) with middle-class assumptions about individual choice, time management, financial autonomy and responsible childbearing (Romain 2012). ${ }^{5}$ Women who consider egg freezing (and who are targeted by clinic marketing) are educated, professional women portrayed as rational actors who manage risk and make sound investment decisions (Martin 2010; Romain 2012). As egg freezing is constructed as extending future choices and preserving the possibility of "having it 
all" (Romain 2012), an "ontological category" is created in which future infertility is extended to all women who are becoming obligated "to ensure their future reproductive capacity" (Martin 2010:531). Given the unknown viability of frozen oocytes, when it comes to egg freezing technology, it is the idea of choice that gets preserved.

\section{Single Mothers by Choice: Class, Race and Respectable Motherhood}

Like anthropological accounts of assisted reproductive technologies in Euro-American contexts, studies of single motherhood among middle-class women have also focused on the cultural idea of choice and its related political implications. Sociological studies suggest that single mothers by choice (SMCs) are primarily Caucasian, well-educated professionals who do not constitute their motherhood as a revolutionary, feminist practice but rather who seek inclusion for themselves and their children within a middle-class morality of good citizenship (Bock 2006; Hertz 2006; Mannis 1999). Bock (2000) argues that SMCs constitute their entitlement to parenthood even before becoming mothers, narrating their experiences as having made responsible decisions: holding out for Mr. Right, building their careers, and securing financial security through employment and property ownership. The discourse of "choosing" to become a mother in women's accounts enables SMCs to frame their decisions as an "agentic odyssey," to present their credentials to become mothers and to substantiate their ability to make the "right choices" for their children (Bock 2000; Mannis 1999:126).

The discursive use of "single mother by choice" makes an implicit claim that one is at liberty to make a decision about motherhood that other single mothers are not in a similar position to make (Bock 2000:64). In other words, the term "single mother by choice" suggests that women from different socio-economic backgrounds did not (and could not) choose to become mothers on their own. In contrast to representations of white SMCs, single mothers of 
color are stigmatized as young, irresponsible, and on welfare (Bock 2000; Ludtke 1997). Thus the category of SMC rests on the fault lines of race and class in the United States that inform the "stratification of reproduction" (Colen 1995), in which childbearing and the reproductive choices of some are privileged over others. When it comes to constructions of motherhood, "choice" whitewashes unequal relations of power and historical formations of class, race, and gender that have informed social constructions of respectable motherhood and the creation of normative American families.

Divisions of class and race have shaped cultural responses to out-of-wedlock pregnancy for over a century (Ellison 2003). In the 1950s, teenage pregnancy among white and black women was treated differently: whereas white teenagers were encouraged to give their children up for adoption, finish their schooling and re-enter society as marriageable women, the possibility of social rehabilitation was not extended to black teenagers (Coontz 1992:39; Ellison 2003). In the 1970s, the availability of contraceptives (especially the birth control pill) and the legalization of abortion resulted in marked decline of white children for adoption (Ellison 2003). Among the minority of white women who chose to keep their children, a discourse emerged about maternal knowledge (making the best choice for the child) and selflessness (Ellison 2003). As white single motherhood underwent a gradual transition toward maternal respectability, national debates about the family and citizenship focused on the black matrifocal family, constructing it as "dysfunctional" (Ludtke 1997). ${ }^{6}$ With the rise of the Christian right and the debate over family values in the 1990s, the social problem of missing fathers-regardless of race and class divisions - became associated with the supposed breakdown of the American family (e.g., Bock 2000; Ludtke 1997; Santorum 2005). 
It is in connection to this deeper history of stigmatized single motherhood that single mothers by choice negotiate the meaning of absent men. In her study of middle class, professional SMCs, Rosanna Hertz (2006) contends that the significance of fathers is being transformed by the commodification of childhood:

Like music lessons, soccer camps, and language classes, men are offered up to children as an essential luxury that women can afford: essential in that men are seen as necessary to raise successful children, and a luxury in that it is women's resources that ensure men's involvement. (Hertz 2006:189)

In this formulation, men become a kind of social capital that will help children become successful, middle class citizens. ${ }^{7}$ Despite the use of anonymous sperm donors, SMCs expose their children to this essential luxury by forging relationships with male kin and mentors as "the final testament to their good motherhood" (Hertz 2006:192). ${ }^{8}$ Hertz concludes that the motherchild dyad has become the center of middle-class family life, as care and nurturance between mother and child replace former ideals of heterosexual romance and love (Hertz 2006). Arguably, the valuation of the mother-child dyad as family among mostly white SMCs is not extended to poor single mothers of color.

Social scientific analysis of single motherhood and assisted conception in the EuroAmerican context demonstrates that these practices of making family are inextricably bound up with the middle class ideal of individual choice (and the race and class divisions "choice" elides). Rapp and Ginsburg theorize that reproduction "provides a terrain for imagining new cultural futures and transformations, through...the contested claims of powerful religious and political ideologies. These imaginings and actions are often the subject of conflict, for they engage the deepest aspirations and the sense of survival of groups divided by differences of generation, ethnicity, race, nationality, class, and, of course, gender" (1995:2). These futures and contested transformations are contingent upon particular historical formations, ideological orientations and 
relations of power and inequality. What "new cultural futures and transformations" are implicated by single motherhood and assisted reproduction in Israel? How do Jewish-Israeli nationalist and religious ideologies concerned with group survival shape debates about the meaning of family and single-mother families in particular?

\section{Single Motherhood in Israel}

In her path-breaking book Reproducing Jews: A Cultural Account of Assisted Conception in Israel, Susan Kahn observed that the stigma of pregnancy among unmarried women "has ceased to retain its cultural force" (2000:17). Noting the extension of health and welfare benefits to single-parent families in the early 1990s, Kahn described the increasing openness of Israeli society to this family form. Despite these changes, she argued that the idea of "choice" (as in the Euro-American idea of single mother by choice) does not retain the same meaning among Israeli women, who do not approach motherhood as optional but rather as obligatory $(2000: 18) .{ }^{9}$ Instead Kahn found that "most unmarried Israeli women see artificial insemination as a last resort and make every attempt to 'normalize' these instances of reproduction by integrating their children into existing family networks" (2000:17). It was from within these family networks that single mothers framed their reproductive agency and their commitment to cultivating kin relationships (Kahn 2000:17, 45). Unlike assisted conception in Euro-American societies, Kahn contended that the children of single mothers "are not conceived as product of individual choice, but are understood to be the product of family relationships" (2000:45). Under the category of family relationships, Kahn referred to both the extended kin of the mother and to source of the genetic material — an anonymous Jewish sperm donor; these relationships made a child "one of 
us" (2000:45). Yet the question remains: why does situating the child as a product of family relationships as opposed to individual choice make a child "one of us"?

Similar to the discursive use of "single mother by choice" as an implicit comparison to stigmatized single mothers in the American context, not all Israeli women are equally in the position to narrate their experience of single motherhood as an extension of an extended family network. Amalia Sa'ar asserts that "despite the widespread inclination to treat it as an essential social category, the [Hebrew] term 'one-parent mothers' (imahot had-horiot) is far from a neutral description of empirical reality. It is rather a symbolic concept, replete with moral undertones that filter back into the phenomenon it attempts to describe" (2009: 470). Making visible these "moral undertones," requires tracing the historical formations and the social and technological changes that shape the Israeli concept of the one-parent mother and the single-mother family.

The devaluation of the single-mother (family) and the privileging of the heteronormative "traditional" family come to the fore in the practices and policies concerning surrogacy in Israel. Elly Teman's ethnography, Birthing a Mother: The Surrogate Body and the Pregnant Self (2010), explores how the bodies of poor, marginalized single mothers are enlisted by state regulations to carry the embryos of married Israeli couples who cannot have children (Jewish law prohibits a married woman from being a surrogate). In this case of stratified reproduction, the wombs of single mothers enable the creation of families for heteronormative, married couples. However, under the terms of the Embryo Carrying Agreements Law (2006) single Israeli women do not have access to in-country surrogacy in order to have their own children. Moreover, the creation of family for the married couple is premised upon the denial of the surrogate's motherhood - she is figured as an "incubator" or "inn-keeper" rather than a mother. Birthing a 
Mother demonstrates how single women's potentially morally problematic reproductive agency is resolved through her heroic act of making a family and "giving life" to a childless couple.

Whereas single Israeli women who desire their own children locate their reproductive agency as part of extended family networks, marginalized single mothers who become surrogates (mostly to support their children) make heroic self-sacrifices to bring normative families into being for married couples. Both Reproducing Jews and Birthing a Mother attest to the absence of individualistic choice in single women's narratives of assisted reproductive technologies (anonymous sperm donation, IVF and surrogacy). In fact, the repudiation of choice and individualistic agency is what enables women to construct culturally-acceptable formations of motherhood - whether it is their intention to raise the child as a single mother or to make a child for a married woman. This distancing of (single) motherhood from individualistic agency exists in relation to layered and contested Jewish-Israeli family ideologies that emerged in dialogue with modern Jewish nationalism, histories of Jewish immigration, and anxieties about familial and national continuity. These Jewish-Israeli ideologies about the family differ in significant ways from Euro-American evolutionary narratives of modernity that conceive of the individual as the basic unit of the nation.

\section{GENDER, FAMILY AND NATION}

\section{Modern Typologies}

Following the birth of the first child through in vitro fertilization in 1978, assisted reproductive technologies have stirred heated discussions about the family and contributed to an extensive body of interdisciplinary literature. In the decades since, reproductive and genetic technologies have made possible previously unimaginable constellations of family. However, 
observations about changes to family organization and debates about the family began long before these recent innovations (Dolgin 1997). In Euro-American contexts, social scientists and historians have described a paradigmatic shift in family organization that has taken place over the past two centuries as one from the "traditional" family of feudal societies, characterized by hierarchal, encompassing relations to the "modern" family following the Industrial Revolution, characterized by individualization, choice and equality (e.g., Dolgin 1997; Grossberg 1985; Shorter 1975). Of the transformation from aristocratic to democratic social relations and the paradoxes it generates, Alexis de Tocqueville astutely commented, "Democracy loosens social ties, but tightens natural ones, it brings kindred more closely together, while it throws citizens more apart" (1990[1840]:197). De Tocqueville recognized that, alongside changes to political governance and social institutions, the idea of family was also undergoing modification: in the American democracy, family was being constructed as the realm of affective and natural ties in contrast to the civic sphere, where individual citizens were being reconfigured as isolated and separate entities. De Tocqueville's ethnographic reflection about the transformation of American society finds contemporary salience in the anthropological project of approaching the family not as a given but as "an ideological construct associated with the modern state" (Collier, Rosaldo and Yanagisako 1997:72; Dolgin 1997).

The historiography of the family is also a "moral history" that, along with sociological analysis, leverages the past to imagine and debate the future of the family (Dolgin 1997:16). This theoretical perspective enables anthropologists to situate the family in relation to broader cultural narratives about modernity and social change. Alongside economic and political transformations, family came to be recognized as a discrete realm of social life in need of protection from negative influences, particularly those stemming from the marketplace (Dolgin 
1997:5). Modern social relations within the domestic domain came to be identified as natural, enduring and affective, while those within the marketplace were constructed as individualistic, competitive and rational (Dolgin 1997; McKinnon and Cannell 2013). In the mid-20 ${ }^{\text {th }}$ century, a popular and sociological discourse reframed this historical transition as an oppositional typology of "traditional" and "modern" family arrangements that were "ideological antagonists in a contest for the future of the family" (Dolgin 1997:15; McKinnon and Cannell 2013). McKinnon and Cannell (2013) argue that the separation of family into an isolated domain of social life and the creation of oppositional typologies (e.g., traditional/modern) derive from the same EuroAmerican cultural construction of modernity.

Social scientists locate this "stereotypical contrastive frame" within an evolutionary narrative that located the "traditional" family in state-less societies and the "modern" family in industrialized, territory-based states (McKinnon and Cannell 2013:5-6). This narrative rests upon several assumptions about the difference between "traditional" and "modern" families. First, the "modern" family is that it is assumed to be collection of individuals rather than a hierarchy of encompassing relations (Dolgin 1997). Second, in modern societies the family is conceptually separated from other domains of social life in which individual actors are imagined to operate (such as politics, economy, and religion), whereas in "traditional" societies these domains are imagined to be expressed in the idiom of kin relations (McKinnon 2013; McKinnon and Cannell 2013). Though depleted of its former influence, the family unit (whether the basis of society or, in so-called "modern" societies isolated in the domestic domain) becomes an indicator of the relative modernity of a given society. Finally, "traditional" family is deployed as a mode of temporal othering, as kinship and family are located outside of history (Fabian 1983; McClintock 1993) or, alternatively as different practices of kinship, family and marriage become signifiers of 
the temporal location of societies in narratives of social development (McKinnon 2013;

McKinnon and Cannell 2013). Although it has been conceptually excluded from other domains and temporalities of social life, the family retains symbolic value and should not be taken as an impartial description of reality.

Social scientific theories of nationalism incorporate these unquestioned assumptions about the family unit, individualism and modernity through two approaches to kinship. In the first approach, the nation is conceptualized as a homogenous, bounded territorial entity—_an imagined community" - made up of individuated actors who share a sense of belonging (e.g., Anderson 1983). Here kinship is ideologically separate from the modern political domain and its individuated (male) actors that constitute the nation. For this reason, when kinship does enter the analysis it does so as metaphor, preserving the boundary between domains that support the nation's modernity (Delaney 1995; McClintock 1993). In the second approach, a distinction is made between modern or "civic" nationalism (individuated model of citizenship) of western states in which nation-state-territory overlap and "ethnic" nationalism of non-western states in which the alignment of these elements is not always realized (e.g., Smith 2010). In the latter, "primordial" kinship relations remain central to these "non-western" nationalist movements and are juxtaposed with the "rational" form of the Western nation (e.g., Smith 2010). These approaches to nationalism rely on a contrastive typology (whether implicit or explicit), privileging a model of the nation as a collection of individuals that assumes personhood based on physical boundedness, autonomy and unique characteristics that "encompass diversity" (Handler 1988; cf. McKinnon and Cannell 2013).

In the modern nation, a gender hierarchy enables the encompassment of diversity as women are subordinated and marginalized within the domestic domain while the political 
domain is populated by individuated (male) citizens - each constituted as a part of the whole (nation). "Despite nationalisms' investment in the idea of popular unity" Anne McClintock reminds scholars, "nations have historically amounted to the sanctioned institutionalization of gender difference" (1993:61): the model of individuated citizenship unifies the spatial and temporal dimensions of the nation through male bodies, while it simultaneously erects boundaries that generate difference and inequality through the family (McClintock 1993). Women belong to the nation through their familial ties to men as wives and daughters; their bodies come to mark the boundaries of the nation (e.g., Delaney 1995; McClintock 1993; YuvalDavis 1997). A consequence of bounding the family as a separate and subordinate domain distinct from the public domain of (male) citizenship is that "the kinship and marriage coordinates of Western liberal, supposedly secular, individualistic, democratic states - and their connection to claims of sovereignty_are, therefore, unmarked and invisible" (McKinnon and Cannell 2013:25). The ideology of the "modern" family is used to naturalize, and nationalize gender inequality, hierarchal relations and the differential valuation of male and female contributions to the nation.

The absence of kinship and family in most scholarship on nationalism is particularly relevant to the Israeli context. In contrast to Euro-American societies, debates about the family in Israel are informed by an alternative, yet largely ignored, trajectory of shifting meanings of family central to modern Jewish nationalism. What follows is not intended to provide a detailed history of changes to the Israeli family, but is rather an overview that highlights the family ideologies that developed in Israel over the last century. While family was supplanted in socialist Zionist thought by a collectivist orientation to the nation, after the creation of the state a particular typology of family came to be critical to the project of building a modern, Jewish 
nation. Together, the pre-state erasure of family and the post-1948 appropriation of family as a nation-making technology by social scientists inform contemporary Israeli thinking about the “modern" family and alternative families, including the single-mother family.

\section{Building the Nation, Negating the Family}

Early Zionist thought identified the institution of family as a hindrance to the movement's revolutionary aim of establishing a new Jewish society in Palestine. In order to bring about the realization of a secular, egalitarian national home, the collective group was to replace the family, which was associated with both Jewish religious tradition and Western capitalism (Bernstein 1992; Shamgar-Handelman 1996). The family stood for the Diaspora, for the past: in the central foundational myth of Zionist settlement, the (male) pioneer is an enlightened individual who leaves his family and the old world of Europe in order "to build and be built" through physical labor (rather than religious study) in the motherland (moledet) (Almog 2000). By undoing the centrality of family, the afflictions of gender inequality and economic insecurity stemming from patriarchal religious tradition and middle-class property ownership would be overcome (Bernstein 1992:235-6). The shift in affective relations from family to collective would contribute to the making of the New Hebrew man.

Although scholars have primarily focused on the male body as the locus of nationalist efforts (e.g., Almog 2000; Biale 1997; Boyarin 1997), reconfiguring family relationships was also a key element of remasculinizing the Jewish man. Zionism emerged in conversation with other fin-de-siècle ideological movements, including psychoanalysis. Even as Zionists were concerned with the inequality rooted in the hierarchal, patriarchal family, they were also troubled by what they understood as its affective yet pathological relationships associated with "Jewish 
degeneracy," which they attributed to problems uniquely affecting Jews, including sexual dysfunction, neurosis, late marriage and low fertility (Biale 1997:180). ${ }^{10}$ Drawing on psychoanalytical interpretations of Jewish degeneracy (and its origins in the emasculated Jewish man), Zionist visionaries believed that utopian male-female relationships and new expressions of solidarity would cure the Jewish afflictions of the Diaspora (Biale 1997:184). They imagined a collectivist utopia founded not on ties to religion and family blamed for Jewish degeneracy, but rather on spiritual ties to the nation. This shift from physical bonds to spiritual alliance was expressed by the writer Zvi Schatz, who came to Palestine during the second wave of immigration (aliyah):

The family is collapsing and religion is dying, but eternal life values are still valid; they will only change their forms because the need for family is deep and organic and the religious relation to life and nature will yet become strong within us and be resurrected in our return to the land and to nature. For these are our true Messiah. Thus, a new family on the basis of a new religion will establish the laboring nation on its soil. The family will be resurrected not on the basis of blood relations, but on the basis of spiritual intimacy. (Biale 1997:184)

This "spiritual intimacy" and erotic love for the nation generated an ethos of ascetic interpersonal relationships and celibacy, "often expressed in the notion that the halutzim were creating a new family in which all were brothers and sisters" (Biale 1997:193). Among the young pioneers (halutzim), couplehood and privacy were sources of mistrust - a combination of ideological and material factors led to group housing ("three to a tent") and to low rates of marriage and fertility (Biale 1997:197).

The Zionist deconstruction of family has had consequences for the historiography of family and the sociological study of family in Israel (Shamgar-Handelman 1996). Despite the ideological rejection of the central social institution in Jewish life in the Diaspora, "the family was almost never mentioned in Socialist Zionist publications on social criticism, or in the social 
alternatives explicitly spelled out by the movement" (Bernstein 1992:236). Israeli historians have focused almost exclusively on the formation of political and economic institutions and on intellectual developments and debates within Labor Zionism (Razi 2010:396). A consequence of this lacuna in Israeli historiography is that it reproduces the myth of Zionist settlement by individual (male) pioneers in rural, collective settlements, while ignoring the experience of the vast majority of immigrants who arrived in Palestine during the first decades of the twentieth century as family units, settling in impoverished urban areas where most of the Jewish population lived (Pfefferman 2013; Razi 2010:396).

Recent studies on the pre-state period suggest that the heterogeneity of immigrant experience contributed to ideas about the family that were "complex and conflicted" (Pfefferman 2013; Razi 2010:401). Whereas the political elites of the Zionist movement deemed the family an impediment to the creation of national solidarity, the urban petit bourgeois identified the family as a key component of nation-building (Razi 2010). Interestingly, both visions of family were interventionist: the collective settlements unmade the bourgeois family through the practice of caring for children away from their parents (e.g., in separate children's houses) and limiting contact to several hours each afternoon; the middle-class philanthropists advocated removing children from the "dysfunctional" homes of the urban poor, many of whom were immigrants from non-Western societies (Razi 2010). After 1948, ideologically-driven interventions in the family became large-scale, institutionalized efforts in a nationalist project of engineering the modern Jewish family as a means of unifying the Jewish nation.

\section{Absorbing Jewish Others through the Modern Family}

The establishment of the State of Israel in 1948 coincided with a number of significant developments that influenced the idea of family and the relationship between models of family, 
modernization projects and nation-building efforts. The early years of statehood saw the massive immigration of Jews from North Africa, the Middle East and Asia (mizrahim); these newcomers and the existing population experienced the social and economic upheavals of life in a new state. The arrival of immigrants had a profound impact on the newly formed disciplines of sociology and anthropology in Israeli universities and on the broader social scientific study of family in Israel. Mid-century theories of the family based on the work of Talcott Parsons and other structural-functionalists in the United States and Europe became incorporated into local theories of social equilibrium and modernization (Shamgar-Handelman 1996). In turn, this imported approach became central to the modernist project of nation-building ("in-gathering the exiles"), of which Israeli social scientists were involved through applied work (Rabinowitz 2002).

As Israeli social scientists took up family as an object of study, they isolated three models of family: the kibbutz family, the "ethnic" (mizrahi) family, and the "rural Arab family" (Shamgar-Handelman 1996). The kibbutz family, made popular through the work of American anthropologist Milford Spiro, attracted international attention as a revolutionary model for its collectivization of family functions (e.g., children's houses). This appellation continues to be applied to the kibbutz family by contemporary scholars, for example in a recent anthropological review article on new kinship practices it was noted as "the most far-reaching transformation ever instituted in family formation" (Levine 2008:378). ${ }^{11}$ Whereas in the first decades of collective settlement movement, the family and romantic relationships were considered an impediment to the fostering of solidarity between kibbutz members who viewed themselves as “one large family" (Spiro 2004:558), as the kibbutz changed over time "the integrative role of the family has been more and more appreciated" (Katz and Peres 1986:157; cf. Agassi 1980). 
In contrast to the discovery of the "integrative role" of the kibbutz family, the mizrahi family came to represent the problem of absorption of immigrants from North Africa, the Middle East and Asia into the new society and their transition to modernity. Following the creation of the State of Israel (1948), large waves of Jewish immigration from Muslim countries in the 1950s and 60s overwhelmed social and economic institutional capabilities and challenged the hegemonic socialist ideology of Labor Zionism. The political leadership viewed the mizrahi immigrants as 'the generation of the 'desert,' the culture of which would hopefully pass away with their own full absorption or at least with the integration of their children" (Eisenstadt 1985:322). The kinship practices of the mizrahi family, resembling those characterizing the Muslim societies in which they had lived, were deemed an obstacle to their modernization and absorption into the new society. Israeli sociologists, led by S.N. Eisenstadt, viewed the socialization of immigrants ("the traditional elements") and immigrant youth through institutions or recognized "frameworks" (e.g., education and youth groups), as the means to eradicate the bonds of kinship and other non-Western practices that hindered them from modernizing and contributing to the egalitarian ideals of the national collective (Eisenstadt 1985:154).

Yoninah Talmon-Gerber, one of the first (and only) sociologists in Israel to primarily study the family, developed a typology that contrasted "Oriental" and "European" family forms in a short article from 1954, entitled "The Family in Israel." Despite acknowledging the diversity of family forms found in Israel, Talmon-Gerber outlined a rigid typology: non-familistic and familistic. The Oriental Jews (mizrahim) "come nearest to the 'familistic' type" while Jews from European countries are non-familistic (Talmon-Gerber 1954:344). This chart summarizes the contrastive distinctions "The Family in Israel" makes between the two types: 


\begin{tabular}{|c|c|}
\hline NON-FAMILISTIC & FAMILISTIC \\
\hline European & Oriental \\
\hline Middle Class - skilled workers/professionals & Traditional occupations \\
\hline Egalitarian between husbands and wives & $\begin{array}{l}\text { Patrilineal, patriarchal, and sometimes } \\
\text { polygamous }\end{array}$ \\
\hline Parent/child relationship not authoritarian & Authoritarian \\
\hline Marriage by individual choice & Parental choice of spouse, marriage exchange \\
\hline $\begin{array}{l}\text { Nuclear family: small, isolated and } \\
\text { independent }\end{array}$ & $\begin{array}{l}\text { Three or four generations living together, } \\
\text { extended family structure }\end{array}$ \\
\hline Unstructured kinship networks & $\begin{array}{l}\text { Extensive kinship networks, community is an } \\
\text { "aggregate of families" (1954:345) }\end{array}$ \\
\hline Low birth rate/older age at marriage & High birth rate/lower age at marriage \\
\hline
\end{tabular}

In addition to being more like European families, the "non-familistic" type is also associated a native type — the kibbutz family — that "evolved" in Israel $(1954: 343,346) .{ }^{12}$ Talmon-Gerber admited that the family type of some Oriental Jews, particularly from urban areas, conforms more closely to the European "non-familistic" type. Nevertheless, she argued that overall Jews from Africa and Asia "come nearest to the 'familistic' type" (1954:344). While both types of families can be found in Israeli society of the mid-1950s, Talmon-Gerber noted that immigration "shifted the balance toward [the] familistic [type]" (1954:346). Interestingly, it is the family pattern from abroad - the "familistic" type - that undergoes social disruption when it arrives in Israel, "The process of neutralization of the 'familistic' characteristics of the Oriental family entails considerable malintegration in many cases" (Talmon-Gerber 1954:345). Although the "non-familistic" type is also, arguably, a model from abroad (Europe), it was not identified as a sociological problem.

The "malintegration" of the mizrahi family became a key object of anthropological study in the 1960s and 1970s, which theorized the "continuity and change" taking place among the new immigrants. Non-western kinship practices are represented as an obstacle in the way of the modernization process, particularly in the ethnographies of Moshe Shokeid and Shlomo Deshen (Goodman and Loss 2009). As Lea Shamgar-Handelman argues, "with time the identification of 
family and kinship systems with the origin of their members became unthinkingly accepted both in popular rhetoric and in sociological discourse (1996:385). For example, a review of family change in Israeli society over two decades states:

The Asian-African immigrants introduced into Israel the patterns of traditional midEastern family life...several common traits of traditional families can be indicated which include young marital age, high fertility, authoritarian gender and generational relationships and the family as "political entity." (Katz and Peres 1986:149-150)

Whether it was the enduring cohesiveness of mizrahi "traditional" families or the disintegration of kinship ties (due to the separation of large extended families), the "oriental" or "ethnic" family was differentiated from the unmarked, European nuclear family assumed to characterize Israelis from western countries (ashkenazim). Despite this opposition, ethnographic accounts portrayed the mizrahim as capable of abandoning their traditional kinship practices as part of a gradual and sometimes conflicting trajectory toward modernization.

In contrast to the construction of the mizrahi modernization process, anthropologists represented Arab/Palestinian citizens of Israel as permanently unmodern: rural, backwards and in the past. Jewish-Israeli social scientists, many of European descent, identified particular characteristics of Arab/Palestinian culture that "are often diametric oppositions of features many Israelis see as typical of their own identity" (Rabinowitz 2002:307). Rabinowitz (2002) calls this politics of representation "oriental othering" through which Israeli cultural signifiers, including the modern family became the unmarked, normative, emblem of progress. In contrast, Palestinian kinship practices symbolize the enduring marker of otherness, of the primitive, backward Arab "trapped in an ancient, rigid social system" (Rabinowitz 2002:315). Indeed, anthropological studies of Arab-Israelis (as they are referred to in the older literature) emphasize that not only are Palestinians bound to their traditional kinship practices (e.g., the extended family or hamula, patrilineal descent and endogamous marriage), but that the strengthening of 
these practices after the establishment of the State of Israel demonstrates their incompatibility with modernity (e.g., Cohen 1965). Thus the anthropological imagination contributed to a narrative of failed modernity: despite the presence of a modern Jewish state, the evolution of Palestinian family and society was thwarted by their kinship practices.

The narrative of failed modernity associated with Palestinian kinship endures in contemporary academic and popular discourses. Even as social scientists occasionally note changes to the Arab family, particularly stemming from their contact with modern (Jewish) family forms, their conclusions diagnose a condition of stasis (cf. Kanaaneh 2002), for example:

In sum, then, new family patterns (smaller kinship units, improvements in women's position, lower birth rates) have penetrated, albeit gradually, Israeli-Arab mores. This transition is, however, partial: traditional values such as female chastity and filial discipline are still strictly and jealously preserved. (Katz and Peres 1986:152)

Among the Jews, there has been a moderate process of individualization of the institution of the family, and the dimensions of familism have declined somewhat in the last 15 years. The situation is quite different among the Palestinian Arab citizens of Israel, whether Muslims, Christians or Druze. Despite slight fluctuations in the various dimensions, Arab society in Israel retains very high levels of familism. (Fogiel-Bijaoui 2002:40-41)

It is the stasis of Arab kinship_ of "high levels of familism" - that anchors the modernity of the Jewish family and nation and preserves the differentiation of Jewish and Arab citizens in an oppositional typology secured by its evolutionary trajectory. ${ }^{13}$

Social scientific representations of mizrahi families have deployed kinship as a nationmaking technology that separated Jewish others from Arab others. While the early Zionists of the pre-state period sought to unmake family, after 1948 demographic changes and the "arrival" of familism brought the centrality of this social institution into focus. In order to absorb and integrate Jewish others into the modern Jewish nation, anthropologists and sociologists participated in the project of eradicating non-western kinship practices, precipitating the 
transformation of "the generation of the desert" and their children into modern families and Israeli citizens. At the same time, non-Jewish citizens within Israel's borders were permanently situated in the past - their intractable kinship practices prevented them from participating in the modern nation. Of the use of family as a nation-making technology, Khachig Tololyan's statement about boundaries in the making of the nation-state is particularly apt:

[In the nation-state] differences are assimilated, destroyed, or assigned to ghettos, to enclaves demarcated by boundaries so sharp that they enable the nation to acknowledge the apparently singular and clearly fenced-off differences within itself, while simultaneously reaffirming the privileged homogeneity of the rest, as well as the difference between itself and what lies over its frontiers. (Tololyan 1991:6)

In Israel, the oppositional typology of modern (Jewish) family and traditional (Arab) family has become one such boundary. Even as mizrahi families and their kinship practices were considered an impediment to the immigrants' absorption, their families became the necessary object of intervention in order to produce a "privileged homogeneity" - the modern, Jewish nation.

\section{Jewish-Israeli Familism}

Over the past two decades, a social scientific discourse about "familism" that explains and distinguishes certain aspects of Israeli social life from American and European countries has gained prominence. Israeli familism (or mishpahtiyut) ${ }^{14}$ is typically represented as a quantifiable sociological fact, identified through demographic figures such as high rates of marriage and childbearing and low rates of divorce relative to other Western industrialized countries. Other "signs of familism" have been attributed to the absence of voluntary childlessness, the high value placed on motherhood, the length of the school day, and the secrecy surrounding donor insemination (Birenbaum-Carmeli et al. 2002; Portugese 1998:61-62; Remennick 2006). It has 
become commonplace for studies of gender, motherhood and reproduction to address the particularities of Israeli society through the encompassing shorthand of "familism," for example:

Israel is a family-oriented society. Familism, the normative family's centrality in the lives of the individual and the collective is one of the central characteristics of Israeli society. (Halperin-Kaddari 2004:229)

[Familism is] a coherent system of beliefs and values that places marriage and children at the center of social life and that divides the spouses familial roles differently and unequally. (Portugese 1998:56)

As a cultural code, [familism] thus dictates to the individual his/her proper way of life: the duty of heterosexual marriage, rejection of divorce, bringing (many) legitimate children into the world, prohibition of out-of-wedlock births, and... an unequal and gendered division of labor. (Fogiel-Bijaoui 2002:38)

Despite its post-industrial economy and Westernized lifestyle, Israeli society is known for its familism and the central role of family (both nuclear and extended) as the primary support network. (Remennick 2006)

Feminist scholars have critiqued the "entrenchment" of familism (Portugese 1998) and the "cultural dominance of familism" (Fogiel-Bijaoui 2002:39), connecting the centrality of family to the oppression of women, the religious control of family law, state pronatalist policies that encourage motherhood, and the militarization of Israeli society (e.g., Fogiel-Bijaoui 2002; Halperin-Kaddari 2004; Herzog 1998; Remennick 2006). Although these scholars foreground the inequalities they see as the result of familism, these definitions and their dissemination in social scientific and popular discourse engender an image of Israeli national culture that is characterized by a fixed set of beliefs and practices involving the family.

Even as "familism" as an indicator of gender inequality is referenced to differentiate Israel from other western countries, it coexists somewhat paradoxically with another socialscientific narrative about the overall similarities shared by these societies. This narrative proposes that, like the rest of the west, Israeli society is also undergoing a process of "individualization." Social scientists have begun to study this process in relation to family life, 
pointing to the emergence of new family forms, including single-mother families and gay and lesbian families as evidence of "individualization" (e.g., Fogiel-Bijaoui 2002). Thus the presence of these "new families" (also called "postmodern" families) indexes on the one hand, an unresolved tension between the persistence of Israeli familism as the unique cultural trait that emphasizes children and family life which has vanished elsewhere in the West. On the other hand, the "new family" is hailed as a marker of the process of individualization that makes Israel and its cosmopolitan center, Tel Aviv, "like the rest" of the post-industrial, developed world. ${ }^{15}$ The tension between the narratives of national particularity and western similarity reveals that the family is constructed as an enduring cultural trait associated with religious tradition and gender inequality, while the individual — though it heralds societal progress — when taken to its extreme is conceived of as the negation of family, of culture and of Israeliness.

Since the 1980s, discourses about Israeli familism have struggled to define the unique cultural traits of Israeliness while attempting to align Israeli society with the evolutionary trajectory of other modern, western societies toward individualism: too much familism is associated with traditional, Arab kinship and, by extension, culture, yet the complete absence of the family would negate a key element of Israeliness on which the Jewish nation's modernity is premised. What is evident is that these layered and conflicting ideas about the family make it impossible to take the family as a self-evident unit of analysis. Nevertheless, most social scientific studies of Israeli society presume the "normative Israeli family" (or sometimes the "traditional" family or the nuclear family) as the basis to contrast alternative family configurations, including single-mother families. Yet it is precisely the ethnic and gender coordinates underlying the differential valuation of Israeli families that make possible an exclusionary configuration of citizenship based on the unit of family. Understanding why the 
single-mother family counts less than the normative family entails attending to the multiple meanings of family at this particular juncture and to investigating the kinds of inclusions and exclusions they engender.

\section{A Critical Age: The Single-Mother Family in ISRAel}

In Israel, women who become mothers on their own at a "critical age" — in their late 30s and beyond - encounter a contradiction. As citizens of a state with subsidized assisted reproductive technologies until the age of 54, regardless of marital status, it would appear that unmarried women face few obstacles to becoming mothers. Indeed, the official figures make evident that more and more Israeli women are using anonymous sperm donation to have children. And these children count as Jewish citizens within the wider politics of reproduction and demographic struggle between Jews and Palestinians. Yet, at the same time, the resulting "single-mother families" occupy a marginalized status: as "one + child" they do not count in the same way as the imagined ideal family - father, mother and children. I argue that, in Israel, where family is the basic unit of citizenship, the "single-mother family" makes visible the differential valuation of Israeli families that enables the reproduction of gender hierarchy, inequality and difference that sustains the configuration of a modern and Jewish nation. Through the lens of the single-mother family, A Critical Age examines the kin relations that are productive of inclusions and exclusions that make family and nation in Israel.

As this ethnography demonstrates, single women's endeavors to make families on their own are limited by a cultural understanding of motherhood as an expression of an appropriate relationship between gendered self and society. This relationship is connected to historical transformations and contested ideas about the family and the making of modern Jewish citizens 
through particular family forms. The broader meaning of family and children, however, is also informed by loss in the past and anticipatory loss in the future as the protracted Israeli/Palestinian conflict shows no sign of resolution. Anxieties about losing relations are deeply part of the on-going creation of Israeli families, including single-mother families. Israeli women's narratives of becoming mothers and cultural debates about single-mother families speak to the nuanced challenges of making families in relation to social and political changes and the uncertainties and possibilities they simultaneously engender.

While much has been written about the demographic struggle between Jews and Palestinians, other significant demographic shifts with consequences for the balance of power within Israel are taking place: namely, the startling growth of ultra-orthodox and religiousnationalist Jewish populations that is apparent in the booming West Bank cities such as Ma'ale Adumim, Beitar Ilit, and Modi'in Ilit as well as in communities west of the Green Line. As the growing religious-nationalist community negotiates a life-world that occupies a place between Israeli secularism and Jewish ultra-orthodoxy, issues that pertain to women and family have come to stand for the larger dilemmas of the community. In particular, debates about the "problem" of later singlehood among religious women expose the differentiation of men and women's contributions to building the Jewish house and the cosmological order this differentiation channels from generation to generation.

In the wake of endless conflict, most recently the Second Intifada (2000-2005) and the Lebanon War (2006), the sense of hope that characterized the mood among Israelis I met while in Israel during the Oslo period (1999) has evaporated. The geo-political shift towards the right (building settlements, the continued occupation of the West Bank, military campaigns) has had repercussions for Israel's relationship with its allies in Europe and the United States. While their 
leaders travel abroad making the case (once again) for Israel, Israeli citizens are inundated by media stories that amplify the nuclear threat from Iran. At this juncture, reservists, soldiers and their families are questioning the once unquestionable tenet of military service. Regardless of political affiliation, Jewish-Israeli parents share the potential loss of soldier-sons, even as the meaning of sacrifice for the nation erodes in the face of an ever uncertain future. Amidst this existential predicament, ideas about the familial and collective obligation to memorialize the dead and honor their bereaved families are being reworked through narratives of assisted reproduction and kinship at the threshold between life and death. The single-mother family has come to symbolize the absence of known men in a society that has understood collective commitment and national continuity through a powerful narrative of male sacrifice between generations of fathers and sons.

By attending to cultural representations of the single-mother family in relation to these different frames of reference, A Critical Age considers multiple and contested ideas about gender, kinship and nation. Although a complex and ever-changing political landscape informs ideas about family, stemming from religious and Zionist orientations with different versions of gender hierarchy, they are interconnected: in these Jewish-Israeli kinship ideologies, it is the encompassment of women within families, through ties to known men, that subordinates female reproductive agency to the collectivist goal of ensuring familial and national continuity.

\section{METHODS}

This dissertation explores the complexities of making single-mother families and aims to situate these families within broader Israeli ideas about gender, family and citizenship. While many ethnographies of assisted reproductive technologies and new kinship practices have focused on the particular world of the clinic and the interactions within, I came to understand 
through preliminary conversations with healthcare professionals like Dorit that my questions would take me beyond the walls of the clinic. Rather than examine the steps to becoming a single mother, I focused on the process of making single-mother families. For this reason, I followed women on their quest to have children and create families - in medical spaces and in their everyday lives — as they sought out donor insemination, underwent fertility treatments, experienced pregnancy and birth, cared for young children, and cultivated relationships with extended families.

Between 2009 and 2011, I conducted semi-structured interviews with 42 women lasting between 2-4 hours on average. This sample included 21 single women ${ }^{16}$ and 21 married or cohabitating mothers, including two with lesbian partners at the time of the interview. ${ }^{17}$ The categories of "single" and "married" sound rigid, however several interviewees started the process of becoming mothers on their own (e.g., making an appointment at the sperm bank), meeting partners during the process. Other women commenced with fertility treatment and donor insemination or with insemination from known, mostly gay friends while dating men, and in some cases women. Some relationships ended while others became serious. All of the women were over the age of 38 when they had a child or began the process of fertility treatments. Of the sample, three women were trying to conceive and another three were pregnant at the time of the interview. The rest had already had children, who ranged in age from infants to over 18 and in the army.

These women and their families did not form a single community or claim a common identity. Other than being "later" mothers, they shared little in common - they resided in different regions of the country and came from different socio-economic, educational and professional backgrounds. Women lived in Tel Aviv, Haifa, Jerusalem and surrounding cities as 
well as on kibbutzim. The single mothers in my study were not exclusively middle-class, educated professionals. Among the women I interviewed, there were mothers who worked as childcare providers and house cleaners, students or those with part-time jobs, and women who shared living arrangements with roommates or other family members. Many received economic assistance and support with childcare from their families; most lived modestly, giving up on extras for themselves (vacations, entertainment, buying clothing) in order to give what they had to their children.

From the very outset, I contacted friends and women's organizations and told everyone I met about my project. I received responses from women all over the country and tried to interview everyone who expressed interest. After this first round, many interviewees volunteered to put me in touch with friends, family members and neighbors who had also become later mothers. Often women insisted at the end of an interview that I wait while they called to check on a potential interviewee, handing me the phone after a brief introduction to schedule with the woman. Israeli women are familiar with research, although less so with qualitative methods. I explained the purpose of the study to all interviewees and received written consent. With the exception of one interviewee, I recorded all interviews on a digital recorder and took extensive notes. Almost all of the women I interviewed were working women. For this reason, interviews tended to take place at night (after 8 or 9pm) although I often arrived as children still struggled to fall asleep. I joined other women before and after interviews, walking with them and their children to or from day care and on various errands or hanging out in the park. I stayed in touch with several interviewees: some sent emails adding to their thoughts or updating me, others with young children invited me to meet again. 
During the second year of fieldwork (2010-2011), I conducted 10 months of participant observation and semi-structured interviews with 23 patients in a maternity unit of a large public hospital. The maternity unit contained a high-risk pregnancy unit, which followed many of the "older" patients including women carrying multiple pregnancies (many achieved through egg donation). Due to the lengthy nature of these hospitalizations, formal interviews often gave way to day-to-day chats as patients tried to pass time in the unit. One woman even asked me to stay with her as she experienced early contractions, thanking me for distracting her! Through these women, I met their family members who regularly visited and conducted follow-up interviews with three women at home several months after they gave birth. In the unit, I also interviewed medical staff (e.g., physicians, nurses and social workers) and observed their interactions with patients and their families. Although the hospital is a "medical" domain, over time my conversations with women and caregivers led me to broaden my questions and to understand this space as another site of making family, albeit one of heightened stress and uncertainty.

Throughout my time in the field I attended over 35 medical and social scientific conferences, workshops and study days on topics related to assisted reproduction, later motherhood, and alternative families. Taking place in hotels, medical centers and universities, these events proved to be important sites to observe contested ideas and animated debates about the overlapping domains of medicine, religion, law and bioethics. The Israeli professionals in attendance felt comfortable publicly speaking their minds and even outright arguing with one another. ${ }^{18}$ In addition to listening to lectures and presentations, I spoke with as many people as I could manage during breaks and used these opportunities to hear audience feedback and to network towards future interviews with health care professionals and visits to their workplaces (e.g., to IVF units). In addition to formal and informal interviews with physicians, I interviewed 
rabbis and policy-makers who are active participants in the broader world of Israeli assisted reproduction.

Accounts of assisted reproduction, later motherhood, and single-mother families are widely disseminated through Israeli media, including newspapers, television and internet sites. Between 2009 and 2013, I gathered these stories in order to trace themes and concepts related to these topics. Israelis I met participated in the collection process, forwarding me newspaper articles and telling me about television news and documentary programs. As I soon discovered, some of what I thought were the most improbable or rare stories (e.g., about posthumous sperm donation) turned out to be unexpected sub-genres of the Israeli "IVF story" with numerous examples that quickly filled binders.

\section{Spatial and Temporal Research Sites}

I created a field base in Tel Aviv, which enabled me efficiently to travel to interview women, conduct participant observation at the hospital and attend conferences all over the country. For most of the two years, I resided with my husband, Nadav, and my daughter, Naomi, in tiny apartment in a crumbling Bauhaus-era building on a tree-lined boulevard a few blocks away from Rabin Square. Living at the very center of the "center" enabled me to participate in the frequent national ceremonies, events and protests in the square and to experience everyday life in the cosmopolitan city. At the same time, by situating myself near to a major train and bus station I was able to commute to interviews, meetings and events in other cities and regions of the country.

Though anthropologists have written about multi-sited fieldwork, this project was also "temporally-sited." Like many Israelis enmeshed in family networks, I spent the weekdays 
(Sunday-Thursday) in our apartment and Shabbat and other holidays with Nadav's family at his father's house in Ashdod, a port city that has been settled by waves of immigrants (first from North Africa and later from the Former Soviet Union) 45 minutes south of Tel Aviv. Although Nadav's immediate family is not religious, different members of his extended family practice various degrees of observance, such as following Jewish dietary laws, abstaining from driving on Shabbat, and attending synagogue. Occasionally, we joined his mother for weekends and holidays in her Jerusalem house. ${ }^{19}$ When we stayed in Tel Aviv for Shabbat, Nadav's family often came to visit. I also made trips to stay with friends and their families in other parts of the country. This temporally-sited mobility allowed me to experience the intensity of Israeli family life in a range of locales with different social climates. Cosmopolitan Tel Aviv pulses with life at all hours of the day, including Shabbat as many businesses and entertainment venues stay open. White-stoned Jerusalem, stretching over mountains and valleys, is the governmental and spiritual center of the country, one hour but a separate world entirely from coastal Tel Aviv. Like Jerusalem, Ashdod has a significant population of traditional (masorti) and ultra-orthodox Jews; on Fridays at sundown the commotion of the city halts, and for the next 24 hours only an occasional car or motorcycle momentarily disrupts the eerie quiet. Ashdod is the fifth-largest city in Israel, but is marginalized as a provincial outpost in secular Israeli mental geography—the kind of place that many Israelis have never visited despite its proximity to Tel Aviv and beautiful stretches of sandy beach. These coming and goings between these three cities and the traffic jams in between form the nexus of the place I lived between July 2009 and August 2011.

My movement between houses and families in these places paralleled the experiences of many women I met. While the majority of the women I interviewed lived in Tel Aviv, Jerusalem and Haifa (or suburbs near these urban centers), they too spent much of their free time with their 
parents and extended family. In some cases, parents lived nearby (even in the same building or neighborhood); in other cases, women they made frequent trips to visit family. There was a wide range of sentiment when it came to women's experiences with their families: some enjoyed the closeness while others felt burdened by the expectations. Still, most women imagined close-knit, multi-generational families as an ideal even if they felt that their own families fell short of it.

Although it is impossible for a researcher to know how she is seen by others, dramatic events and life-changes over the course of fieldwork help make explicit how others see us while altering our relationships with our informants. While Clifford Geertz found acceptance after fleeing the police break-up of a Balinese cockfight, nine months of pregnancy, enduring hospital birth, and becoming a mother in Israel changed the way Israelis saw and interacted with me. As my pregnancy became more visible, I became the object of inquiry, concern and advice from Israeli women — friends, interviewees and complete strangers. They worried about me because I had "no family" and was "alone" (they were tremendously relieved to find out that I had my partner, Nadav, and his extended family). After Naomi was born, she traveled with me to many interviews and even slept through a few conferences. We passed much of our free time visiting almost every playground in central Tel Aviv; strolling through the city and riding the bus; resting on benches that line the city's boulevards; hanging out in cafes; and going to the monthly mother-child clinic and doctor's appointments. Through our daily amblings, we met other mothers, grandmothers, childcare providers and even a few fathers. Some of these informal meetings in our neighborhood grew into close friendships. My day-to-day existence as a new (and inexperienced) parent produced many conversations, insights and questions that enriched my ability as a fieldworker to understand the experiences of the Israelis I met and their locatedness within families. 


\section{DisSERTATION OVERVIEW}

The chapters in a Critical Age are divided into two thematic parts. In the first part, "Making Family" (Chapters 1-3), I focus on the dilemmas that arise when single women in their late 30s and beyond reach "a critical age" and embark upon kinship arrangements that encounter the limits of what counts as a normative Israeli family. In particular, these chapters explore the multiple ways that women endeavored to create families in the absence of a known father and/or a heterosexual relationship (whether through marriage or cohabitation). Despite women's creativity in making kinship, these three chapters demonstrate the enduring salience of Jewish men, both as fathers and conjugal partners, for making Israeli families that count.

The second part of A Critical Age, "Making Nation" (Chapters 4 and 5), examines male procreative contributions that are vital to making family and nation. In these chapters, I consider religious and nationalist discourses in public debates concerning two uncommon, though controversial, reproductive routes for single women in Israel: egg freezing technology and posthumous sperm donation. I trace how, across different spaces and communities, Israelis discursively evoke a cultural idea of familial and national continuity at "a critical age" amidst anxieties about the nation's future. According to Janet Carsten, recent studies of kinship "have illuminated the experiential, emotional and everyday dimensions of relatedness, but have tended to leave aside the political significance of kinship" (2007:7). ${ }^{20}$ By foregrounding family as the unit of citizenship, the chapters in this dissertation investigate the possibilities and limitations of making single-mother families — at a critical age for women and the Jewish nation. 


\section{Part I: Making Family}

In Chapter 1, “A Single-Mother Family” I draw upon interviews with single mothers who had children through anonymous donor insemination. Despite the widespread sentiment that single motherhood is "acceptable" (mekubal) for older women, my interlocutors emphasized the social difficulties of becoming mothers on their own, outside of the moral order of a normative family "framework" (misgeret). Instead, they constructed their motherhood as "accepted" and even desirable, despite a lingering sense of uneasiness about becoming mothers on their own. The source of this apprehension, I contend, is the possibility of being marked as "alone" and thus lacking recognized ties both to male partners and to extended kin that are understood by Israelis to embed persons within family. The fragile ground between single motherhood as "accepted," when linked to appropriate kinship relations, and "alone," produced through the absence of family, shapes single women's reproductive experiences. Becoming a single mother may be viewed by others as an expression of individualistic agency, which is perceived to undermine the gendered subordination of self to society central to an ethos of motherhood that is deemed a national contribution.

In Chapter 2, “'Revaka + 2': Single Mothers and the Multiple Meanings of Children,” I consider how women using donor insemination struggled not only with the absence of a known father, but also with the idea of having an only child. The insecurity of everyday life in Israel saturates the cultural logic of having more than one child and the anxiety surrounding the birth of an "only child." Jewish-Israelis value having at least two children: a preference attributed to religious tradition, the trauma of the Holocaust, the demographic struggle between Jews and Palestinians, and the insecurity of daily life in Israel (Kahn 2000; Teman 2010). This chapter provides an ethnographic account of the medical and social dilemmas encountered by older 
single mothers who endeavored to have more than one child. As women's stories reveal, conceiving and carrying a pregnancy at "advanced maternal age" can be fraught with unexpected complications and prolonged uncertainty. Yet even when single women had more than one child, they did not easily qualify themselves and their children as a "family" — a situation they strove to remedy by building strong relationships between their children and male members of their natal families.

In Chapter 3, “'A Syringe and a Cup': Making Families through Shared Parenthood,” I focus on the increasingly popular arrangement of "shared parenting" (horut meshutefet) between a single woman and a gay man, often based on legal contract. Many Israelis consider shared parenthood a way to overcome the social uneasiness surrounding anonymous donation and the missing "father figure" in the child's life. This chapter explores the array of processes and diversity of practices that are productive of Israeli family. While individual choice and contractual relationships are often associated with the "postmodern" or "new" family, as shared parenting is often categorized, women underscored the close friendship with their children's fathers and the care, love and nurturance that made their partnerships into families. Women in shared parenting arrangements downplayed the contractual basis of their relationships. Instead, they underscored the friendship at the heart of shared parenting. Still, in the absence of a conjugal bond or intimate "relationship" with a man, women in shared parenting arrangements felt that they remained single mothers. When the everyday practices of kinship disappear, shared parenting relationships attest to the fragility, rather than the permanence, of conjugal unions. 


\section{Part II: Making Nation}

In Chapter 4, "Establishing a Loyal House: The 'National Problem' of Older Single Women," I investigate single motherhood through donor insemination and egg freezing technology for observant single women in their mid-30s and beyond. In the era of assisted conception, the absence of a husband no longer prevents an observant woman, at least conceptually, from becoming a mother. Over the past decade, a handful of Orthodox rabbis have declared that donor insemination is acceptable on a case-by-case basis for women in their late 30s. Concomitantly, egg freezing technology is envisioned and contested as a solution to the medical and religious predicaments faced by older unmarried women. Together, the options of donor insemination and egg freezing foreground a debate between the secular idea of reproduction as a citizens" "right" and the Orthodox Jewish understanding of procreation as the exclusive obligation of men. In this chapter, I argue that a rabbinical discourse of "establishing a house" has developed as a way to encompass single women's reproductive agency while bypassing technical discussions grounded in religious law. In so doing, rabbis reject the threatening idea of reproduction as individual choice, while delimiting procreation as a divinelyordained male obligation to "build" the world.

In Chapter 5, “'Let Israel Remember': National Sacrifice and the Logic of Male Continuity," I consider how posthumous sperm donation makes visible a gendered logic of continuity through which Israelis make meaning of tragic deaths of soldier-sons and their disrupted futures as husbands and fathers. I show how understandings of male generative power naturalize and nationalize differences between male and female contributions to the making of family and Jewish nation. By analyzing policy discussions, legal cases, and media representations of posthumous conception, this chapter attends to the ways the ideology of 
national sacrifice and the logic of male continuity intersect as Israelis conceive of procreative unions between young deceased men and older single women, who have never met. I argue that in these discourses, the transmission of continuity entails the exclusive procreative power of (deceased) known men ("the living-dead") and the encompassing of (single) mothers within conjugal and generational relations. Men are constructed as procreative agents, whose “sperm/seed" (zera) conceives a child through the mother's body; encompasses the mother-child dyad within his family; and engenders familial and national continuity.

A Critical Age situates women's experiences of becoming mothers on their own in relation to cultural ideas about gender, family and nation. In so doing, it moves beyond EuroAmerican categories of choice, autonomy and individuated actors - categories which inform assisted reproduction, single motherhood and ideas about citizenship in these contexts. At the same time, this study adds a layer of complexity to the tendency to explore assisted reproduction in Israel through the lens of Jewish kinship in the sense of religious law, broadening the scope to consider the coordinates of ethnicity and gender that overlap to fashion a particular JewishIsraeli family ideology. Culture, according to Marilyn Strathern, "consists in the way analogies are drawn between things, in the way certain thoughts are used to think others... all the artifacts we make and the relationships we enter into have in that sense 'cultural' consequences, for they give form and shape to the way we think about other artifacts, other relationships" (1992:33). Drawing on this insight about culture as a set of possible analogies and as the relationships we enter into, or are denied from partaking in, A Critical Age ventures to understand why the singlemother family is an "entirely different" constellation of Israeli family. 
Part One: Making Family 


\section{Chapter ONE \\ A Single-Mother FAMily?}

Who of us doesn't know a woman who is a single mother (em had horit)? This phenomenon has become increasingly prevalent in Israel, like the rest of the western world. - Amia Lieblich (2003:81)

In her groundbreaking ethnography of assisted reproduction in Israel, Susan Kahn observed well over a decade ago that Israeli women who had children on their own through donor insemination were part of a growing "imagined community" (2000:13). Even as this practice was "accepted" (mekubal) by many of her interlocutors, Kahn noted that they did not conceptualize single motherhood as a choice, but rather as the only available (and acceptable) option (2000:18). By the time of my fieldwork (2009-2011), women having children on their own were everywhere: in clinic waiting rooms, neighborhood playgrounds, online forums, and television programs. There were birth classes and doula services for pregnant single women, meet-up groups for new moms, and children's books addressing the subject of single motherhood. Single motherhood through donor insemination was a ubiquitous topic of discussion for Israelis, whether during intimate family meals or on radio talk shows. Indeed, almost everyone I met knew or knew of a woman who had become a mother on her own. Like Kahn, I heard from many Israelis that single motherhood was now "accepted." Yet, despite the significant growth of this reproductive practice since the mid-90s, the Israelis I encountered almost never referred to single motherhood through donor insemination as a choice in the way it was concomitantly formulated as "single motherhood by choice" in the United States.

While it might be tempting to equate American middle-class, educated, professional single mothers "by choice" with their Israeli counterparts, this would elide the complexity of this reproductive route. Undoubtedly, Israelis are exposed to the American concept of "single mothers by choice" through American television shows and films, websites, translated books and 
other media. While these imported concepts are avidly-consumed by Israelis of all backgrounds, simply translating the concept of "by choice" into Hebrew is problematic. As discussed in the introduction, the American category of "choice" used to theorize reproduction (by both feminist and legal scholars) (Franklin 1997; Hertz 2006; Robertson 2003; Thompson 2005) is complicated by the example of single motherhood in Israel. To appreciate why "choice" is transliterated but is not translatable requires situating contemporary Israeli notions of family, belonging and citizenship within a historically and culturally particular, ideological coconstruction of self and society.

Even as older single women increasingly become mothers on their own and may "realize" (memamesh) the Israeli ideal of motherhood, their narratives often reveal a process that remains marked by perceived difference. While the absence of a husband or male partner is constituted as part of this difference, the participation of extended kin is also central to unpacking cultural understandings of "family" (mishpaha). In order to maintain a distinction between the English word "family" and the Israeli concept of family (mishpaha), I will use family to refer to the latter. In this chapter, I explore the predicament single motherhood brings to the creation of family in contemporary Israel, one that concerns the relationship between self and society, the gendered dimensions of this relationship, and the production of difference.

In the first part of the chapter, I consider how becoming a mother alone has the potential to constitute Israeli women as individuals and their motherhood as a form of "self-fulfillment" (hagshama atzmit). In their accounts, women distance themselves from what might easily be interpreted by others as acts of choice, autonomy or individualistic behavior. This finding corroborates Susan Kahn's finding that "the 'choice' to get pregnant via artificial insemination is often not articulated as a choice between having a child within a marriage or outside one, but as a 
more basic choice between having a child or not having a child" (2000:18). Indeed, the women I interviewed overwhelmingly referred to single motherhood as "not giving up" (lo l'vater) on motherhood, rather than as a choice at all. For this reason, holding on to the analytic category of choice to make sense of Israeli single women's reproductive experiences is problematic.

Rather than juxtaposing possible choices ("having a child or not having a child"), this chapter situates women's experiences of becoming single mothers in connection to broader Israeli understandings of the self, family and nation. I endeavor to move away from choice by drawing upon the image of a "route" (maslul) that is frequently employed by Israeli women and health care professionals to describe the complex encounter with assisted reproduction. This term refers to the personal journey—sometimes involving physical travel—as well as to conforming to social expectations of being on the correct path. As I show in this and the following two chapters, women narrate their routes to motherhood in ways that tend to support, rather than challenge, Israeli assumptions about the relationship between family and gendered life course.

Single mothers construct their motherhood as "accepted" (mekubal) and even desirable, despite a lingering sense of uneasiness entailed by their reproductive routes. The source of this tension, I suggest, is the possibility of being marked as "alone" (levad) —and thus lacking recognized relationships both to male partners and to family that are understood by Israelis to embed persons within larger social units. I trace this tension between individualism and collective purpose captured in the concept of "fulfillment" (hagshama) to the period of idealistic nation-building in the first half of the twentieth century. Though much has changed since this formative period, an association between motherhood and fulfillment as ideally a contribution to the nation, rather than an individual act, remains salient in contemporary Israel when it comes to 
creating families. Thus, the act of becoming a mother on one's own makes evident the social limits of single motherhood as accepted.

In the second part of this chapter, I contrast the notion of single motherhood as accepted with a counter-discourse about single motherhood as a contagion or pathology. Given the subsidization of fertility medicine in Israel, single women of diverse socio-economic backgrounds have had access — unprecedented anywhere else in the world — to this reproductive route since the mid-1990s. This same period has overlapped with massive changes to the demographic composition of Israeli society, including the arrival of nearly one million Russian immigrants, many of whom were single mothers. In fact, the very terms to describe single motherhood in Hebrew are inextricable from the stigma encompassing these newcomers and their families, who in many cases did not fit the ideal construction of family. Taking into account this recent history, I argue that the acceptability of having children through donor insemination is further circumscribed for women from immigrant and other minority communities who are perceived of as on the margins of Israeli society.

Single women who become mothers on their own risk becoming associated with bedidut ("loneliness"), but in a broader context this term refers to Israelis without recognized family. As I argue throughout the chapter, the distance between bedidut and mekubal ("accepted") is tenuous for all single mothers and is maintained through relations to family, the relational web through which Israelis become culturally intelligible persons. These social ties situate Israelis as a part of an acknowledged "framework" (misgeret), shorthand for participation within social institutions that enable the cultural work of differentiating individualistic actions from those which are perceived as a contribution to society (referred to in Hebrew as "the collective" - hakolektiv) and thus the nation's future. However, as the accounts in this chapter demonstrate, women from 
marginalized communities are more likely to be perceived of as without frameworks and therefore as existing in bedidut. The fragile ground between single motherhood as "accepted" (mekubal) when linked to appropriate frameworks and "loneliness" (bedidut) marked by the absence of family exposes a gendered ethos of the relationship between self and society that shapes women's reproductive routes in the post-Zionist age.

\section{MOTHERHOOD AND FULFILLMENT}

Single, 39 years old, Adi rents a small flat just east of Tel Aviv and works as a graphic designer. Ever since she can remember, Adi dreamt of getting married by 25 and of having three children and of living in a house with a garden in a collective village (moshav). She told me, "I thought that the center of my life would be the family and the children." Adi called me to move our meeting to a lively cafe at the end of her street—she couldn't stand to be at home any longer. When I arrived, she was standing near the entrance, uncharacteristically early. We sat down at a corner table, and Adi placed her phone on the edge of the table. She kept her hand alongside it for the next two hours while we talked; she explained that a nurse from the clinic might call at any minute with the results of her pregnancy test.

A few months earlier, Adi made an appointment with a fertility specialist at a medical center in Tel Aviv. She was worried that, at her age, it might be difficult to conceive. Adi, like all female citizens of Israel, has access to assisted reproductive technologies (ART), including high-tech medical procedures such as in vitro fertilization (IVF), until the birth of two children. This has been the case in this country of seven million people since the passage of the National Health Insurance Law in 1994. As discussed in the introduction, the facts and figures of Israeli high-tech reproduction are widely-acknowledged, repeated and circulated in local and international medical, social scientific and popular discourses: Israel is known as "the world 
capital" of fertility treatment (Kraft 2011); per capita, it has the highest rate of treatment cycles and the most fertility clinics in the world (Birenbaum and Birenbaum-Carmeli 2010).

In the shadow of high-tech fertility medicine, the routinized preconception and prenatal care Israeli women receive is less often the focus of contemporary study. ${ }^{21}$ These extensive medical services, including genetic testing, diagnostic imaging, pregnancy follow-up, hospitalization, labor/delivery and peri-natal care, are neither inconsequential nor low-tech in their own right. Given the high rate of multiple pregnancy and the risks of "advanced maternal age," many older first-time mothers experience complications at some point during their pregnancies (see Chapter 2). For Israeli women like Adi, fertility treatment and prenatal care, though not free of charge, are not experienced as financial obstacles in the way of having a baby. ${ }^{22}$ This access to a medical system that promotes both high-tech reproductive technologies and prenatal medicine enables thousands of single Israeli women like Adi-in their late 30s and beyond - to have children on their own.

We had been sitting for nearly an hour and Adi still had not received a call from the clinic. As we waited, she told me about her personal journey over the years, the reflective practices — drawing, journaling, yoga, and psycho-analysis - through which she located and learned the contours of her desires, and later, the fears of taking this route to motherhood. She spoke about her success as a designer, which she described as her "accidental" career, since she had studied engineering in university. Despite her pride in her professional accomplishments, Adi explained that she did not wait to have a child because of her career. Rather, she told me: "I didn't find a male partner" (lo matzati ben zug). I heard this phrase from many other women I interviewed, from diverse socio-economic and educational backgrounds. The construction "I didn't find" implies that one was actively looking for a male partner, and thus acting in 
accordance with cultural expectations that one marry (or at least cohabitate) before having children. As such, this expression emphasizes life circumstances over the "choice" to become a single mother or the priority of other goals including professional accomplishments.

When I asked Adi what the term "later motherhood" meant to her, she answered by contrasting the Israeli context with what she perceived to be the experience of American women, who in her understanding, choose to wait because of career and education. While familiar with the American concept of later single motherhood by choice, as she had lived in the US as a young adult for several years, Adi explained why Israeli women's experiences were different:

In general, it's a conflict (konflikt) when you say "later motherhood." Let's truly assume that a woman, with the whole feminist revolution, is enabled and puts self-fulfillment (hagshama atzmit) of the woman at the head of priorities, so her self-fulfillment comes before [her] fulfillment (hagshama) as a mother. When a woman realizes her womanhood/femininity (nashiut) in this way, realizes motherhood in this way so you (at) are in a conflict, in front of your westernness (hama'araviut shelakh) and on the side, something that I think is submerged very powerfully in the Jewish genotype (genotip) that needs to worry about the next generation, that needs to realize the maternal potential, to continue to bring children, to worry that there will be a skeleton (sheled) for the family, that it will be passed, that the genes continue, and it's very powerful. To a great extent, it's stronger than the need to clarify "who you [are]" and to ask yourself (atzmekh) the individual questions.

In Adi's formulation, becoming a mother is a kind of "fulfillment" that contradicts "selffulfillment" (hagshama atzmit). Though the "feminist revolution" has increased opportunities for professional, middle class women, situating motherhood in relation to other individual priorities (education and career) engenders a conflict for Israeli women. According to Adi, the construction of motherhood as an individual priority is part of "westernness" that contradicts the passage of Jewishness, constructed here as a biologized essence or literally "genotype" (genotip), a Hebraized take on the English word. Thus becoming a mother fulfills a contribution to the generational continuity of the Jewish essence; it is a duty that is future oriented and concerned with the passage of this essence. This orientation puts motherhood ahead of what Adi 
understands as the western preoccupation with asking "individual questions" and striving to find an authentic "self."

For women like Adi, contemplating the act of becoming a mother on one's own exposes a gendered opposition between self and nation. This tension emerges when motherhood is placed in the category of "individual priority" and therefore is a practice of "self-fulfillment." In contemporary Hebrew "self-fulfillment" (hagshama atzmit) and "fulfillment" (hagshama) are practically synonymous. Given this overlap, Adi's statement, which places these terms in opposition, is striking. Making sense of this salient distinction requires travelling back in time to the period of Zionist settlement and nation-building that produced the cultural ideal of "fulfillment" (hagshama).

\section{Collective Terms of Fulfillment}

Hagshama was part of a "linguistic code" that came into widespread use in oral and written discourse in the 1930s and 40s among the young labor movement participants (Almog 2000: 63-64). Used as both verb and noun, the term captured the Zionist objective to create "the new Jew" through the redemptive activities of labor, settlement, and later, defense. Together these socially exalted practices were captured in the overarching ideological concept of hagshama, setting into motion the material transformation of both bodies and territory deemed foundational for the Zionist project. This transformation involved a shift in purpose, from the spiritual orientation of Judaism in the Diaspora toward the world to come (olam haba) to the physical toil demanded by the Zionist movement in the land of Israel—labor which would redeem the Jewish people in this world. Thus, hagshama means "actualized" or "realized" through physical activity that produces material rather than primarily spiritual results. 
The pioneers (halutzim) who fashioned themselves as the elite vanguard of the labor movement and lived under the banner of hagshama rejected the socio-economic ideological order behind the concept of the western individual. Representative of the Zionist ethos from the period, hagshama divulges the "sense of intoxication and idealistic enthusiasm and commitment" to the collective nation-building project for which this generation is remembered and immortalized (Almog 2000:63-64). In this revolutionary orientation, one's personal fate and the national mission of settling and defending the land became inextricable. Further, amongst the pioneers it was only through hagshama atzmit that one became part of "a chosen group that took matters into their own hands" - being an individual apart from the group cast one as an outsider, as a "remnant," the very object that stood for the failure of Jewish life in the Diaspora (Luz 2003:76). During these formative decades in Israeli history, the individual "self" was insignificant outside of his commitment to building (and actualizing/realizing) the collective in the Jewish homeland.

According to Israeli historian Gershon Shafir, in the Labor Movement's worldview “the strongest commitment to the national goals was expressed in the practice of hagshama atzmit, a term seemingly easily translatable as 'self-fulfillment' or 'self-realization'” (2002:43). Yet, Shafir is careful to emphasize that the "individualist bent" of the term when glossed in English is completely absent in Hebrew (2002:43). This difference is made even more apparent by the fact that from its origination as linguistic code in the 1930s and its continuing usage well into the 1960s, fulfillment (hagshama) and self-fulfillment (hagshama atzmit) "were synonymous"they referred "not to an individual's act but the self-realization of the virtuous citizen, namely, the carrying out of the movement's pioneering goal by the individual member as his/her duty qua 
citizen. Hagshama atzmit meant personal participation in the collective endeavor of transforming Palestine into a Jewish homeland" (Shafir 2002:43).

Although egalitarian relations between men and women were part of the Zionist ideology, the focus of the movement was on the young Jewish (Ashkenazi) male. ${ }^{23}$ The effeminate Jewish male of the Diaspora was to be remasculinzed by "making the desert bloom," as he worked the virgin soil of the land of Israel by digging, planting, and plowing; by moistening it with blood, sweat and tears (Neumann 2011:5-7). Women's participation to this national project was secondary. Male sexuality, perceived as impaired from its physical, generative function by the Diaspora, when channeled as procreation (through women's bodies) appears to have been constituted by early Zionists as a dimension of hagshama (Biale 1992:189). ${ }^{24}$ The "fulfillment" (hagshama) that subsumes body to collective through erotic encounter with the feminized land tends to assume a male agent. ${ }^{25}$

Since the period in which hagshama became a linguistic code, Israeli society has undergone drastic political, economic and social changes. In the wake of the 1967 and 1973 wars, cracks emerged as Israelis began to challenge the ideological tenants of Zionism and to expose inequalities within the façade of egalitarianism. During this period, individualism gradually replaced the collectivist ethos as a consequence of the expansion of a free market system, the influx of consumer goods, and for many, a rise in standard of living (Hazan 2001:16). ${ }^{26}$ As the influence of Labor Zionism waned, so did the linguistic codes that shaped the movement.

In contemporary usage, hagshama atzmit has become synonymous with another term for "self-fulfillment" that became popular in the 1980s (mimush atzmit—also translated as selfactualization or realization) (Shafir 2002:43), which lacks the deeper etymological history. ${ }^{27}$ 
These terms are widely employed within self-help, counseling, life coaching and other therapeutic practices that have become commonplace in Israel since the 1970s. On the surface, the proliferation of "self-fulfillment" in Israeli popular, new age and psychological discourses suggests that the modern subject—-the unique, self-determined, bounded individual—has entirely supplanted the earlier Zionist subject, whose selfhood was materialized through hagshama and his unwavering contribution to, and even death for, the collective. Yet even as Israelis proclaim the possibility of "self-fulfillment," its earlier meaning often resurfaces, which in turn creates nuanced cultural palimpsests.

\section{The Gendered Dimensions of Self-Fulfillment}

Even though hagshama atzmit and mimush atzmit can refer broadly to any kind of personal process of improvement in contemporary speech, the phrase "to realize oneself" (le'mamesh et atzmech or le'hagshim et atzmech) remains tied to its earlier linguistic codes and to their gendered dimensions. For example, in a song titled "Hagshama Atzmit" (selffulfillment) on his 2009 album, pop singer Eric Berman cynically bemoans the expectation that, as a left-leaning celebrity, he has a duty to the country:

I go up (oleh -literally ascend) to Jerusalem, to a party of so-and-sos (mi v'mit). I go to wash my hands in the local scene (habitza hamekomit) I will put a note or two in the Godly wall (hahoma haelohimit) Not in the name of heaven (shamayim), but in the name of self-fulfillment (hagshama atzmit)

I will lead battalions of youth in the existential war, They will write to me in the mail, I will autograph them with my name To the prisoner in the jail, to the terminally-ill

Not in the name of purity, but in the name of self-fulfillment (hagshama atzmit)

Chorus:

Some woman once told me that all of this won't do me any good, But what does she understand? In another second I'll reach it. "Keep your dreams for yourself and for the nights So that you'll be able to wake up, otherwise you'll go crazy" 
I'll sing a song for peace on the national square (kikar haleumi)

I'll vote for peace on the empty square

I'll salute to peace on the square of speeches

I will bring the peace, yes self-fulfillment.

Along with his whiny voice, Berman's angry words convey the disillusionment of young, leftleaning Israelis in the post-Zionist era. In the first stanza, Berman begins "I ascend to Jerusalem" using the word oleh used to signify the holiness of this act. On the way, he tucks a note into the crevices of the Western Wall (hakotel) — the last remaining wall of the Second Temple), which is considered one of the central components of religious pilgrimage to Jerusalem. Yet, Berman refers not to the Western Wall as hakotel but as "the Godly wall" (hahoma haelohimit), implying a wall of defense and belittling its holiness by turning "God" into a mere adjective. His note does not concern spiritual matters (literally: in the name of heaven/the skies), but instead in the name of "self-fulfillment." ${ }^{, 28}$ In the second stanza, Berman mocks his participation as a soldier and as a celebrity expected to guide the angst ridden youth in the era following the Second Intifada and the Lebanon War. Instead, he imagines that, under his leadership, the battalions of youth will refuse to serve the country—instead they will be imprisoned as conscientious objectors or labeled medically incapable (here literally dying). In these two stanzas, "self-fulfillment" is explicitly constructed against the collective symbols of religious devotion and national service.

However, it is the chorus of the song that makes the gendered dystopia of Berman's rant apparent. In these memorable lines, "some woman" tells the pop star "keep your dreams for yourself...so that you'll be able to wake up," reminding him of his obligations; she cannot "understand" his desire for "self-realization" and further scolds him for dreaming and tells him to 
"wake up." Here the opposing actions of contributing to the national purpose or rejecting these duties in the name of self-realization are both constituted as "male" possibilities. On the other hand, "some woman" is a reminder of the place of women in Israeli society as neither defenders of the nation nor rebellious individuals. The generic woman's role is to chide Berman to abandon his narcissistic fantasy of abandoning his obligations - in this case, to perform the expected role of singing for peace on the national square. Insofar as "some woman" stands between Berman's "self-fulfillment" and his national commitment to serving the country as a Jewish-Israeli man, how do Jewish-Israeli women experience the relationship between self and society/nation?

When I asked an Israeli friend, who identifies as staunchly secular, whether motherhood could be a kind of "self-fulfillment," she seemed shocked by my question. "It sounds funny to say 'to realize yourself as a mother." Sensing my confusion, she added, "I didn't choose to [become a mother]. Motherhood is an obligation (hova)!” In fact, the contemporary understanding of hagshama atzmit sounds jarring to some when applied to motherhood. While motherhood and self-fulfillment are in tension, self-fulfillment is not equally available to men and women. For example, an Israeli social worker in her 30s and mother of three children told me, "There is no man who needs to realize himself (l'hagshim et atzmo), he is already there ( $h u$ kvar sham)." She continued, self-fulfillment is "not staying at home with the kids." In her understanding, Israeli men already exist within the realm of fulfillment while women struggle to achieve this goal, for it is the ideal of motherhood (caring for children) that blocks the very possibility of self-fulfillment.

Likewise for Adi, a conflict exists between self-fulfillment and fulfillment as a mother. Insofar as single motherhood is constituted as an individual choice it belongs to the realm of 
Westernness and the modern subject. Motherhood is not part of "self-fulfillment" because it is encompassed by the demands of the Jewish people for the preservation of collective "continuity" (hemshekhiut) through women's bodies (see Chapter 5). In Adi's understanding, motherhood is a woman's contribution to the continuity not of individual genetic essence, but of the essence of the Jewish people; motherhood means worrying not about her children, but about the future Jewish generations that enable one to fulfill one's "maternal potential." As such, constituting motherhood as the "self-fulfillment" of individual desires conflicts with the cultural ideal of motherhood as the fulfillment of existential obligation.

Even as they shared their personal journeys to motherhood and the kinds of self-help and self-awareness methods that enabled them to come to a decision, the Israeli women I encountered did not consider motherhood as an individual goal or choice, but rather as a duty, obligation or expectation. Their accounts reveal that the meaning of single motherhood remains deeply enmeshed in gendered ideas of personhood and citizenship, national belonging and modernity, and the historical relationship between self-fulfillment and collective purpose. A key dimension of this understanding of motherhood is that of a particular cultural temporality, a flow that binds individual lives to national experience.

\section{The Flow of Life}

"No, no, no! You're trying to put this into the American framework of thinking," Dr. Geva interrupted me, mid-question. I had asked her about waiting to become a mother, and she was responding to my use of the word "waiting"; this exposed, as she put it, "your American way of thinking." "I'm glad you bring that up, the American context...there is something different here [in Israel]," I replied. "Very much so," Dr. Geva nodded her head in agreement, and she continued in English, “I don't think I know one woman among my Israeli friends, of all 
ages, who decided 'I want to finish my career first." Dr. Geva had lived in the States for a few years during her mid-30s, while pursuing a prestigious fellowship on the East Coast. Several years later, after returning to Israel, she had become a single mother through anonymous donor insemination. Given this experience, she was able to articulate the difference between what is known as "single motherhood by choice" in North America and to what she referred to as "solo motherhood" (emahut yehidanit) in Israel.

Without prompting, Dr. Geva compared the way Israeli women think about having children to the way middle class American women "plan" to have a child. When American friends had shared their "plans" and "decisions" about having children, she admitted how strange she found this way of thinking about life. She explained to me, "It's paradoxical, because Israelis are open to talk about everything and the boundaries of conversation are flexible, but on the other hand, Israelis won't talk about deciding to have a child." In fact, Dr. Geva admitted she was bewildered by conversations she had with married American acquaintances on the East Coast who disclosed to her that they were actively "planning" to have a child. She juxtaposed their way of thinking about reproductive decisions with what she asserted was the normative Israeli way, "If [an Israeli couple] married six months ago, and they're not pregnant, somebody would say something. And they will say, 'We're working on it,'-like, we're having a problem. But it's not like one, two, three: 'we've got to this decision to actually work on it.'” Dr. Geva had strong feelings on this subject, and before I could ask her to expand, she volunteered an explanation:

In Israel, everything sort of flows, its normal and its expected that you get married...say around 27 to $33 \ldots$ and then within the first year, regardless of what you do, you get pregnant. And if you don't get pregnant, then the family starts asking questions, first behind your back and then straight in your face. And then they start asking, "Did you ovulate?" 
For Israeli women, including those in the secular (hiloni) community, getting married and having children are practically synonymous. (Of the five Jewish weddings I attended during my fieldwork, all of the brides gave birth within a year—or less—of the wedding.) Fertility specialists I spoke with commented on the tremendous anxiety felt by newly-weds, who arrive for consultation after fewer than six months of attempting to get pregnant. What Dr. Geva adds to this picture is that couples' experiences are embedded within the expectations of their extended families, and that married woman are subject to the stomach gazing, gentle prodding ("so" $-n u$ ?), and sometimes interrogative questioning by their concerned relatives.

Dr. Geva's emphasis on "regardless of what you do" speaks to the widespread understanding that a woman's other life activities, her personal ambitions and financial situation should not hinder her from becoming pregnant. That is, once a woman is married (or is in a cohabitating relationship resembling marriage), nothing should stand in the way of having a baby. For Dr. Geva, this urgency was the salient difference between my "American thinking" and Israeli women's experiences. Like Adi, she tried to explain her ideas by offering a comparative analysis of American middle class parenthood:

I think in the US, not only is everything compartmentalized, its also sort of organized, like you get married and then you finish your career stage whatever it may be, and then you discuss it, and you make decisions and you have a project. So you go about doing the project, while at the same time, you start decorating the baby's room. Am I drawing the picture? I'm exaggerating for the sake of conversation.

Dr. Geva was quite animated, even passionate on the topic. She admitted that her experience of America was confined to "East Coast professional [women]...a thin social layer, it's not like we can discuss the American woman." She was also careful to qualify that she was not claiming to speak for all Israeli women or for all Israeli single mothers. Despite her self-reflexive 
"exaggerating" style, I sensed that her distinction between the cultural ideas about reproduction in Israel and the United States was germane.

Dr. Geva found the linear organization or, in her words, "compartmentalization" that imagined commonsensical to American middle class women - incongruous with the condition of life in Israel. "Israeli women have a lot more pressure put on them, because of this invasion of privacy and having a disorganized life. [It] is much more difficult [here]," she reasoned. Dr. Geva remembered a scene at the hospital during the second Lebanon War in 2006. She had brought her then four-year-old daughter to the emergency room, where she was working a roundthe-clock shift. It was a last minute decision on her part, but she did not want to leave her at home, given the tension and uncertainty in the air. (Would there be a missile strike that could reach them in Tel Aviv?) Dr. Geva recalled the chaotic scene in the emergency room, as she and her colleagues stood by, waiting for incoming causalities and fearing the worst, while her daughter played in the unit's corridors. In this moment of national insecurity, of imminent crisis, Dr. Geva's lives as physician, mother, and citizen were inextricably tangled and all at once called to the front lines. When Dr. Geva spoke about her work and her career, she enmeshed it within her unit, the work of her team in running in major unit in a central Israeli hospital. In these moments of national emergency that punctuate daily life in Israel, the "we" tends to dominate the narrative, as the individual person dissolves into the plural.

I think that this dissolution of the individual is what Dr. Geva meant by "invasion of privacy" and "disorganized life." To her, it was ridiculous to operate as though one is in control of one's individual choices. Having children is inextricable from living under the shadow of uncertainty and insecurity, a front that threatens to emerge at any moment that makes planning for the future seem ludicrous. Though the political "situation" (hamatzav) waxes and wanes, this 
flow of life subordinates personal lives to the nation's (in)security (see Ochs 2011) and to the "binding force" of Israeli collectivist ideology (Hazan 2001:14). As Dr. Geva explained, it is hard to have fantasies of an organized path and of a settled future, impossible and even foolish to make "decisions" and to rationally plan amidst these existential circumstances that can, at any moment, no matter who you are, so violently and unexpectedly usurp the flow of life. It is against the backdrop of this "situation" that women like Dr. Geva become mothers on their own.

Like the close knit hospital team she worked with, Dr. Geva described the way that, ideally in her eyes, single Israeli women should become mothers "with the mother's extended family's support." Even as Dr. Geva emphasized that single motherhood was a reproductive route embarked upon within the context of a broader family that would help raise the child, her parents were no longer living by the time she had a baby. This absence, she told me, was the most difficult part of becoming a parent on her own. Yet despite her own personal circumstances, she nevertheless generalized that single women who become mothers with the support of their kin are constituted as a family. While many interviewees like Dr. Geva commented on the care that they might have received from grandparents and grandmothers in particular, this care went beyond its material and affective dimensions. Having a child with "the mother's extended family's support" meant that one would not be alone (see Chapter 2). The anticipated participation of extended family in the care and nurturance of young children is a central trope in Israeli popular discourses that constitute single motherhood as "accepted." In this understanding, single women's reproductive routes are not individual choices, but rather conform to the flow of life, to building family networks, and to motherhood as fulfillment. 


\section{No Other Choice}

In her early 40s, Dr. Geva had undergone anonymous donor insemination with IVF and, after more than 10 cycles of treatments, became pregnant. On the surface, she seemed to fit the Euro-American model of a later (single) mother, as a woman who had completed extensive education and worked hard to build her career in Israel. Yet even as Dr. Geva occasionally used the English expression "single mother by choice" when talking to me, she reconfigured its meaning. On becoming a single mother, Dr. Geva told me, "Having no other choices, then I'll take that path, and it will better my fulfillment." We were speaking in English, and so I interrupted her to ask, "What word would you use, in Hebrew, for fulfillment?" She volunteered two words, "mimush atzmi" and "hagshama." Unlike Adi, who contrasted self-fulfillment (hagshama atzmit) with fulfillment (hagshama), Dr. Geva equated these two concepts. She did not construct single motherhood as a kind of "self-fulfillment" in opposition to the fulfillment of motherhood as a national obligation. Nevertheless, she emphasized that it is the very lack of choice that brings to fruition this fulfillment. As I understand her explanation, when becoming a single mother is not done on one's own, when circumstances replace intention and life flows, then the only available route leads to fulfillment.

In women's accounts, single motherhood is contrasted with individual choice. It is following the expected flow of life — becoming a mother and having a family — that engenders self-fulfillment. Ayelet, a 39-year-old single woman who grew up on a secular kibbutz and now worked as a university lecturer in Jersualem, told me of her desire to become a mother:

I've already understood for a while that I haven't succeeded to realize/fulfill (lo matzlikha l'hagshim) the dream of a complete family (mishpaha mushlemet). No doubt that part of that is from choice, of who I grew up to be and my priorities. I have no doubt that part of it is that I simply haven't succeeded. 
According to Ayelet, a complete family is something that can be "realized/fulfilled," while choice and individual priorities lead away from this possibility, and from the gendered Israeli ideal of success. For Ayelet and Dr. Geva becoming a single mother is not constituted as an individual choice that leads to (self)-fulfillment, but rather a path that conforms to the normative expectation of motherhood and with it, success.

While many Israelis now use hagshama and hagshama atzmit as synonyms, the historical layers within these terms remain central to understanding a salient difference that is all too easily

glossed over in translation. When reproductive agency is considered through the cultural lens of fulfillment, the gendered relationship between self and society (Jewish collective) comes to the fore. This relationship shapes the experience of reproductive temporality. For Israeli women, the flow of life is nationalized: it isn't something that one chooses or controls. Motherhood, in this understanding, cannot be fulfillment when it is constructed as an individual choice. Further, in idealized accounts, single motherhood involves the participation, care and support of extended kin; it is thus situated in the context of family rather than individual experience. Yet, when single women narrate their motherhood in the conventional terms of fulfillment, they are aware of the fragile negotiation between single mothers as "accepted" and as others, who are considered "alone."

\section{Foreigners}

As she waited in anticipation for the news of a much-wanted pregnancy, Adi struggled with the idea of an anonymous donor. She spoke not of being a single mother but instead of her observations about single motherhood in Israel: 
There is a social stigma on single motherhood (imahut yehidanit). The secular society is supposedly more open, especially in the center (hamerkaz), but to a large extent [this society] does not accept foreigners (lo mekabelet zarim).

Adi, like Dr. Geva, used the recent, updated and more politically-correct sounding term for women who become mothers on their own, "solo motherhood" (imahut yehidanit). When speaking about stigma, Adi might have used the more common term, single parenthood (had horiut also "lone parenthood"), now in use for over two decades, which encompasses circumstances considered unfortunate: divorce, widowhood, separation, agunot (abandoned women according Jewish law), all stigmatized in different ways. Whereas had horiut can refer to women's (and men's) status in the wake of intimate relationships that dissolve, imahut yehidanit indicates an emergent kind of parenthood—-solo mothering. This term refers to women who become pregnant using anonymous donor insemination with the intention to parent on their own. Solo mother (em yehidanit) contains an implicit contrast to single mother (em had horit); only the former raises questions about unknown paternity.

While "single parent" (had hore) can be masculine, it is almost always feminized in context. This is due to the fact that the vast majority of single parents in Israel are women. Indeed, as of 2008, over 95 percent of single parent families in Israel were headed by women (Ministry of Welfare 2008). In 2010, 37 percent of these families were deemed at risk of poverty (Druckman 2012). And while imahut yehidanit carries a ring of political correctness, some Israelis are uncomfortable with the term, expressing their discomfort to me by scoffing at its "feminist" ring. ${ }^{29}$ Others who used this term recognized this negative association. For example, Noga who self-identifies as a radical feminist and "solo mother" (em yehidanit) said of the term, "It threatens, [because] it breaks the structure of the normative family." Given its "feminist ring" and thus its threatening implications, in everyday speech "single parent" (had horit) endures as 
the more commonly used term to describe single motherhood. ${ }^{30}$ As such, it always already encompasses solo mothers within the overarching category of women and children living at the social and economic margins of Israeli society.

By using solo motherhood (imahut yehidanit), Adi set this route apart from other circumstances encompassed by single motherhood (had horiut). However, even while employing this more progressive sounding term, Adi called attention to the enduring stigma that supposedly no longer exists in "secular society," the cosmopolitan spaces associated with progressive political leanings known to Israelis in Hebrew as "the center" (hamerkaz). The distinction between the center and the periphery is one made in both local academic and popular discourses. The center, however, is not entirely a spatial or territorial notion but a conceptual and ideological terrain. To set it apart from the rest of the country and from urban spaces like Jerusalem and B'nei Brak inhabited by ultra-orthodox Jews, the secular center is jokingly called "the State of Tel Aviv" (medinat tel aviv) - a play on "the State of Israel" (medinat yisrael), the country's official name. Medinat tel aviv refers to the existential state of being, to urban and secular subjectivities of the country's center, in contrast to the ways other Israeli spaces are imagined from its economically-privileged vantage point as less tolerant, cosmopolitan or modern. Hence, it points to the possibility of an alternate state of existence to the ever-encroaching religiousnationalist tide felt by many Israelis who identify with the secular center.

Even more striking is Adi's use of the word "foreigners" (zarim) to refer to the otherness of single mothers within secular society. In Biblical and contemporary Hebrew, zarim differentiates between Jews and non-Jews. In the wake of the Second Intifada, it has taken on new meaning as foreign workers from the global South replaced Palestinian workers, who are no longer able to enter the country. ${ }^{31}$ At the time of our conversation the zarim referred to foreign 
workers either as a stand-alone noun or adjective affixed to "workers" as in "foreign workers" (ovdim zarim), a category that includes legal and undocumented labor migrants. Many of these foreigners live in the "center" with their Israeli-born children, who may speak Hebrew, but who can never fully belong to the "secular society" or the nation as citizens (see Willen 2007). ${ }^{32}$

While the children of Jewish-Israeli single mothers through donor insemination do not share the precarious situation faced by the children of foreign workers who live at risk of deportation, Adi's implicit comparison to this insurmountable otherness is illuminating, particularly since she is a second generation Israeli. Amidst this shifting political-economic context, Adi's use of zarim implies that single mothers and their children from anonymous sperm donation are more akin to foreigners and their children (yaldei ovdim zarim) than to native born Jewish-Israeli children. That is, the children of single mothers through donor insemination will always be marked by their uncertain status - a son or daughter from the sperm bank (yeled mibank hazera), a child from somewhere else, from a source that is unknown and unknowable. Their situation contrasts with the children of Jewish-Israeli couples, whose belonging, authenticity and Israeliness is unquestioned.

\section{Peripheral Mothers and the Construction of "Frameworks"}

While women like Adi and Dr. Geva grapple with the meaning of becoming a single mother in relation to Israeli ideals of motherhood as fulfillment, women on the margins of Israeli society narrate different struggles. In the accounts that follow, I move from the socio-economic center to the Israeli periphery, from single motherhood that offers tenuous membership to the collective to single motherhood as contagion or pathology. I demonstrate that, for marginalized women, becoming a single mother risks the social censure of "loneliness" (bedidut) associated not only with the absence of fathers, but primarily with the absence of family. Bedidut is 
associated with those who lack ties to recognized social institutions, frequently called "frameworks" (misgerot, singular: misgeret), which are understood as the way individuals are incorporated into the larger society (hakolektiv). Together, the narratives of single mothers from diverse socio-economic, ethnic and religious backgrounds point to the multiple ways that bedidut is produced through encounters with medical, state and religious institutions and contested by women.

Those who are deemed as lacking family are often considered in both popular and professional discourses as in need of a "family framework" (misgeret mishpahtit). The word "framework" (misgeret) is ubiquitous in contemporary Hebrew, among social scientists and laypersons. It often is employed to describe social institutions such as the army, early childhood education (gan) and youth groups that once held a central role in the production of the Zionist collective. For example, of a toddler it is commonly asked, "Is he in a framework (misgeret)?" with the word "framework" substituted for preschool ( $\mathrm{gan}$ ), which is understood in context. Of a troubled young adult, it might be said "he has no framework" (ein lo misgeret) or that "he needs a framework." The assumption is that once in a framework, his individual problems will be resolved through the socialization of the group. Insofar as a vital component of family is identified as missing, a "family framework" (misgeret mishpaha) is deemed necessary to prevent social breakdown. Indeed, in the early years following the creation of the state, orphans and abandoned children were placed in kibbutzim and residential educational institutions (Razi 2010). Similarly, soldiers without families (oftentimes recent immigrants) are considered "lone soldiers" (hiyalim bodedim) and are placed with foster families, who care for them during their army service. (Typically, Israeli soldiers receive extensive support from their families, returning to their homes on Fridays to enjoy meals and have their laundry done.) 
Single mother families are also considered in need of frameworks. For example, in conjunction with the Ministry of Welfare, Israeli municipalities including Haifa, Jerusalem, and Tel Aviv run special programs for single parent families who are considered "at risk" (b'sicun). Among the goals of these programs are:

[To] provide assistance to ensure family, personal and social functioning of single parent families (mishpahot had horiot). Creating a supportive framework (misgeret) from which a mutual support can grow. Concentrating professional information and updated material related to single parents (feminine - parents had horiot) and a link to other aid organizations. ${ }^{33}$

In this mission statement from the city of Haifa, nearly identical to those from Jerusalem and Tel Aviv, the provided framework enables the development of support. Frameworks are social institutions that mold single-parent families into functioning entities. The gendered language of these statements implies that the single parents (had horiot) in need of these supportive frameworks because they deviate from the normative family are women.

Although unmarried women seeking to become mothers tend to distinguish their intentions from women who became single mothers through divorce, the state groups these women within the same category - the single-parent family. When it comes to creating families, unmarried women with fertility problems encounter discrimination sanctioned through Israeli legislation. The heterosexual, married couple is the privileged family, while single women and their children are constituted as needing external "frameworks" and extra institutional support in order to function. Regardless of background circumstances, the single-mother family, on its own, is not conceptualized as a complete family framework. This categorization has consequences for the limited range of options single women have to become mothers in Israel. 


\section{A Chocolate Baby}

"My life was children, but not ' $m y$ ' children," Ofra told me. For as long as she could remember, Ofra had looked after children: as the oldest child growing up in large mizrahi family, she helped raise her five siblings; as a cousin and aunt, she had cared for the family's younger generation while their parents worked; and as a teacher, she had worked with hundreds of students. Surrounded by her siblings, close friends, and colleagues, Ofra was seldom alone; it was this "environment" ( $s$ 'viva), in her words, which supported her quest over many long years to become a mother.

When she turned 40, Ofra went to find out about donor insemination at a sperm bank in Tel Aviv. A nurse explained the bureaucratic and medical aspects of the procedure. Feeling encouraged, Ofra asked to schedule another appointment. However, the nurse entreated "What do you need this [for]? You're still young!" She reassured Ofra that she still had more time. That is, the implicit message was that Ofra was "still young"- that she should continue to look for a husband and that single motherhood through donor insemination should be the very last resort. "So I left," Ofra explained, "and when I returned [to the sperm bank] at age 43, it didn't work." Whereas at 40, Ofra was told that she should not give up on finding a husband, when Ofra returned three years later, the clinic's director admitted that it was likely too late for the treatment to be effective. However, the health policy entitled Ofra to unlimited trials of IVF until she reached the end of her $45^{\text {th }}$ year. Though she knew the odds of becoming pregnant this way were next to none, Ofra persisted through round after round of fertility treatment. Yet, after she had undergone five cycles of IVF, it was too much: the fertility treatments had taken a toll on her physically and emotionally. Ofra mustered her strength and went to the nearby Israeli social services branch to inquire about adoption. 
Ofra knew that as a single woman her chances of receiving a young infant were not good. There are fewer than 250 in-country adoptions nationwide each year (Hacker 2005) (some years significantly less) and the waiting list is long, particularly for infants and young children. The adoption authority prioritizes married, heterosexual couples with medically-documented infertility. Based on this information, Ofra requested an Ethiopian baby, ${ }^{34}$ because she knew they were considered less desirable by most adopting families:

It really enchanted me (kesam li) to receive a ready infant (tinok mukhan); it enchanted me to receive an infant from chocolate (tinok m 'shokolad), it enchanted me, you see I work in a school [with many Ethiopian children] and I come from a place of adopting the Ethiopians to Israel (ba'aretz) and to advance them (l'kadem otam).

Ofra's enchantment came not only through her longing to care for an infant (as opposed to an older child), but through a sense of higher purpose - "to advance" the Ethiopians and make them a part of Israeli society. The ideology of an "ingathering of the exiles" was central to the nationbuilding project that followed the creation of the State of Israel in 1948 and the arrival of Jewish communities from all over the world (see Dominguez 1989).

However, the process of "absorption" (klita) was not an equal one: a key element of the ideology of "mixing the exiles" (mizug galuyot) held that through marriage (and eventual reproduction) between Jews from the Middle East and North Africa (called mizrahim) and those from Europe (ashkenazim) would help civilize the former and help them adapt to "modern" life in Israel. The Zionist ethos of absorption fashioned the incorporation of citizens through the technology of kinship (mixed marriage and reproduction) into the modern nation (see Introduction). Ofra's desire to adopt an Ethiopian baby mixed personal desire with a selfacknowledged nationalist mission; she was quite reflexive about the process of "being absorbed" into Israeli culture that her Moroccan-born parents had undergone. Several of her siblings had 
married Ashkenazi spouses, unions that Ofra judged beneficial for they demonstrated that in one generation, her family had mixed into Israeli society.

Yet Ofra's nascent fantasy of adoptive motherhood came to an abrupt halt. When the date of her meeting at social services finally arrived, the social worker bluntly levelled with Ofra, "You have no chance [of getting a baby]." Again, Ofra learned that she had waited too long. She was over the age of 44 , and not only was it a long bureaucratic procedure, taking upwards of several years to complete, but because of her age and marital status she would not receive a baby, not even an "unwanted" one. With some luck, she might be able to adopt an older child. But, the social worker also told her that with an older child there was a risk that he would have emotional and health problems. She told me, "because you are alone (levad), so you'll only get a child above age 6 and with problems...who would take a child with problems? I, alone (levad), will take a child with problems?" Marital status, age and economic circumstances mixed together, erecting an impassable barrier to becoming a mother through adoption.

Ofra had been through too much to contain her emotions. Her voice rose, as she repeated the words she had angrily spoken to the head social worker, "Do you prefer that women like me will go and do [fertility] treatments, and will have more children instead of taking the children who don't have anyone to take care of them?" Although she had benefited from heavily subsidized medical treatments, available to a person who in any other context could not afford them, Ofra identified a violence within them that threatened to foreclose her chance of becoming a mother. She was ready to give herself to the greater social good by raising (and thus “absorbing”) an Ethiopian child. When she left, Ofra remembered, "I asked myself, what is behind this whole thing, of allowing women like me to do this? They are not so much [interested] on my rights, do you understand? It was the politics (mediniut)-it's so idiotic!" Ofra derided the 
very system that gave her the "right" to continue futile fertility treatments, injecting herself with false hope month after month, but not the right for women like her-older and unmarried — to adopt a young child.

As Daphna Hacker (2005) has demonstrated, Israeli social policies, based upon kinship categories of Jewish law, penalize unmarried women by excluding them from becoming mothers through in-country adoption, surrogacy, and, until 2010, egg donation. Single mothers can give their children up for adoption, can serve as gestational surrogates (see Teman 2010), and can donate their extra eggs from fertility treatments. When it comes to adoption and surrogacy, Israeli legislation prioritizes married heterosexual couples with infertility problems over unmarried women. It is precisely because single-mother families are not deemed "frameworks" (either from the perspective of Jewish law or government social services agencies) that they can be enlisted, by the state, to produce children for others.

Ofra could fantasize about making a child into an Israeli and thus contributing to the work of the "melting pot." However, because of her marital status she encountered the state apparatus that paradoxically promotes the use of reproductive technologies among single women, while limiting other routes to married couples - to childless men and women who require a child to become a family. While access to reproductive technologies has become constructed as an individual right of all women by the Israeli courts (Shalev and Gooldin 2006), motherhood is not constructed as a choice for married women. Thus, when it comes to state resources, fulfilling the motherhood of married women still takes precedent over fulfilling the motherhood single women. In the case of infertility that can only be solved through alternate routes including adoption and surrogacy, the exclusion of single women becomes apparent. In the end, Ofra travelled to Eastern Europe to undergo egg donation with donor eggs. Rather than 
help absorb a "chocolate baby" into the Jewish collective, Ofra conceived with donor eggs from a light-skinned Russian egg donor, endured a difficult high-risk pregnancy and gave birth to twins when she was 49. And yet for other Israeli women, it is the stigmatized status of being a single mother and an immigrant, particularly from the Former Soviet Union, that paradoxically limits their reproductive routes. Instead of participating in the project of in-gathering the exiles, it is they who are perceived to be in need of absorption into the Israeli collective through the creation of kinship ties.

\section{“The Way that Isn't Right"}

Growing up in Belarus, Anna heard her elderly grandfather mumble things in a language she could not understand. Her aunt and uncle sprinkled their private conversations with unfamiliar expressions. As a young woman Anna took little notice of these familial idiosyncrasies. Then in 1989, when she was 27 and recently divorced, Anna became aware of her family's difference: they were Jewish. Three years later Anna, her elderly parents and her son, who was born six years earlier on Soviet Army Day, joined hundreds of thousands of Jews from the FSU and made aliyah.

In the decade following Anna's arrival, the Israeli law created new categories to recognize the needs of single mother families. This was partially in response to the wave of immigration from the Former Soviet Union that increased the number of single-parent families in Israel by 44\% (Herbst and Benjamin 2012:33). The One-Parent Family Law (also translated as "Lone Parent Law"), enacted in 1992, extended the social and financial benefits once reserved for widows to divorced and "never-married" mothers with dependents as well as to women who separate from their spouses. Following these demographic and legal changes new Hebrew terms 
were coined, including "one parent family" (mishpaha had horit) and "one-parent mother" (em had horit) (Sa'ar 2009:454).

As a single mother (em had horit), Anna was entitled to government services she received as a new immigrant (sal klita), to a monthly stipend all mothers of legal minors receive through national insurance, and now to additional welfare benefits under this category. These benefits included health care, annual education vouchers for her son, and a small monthly stipend until her son finished the army. Despite these benefits, Anna struggled, living month to month in a rundown apartment in Ashdod. The little money she brought with her and the small one-time government grant she received upon her arrival had dwindled. Although Anna came with aspirations for a better life and new beginnings, she now felt disheartened. In Belarus, she had been a nurse and taken pride in her care of others and her ability to support herself and her son; in Israel, she worked cleaning offices "for pennies" (grushim). She explained of her experience during this time, “sometimes a person keeps going and going and doesn't know that he's making a mistake, that 'the way isn't right' (haderekh lo nekhona)." Anna believed that mistakes she had made in the past shaped her present misfortune.

Anna eventually found work in an upscale mall selling imported housewares to middleclass Israelis living in the gleaming apartment towers nearby. Yet, even as Anna had entered the world she desired to be a part of, more than ever she realized that she was not a part of it at all: she was an immigrant, she was poor, her Hebrew was marred by a thick accent, and she was a single mother—an em had horit. In Russia, having one child in one's early 20 s was a reproductive norm, as were divorce and raising the child as a single mother (Remennick 1999). Upon immigrating to Israel, women like Anna were no longer part of the norm; they were marked by their reproductive practices characterized by high rates of divorce and single 
motherhood, the frequency of having "only" children, and the use of abortion as contraceptive; by their questionable affiliation with Jewish tradition given the process of secularization under Soviet rule; and by their association with being recipients of state welfare. Together these social differences led to the stigmatization of Russian women in the eyes of the Jewish-Israeli public as "whores and bad mothers" (Lemish 2000:346) ${ }^{35}$ Further, Jewish-Israelis interpreted the high rate of single mothers and children without sibilings among the newcomers (see Chapter 2) as evidence of Russian women being alone "disconnected from collectives, unrelated to structuralsocial processes and constraints" (Golden 2003:88-91). A damaging association between prostitution and "family breakdown" emerged in public discourses, which further stigmatized Russian women in Israel (Golden 2003). Despite the ideology of inclusion in "the ingathering of the exiles," Russian women were viewed with suspicion and as a threat to Israeli social order.

As time passed and Anna explained, "I thought [to myself], what can I do with my life? What do I want to do?" Her Israeli co-workers were living out the expected course of life: they were getting married and having children. For Anna, this was a difficult experience:

When I looked, at age 30, at the women at work [who were] pregnant, it was so painful to me that I can't do that because there must be a father for a child (b'glal shtzarikh l'hiyot abba l'yeled) and [I can't] just go to make a child [without a father] (stam l'lekhet la'asot yeled).

In the pregnant bodies around her, Anna recognized her growing desire to have another child. However, she also acknowledged that in her situation as a Russian woman, "there must be a father for the child." Although she knew that other routes to motherhood were possiblenamely, going to the sperm bank-Anna understood that she could not partake of this option. During her 30s, Ann a worried that time was passing, but she also felt that "I [didn't] have a normal partner (ben zug) with whom I could build something...[the child] must be registered, if there isn't a father, then [the child] isn't okay in terms of Jewish religion ( $h u$ lo beseder 
m'bkhinat dat yehudi[t])." Though she and her son were considered Jewish in Belarus, in Israel they were Russians. Their Jewishness was doubted by the rabbinate, which meant that their legal status in terms of family matters (e.g., marriage, divorce, burial) was permanently uncertain. ${ }^{36}$

In her years in Israel, Anna had not enjoyed the new life she once dreamt of making for herself. Through the Russian self-help books borrowed from her neighbor, Anna began to look differently at the world around her as she explored her innermost feelings:

Sometimes a person thinks what can I do for me that will bring joy to life, what can I achieve? What will give me life? What I can do, I can give birth (ani yekhola l'ledet). Maybe [then] I will have happiness in life. I went through so many things that were not right because of my fear and insecurity. This will give me happiness. This will give me life.

While most native Hebrew speakers may share their wish to "become pregnant" (literally: to enter into pregnancy) or "to bring a child into the world," Anna's was a translation to Hebrew from the Russian expression "to give birth" (l'ledet) ${ }^{37}$ She spoke not of a desire to be pregnant (as so many Israeli women do), but of giving birth in order to live. Yet, despite this strong feeling she did not see herself having a child on her own. She explained, "I didn't see myself in a family, even though I wanted [one] because I had been a divorcee for many years. I saw negative things (davarim shlilim)." Although Anna wanted to have a child, as an unmarried immigrant she felt that she could not do it on her own. She also feared that those around her would judge her because of her age.

Anna was embarrassed by the very thought of being pregnant in her 40s. Nevertheless, the prospect of being able to give birth filled her with hope. As she spoke of her longing to give birth, I recalled a conversation I'd had years earlier with a brusque fertility specialist at an IVF unit in Haifa. When I asked him about older mothers, he launched into a tirade:

Women come from Russia where they have one or two kids, but when they come to Israel they see their neighbors have three kids ...so [by then] they are in their 40s and I 
ask them why didn't they have [another child] sooner...they get some bug (juk) in their head and insist on becoming pregnant again. (Interview July 2007)

For the fertility doctor, the desire of older Russian immigrants to become pregnant was a noisome contagion, a bug (juk) that entered their heads and disturbed their better judgment. ${ }^{38} \mathrm{He}$ did not accept that their desires were genuine, but rather adopted or absorbed from their interactions with Jewish-Israeli women.

Around this time, Anna was introduced through friends to an Israeli man, named Yitzhak, who was in his late 40s. They started dating, and though Anna preferred to live separately at first, she moved in with Yitzhak after a few weeks. She told me that, although she was uncomfortable with living with a man she barely knew, she had run out of options. Under Soviet rule, women were accustomed to the idea of early marriage, with high likelihood of divorce, but nevertheless cohabitation without marriage was an unaccepted arrangement (Remennick 1999:443). A few months after moving in together, Anna and Yitzhak got married in a small ceremony officiated by a Reform rabbi. She declined to explain to me why the rabbinate had refused to perform the wedding, emphasizing instead that she would have preferred an Orthodox ceremony because their marriage did not receive full recognition.

A few weeks after her $44^{\text {th }}$ birthday, Anna learned that she was pregnant. Despite her excitement, Anna was worried about telling people. Four months later, her sister discovered the pregnancy and asked her "What, have you gone crazy?" "Yes!" she said as her pride and embarrassment churned together. Anna tried to explain to her concerned sister, "It seems that my life had been not correct here [in Israel]. I want to achieve something. To do something that gives me the motivation to live.” Anna felt happy being pregnant, even though she remained self-conscious because of her age. Nevertheless she believed "this is what needs to be, to be something different (l'hiyot mashehu aher)." 
After the birth, she registered her daughter with the Ministry of Interior clerk at the hospital, under her husband's family name. She explained, "It's preferable that she be registered in his name." When combined with her daughter's first name, Tamar, it had a thoroughly Israeli ring. Despite the disappointments and difficulties, Anna had brought new life into being, a bridge between her old life and the new. With her marriage to Yitzhak and her newborn daughter, Anna could face the world around her, that although imperfect, she began to feel a part of. By marrying an Israeli man and conceiving his child, Anna was no longer a single mother on her own: she now had a family. In contrast to marginalized immigrant mothers like Anna, I now turn to a case that reveals the impossibility of inclusion among another stigmatized community.

\section{"Do You Understand the Pathology?"}

As the staff meeting in the high-risk pregnancy unit was breaking up one afternoon, Talia, the head nurse, mentioned a 52-year-old woman, “a sotzialit,” whom I might try to interview. Although she doubted that the patient would be receptive to the idea, Talia thought it was worth a try. When I arrived in the unit the next morning, the nurse on duty, Miriam, told me about the same older patient, "she's a sotzialit," she said, repeating the same term as Talia. Sotzialit is clinical shorthand, a loan word from English that the staff use when discussing difficult cases in which social workers and/or the psychologist assigned to the unit get involved.

[With a feminine ending (--it), it describes a female patient.] Social work (avodat sotzialit) seems to be the origin of the expression. Of this particular patient Miriam added, "she is single...it's IVF and egg donation, twins...she's religious and lives in a room (heder), not even in an apartment." ${ }^{39}$ This was not the first time I had heard the expression used in connection to an older woman. I wondered: what made this patient a sotzialit? 
When I entered the room, Rivka was pacing around her curtained half of the room, wearing the pink hospital gown stamped with the medical center's insignia, a sandy brown wig sat askew on her head and her feet swelled inside worn house shoes. Without speaking, she gestured to the open prayer book in her hands as if to say: come back later. At lunchtime, I spotted Rivka in the unit's dining room. She was sitting with two religious patients wearing headscarfs, picking at a mound of yellow rice with her fork. When she saw me, Rivka stood up and led me toward an empty table in the back corner of the room. She was wary of me, I think, but agreed to be interviewed. Though Rivka did not self-identify as a member of the ultraorthodox (haredi) community, her modest dress, way of communicating and body language was "read" as haredi by the nurses and social workers, whom I later interviewed about this case.

Like all of my hospital interviews, I began with the background questions approved by the medical center's ethical review of my research. Rivka answered my queries about her city of residence, age and marital status: B'nei Brak, 52-years-old, divorcee. Like many other "older" patients I met, Rivka subtracted a year off of her age when she introduced herself. But, the difference that turned out to matter the most was not residence or age, but marital status. As we spoke, it became clear that not being a single woman (revaka) was crucial to Rivka's understanding of her experience.

Rivka was married for five years to a new immigrant (oleh), a religious man originally from London. She quickly learned that her new husband did not want to have children with her (he was supporting three children from his first marriage). In any case, the couple went through many unsuccessful tries of IVF. During this time, her husband encountered difficulties adjusting to life in Israel. This failure to become a part of the community and to conceive a child together informed the eventual dissolution of their marriage. Rivka told me, "If I had married an Israeli 
man, it might have been different." Even as she imagined things working out differently, Rivka emphasized that she never would have considered becoming a mother if she had not gotten married first. She contrasted her situation with other religious ravakot, who now become mothers on their own, in their late 30s: the difference was that her intention was correct.

Becoming a mother in her situation, Rivka explained to me, "is not against Jewish law" (ze lo b'nigud lehalakha) because she did everything to conform to a proper way of life. I asked her whether she had consulted a rabbi before returning to fertility treatment after the divorce (the majority of rabbis would not see this decision as permissible according to Jewish law—as discussed in Chapter 4). Many observant Jews regularly seek advice from rabbis when making weighty decisions, particularly if there are questions of Jewish law concerned. Rivka was silent for a long time. Eventually, Rivka spoke, but instead of answering my question, she told me about a television documentary that she had heard about on single motherhood. ${ }^{40}$ One of the interviewees on the program was a religious woman from Jerusalem who had become a mother on her own, through donor insemination. Through her second-hand knowledge of this program, Rivka learned of an Orthodox rabbi, who permitted this practice for older women. Though she could not remember the name of the rabbi, Rivka assured me that he was, in fact, a legitimate decisor (posek). This exposure to ideas beyond her community, albeit through indirect exposure (she did not own or watch television), helped her cope, knowing that "in Israel [single motherhood] is accepted" (ba'aretz ze mekubal).

Rivka went to a fertility specialist in Tel Aviv, who reassured her that her health was excellent and that she had a good chance of becoming pregnant through egg donation abroad. After the appointment, Rivka pulled together enough money to undergo the treatment in Kiev and became pregnant with twins. From the beginning, she was nervous about her health, but 
managed until her seventh month of pregnancy when she fell while trying to board the bus to work. She was taken to the emergency room - an X-ray showed that she had fractured her right ankle, but the attending physician also found that she had early contractions and hospitalized her in high-risk pregnancy for further monitoring. Rivka dreaded the possibility of being discharged and worried whether she would be able to function on her own with her leg in a cast. The doctors ordered rest at home for the remaining weeks.

For Rivka, going home meant facing her situation on her own. Her family strongly disapproved of her becoming a mother "without a family framework" (lo b'misgeret mishpahtit). They did not accept the idea of becoming a mother "in this way" (b'tzura kazot), nor did they recognize the distinction she made between being a divorcee (proper intention) and having a baby as a single woman (improper intention). To them, Rivka's motherhood was not only outside marriage, but was entirely outside of family and community. Nevertheless, for Rivka the pregnancy was "the will of hashem (literally: the name). G-d blessed me with this." From her perspective, by becoming a mother, she was submitting to divine will. In fact, throughout our hushed conversation Rivka repeatedly whispered, "I didn't choose this" (ani lo bakharti et ze) as if to insist that, like the barren women in the Torah, this was G-d's will.

Two weeks later, when I arrived in the unit Talia told me that Rivka had given birth through caesarean. ${ }^{41}$ Of the present circumstances, the head nurse summed it up in one word“miserable" (zeva'a). She added, "she looks terrible, like she's 80 years old...spent all her money on egg donation...thought she could put the babies in the kitchen," referring to Rivka's housing situation. With the twins in intensive care, Rivka's case became an agonizing one for the nursing staff and social workers, who worried about the infants' future well-being. They managed to secure a caregiver for the frail infants through social services, but this would only provide 
temporary assistance. A veteran social worker exasperatedly commented to me on the case, "Do you feel the pathology here? How much she is alone in the world (bodeda b'olam)? They reject her (dokhim ota) from everywhere, from work, from family." Even as they focused on the haredi community's treatment of a woman who became a single mother, the medical staff rejected the meaning that Rivka ascribed to her actions-“it is accepted in Israeli society."

The moral drama that ensued in the high risk unit over the next weeks pushed me to ask: what made Rivka's case so extreme? I believe that for the professionals involved in Rivka's care, the pathology is not solely related to medical diagnosis, maternal age or socio-economic status, but to their perception that she was alone, without family or community. I asked another social worker whether she thought that she could have interceded, and if so what she might have tried to do. She replied, "I would try to convince her not to [become pregnant]...though I'm not sure she would hear me. In the end, she might still do it, but at least [she might] be accompanied by a social worker, and not to remain in this horrible loneliness (lo l'hishaer b'bedidut hanorait hazot)." This concern with loneliness was echoed by a health care professional, who explained of her own research on single mothers, “[These women] weren't capable, emotionally, of dealing with the loneliness (l'hitmodded im habedidut)...It was depressing, it's so sad to see the child growing up alone." Her colleague interjected, "it's pathetic." She agreed, "Yes, very pathetic."

\section{Producing Fulfillment through Appropriate Family Frameworks}

In professional discourses on later single motherhood in Israel, the choice to become a mother is read as individualistic and thus potentially productive of bedidut in the absence of proper frameworks, particularly when a woman is already marked by her economic situation or religiousity. It is a woman's embeddedness in family that prevents this outcome. Of cases like Rivka's, a veteran social worker explained: 
As a citizen, I ask, why does the State need to pay for a woman like that? Because of her narcissistic ways [she] chose to give birth at an old age. It is really bothers me. There are plenty [of others] who really do need help. Why does the state need to help [her]? This is from the beginning to put the children into terrible loneliness (l'hakhnis et hayeladim l'bedidut norait).

Here state-subsidized fertility treatments have not contributed to the national collective, but rather to narcissistic choice and to producing children in a state of "terrible loneliness." In this situation, a woman's individual choice is contrasted with other women "who really do need help" in order to fulfil their motherhood.

Returning to Dr. Geva's formulation of appropriate single motherhood: when done with "the mother's family's support" becoming a single mother engenders fulfillment. Further, when the intention to become a mother is, in Adi's understanding, not an act of "self-fulfillment," but a contribution to the Jewish people, it is perceived as an "accepted" route. For women like Ofra who have fertility problems that cannot be cured with new reproductive technologies such as in vitro fertilization, the state legal apparatus denies them access to adoption and surrogacy, and therefore the possibility of this fulfillment. These policies reveal that despite making fertility medicine available to single women, the state continues to privilege married heterosexual couples as the proper family. In the past, the state placed children from problematic (immigrant) families in the care of frameworks that were considered appropriate environments for socializing the youth towards the goals of the collective. In the present, limited reproductive routes including surrogacy and adoption are reserved for families that are entitled through the logic of fulfillment. In contrast, single-mother families are assumed to require a recognized "framework" in order to function and they risk being marginalized as individualistic rather than contributing to society.

Not all single mother families are equal: those headed by women marked as others are not only deemed to be on the margins of society, but their possibility of fulfilling motherhood 
through appropriate family frameworks is limited. Ofra was not only excluded from adopting a child, she was also excluded from participating in a kind of moral citizenship of absorbing “others" into Israeli society. Whereas her own family had undergone this process a generation earlier, her marital status and age combined to limit her motherhood. In the end, she was left with no other choice but to pursue egg donation abroad — and to use the eggs of a Russian donor in order to become a mother. The ironies and complexities engendered through layered histories of Jewish immigration, discrimination and stratified reproduction take on new configurations through single mother families in the present.

Since the 1990s, single Israeli women have had increasing access to fertility treatments. This same period has overlapped with massive changes to the composition of Israeli society, with the arrival of nearly one million Russian immigrants. For newcomers like Anna from the Former Soviet Union, their authentic desire for motherhood is questioned and even constituted as a contagion (a bug) rather than naturalized as it is for Jewish-Israeli women. As outsiders to the normative structure of family, single mothers like Anna were viewed with suspicion and as threats to Israeli morality. The discourse of single motherhood as "accepted" (mekubal) among native born Israeli women who are primarily middle class and educated, must be read within the larger historical context of the arrival of thousands of single mothers and their children, who were viewed by the Jewish-Israeli public as disconnected from the collective and as a drain on the welfare system.

Finally, for haredi women like Rivka who are considered part of a community that is outside of the Jewish collective because they do not serve in the army or contribute tax revenue — single motherhood produces them as individuals, cut off from family, community and Israeli society. Even as Rivka believed that becoming a single mother was now "accepted" in 
Israeli society outside of the haredi community, health care professionals dealing with her case saw the absence of family as generative of bedidut in place of belonging. Here, Rivka's "choice" marked a pathological subject—a sotzialit—whose condition might have been avoided had she been incorporated through the proper social framework of family that preserves motherhood as fulfillment.

While the single-mother family reveals the tension between the possibility for single motherhood as either "accepted" or, alternatively, as resulting in the production of "loneliness," notions about Israeli family are deeply informed by experiences of loss in the past and anxieties about future uncertainties. As I explore in the next chapter, the ideal family in the Israeli context involves more than a biological father, mother and a child. The single-mother family makes evident the powerful intersection of kinship and loss that shapes the creation of families amidst the enduring uncertainty of the Israeli-Palestinian conflict. 


\section{Chapter Two \\ “REVAKA + 2": Single Mothers AND the Multiple Meanings OF ChILdRen}

It is not clear whether [single mothers] want to compensate the absence of a father with more siblings or just to have a larger family resembling the family size prevalent in Israel. These children have a smaller social and kin network because of the absence of a father and his family. Thus, perhaps the children of these older single mothers intuitively seek to be part of a larger family unit that will shield them from loneliness. -Weissenberg and Landau (2012: 527)

A few months before departing for Tel Aviv in 2009, I came across an online newspaper article on single motherhood titled "Revaka +2 " and saved it in a newly created folder. Nearly two years later, upon reviewing the amassed collection of newspaper and magazine articles, this early clipping caught my attention anew. The introduction, in bold type, proclaimed:

The new family revolution enters the next stage: more and more single mothers are deciding to bring into the world not one child, but two. Yes the economic and logistical burden isn't easy and [you can] forget about dating at all, but women who do this unanimously rule: happiness from expanding the family compensates for everything. (Shtutland and Melomed 2009)

Though the "phenomenon" (tofa'a) of single later motherhood makes frequent appearances in Israeli popular media, this article became increasingly salient as I began to analyze my data. When I started fieldwork, I had not expected to encounter so many women who made significant efforts to have a second child on their own. Many of the women I met had undergone moderate to extensive medical interventions to conceive their first child. While only a small fraction succeeded in having another child, the majority of women I interviewed had, at some point, considered having another child. And due to the practice of multiple embryo transfer among women of "advanced maternal age," accounts of twin pregnancies were not unusual.

Beyond the "economic and logistical burden" of having a second child, the confluence of the cultural logic of "expanding the family" and the accompanying medical dilemmas shapes the experiences of single later mothers in Israel. In Euro-American contexts, anthropologists have observed the paradoxical intertwining of hope and failure in accounts of assisted reproduction 
and of in vitro fertilization (IVF) in particular (Becker 2000; Franklin 1997; Thompson 2005). Further, as Sarah Franklin suggests, "Condensed in the IVF story... are wider stories about how the future can be imagined and pursued. In the conjuncture between reproduction and technology are combined two of the most powerful Euro-American symbols of future possibility: children and scientific progress. It is for this reason that the IVF story is inevitably concerned with the meaning of progress, the character of hope, the desire for children and the will to overcome adversity" (1997:166). Although narratives of scientific progress are a powerful thread running through the Israeli IVF story and the medicalization of reproduction in Israel (Hashash 2010; Ivry 2010), children in this context are more than symbols of "future possibility." As I explore in this chapter, the Israeli IVF story is simultaneously about future possibility and the possibility of loss: the insecurity of everyday life in Israel saturates the cultural logic of having children and of having more than one child. Examining narratives of assisted conception divulges an anxiety, not only about catastrophic reproduction (Ivry 2010:53), but about bringing into being children who may be left alone (levad), rather than enmeshed in a web of relations through family ties. The tension between possibility and loss, between being part of a family and being left alone comes to the fore in women's accounts of their endeavors to have more than one child.

Having another child at "advanced maternal age," however, is often met with obstacles and the production of iatrogenic conditions. Women may endure the physical and emotional strain of exposure to repeated hormone treatments, the added complexity of egg donation, the uncertainties of high risk pregnancy and hospitalization, and even the loss of a fetus through miscarriage or a form of termination known as selective reduction (dilul ubarim, hafhata). Yet, these prenatal losses, whether experienced or anticipated, spontaneous or induced, are not 
conceptualized within the larger Israeli narrative of assisted reproduction that weaves together the miraculous creation and tragic vanquishing of life. As such, the accounts of single mothers who endeavored to have more than one child afford significant insight into the multiple ways that notions of loss, generational distance, and relatedness inform the cultural logic of extending family.

This chapter explores three interrelated issues that emerge through the accounts of single mothers who desired more than one child. First, I situate the significance of children and familysize in the broader Israeli context by drawing on ethnographic and historical data to examine notions of "children as happiness," having "at least two" children, and the unease with "an only child." Second, I build on this discussion in order to consider the social and medical complications experienced by single women of "advanced maternal age" who endeavored to have more than one child. Third, I seek to demonstrate that while children are seen as integral to the existence of family in Israel, even after having more than one child, single mothers deemed it necessary to engage in creative practices to connect their children to (male) kin and "complex" constellations of family.

\section{The Multiple Meanings of Children}

The Euro-American IVF story restores the continuity of having children to disrupted individual life trajectories imagined to make measurable linear progress, within an enterprise culture of increasing choice and rational order (Franklin 1997; Strathern 1992). In contrast, the Israeli IVF story is steeped in nationalized memories of traumatic loss and narrated in relation to ever-growing anxieties about the continued existence of the State of Israel. These uncertainties about bringing children into being are inextricably personal and national. Janet Carsten urges anthropologists to move beyond studying the lived experience of cultivating kinship to consider 
"how subjects... are located in personal and familial histories that connect to the wider political formation of which they are a part" (2007:2). Toward this aim, Carsten proposes the intersection of memory and relatedness as a productive site through which to theorize the workings of political formations in the lives of individuals, families and communities. Anthropologists have observed the subtext of loss and remembrance in relation to Israeli practices of reproductive technologies. In Susan Kahn's Reproducing Jews and Tsipy Ivry's Embodying Culture the trauma of the Jewish past, redeemed through the creation of the state informs women's experiences of artificial insemination and prenatal diagnosis, respectively. Kahn shows how personal loss is elevated, through assisted reproduction, into the cosmology of national memory, fusing individual and collective desires. She writes of the women she interviewed:

[T] he decision to reproduce via artificial insemination does not evolve 'naturally' along a continuum of reproductive choices but stems from a larger sense of loss or from a sense of responsibility to the Jewish family conceived more broadly. Their desire to conceive babies via artificial insemination is a response to the circumstances that are particular to the Israeli context. These stories vividly illustrate how the individual's desire to reproduce overlaps wish the collective's desire to overcome tragedy; and reproduction as a response to tragedy is one of the most prominent characteristics of Israeli pronatalism. (Kahn 2000:60, my emphasis)

While "reproduction as a response to tragedy" is a key dimension of the Jewish Israeli quest to have children, I propose that a future orientation towards the possible loss of relations informs reproductive routes in the present. Thus, past tragedy is more than something to "overcome" analogous to Franklin's hurdle to progress: in Israel, loss infuses the very creation of life. Moreover, while Kahn explores this dimension of Israeli pronatalism through the accounts of particular women who experienced loss as a kind of postscript to a longer chapter on artificial insemination, I seek to show how this dimension of loss, spanning past and future, permeates conceptions of children and family more broadly. 
In her study of prenatal diagnosis and ultrasound imagery, Tsipy Ivry (2009, 2010a) contends that past trauma finds its way into the present, through a "politics of threatened life" that renders all pregnancy in Israel as high risk. Pregnancy becomes the embodiment of potential catastrophe and the fetus is attributed the perpetrator of this trauma. In Ivry's account of the public presentation of ultrasound images to audiences of pregnant women and their partners, reproductive technology is not "giving nature a helping hand" (Franklin 1997:209-10); in this context, the use of high-tech ultrasound imaging acts more like a metal detector, screening for a potential bomb (the damaged fetus) that must be eliminated. Ivry demonstrates the effects of these "horror shows" on Israeli women with healthy pregnancies, who postpone conferring their fetuses with personhood until birth. However these prenatal losses, as I discuss below, are not conceptualized within the dimension of reproduction in dialogue with future loss. Thus while the past informs what Ivry calls "the politics of threatened life" where the woman's life is privileged over the unborn fetus (and especially over the disabled or deformed fetus), these potential reproductive catastrophes are limited to the pregnancy rather than extended beyond it. I build on the work of Kahn and Ivry to ask: what kinds of future conceptions — at the conjuncture of possibility and of loss - are revealed in the Israeli IVF stories of older single mothers? Given these conceptions of the future, what is the import of the work undertaken to bring about the construction of single mothers and their (multiple) children as "a family"?

\section{Children are Happiness}

Rita, a lithe Israeli pop-icon, dances beneath the flashing lights of the stage. The end of her act is approaching, and she closes with a favorite. As she sings the opening lines, the audience is delighted, clapping and joining in: "Bring two, bring three. Bring four children." 
Nearing 50, Rita twists and turns, her long black hair bounces, and her torso gyrates in a tight black tank top and black jeans, her hands thrust out, palms turned up toward the sky:

Bring two, bring three

Bring four children.

You'll get housing ${ }^{42}$ with an entrance and a kitchen

And two small rooms

Bring four, bring five

Bring six children

You'll get pleasure and respect from relatives

You love children

When she gets to the chorus, Rita stops singing and holds the microphone out to the packed crowd; they continue for her, singing with delight: "children are happiness, children are a blessing." This refrain—“children are happiness" (yeladim ze simha)—is widely used in everyday Jewish-Israeli discourse; in this expression, happiness is equated with children in the plural. Occasionally in Israeli comedy sketches or newspaper articles poking fun at Israelis' selfacknowledged obsession with reproduction, it gets posed as a rhetorical question rather than a cultural, national and religious axiom. Yet, in this performance, the latter meaning with all its overlapping complexity is evoked. Rita joins in with the audience:

And you have a heart of gold

It's written in the Torah

Maybe in the Gemara

Go ask the rabbi

Bring six, bring seven

Bring eight children

This is not a joke

The country ( $h a^{\prime}$ 'aretz) needs lots of nice young people

Bring a dozen, why not live?

Bring ten children

God will already provide

The welfare [office] ( $\left.s a^{\prime} a d\right)$ as well

What [they] need is children 
This version of "Children are Happiness" is the Iranian-born star's cover version of a song by the popular folk group Habreira Hativit (The Obvious Choice). Over four decades ago, a group of hippy-looking men with acoustic instruments led by Shlomo Bar set the playwright Joshua Sobol's words from the 1976 play "Crisis" (Kriza) about ethnic tensions to music; they sang about the happiness of having large families as a biting and ironic condemnation of the government's economic policies against Mizrahi families - the song, like the play, became a nation-wide hit.

In contrast to the image of the native-born Israeli or sabra, who stood for the national vanguard, the Mizrahi Jew was constructed as the Israeli-Jewish other, characterized by patriarchal extended families of (too) many children. This is caricatured in the opening sequence of Sallah Shabati (1964), the first Bourekas film. ${ }^{43}$ In this memorable scene, Sallah arrives on the tarmac of the Tel Aviv airport with his seven children and wife; his large Mizrahi family and their chaotic arrival is preceded by an American middle-class couple, wearing suits and carrying expensive luggage, who arrive without children; this sequence establishes an immediate contrast between "primitive" Mizrahim and "modern" Ashkenazim (Peleg 2008:122-3). While these Mizrahi immigrants, with their "heart of gold," as the song's lyrics suggest, were imagined in popular discourses as adoring children and trusting that, somehow, God would provide in their return to the land of Israel, the circumstances they encountered upon settlement forced them to confront a painful reality: the cramped public housing that consisted of not much more than "an entrance and a kitchen" and the welfare they received was not enough to manage. In this context, Bar's interpretation of Sobel's lyrics set to a Mizrahi melody highlighted the suffering and disenchantment of these recently arrived Israelis, who unlike their Ashkenazi counterparts, endured poverty and marginalization in the dead-end, yet strategically located "development 
towns" (near the nation's under populated border areas) and urban housing projects where they were settled. The nation needed more Jews to win the demographic struggle within its borders and it needed more young Jewish men to participate in the armed conflict that threatened from beyond its borders. In the original version, the 1979 song addresses the tension between the religious trope of "children are happiness" and the new nation's "need" for soldiers; and between offspring as the source of life and the fate that these "nice young people" will meet defending their country.

Though this past remains tangible in the present, in Rita's beloved interpretation, "Children are Happiness" has morphed into an entirely different song. It is now an upbeat dance hit that has the audience dancing hard, foreheads beading with sweat, throwing their hands into the air, hugging one another as they sway and her powerful voice magically soars through the air. It celebrates something that is self-consciously Israeli-the confluence of religious tradition, nationalist mission, and "a heart of gold" that locates joy and the affirmation of life itself in the bringing of children into the world. By 2011, it is hardly a protest piece or a "Mizrahi" song. ${ }^{44}$ On this balmy night in mid-May, it is sung by Rita as part of the official celebration for Independence Day in Tel Aviv's Rabin Square, a plaza in front of city hall that, only hours before, served as a central site of national mourning on Memorial Day for Israel's Fallen Soldiers. Though family-size retains elements of cultural constructions of Jewish-Israeli ethnicities, religiosity and otherness of non-Jewish communities, the central tension in the song—-between children as happiness and the loss of children endures over time. This intertwining of joy and sorrow touches all Israeli lives; the traumatic past casts a long shadow over present anxieties about the uncertain future. Children are at the heart of this matter. 


\section{An Only Child}

Just as ideas about family-size have fluctuated, so too has the negative discourse on "the only child" (hayeled hayehid). In the pre-state period (yishuv), having an "only child" was strongly discouraged. In the 1920s and 30s, physicians wrote parenting manuals on the proper upbringing of Zionist children. Alongside advice about hygiene, breastfeeding, nutrition and toilet training, mothers were warned that an "only child" is a spoiled child, "cowardly, fretful and stubborn" and thus unable to contribute as citizens to the new collectivist-oriented society (Stoller-Liss 2003:113). In contrast, the kibbutz child or native-born Israeli (sabra) is most often portrayed in children's literature of the 1940s and 50s as immersed within the collective adventures of his age-set group (hevre) rather than as an individual child within a nuclear family (Darr 2011). The only child as a spoiled child manifests in best-selling Israeli novels. For example, in Amos Oz's novel My Michael (1968) which takes place in Jerusalem in the 1950s, the unhappy wife/narrator, Hannah accuses her husband of inappropriately coddling their only son. But her husband, Michael, was also an only child and she insults him, "you must have been a pampered child" (Oz 1968:35). In later decades, only children are depicted as lonely, detached and even socially dejected. In A. B. Yehoshua's novel, The Lover (1977), one of the main characters is Dafi, a teenage girl whose parents' relationship has fallen apart after the death of their young son in an accident, which occurred before her birth. Dafi hardly shows up for school, sometimes leaving early to aimlessly wander the through the city, and over the course of the novel enters into a romantic relationship with an Arab boy who works for her father. These activities - her drifting apart from her peers, her delinquency and purposeless itineraries and most of all her secret relationship with a boy from the West Bank all attest to her experience as an outsider, her loneliness that is the product of family anomie in the wake of personal loss. 
These best-selling literary representations of dysfunctional family life in the shadow of war portray the only child as the outcome of failed relationships between men and women; in these narratives, the only child is a product of a disintegrated family damaged by previous loss. ${ }^{45}$ It is this absence of relations that makes the child unable to integrate within her peer-group, undermining the creation of hagshama (self-fulfillment through collective purpose) in the contemporary generation and his commitment to the nation's future.

Negative sentiments about the only child and his socialization into society remain salient in Israeli women's assessments of contemporary motherhood. Yet, the concern has shifted from the capacity of the child to participate in the production of collective sociality to one of social deficiency and emotional impairment: the "only child" is pitied for being alone and as a kind of liability in the face of familial and national uncertainty. For example, Rachel, a woman who made aliyah from New York in her early twenties and married when she was 41, described her situation as the parent of an only child by repeating the remarks she received from acquaintances and sometimes, complete strangers. "[They think] you should have children and one is not enough. That you're doing a real disservice to your child and they feel very free about saying it [to me]." She then switched into Hebrew with a strong Brooklyn accent, her voice rising as she mocked the Israeli women who asked her unsolicited questions:

You have only one [child]? (yesh lakh rak ehad?)

Why? Make another one! (lama? ta'se 'od ehad)

What are you doing to her? (ma at osa lah?)

Returning to English, she said, "They express their opinion very freely, the principle (she used the Hebrew word ikar) is that you should have more than one child." The comments from women Rachel barely knew all made the assumption that it is the mother who does something 
harmful to her child's well-being by not having more children. By employing the feminine singular, these injunctions only address the "disservice" she, as a mother, is doing to her child, rather than her husband's participation. Though she wanted more children, because of her age, it was not possible for her to easily "make another." While she had grown thick skin during her years in Israel, the commonsense value that life as an only child was somehow a "disservice" that she as a mother had done to her child did sometimes get to her. In particular, this feeling surfaced when her daughter asked questions about why she was "the only kid in [the] class that doesn't have a brother or a sister." In fact, out of a class of 30 students in a well-to-do Tel Aviv suburb, her daughter was the only "only child." Whenever her daughter raised the subject, Rachel sympathized with her disappointment and the sentiment of feeling different. However, understanding the complexity of these women's accusations of parental disservice done by bringing an "only child" into the world requires consideration of another oft-heard trope about having children in the Israeli context. As a female anthropologist in my early 30 s, I not only recorded the experiences of Israelis like Rachel, but became the object of inquiry and subject to moral instruction.

\section{"Two is not enough"}

Nadav and I are seated around the dinner table in Yaacov's ninth floor apartment in Ashdod, a port city south of Tel Aviv where new neighborhoods steadily replace sand dunes and cranes crown ever-growing high rises; these housing complexes are marketed with shiny brochures that display floor plans designating "parents' bedroom" and several "children's bedrooms." An old friend of Nadav's father, Yaacov revels in good food and company, especially on Shabbat, as he is divorced from his wife and estranged from his three adult children 
and his grandchildren. There is not another space on the white tablecloth, cluttered with bowls of colorful salads, bread crumbs and olive pits, wine and water glasses. We are fortunate guests at seam-splitting meals like this one, which often stretch the better part of these leisurely Saturday afternoons. Among his father's long-time colleagues, friends and neighbors, Nadav and I are welcomed as "the young couple" (hazug hatzair). This appellation is less reflective of our ages (39 and 31), as it is attentive to perceptions (or perhaps expectations) of our future reproductive potential. As the wine is poured and "to life" (l'haim) proclaimed in unison as our glasses chime, inquiries from our hosts and fellow diners begin. After years of living in Israel, I am no longer surprised by their first question: do you have children ${ }^{46}$ And for those who know us better, the question is expressed through one drawn out syllable: $n u$ ? (so-why not already?)

Yafa is seated next to me. A childhood friend of Yaacov's, she has become a regular at this table since her husband passed away from a heart attack. I have hardly been introduced by our host, when Yafa asks the question I'm already expecting. But Yafa, dressed in a bright pink and white track suit with nails to match, doesn't wait for me to ask about her children in return. Instead, she launches into a matronly speech about the importance of having many children. Though everyone around the table is listening, I sense her words are meant for us, the "young couple." She leans in close, "You see, two [children], that's not enough. I grew up in an Ashkenazi house where having two children was the norm." Yafa explains that her parents came from Germany before the war, and that their family was like other middle class families from similar backgrounds in Tel Aviv. For her parents, this was the "proper" size for a family in their circumstances - they had a daughter and a son. As she clasps the stem of her wine glass, Yafa's hand trembles, rivers of blue veins trace its creased topography. Her own family, though no longer living in a modest Tel Aviv flat, resembled the one she had grown up in. "I also had two 
children, a girl and a boy," she tells me in a steady voice. Before I can ask her about them, she says, "My son would have been 53 [years old] this year. He fell in the Yom Kippur War." "I'm sorry for your loss," I mumble, not sure whether this is an appropriate thing to say at this moment, given the decades that have passed.

Yafa doesn't seem to notice. She continues, telling me about her daughter who is 41 and lives in Tel Aviv with her husband and child. Yafa makes no effort to conceal her disappointment; she assures me that this is a decision that her daughter will come to regret in the future. Yafa knows this is a mistake, for the extent of her own loss grows over time: she lost a son, barely out of his teens; she was left with her daughter, now her "only" child; they are "alone" (levad) in her words, since her husband suffered a heart attack. Her daughter, Yafa believes, has not thought it through enough. I am struck that she doesn't seem to consider that it may not be a willful act "not" to have another child, but instead her daughter, now in her early 40s, may no longer be able to become pregnant. Yafa changes the topic and her manner lightens as she praises her granddaughter's virtues and accomplishments, yet I can tell that her family's future weighs heavily on her. Through her autobiography of loss that bridges the decades from the past into the precarious future, Yafa has made her point: you could lose a child. Although she is speaking to other dinner guests, her words seem directed toward me, a woman who is six months pregnant.

While ideas of appropriate family-size and discourses on having an "only child" have changed from the pre-state period to the present, anxieties about being left alone and the seeming inevitability of future loss are integral to understanding the trepidation that informs the ways Israelis conceive of having children. Life itself, in Israel, is precarious and is often rendered through experiences and imaginings of past or anticipated loss. This loss is not of individual 
bodies or persons, but is the result of the loss of relations, the loss of family, of surviving amidst tragedy, of remaining "alone." Perhaps the most telling example of this fear is the Israeli army policy that forbids soldiers and reservists who are their parents" "only child" from serving in combat units. ${ }^{47}$ The anxiety about being left "alone" in the wake of loss fills Israeli dramasfilms and novels abound with characters left alone after the loss of a child, sibling, spouse or parent. The misfortune of the only child is often compounded by the loss of a parent or sibling, whom the living has never met (e.g., the war orphan), yet remains haunted by their enduring absence. The figure of "an only child" comes to stand for the traumatic possibility of being left alone, and being left alone becomes an overarching trope for thinking through the annihilation of relations, the destruction of family ties that make possible present belonging to the larger collective and participation in its future continuity.

\section{Israeli IVF Stories}

The intertwined narratives of children as future progress and of children as potential loss heighten the dramatic tension in Israeli IVF stories. Assisted reproduction becomes not only an account about technology giving a helping hand to the nature (Franklin 1997), but also it serves a powerful moral correction to the suffering, both of individuals and the Jewish people. One subgenre of IVF story highlighted by the mainstream Israeli press is of later motherhood following loss of a child (and of an "only child" in particular) in the army, terrorist attacks and traffic accidents. For example, Channel Ten news presented the tragic stories of three mothers in their 40s who gave birth to baby boys after tragically losing their first-born sons during the Second Intifada. One mother explained of her decision to undergo fertility treatment at the age of 43, "It was clear to me that this is what I'm going to do, even at any price." Another shared that the 
idea of having another child came to her as she observed the seven-day mourning period (shiva) for her son. Even as the narrator praises all three women for their ability to overcome extreme grief through "conceiving again," the segment carefully balances its portrayal of having another child as "a choice of life" with maternal activities of bereavement, such as maintaining the childhood room of the deceased, tending the gravesite, and remembering him through photographs and videos.

The story of Tzvia Rivin powerfully demonstrates the Israeli narrative of bereaved mothers "choosing life" after experiencing unbearable tragedy. The Israeli public became captivated with Tzvia's televised quest to "return to motherhood" after her first and only son, Elad, died as a volunteer firefighter in the Mount Carmel forest fire (2010). Elad was conceived through multiple tries of in vitro fertilization when Tzvia was 39 years old. Now in her mid-50s, this bereaved mother was assisted for the second time by Israeli reproductive technology. With the help of an Israeli surrogate, Tzvia became the mother of twin girls. These stories of loss feature the gendered trope of bereaved mothers returning to life after the death of their sons through birth.

In several IVF clinics that I toured, newspaper accounts of assisted reproduction after the death of a child in the army or a terrorist attack were displayed on prominent locations in the hallways. In a Haifa clinic, a nurse referenced one framed image adjacent to the entrance as she explained how a number of women who lost children in a bus bombing that happened on the same line that serves the unit later became patients. These moving accounts of loss are pregnant with national meaning; they become parables about who is a good mother, about proper sacrifice and mourning through the creation of new life. 
While these stories of heroic later motherhood receive prominent attention, another image that receives its own share of media attention dominates the hallways and offices of Israeli fertility clinics: pictures of infant twins and triplets. Propped up next to each other and wearing cute outfits and hats, these siblings communicate the anticipated joy of the "instant family" promised to infertile patients through multiple embryo transfer. Although over the last two decades there have been fewer triplet and higher order pregnancies (and practitioners voice concern about this outcome), the pictures - juxtaposed with media accounts of loss that circulate in images and conversations-relate a narrative about procreation that powerfully connects future possibility with the possibility of personal and national loss. ${ }^{48}$ In the clinical space, these stories communicate not only a valorized motherhood and the promise of high-tech medicine to produce "miraculous" births; to those patients anxiously waiting opposite the fading photographs of smiling infants, it struck me that the association of assisted reproduction and multiple births with moving accounts of tragic, untimely death reiterates Yafa's message: you could lose one.

These nuanced meanings of children resonate in single women's accounts of trying to have a second child, through accounts that braid together "children are happiness" with the unease of imagining an only child and the fear of future personal and national loss. On the one hand, the increased generational distance between mothers and children increases the likelihood that the child may lose her mother before she is an adult. On the other hand, conceptualizing reproduction, children and the future is set against the rise of pessimism amongst the JewishIsraeli public and of the perceived existential threat as the broader Middle East enters a period of increased political instability. As Israelis face the future, Rita's words remain ever salient: the country needs a lot of nice young people. 


\section{The Multiple Dilemmas of Becoming a Single Mother}

In this section, I examine the complexity of future loss in the practice of technologicallyassisted later motherhood. First, I consider how the desire to have more than one child in this context informs single women's successive attempts at in vitro fertilization. I then explore how iatrogenic conditions resulting from practices of assisted reproduction, including multiple embryo transfer and fetal reduction, take shape as both social and medical dilemmas. These reproductive routes to having children, and their dramatic moments in particular, make explicit the multiple ways Israeli IVF stories, spanning from conception to birth, figure children as happiness and at the same time, as losses that induce the anomie of "being alone," without family.

\section{"I knew that I needed two children"}

I met Dana in the main parking lot of her kibbutz, an hour by bus from Haifa. She pulled up in a rickety golf cart. I got in and we set off down a narrow concrete path, bumping and lurching through the center of the settlement. Dana pointed out buildings of interest as we approached them: the dining hall, community center, library, clinic, grocery, preschool (gan), senior house and memorial to the fallen IDF soldiers from the kibbutz (yad lebanim). We drove past the swimming pool surrounded by an expanse of grass and a cluster of towering trees and beyond clusters of multi-level housing. Like many other kibbutzim I visited, this one shared a similar layout: communal life in the nucleus, residential quarters radiating outward, industrial buildings bordering the main road. Modest houses and apartment buildings in rows are separated by lawns and sheltered by trees planted long ago by the founding members. Unlike many other communal settlements that have undergone what is now understood by many as the inevitable 
process of privatization, Dana's community has managed to survive, at least for the time being. Nevertheless, over the past 45 years the kibbutz, as a way of life, has undergone drastic changes. Like the place she had grown up, Dana's own life trajectory looked quite different now from the way she had imagined it would be.

With the exception of three years in Tel Aviv, Dana had spent her entire life in this small world. Even as she had enjoyed living in a cosmopolitan expanse of the city, with its amusements and anonymity, she returned to her family and the kibbutz in her mid-20s. It was not only the landscape and the economic security that drew her home, but also the feeling of being surrounded by her family, by a "feeling of completeness." She envisioned that her life would unfold in this environment. Dana told me, "As a girl, I always thought that I would have a family, that I would get married. That was clear." She knew that, somehow, things would happen in this way, "I just didn't know the 'what and how."

A few weeks before her $38^{\text {th }}$ birthday, Dana told herself the time had come: she gave herself another year to examine what she wanted from life. "I realized that I didn't want to miss the matter of children (l'fasfes et ha'inyan shel yeladim)," she said. For some time, Dana had avoided the family-centered activities on the kibbutz, gatherings of friends and their children, and events that as a young adult she had looked forward to, like the upcoming holiday of Purim. In these spaces, Dana explained, she felt more self-conscious about the difference between herself as a single woman (revaka) and the married couples and their children. Despite her efforts to evade it, the all-encompassing social world of the kibbutz was impossible to avoid:

The environment really pressured, you feel stressed when there is no ben zug (male partner), and everyone already has children, and at some stage, you stop seeing families with children, because this feeling is uncomfortable. When they invited me to all these [events] with children, I didn't go sometimes. 
As Dana thought about her own desires during these months, she continued to encounter the assumptions of what was expected from her and what was considered desirable. Children, their artifacts and their noises permeate the kibbutz lifescape. Their existence resounds in Dana's explanation; the word itself children (yeladim) populates her speech in its plural form. Dana's mother, before she died of breast cancer when Dana was 35 years old, would gently prod her from time to time, "Nu, have children ( $n u$, tavi yeladim)." She even joked that she would adopt grandchildren since she could no longer wait for her daughter. Like Dana's speech, her mother's wish was always in the plural, for grandchildren: not a child (yeled) but children (yeladim), not a grandson (nekhed) but grandchildren (nekhadim). Though she longed to become a mother, Dana also longed for children.

Dana was troubled by another matter: she already knew that she desired at least two children. This, in fact, was a source of tremendous anxiety from when she began fertility treatments with donor insemination. "I thought, what will happen if I'll have [an only child], and God forbid (has v'halila) something happens to him," she told me. Dana's use of has v'halila captures the uncertainty of life and ubiquity of death in Israel that Yafa explained to me over Shabbat lunch in Ashdod: it is a self-evident expression that is widely used by Israelis to gesture towards the worst-case scenario. As Juliana Ochs shows in her ethnography of security during the Second Intifada, fear is experienced by Jewish-Israeli women as a "bodily feeling" rather than an explicit topic of conversation (2011:73-77). The fear of losing a child and of losing an only child in particular (especially a boy) in war, an accident, a terrorist attack, without warning is ever present, yet seldom articulated. Though Dana admitted that she fantasized about having a girl, like other women I spoke with, she used "him" to describe the imagined (male) child (yeled). ${ }^{49}$ Dana continued, "I knew that I needed two [children]. That was a goal. I knew that I 
don't want an only child (yeled yahid)." Dana's desire to have children was inseparable from imagined death of a son.

In addition to her fears about losing a (male) child, Dana also worried about having an only child because of the ambiguous future of the Israeli kibbutz as an institution that is undergoing a process of privatization. For Dana, this intersected with the knowledge that the generational gap of four decades between her and her child would mean that he might lose his only parent and the kibbutz (which Dana understood as an extension of family) around the same time. Though she tried to not think about this possibility, these thoughts were impossible to avoid, clouding her conception of her children's futures. In Dana's account, her longing to become a mother is inextricable from a world filled with children on the kibbutz as much as it is from imminent uncertainty that threatens an entire way of life.

\section{“One Child Is Not Good”}

Like Dana, Yael knew from the outset that she wanted to have more than one child and dreaded the prospect that, because of her age, she might only be able to have an only child. "I grew up [with the idea] that one child is not good, that it's not healthy," Yael told me, "I come from a family of five children ... Somehow it entered my head [that] one child is not exactly optimal." She was raised not far from Tel Aviv; her father was from a large Iraqi family with many siblings and her mother came to Israel from Romania with her family, which included two siblings. Unlike Dana, Yael did not raise the issue of losing a child but instead focused on the well-being of a child without siblings. When, at 40, Yael began donor insemination she thought a great deal about the difficulty of raising a child on her own and without a father for her child. Yet what concerned her the most was having "more than one" child. This feeling only 
intensified after the birth of her son. Even as Yael wanted another child, the second time around was more difficult. Yael said, “[I thought] alone, I won't do it, it's too hard, but it worked out differently!"

Although Yael struggled to get by in a Tel Aviv suburb where the cost of living is considerably higher than elsewhere in Israel, the thought of bringing an "only child" into the world remained a main concern. At the time, she was exhausted from a sleep-deprived first year, working full-time, commuting to her office in Kfar Saba, and paying most of her salary to a babysitter who arrived at seven each morning to look after her son. Despite these circumstances, "I didn't want to be sorry, looking back, that I didn't have another child," she said while folding toddler size shirts and stacking them into neat piles on the sofa. While Dana had bought several vials of sperm from the same donor at the very beginning of the process, Yael did not store samples from the same donor she used to conceive her son. Yael accounted for her decision not to buy more from the donor at the outset of beginning fertility treatments because she was adamant that she would have a second child only after finding a partner (ben zug). That is, when Yael went to the sperm bank she believed that she was postponing, but not "giving up," on finding a man and getting married. She imagined that she would become a mother first, a wife second and then have another child with a "known" father. Yael laughed, "After the birth of my son, I was far too busy to even think about going on a date!"

One day at work, while preparing for a meeting, a male colleague announced to Yael that his wife was pregnant for a second time. Yael congratulated him, but then he asked her, "Nu, what about you?" Had she been married, Yael would have received this question from everyone around her, whether she knew them well or not. Since she was on her own, it was rare that anyone asked her about a having a second child. The rest of the afternoon, she felt distracted by 
her colleague's inquiry. Until then, Yael had pictured finding a partner (ben zug) before having another child. Her colleague's unexpected question pushed her to act. "That same day" she remembered, "I called the sperm bank and made an appointment."

Despite her quest to conceive for a second time, Yael was correct in her assessment that those around her would disapprove of her having another child on her own. For this reason, she told only her closest friends. Shortly after she returned to fertility treatments, her company downsized and she lost her job: this coincided with a pregnancy following the first round of IVF. With this unexpected news, Yael worried about telling her father; he would ask her how she would manage alone with two kids, a cramped apartment, and now following the layoff, without a regular income. Even as she was concerned about what her father would think, Yael received other lukewarm responses from some of her family members. A few weeks into her first trimester, she felt weak and nauseous while visiting her aunt and uncle for Shabbat lunch. Her uncle sensed that something was wrong, as Yael is usually a boisterous participant in family conversation, and asked her whether she was ill. Not yet visibly pregnant, but not wanting to lie to him, Yael revealed that she was pregnant. Taken aback, he looked at her, and blurted out, "What, [pregnant] again?" Although her aunt and uncle had rejoiced in her news the first time around, she could tell that her unanticipated announcement made them uneasy. Yael had worried about their reaction to her having a second child, since they disapproved of the fact that she was an unmarried woman. Soon after this occasion, her father heard that she was pregnant—his immediate reaction resembled to his brother's outburst.

Similarly, Yael's older sister, who had helped her raise her son, was also uncomfortable when she heard about the pregnancy. While Yael's father and her elderly aunt and uncle were troubled because she was (still) not married, Yael's sister raised the issue of maternal age, 
reproaching her, "You're too old to be a mother!" Her sister, who had given birth to three children in her 20s, thought that carrying a pregnancy at the age of 44 might harm the baby. Her doubts aside, she nevertheless recognized that it was better for her nephew not to be an only child, particularly because of Yael's older age. She feared that if something were to happen to Yael, her nephew would be left alone. Many of Yael's closest friends shared her sister's reaction; they were concerned that a pregnancy at Yael's age might be difficult yet recognized her act as a selfless one since she sought to give a sibling to her son. Yael explained of her friends responses, "There are those who say 'with respect' (kol hakavod) [because] they think that it's better (nakhon yoter) to raise two [children] and not one." Thus, her friends, like her sister, respected her in part because they understood the benefit of having more than one child. In the case of women like Yael, "age" and "family status" are co-configured through cultural calculations of family size, generational time, economic situation and health outcomes. For these women, the idea of not being "alone" was more important than the social status of marriage, the economic situation to manage raising two children, or the influence of biological age on fetal development. Beyond her family and friends, Yael received comments from people she hardly knew. When she was five months pregnant, Yael found a new job. On the first day at work, she had an unpleasant encounter with an employee in her unit. A thin, tall woman, her pregnancy was quite noticeable by that point. By way of introduction, her co-worker asked, "What does your husband do?" Annoyed by the question from someone she had never met or spoken to before, Yael also knew that the co-worker was aware that she had another child at home. His assumption, like many around her, is that a woman pregnant with a second child is a married woman. While Israelis are sympathetic toward single women who have a child on their own, Yael acknowledged that she felt much less support when it came to having a second child. She 
experienced how having a second child without a husband did not seem as "acceptable" (mekubal) to them. The reactions that Yael received from her family, friends and strangers reveal a tension between a course of action that is "more correct" and one that is morally problematic. Having another child is constructed as a selfless act that creates a tie for the existing child, who will not be an "only child." At the same time, the empathetic response to a single woman having a child became a judgment when it came to having children on her own.

Dana and Yael wanted to have a child and reconciled the absence of a male partner (ben $z u g$ ), yet both women felt from the outset that having an "only child" was not desirable. For them, the imagined health and well-being of their future child was inextricable from fear of aloneness (bedidut). Further, the dreaded loss of a child or their own eventual deaths when their children would be starting their own adult lives rendered the misfortune of being alone (levad) inevitable. While they came from different backgrounds, these two mothers' accounts foreground the supposition that I often encountered among Israelis - that an "only child" is not good or healthy. Yael and Dana were among the minority of single women I met, who became mothers of children through successive pregnancies achieved through several more rounds of IVF. $^{50}$ The second time around, Dana got pregnant after four cycles of IVF and Yael conceived on her first cycle of IVF. More frequently, I heard from women who had tried, sometimes for years, but had not succeeded in having a second child or from women who had carried twin pregnancies, often through egg donation. I turn now to the cultural understandings of children, family and loss that animated these extended IVF stories through the uncertain months following embryo transfer and a positive pregnancy result. 


\section{Future Loss and Multi-Fetal Pregnancies}

For women who endeavor to become mothers, assumptions about single motherhood, "only children" and anticipated loss intersect during the procedures that surround the medical management and delivery of multiple fetuses. In the accounts that follow, I consider the unexpected outcomes of multiple embryo transfer. Israeli interpretations of twin pregnancies afford a revealing window into the meaning of children in relation to future possibility and to the possibility of loss. Even as the anthropology of assisted reproductive technologies has covered a wide swath of issues in Euro-American contexts and beyond, there is a surprising lacuna when it comes to analysis of multi-fetal pregnancies, despite the fact that this not an uncommon outcome of fertility treatment whether through the use of hormone therapies, IVF, or egg donation. ${ }^{51}$ Perhaps this absence of anthropological discussion points to the naturalization of twin pregnancy in these diverse contexts.

Twin births in Israel account for about five percent of all births - this is double the rate observed in the era before the advent of assisted reproduction (CBS 2011b). This rate, however, jumps fivefold for women in their mid-40s, due to the practice of combining multiple embryo transfer and egg donation, as the quality of eggs reflects the biological age of the donor, typically women in their 20s and early 30s. Given the widespread practice among fertility doctors of implanting more than one embryo in older patients, nearly a third of all pregnancies among women in their mid-40s at the large hospital where I conducted interviews were twin pregnancies. This appears to be a nationwide pattern. In 2009, twin deliveries accounted for over a quarter of all births among Jewish women age 45 and above (CBS 2009). ${ }^{52}$

Over ten months of participant observation in one of the largest hospitals in Israel, I witnessed how the confluence of multi-fetal pregnancy, advanced maternal age, underlying 
chronic diseases and the onset of pregnancy-related conditions informed distressing, and sometimes heart-wrenching moral dramas in the high-risk maternity unit, as patients struggled to get through "one more day" of gestation. Each day contributed to the odds of viability. Each day harbored new knowledge of maternal and fetal health assembled through lab results, ultrasound monitoring and examinations. And each day contained the possibility of delivery from the boredom of hospitalization and the end of the "tentative" pregnancy (Rothman 1986).

I discussed prenatal testing, multiple embryo transfer, embryo reduction, and twin pregnancies with women hospitalized in the high risk unit, reproductive endocrinologists, perinatologists, and health care professionals in related fields. At medical conferences, I listened to presentations and roundtables on different aspects of advanced maternal age, including the management of multi-fetal pregnancies, from conception to delivery to postpartum care. In these conversations and presentations, Israelis' interpretations of these sometimes medicallyprecarious pregnancies and clinical interventions were inseparable from the widespread value placed on having more than one child. As one perinatologist told me, "In Israel, we don't talk about family planning until a woman has had two children." Although she was ambivalent about following women with successive high-risk pregnancies, the doctor acknowledged these patients would go elsewhere for help if she were to turn them away. As the mother of two children, she identified with their desires and was empathetic. At the time, she was caring for a patient who was 51 years old and pregnant with twins. When I asked her what she thought about the situation, she confessed in a low voice, “I think it's a bit nuts!” This physician's viewpoint echoed in discussions with health care professionals, who expressed a sense of duty to help older women "who will go elsewhere," yet simultaneously recognized the risks of resulting 
pregnancies and - more often - the sorrow of failed reproductive attempts and their ensuing "pregnancy wastage," as it is called in medical jargon.

As one gynecologist explained when we discussed twin pregnancies and fetal reductions in his office between deliveries, "[Older] women want twin pregnancies because it gives them an 'instant family' (he used the English expression).",53 This expression refers to the creation of "family" through one, instead of through successive, pregnancies. The physician, like the perinatologist, admitted that twin pregnancy among women of "advanced maternal age" is known to involve more complications; at the same time, he grasped the implicit benefit of having more than one child. Yet, while women carrying multiple fetuses were encouraged by those around them to interpret their pregnancies as a "blessing" or "gift" — as their children would be part of a family and not "alone"-I came to learn that for mothers-to-be a twin pregnancy was sometimes a quite unexpected and even undesirable result of transferring more than one embryo. Single mothers who had more than one child, whether through successive or twin pregnancies, shared with me that they did not spontaneously achieve the "instant family" as envisioned by the veteran gynecologist. Further, on their way to having more than one, some women nearly lost everything along the way. Given these variables, how is pregnancy loss through miscarriage (hapala) or fetal reduction (dilul) conceptualized in relation to broader cultural understandings of children as future possibility and as future loss?

\section{“You Got a 1+1": Twin Pregnancies as Blessings, Gifts and Deals}

Following two exhausting weeks in the high risk unit with preeclampsia, Sigal was beaming with happiness when I met her, a short time after the birth. She was now the mother, at age 44, of twin girls, who were being cared for in the NICU (pagia). Earlier in her second 
trimester, her doctor had advised her to consider fetal reduction due to her worsening health situation. Yet Sigal opposed undergoing this procedure from the moment her daughters were conceived through egg donation. She told me, "I decided when they transferred two embryos, not to do fetal reduction (dilul)." Although her doctor had raised it even then, as a distant possibility, Sigal explained, "It is what God blesses me [with]," gesturing with her hands toward the sky. Even in the most difficult moments of hospitalization, including a week where she did not leave the bed, tethered to a magnesium drip ("I thought I was going crazy"), Sigal did not doubt the gift she had been given. A self-identified secular Jew (hilonit), Sigal nevertheless experienced her twin pregnancy as a blessing; she felt that having two children was better than having an only child, particularly since she conceived of her natal family as a "small one." Here the blessing is not confined to the child she receives but is experienced through the extension of family - the blessing that her child will not be alone. Like the women described in Elly Teman's account of Israeli surrogacy (2010), by deferring to God's will, Sigal did not conceptualize fetal reduction as a choice or herself as an individual agent. Even as she worried about the medical complications and suffered terribly during the final months of pregnancy, putting her own life at risk, Sigal struggled to keep both twins alive throughout. In contrast, other women carrying twins did not understand their pregnancy as a gift or a blessing — at least not at the outset.

After trying for over a decade to conceive, Limor went to a private clinic in Tel Aviv, headed by one of Israeli's most prominent IVF specialists. Once a month, the clinic sent a physician and between 20-30 Israeli women and couples to undergo egg donation at a partnering clinic in Kiev. Limor joined one of these chartered trips. A high school teacher who lived on a modest income, it was her second time outside the country. Shortly after her return, she learned that she was pregnant, at 47 . But when she received the positive results of a blood test, she 
admitted, “I wasn't really happy. I didn't quite know what I feel....I didn't quite know where [am] I...I didn't yet know what I am doing with this." In all the years of trying to have a child on her own, Limor had never become pregnant. During the weeks that passed between the positive blood test and the first ultrasound, Limor digested the idea as she shared it with those closest to her, who for years had supported her quest to become a mother. Her initial shock and disorientation settled into an apprehensive happiness, as each week passed and the pregnancy became tangible through her tightening clothes and insatiable appetite.

Then in her eighth week as she lay on the exam table, her doctor uncomfortably angled the sonogram wand in her to get a better view of the uterus, Limor received unexpected news: he showed her that there were two fuzzy, but clearly separate, embryonic sacs on the monitor. The idea of being pregnant with twins, Limor admitted, "was a hit to the head (makel b'rosh)," the palm of her hand colliding into her forehead. She had wanted for so long to become a mother, but as the years went by her dream had faded. With all the disappointments she endured during this time, Limor had never once considered that she might have two children, let alone twins. She laughed, "I had thought about one [baby] all the time!"

After receiving the results of the ultrasound, Limor updated her friends and family. Much to her further surprise, not only did they marvel at this miraculous feat of having children "at your age" (b'gil shelakh), but they praised her "with all respect" (kol hakavod). Further, they conveyed their relief that she was having twins and not only one baby, reassuring her that this outcome was desirable, for her children wouldn't be left alone if-“God forbid" (has v'halila). With this expression they expressed their fears that if either something were to happen to Limor, whose own mother had died in her early 50s, the children would have each other; or, if something were to happen to one of the children, Limor would not be left alone. It was their 
comforting responses that helped Limor come to terms with the situation. With the outpouring of blessings from her religious-traditional (masorti) family and friends, Limor, a self-identified secular Israeli gradually came to realize "what a gift I had received from God." Like Sigal, the idea of the divine intervention here is not a gift of an individual child, but in a world of potential loss, the gift of relations that may endure despite the uncertain future. Through the remainder of the pregnancy, Limor's belief that the twins growing within her were a "gift" helped her get through many difficult days of hospitalization, recovery from the birth and weeks of waiting until her prematurely-born son and daughter were discharged from the NICU (pagia).

In contrast to these understandings of twin pregnancies as divine gifts and blessings for creating relations in response to the potential of future loss, for other women, the idea of having twins brought on fear and anxiety about the future that increased over the duration of the pregnancy. Even though we sat alone in her Jerusalem apartment, Keren lowered her voice considerably as she recounted her quest to have a child. She had endured years of fertility treatment, including seven cycles of IVF, three early miscarriages and serious bouts of depression that accompanied each. With her doctor's encouragement, Keren decided to travel to Eastern Europe in order to undergo egg donation there. In the foreign clinic, an Israeli doctor had transferred the three most viable embryos made from the sperm of an anonymous donor from a California bank and an anonymous local egg donor. A few weeks after she returned from the embryo transfer abroad, Keren received a positive pregnancy test. She was stunned by the result. Filled with overwhelming fear that she would lose the pregnancy, as she had in the past, she minimized her physical movements and limited her daily routine as much as possible. A close friend, trying to cheer her up, encouraged Keren to be more optimistic and convinced her that she needed to get dressed and leave her apartment for a change of scenery. A few days later, while 
sitting in a neighborhood café with the friend, Keren started to bleed heavily, so much that before she realized what was happening, blood had soaked through her clothes.

An ambulance rushed Keren to the nearest hospital. "I was completely hysterical," she remembered, rushing through the details of the experience. Upon arriving at the ER, the on-call gynecologist checked her. As he looked at the ultrasound monitor, she received an even greater shock. "I see you have one spare [fetus]," he joked, "both have strong [fetal] pulses, so bleed as much as you want!" Though the doctor tried to allay her fears with his macabre sense of humor, the news of a twin pregnancy sent Keren's sense of relief plummeting. As she tried to rest at home over the next few days, she felt disturbed by her thoughts: how would she copefinancially, emotionally, physically_with twins? Although she had always wanted more than one child, this was not the picture of motherhood she imagined. Even as she owned her apartment and had many close friends willing to help, Keren was not sure she would be able to manage on her own. This was compounded by the fact that she was now responsible for caring for her mother, who had developed Alzheimer's, but still did not qualify for more social services, including nursing care. Despite the doctor's reassurance that things were fine with the pregnancy and that she could "bleed," Keren felt that she was living in a nightmare that would soon materialize. How would she handle the threefold responsibility of caring for infant twins and an ailing mother?

Keren's fear was so overwhelming that she began to think about fetal reduction (dilul ubarim). Over the next few weeks, she spent her time scouring the internet, reading everything she could in Hebrew and English to find out about the procedure. She learned from this research that she could lose both fetuses from such a procedure, yet she still went to ask her doctor. He tried to help her see her pregnancy differently, telling her to look on the bright side, "You got a 
$1+1$ !" This expression refers to the "buy one, get one free" deal (mivtza) that is ubiquitous in Israeli chain stores. Similarly, when they heard she was considering a fetal reduction, Keren's closest friends tried to encourage her to understand her twin pregnancy as a beneficial situation:

My friends asked me, "Are you crazy? You won the lottery of pregnancies. [You should] be happy. It will be an 'instant family' (English) and not the symbiosis (symbioza) of mother and baby, but instead you (atem) will have a complex family (mishpaha morkevet)... It's more correct, more balanced and you won't have to become pregnant again in a few years.

Although Keren only wanted one child at a time and not twins, she explained that when she thought about the image of a single mother with a child, "something was different; it didn't give me a good feeling." The language of "symbiosis" (symbioza) drawn from the biological sciences to describe an enduring relationship between two species, in which one cannot live without the existence of the other, has been adopted by developmental psychology in Israel to describe the mother-child bond that is interrupted by the father. Keren elaborated that by symbiosis she meant "the feeling of me and you versus the world" - a feeling of opposition instead of being a part of something larger. By contrasting an "instant family" with a "symbiosis of mother and child" suggests two people bounded within a dyadic, contained relationship rather than a web of more complex relations do not constitute a family. Keren's friends assumed that if she were to have a singleton, she would "have to become pregnant" again. In the commonsense rendering of reproductive trajectories, as discussed above, having an "only child" is not a socially appropriate or morally sensible outcome. Having twins now, though perhaps difficult in the early years, would avoid the impossible (another pregnancy) and the undesirable (having an "only child").

Keren agreed with her friends' assessment that it took more than one child and one parent to make a family. While her friends consoled her that though caring for twins might present difficulties at first, in the long term it was a preferable outcome. She explained, "My friends 
convinced me that it would be a family and not just 'mother and child' (v'lo rak ima v'yeled),', or the social symbiosis of a dyadic, insular relationship of which she disapproved. In the end, Keren decided not to undergo a reduction, in part, because she believed that it was better for her children to have "a family" instead of what she understood to a more limiting mother-child relationship. While the medical risk of such a procedure did weigh on her decision, as there is a chance that the surviving twin will miscarry, in Keren's retelling, the social calculation of extending the family beyond a symbiotic relationship took precedent. Keren felt that she was fortunate: the rest of her pregnancy was uneventful and she delivered by caesarean at the end of her $36^{\text {th }}$ week. In contrast, other women carrying twins developed complications and delivered pre-term babies, who required extensive and prolonged care.

\section{“Until I Hold Them in My Arms"}

Miri lay beneath a moveable table reaching across the width of her bed, which held a stack of magazines and her new laptop, which she used, among other reasons, to google her health conditions. The window sill was lined with gold-lettered religious books and bottles of shampoos, lotions, conditioners, and hand sanitizers. Her mother had brought more items from Miri's apartment than there was space for in her third of the hospital room. Whenever I came to visit, Miri spoke to me freely as her mother, who visited daily, tended to her daughter: highlighting her hair, tidying the room, and serving her homemade meals. This was her first pregnancy that went beyond 24 weeks; before that point, women with complications are housed in the women's unit. In tears, Miri recounted a previous hospitalization in "the other unit" that had ended tragically. This time, she was more hopeful. And this time, she was carrying twins. 
"Did you want twins?" I asked. Miri gestured her hands toward the ceiling, "As many as possible, with blessing" she smiled, wincing at the same time from lower back pain.

When she was 43, Miri consulted with a fertility doctor, who convinced her that it was not too late to have children; he was optimistic even though she was older and had chronic hypertension. Her mother, who wanted her eldest daughter to get married, was less assuaged by the doctor's medical recommendation. ${ }^{54}$ I asked Miri whether she discussed the risks of carrying a multi-fetal pregnancy before undergoing treatment. She replied:

When I went to [the fertility doctor], he said "there aren't risks [with being older] but that with twins there is more risk." We discussed how many embryos to transfer. The first time, I wanted more [than two] because the chance is higher that they'll implant, but he explained that it's dangerous.

That conversation took place during her first round of IVF. One embryo was transferred"because that's all there was," her mother interjected—and it implanted. Despite the initial prognosis of a healthy singleton pregnancy, Miri suffered a miscarriage in the second trimester. As advised by her doctor, she waited two months before returning to his clinic. The second time, there were two viable embryos to implant and Miri wanted both. Before the transfer of two embryos, however, the doctor gave her a consent form to sign that, in the event of a multi-fetal pregnancy Miri would agree to undergo embryo reduction. Later, when she received results that the two embryos both implanted, "[The doctor] gave me a form to sign [stating] that I don't agree to embryo reduction (dilul)." Though the form explained the risk factors in carrying a multiple pregnancy, it appears to be offered to women like Miri as a kind of formality mandated by the Ministry of Health. Of this two-tiered consent practice, a fertility doctor at the clinic where Miri underwent treatment told me, "We tell [the women] what can happen with a twin pregnancy, the problem with preterm pregnancy and the consequences of prematurity. Some take the chance not to reduce...they want two children." According to the doctor, who participates in 
an egg donation program between his clinic and one in Kiev, two thirds of the patients decide not to undergo reduction. In this case, Miri understood that there was perhaps more risk involved, but having miscarried before she believed that whether it was a singleton or a multiple pregnancy, it was out of her hands.

Even though she interpreted the twin pregnancy as a blessing, Miri revealed that she was not happy when she heard the news. "The first time I was pregnant, I feared being happy, that [the pregnancy] would be lost (lit: fall). And this time, because of the [miscarriage]...until now I'm not happy. Until I hold them in my arms, I won't be happy." ${ }^{, 55}$ Only after the birth could she experience the joy for which she had suffered. While she was not happy about carrying a twin pregnancy and was concerned with the possible risks, Miri regarded it as fortunate, even a blessing, to have "more than one." This blessing, however, was also a laborious trial.

Throughout the first trimester, Miri had experienced heavy bleeding and was put on bedrest. Once she had gone to the bathroom and was shocked by the amount of blood, "I had thought they had fallen [miscarried]." She called her parents right away, and her father drove her to the emergency room. When she underwent an exam, the attending physician told her that one of the twins "wasn't normal" (lo takin). Although it was eventually determined that the bleeding came from outside the amniotic sac, and thus the health of the fetus was not compromised, she was admitted to the hospital for high blood pressure and dehydration. Since then, Miri had been in and out of the high-risk pregnancy unit and the emergency room, discharged for a few days at a time, but only to return with another complaint. She joked that she had become a pregnancy expert; since that episode she had experienced almost every possible complication from gestational diabetes, to preeclampsia and cervical shortening. She had spent an entire week in "Room 8 " on a 24 hour a day magnesium drip to prevent pre-term labor. Women described the 
excruciating side effects of this treatment to me including hot flashes, weakness, dizziness, red burns on the body, extreme headaches, and even "torture." These horrible physical symptoms are compounded by the fear of losing the pregnancy or of pre-term delivery and by the boredom of being confined to a hospital bed for days on end. In the unit, whenever I passed by Room 8 at the end of the corridor, the lights were off and the curtains drawn shut, sometimes relatives stood quietly by the door. The room seemed to emit an aura of dread. "I cried day and night there" Miri said, "It was very difficult. I thought that I had lost everything, but I survived."

Miri looked relieved when I visited her a few hours before the scheduled caesarean birth. She had survived the many hospitalizations, the ups and downs of medical complications, and the monotony of bed rest. Miri told me that she was "ready to be happy" and sounded more upbeat than she had in weeks. Her mother sat nearby, putting the sections of the daily newspaper back in order. An older leather suitcase, a duffel bag, and plastic shopping bags packed with most of her things were clustered at the foot of her bed. Miri was 31 weeks and 5 days pregnant and had calculated that, after four mandatory days of recovery, she might even be able to be home for Shabbat.

The next day, I called the nurse coordinator of the unit to find out how Miri was doing after the birth. I knew she would be tired from the surgery and did not want to disturb her, even with a text message. The coordinator sounded irritated, and answered frankly, "things are not good" explaining that the babies were struggling in the pagia. When I saw Miri a few days later, her mother was pushing her down the hall in a tattered wheelchair; she looked pale in her hospital gown and white bathrobe, her feet and ankles swollen. She waved me over, explaining that she was headed to the pagia to visit her children, whom she had named after her four grandparents by giving them each a first and middle name (highly unusual in Israel). Late one 
evening a few weeks later, Miri called me. She told me that after the birth, she nearly lost both her son and daughter who caught an infection in the pagia. Two days earlier, the twins had been transferred to a regional medical center that was closer to her house. She sounded stressed and told me in a hushed voice, "Their condition is not good...they are very sick." Miri and her mother were taking turns, staying "on guard" (mishmeret) with them around the clock. She apologized, but she had to end the call, it was time for her to relieve her mother's shift.

Several months later, I unexpectedly got another call from Miri with different news. The twins were finally home in Ashkelon and beginning to thrive. She had even gone back to work part-time and her mother and a nanny were helping to take care of them. Her cousin was returning home after three years of army service, and Miri invited me to meet the twins and come celebrate at a mangal (barbeque) with her family. The week of the party, however, missiles fired by militants a few kilometers away in Gaza began to fall heavily in southern Israel, and when we spoke again Miri decided it was best for my safely not to visit. In any case, the family had called off the celebration; it was deemed too dangerous to be outdoors when air raid sirens were going off day and night. So far the "iron dome" (kipat barzel), as the Israeli air defence system is called, had intercepted most of the missiles, but a few had come through, landing mostly in empty fields. "With the help of G-d" (b'ezrat hashem), Miri proclaimed, I would meet the twins soon, when things quieted down. Miri's story demonstrates how personal and national traumas are intertwined in the context of everyday life in Israel. In this instance, national crisis thwarted her long-awaited relief that her children were safe and overshadowed the risks that she endured during pregnancy.

In the above accounts, women encountered multi-fetal pregnancy as a blessing, gift or beneficial situation for the children and the kin relations it might produce. Within these accounts 
pregnancy loss, whether feared or experienced, is a painful personal event, it is not rendered within the larger construction of the loss of children and relations amidst future uncertainties. In women's understanding of twin pregnancies, it is the future anticipation of losing kin that shapes their interpretation of risk and the salience of having (or being given) "more than one" despite the personal hardship these multiple conceptions and resulting pregnancies might entail.

\section{“COUNTING THE MANY": Single MOTHERS AND THE WORK OF EXTENDING OF FAMILY}

One quote in "Revaka +2 ," the article I began this chapter with, stood out as it resonated with the experiences of mothers I interviewed. A single mother told the reporter, "When my second daughter was born, we [really] became a crystallized family (mishpaha megubeshet). The girls feel family; they don't feel alone (levad); they don't feel different" (Shtutland and Melomed 2009). In everyday Hebrew, school classrooms, youth groups and military units are conceived of as ideally undergoing a process of crystallization (gibush) through which individuals are subsumed into collectively-oriented subjectivities (Katriel 1991). In the context of school classrooms, Tamar Katriel suggests that a well-defined social unit is like a crystal; it has unambiguous boundaries, is integrated and has inner strength, is internally homogeneous, and forms under specific conditions (1991:18). Other social groups may be described as having this quality or in need of developing it, including work groups, military units and even the nation as a whole. Yet, the Israeli family (mishpaha) is the one social group where the process of crystallization (gibush) is not applicable, but is instead "semantically anomalous" (Katriel 1991:25-26). Thus, it is not common usage to speak of becoming a "crystallized family" (mishpaha megubeshet). When I asked several Israelis why this is the case, they all reasoned matter-of-factly: "the family is already crystallized." 
In this section, I explore the meaning of family for single women who have more than one child, either through successive or single pregnancies. I suggest that despite the possibility of an "instant family," a single woman and her children are not easily conceptualized as "a family." Insofar as the family is taken to be "already crystallized," rather than a social unit that is made and that cancels out difference between individuals, what is the import of single women's efforts to make children into family?

Hadas shared a recent source of tension between her twins, a five year old boy and girl. They argued about whether they have a father, or not. Earlier in the week, as she tried to doze on the futon which serves as her bed in the living room, her son came to her in tears. He had fought, again with his sister about whether they have a father. He reported what had happened to his mother. He had told his sister, "We once had a father," but as usual, his sister corrected him, "We never had a father." This left him angry and he sought a different answer, "Mom, did we once have a father?” Hadas answered, "No, we never did.” Like her son's desire to know his father, she too secretly believed that one day they might know. Though Hadas conceived with sperm from an anonymous Israeli donor, and knew that the donor's identity would never be revealed, she nevertheless believed that eventually the current Israeli policies would change, and somehow his information would be released. Her children, she hoped, might learn the identity of their father. At the moment, she only knew that he was a graduate student from North America, of Ashkenazi origin and that he was tall (almost all sperm donors are over 1.8 meters). Yet, for Hadas this limited knowledge and her steadfast hope would not change the fact that although her children do not have a father, they do have a family.

From the moment the twins began to speak, Hadas talked to them about what they did have, a family, rather than what they didn't have, a father. When the subject of their father came 
up or when she sensed the children had questions, she would tell them, "We are a family that has no father, but we are a family, we have a very large family." Hadas and the twins would count her six siblings, and then count their six wives and husbands, and then count all of their children, her children's cousins and their children. Through this practice of counting their family members, Hadas instilled her children with the message: they were a family. This family of many that cared for them was more important than one (missing) person. As Hadas held her son to calm him on that occasion, together they once again "counted the many."

Nurit was 39 years old when her daughter was born. Like Hadas, she came from what she considered a "traditional" (masorti) Moroccan-Israeli family, but she identified herself as “secular" (hilonit). Her long straightened hair, off the shoulder blouse, tight jeans and high platform shoes set her apart from other women in her family, who dressed more conservatively. When she first told her parents and siblings she was undergoing donor insemination as an unmarried woman, "The decision [to have a baby] was difficult for them, to say that "Nurit is pregnant' without a husband.” Nevertheless, like other Israeli parents, they helped Nurit, a physical therapist, to buy an apartment on the first floor of a four story building (their apartment is on the second floor). Her older sister lives in the adjacent building. With her parents so close, Nurit's mother takes care of her daughter almost every day.

When I met her at her apartment in Bat Yam, her daughter had celebrated her third birthday the week earlier, and sagging balloons drooped from the staircase railing into a weathered stroller below. Over coffee and leftover pastries from the party, Nurit told me that, since we last spoke, she had begun IVF treatments again. Though it had been difficult for Nurit to become pregnant the first time, she persevered with the treatments now because she wanted "to expand our family." She explained, "I came to the conclusion that we need the complex 
family (mishpaha morkhevet) because we are only two at the moment." That is, part of her desire to move to her parents' building was not only the convenience of the arrangement, but a need because of their being "only two." After the move, she did not feel that her daughter was alone because "here at the [new] house, she has family space (merhav mishpahti)," referring to all of the family members who live nearby and spend significant time with them. As she explained "We're not lacking family, I come from a family of 11 brothers [and sisters]." She continued, "Understand that it's not lacking, but that in our small/condensed family (mishpaha metzumtzemet) there is room for another brother." Though Nurit dreams of having another child, despite the physical toll of hormone injections, she saw her efforts to have another child as expanding both her small/condensed family and the larger extended/complex family. She explained, "I emphasize what we have: a grandmother, a grandfather, uncles [and aunts] and cousins. I have seven brothers and each [treats her] like she is their daughter." For Nurit, like Hadas, situating their children within "the many" of a larger family, in close spatial and emotional proximity to grandparents, uncles and aunts, cousins and their children meant that their children were not alone.

In contrast to Hadas and Nurit, Dana tried to make distinct space and time for her and her two young sons. She told me that she aimed to create a sense of "togetherness" (b'yahad) without other family members. The Israeli use of the word mishpaha (family) often blurs the distinction between what might be referred to as a "nuclear" family and an "extended" family (though both terms are sometimes used for specificity). For example, Dana did not make the distinction between a "nuclear family" and "extended family" but instead commented that she sought to spend time with her sons - "without the family"-referring to her father, sister's family and her brother as well as an elderly aunt who visited most days. So while the terms nuclear and 
extended family do exist, in everyday conversation, mishpaha is used interchangeably and the boundaries of family are less rigid than suggested by "the nuclear family." What constitutes family is not necessarily limited to the space of the house (residence), but in Dana's case this differentiation is what encompasses the three of them, making them "a small family."

Even as Dana endeavored to make special space and time for her and her sons to be together, they remained different from the other families surrounding them. Dana told me, "I explain to [my sons] that there are other families like [ours] in the world, but they don't know of any [single-mother families]." For her sons, their family was different from others on the kibbutz. At their age, they spent almost all their time on the kibbutz, in day care and activities. Given that Dana was the only "never married" single mother on the kibbutz," her sons rarely encountered other children in their situation. Dana shared that she struggled with the tension she felt between "the aloneness" (habedidut) of being with her sons and "the togetherness" (habeyahad) she felt when the three of them were with her natal family, and with her father in particular, despite the feeling of "togetherness" she tried to create alone with her sons.

Although Dana felt the absence of her mother, who had died before her sons were born, her father was enmeshed in her boys' day-to-day lives. He met them in the playground most afternoons, where he was loved by many children, carrying them high upon on his broad shoulders, and making up stories and games to amuse them. Dana's father also joined them almost every night for dinner at her house, picking up food from the dining hall on his way over from the kibbutz factory where he and Dana both worked. When the subject of fathers comes up, her boys proudly tell their friends, "We don't have a father. We have a grandfather (ein lanu abba, yesh lanu saba)." Dana explained, "Like, [their response] comes from 'Yes, we [do] have a family' (k'ilu min 'ken' yesh lanu mishpaha)." While Dana felt that she and her sons were at 
times a family (mishpaha), her sons' formulation and her interpretation of its meaning sheds light on the enduring hegemonic idea of family as including a father figure and as containing intergenerational relationships. When her sons assert that "yes" they have a family, they do so in part through the presence and involvement of their grandfather.

Similarly, for Yael, the question of what constitutes a family remained salient, even after having a second child. "What is a family?" I asked Yael. "It's hard to say" she paused to think, "on the level of definition, yes, it's a kind of family, even when [there was] one child." I wondered if having a second child changed the way she saw her relationship. "So, you feel that you're a family?" Yael answered:

For my son, sometimes it's not enough, me and the baby, he complains that he wants more people...I don't know what it is to 'feel' family...I have two children... On his birthday [at preschool] they asked my son 'what family celebration do you want?' so he didn't answer about the small family (ha mishpaha hametzumtzemet)...he doesn't like that it includes only the three of us, he wants it to include the uncles and aunts... I always feel that I have two children, rather than a family. Yes, I have a family, but, I don't know.

Yael's ambivalence about whether she and her children are "a family" or perhaps "a condensed family" complicates the narrative of expanding the family in "Revaka +2 " and the possibility of crystallizing children and the single-mother family into a socially-recognized family. Even as single motherhood is increasingly accepted among the Israeli public and the secular public in particular, having children on one's own is not equated with family nor is family something that can be made through women's reproductive agency alone.

\section{"A Mother in Happiness and Sorrow"}

In this chapter, I have explored the multiple ways that loss-experienced in the past and imagined in the future-intersects with Israeli single mother's accounts of bringing children into the world. These accounts are informed by cultural ideas about family size and the meaning of 
children and by shifting historical constructions of the "only child." The medical and social complications that arise during women's attempts to have children, including multi-fetal pregnancies, are inextricable from this broader cultural context. Yet even among Israeli single mothers who have more than one child through assisted reproduction, their creative endeavors to connect their children to extended kin reveal the complexity of constituting family as a womana subject I return to in greater detail in chapters four and five.

I want to conclude with an example of how ideas about children, family and motherhood are woven together in a media account of assisted reproduction. This IVF story, featured on the front page of Israel's largest daily paper, is titled "In Pain You Shall Give Birth" (b'etzev tildi)— a quote from Genesis 3:16. It presents the story of a 51-year-old single woman who became pregnant with twins after 13 years of "fighting to bring children into the world" after failed fertility treatments and seven miscarriages. During her third trimester, the woman developed complications and was hospitalized in Hadera where she gave birth at 28 weeks gestation to a live daughter and a son, who did not survive. Much of the article relates the traumatic birth, the mother's emergency hysterectomy, her own near death and the medical malpractice case that ensued. These details, however, are not the entire story; the article concludes, "Despite what happened, S. wants more children. She has a few more frozen embryos, but because she doesn't have a womb, she needs to find a surrogate mother abroad" (Yarkoni 2011:15). This temporary closure aligns S. within the normative expectations of having a least two children. Thus, the reader is left to imagine that S.'s struggle is not over.

What sets this IVF story about later motherhood apart from those discussed above is the absence of loss of a child through past violence. By reading the article in relation to surrounding texts, the loss implied through the juxtaposition of words and images occurs in the future. On 
the front page of the newspaper, the main headline reads, "Asad: Loses Control" and picture of Syrian military forces dominates most of the page. Directly underneath, a smaller pictures shows S. and her daughter smiling at one another, and the caption reads "A Mother in Happiness and Sorrow." The full article is a two-page spread, featuring the mother-daughter in a full-page color photograph, the same size as the text box of the article to the left. To the right of their photograph is a smaller column featuring two stories about medical miracles: a story of a terminally-ill cancer patient in his 20 s, who received experimental treatment and survived; the other a story of a young Israeli girl with a rare form of cancer, whose parents have taken her abroad in search of a cure. In this combination of text and image, the borders between personal tragedy and national insecurity blur together as the possibility of miraculous medical technology fuses together making family with the possibility of loss. In this context, as single women navigate the possibilities and limitations of assisted reproductive technologies and situate their children in relation to extended kinship networks, novel family constellations emerge. The next chapter turns to one such constellation that is quickly becoming a recognized reproductive route in Israel. 


\section{Chapter Three \\ “A Syringe ANd A CUP": MAKIng FAMIlies Through ShaRed PARENTING}

This chapter explores novel parenting arrangements between single women and gay men in Israel. Single women are increasingly weighing the route of "shared parenthood" (horut meshutefet) as it becomes an acknowledged way of making family beyond the cosmopolitan bubble of Tel Aviv. Over the last decade, organizations, websites, and individual Israelis have contributed to the growing visibility of shared parenthood, rendering it a legitimate option for much of the secular Israeli public. Concomitantly, shared parenthood has come to be widely conceived of as an alternative to single motherhood through anonymous donor insemination for women in their late 30s and beyond who have not found a "partner" (ben zug). Many Israelis consider this emerging route a way to overcome the social uneasiness surrounding anonymous donation and the missing "father figure" (dimui av) in the child's life. As Israelis consider shared parenthood, they weigh the presence of a known, albeit gay, father, against the absence of a conjugal tie or intimate relationship (kesher). In this chapter, I examine how this emergent practice displaces assumptions about heterosexual unions as the basis for procreation between men and women even as it retains ideas about the relationship between gender and kinship that inform Israeli ideas about family.

The study of gay and lesbian kinship in the United States has provided a key site to problematize the symbolic categories of blood and choice and the underlying symbolic mediator of heterosexual intercourse that David Schneider identified as central to American understandings of kinship (1980[1968]). For Schneider, blood and choice in the American context stood for two symbolic orders - that of nature based in "shared substance" (biology/blood) and that of law based in a "code for conduct" (contract/marriage). Located in 
the facts of nature, shared biogenetic substance or "blood ties" are held to be permanent and unbreakable, while relationships grounded in law such as marriage can be severed (Schneider 1980[1968]:24). Historically, in the United States, gays and lesbians were relegated beyond both of these symbolic orders, their sexuality and their families pronounced "unnatural" or artificial and "illegal," as grounds for excluding them protection and rights under the law (Weston 1991). Rather than find these categories distinct and defined in opposition to one another, anthropologists since Schneider have discovered the creative and contested ways blood and choice inform emergent kinship practices in the United States, including those entailed by the use of new reproductive technologies (NRTs).

Kath Weston's classic work Families We Choose (1991) illustrates how gays and lesbians in San Francisco's Bay Area mobilized the symbolic categories of blood and choice and the tensions within them to create families. Weston showed how understandings of friendship and family infused gay kinship with dynamic possibilities for constructing and contesting meaning amidst a larger terrain in which gays and lesbians were deemed "exiles" from kinship and threatening to American family values. Coming out to one's birth family put the realness of biological kinship to the test, whether told that one was no longer a son or daughter, or that, alternatively, one would "always" be kin. These stories expose that biology, like choice, is constructed and sometimes remade. Beyond what Weston's informants told her about their families, she highlighted the day-to-day practices - the care, nurturance and love - that were key ingredients in the making of kinship. ${ }^{56}$ Insofar as Euro-American ideas about heterosexual procreation privilege ties of blood and the so-called natural facts, chosen families afford anthropologists a framework to take seriously the innovative array of processes and diverse practices of doing kinship, as well as to examine the opportunities for reconfiguring power 
differences in hegemonic gender relations. This endeavor requires attending not only to these dynamic processes and practices as they are experienced, but to their relationship to larger social, economic, religious, and political formations.

Ellen Lewin's study Gay Fatherhood (2009) situates an ethnographic portrait of gay families within the divisive cultural debate about gay marriage in contemporary American politics. She follows the accounts of gay men and couples as they narrated their experiences of becoming fathers through fostering, adoption, surrogacy and shared parenting. Lewin's work points to the ways that race, class and sexuality reproduce inequalities when it comes to expanding and limiting options for gay men. For example, only wealthy gay couples have access to gestational surrogacy, which is the most expensive route to parenthood. Yet gay men of color may have greater access to adoption, given policies that discourage the placement of minority children with white parents. Making families and producing "choice" when it comes to kinship are never inextricable from stratified reproduction (Colen 1995) and the fault lines of race and class divisions in the American context. In later work, Kath Weston argued that there is "a persistent (mis)reading of chosen families as 'freely chosen"' (1998:85). Lewin's work adds to the growing anthropological awareness that reproductive routes are not "freely chosen" individual projects, isolated from larger social and political contexts and that, in fact, the availability of reproductive routes for some, may limit (or increase) the options for others.

Together, Weston's Families We Choose and Lewin's Gay Fatherhood contribute nuanced portraits of gay kinship practices in the United States. However, as both accounts make clear, relationships sometimes dissolve, making evident the centrality of day-to-day practices of care that generate the bonds of kinship, whether aligned with the symbolic order of blood or choice (or both). Finally, both accounts suggest that for members of ethnic minorities, including 
Jewish Americans, the meaning of blood and biology takes on additional nuances-it may tie people to earlier generations and, in the wake of the Holocaust, produces other kinds of obligations to one's community.

Drawing inspiration from these path-breaking studies of gay kinship, this chapter offers a fine-grained account of the array of processes and diversity of practices that are productive of family. These included, but are not limited to celebrating holidays, birthdays, and life cycle rituals; enjoying weekend outings and Shabbat meals; visiting extended family; merging travel and leisure activities; living in the same neighborhood, street, apartment building, or even house; attending medical appointments and assisting at births; juggling childcare duties; cooperating with financial planning; and attending therapy sessions together. In various combinations, this doing is what makes shared parents and their children into families. However, when these are undermined, whether they are weakened or in some cases, cease altogether, the fragility of kinship comes to the fore. ${ }^{57}$ Thus, shared parenting is constituted in women's accounts as similar to heterosexual marriages with "everything but the sex" but when the doing of kinship is diminished, they risk being categorized as "like divorce" (see Segal-Engelchin et al. 2005). As such, shared parenthood is analogous to gay "coming out stories" that make visible the tenuousness rather than permanence of American kinship: there is an assumption that love, care and nurturance are inevitable aspects of marriage and family in general, yet shared parenthood demonstrates that in the absence of the everyday doing of kinship the salience of conjugal ties is destabilized.

In the first part of the chapter, I introduce the contrasting worldviews of two organizations that assist women and men seeking to become shared parents by providing matchmaking services and legal support. In the second part of the chapter, I consider the 
narratives of three women in shared parenting arrangements. These in-depth accounts do not easily resonate with either organization's claims about shared parenthood. Although Israelis in communities throughout the country are engaging in conversations about shared parenthood, single women forging these arrangements with gay men struggled to define their families. While shared parenting is sometimes encompassed within the category of "postmodern" or "new" family by Israeli academics, activists and journalists, my interlocutors did not affix these adjectives to their descriptions of making family. At the same time, their parenting relationships are not easily subsumed within the category of "modern" Jewish-Israeli family (discussed in the Introduction), which is based on an ideal of equality, love and heterosexual intimacy. In the absence of a conjugal tie with their gay co-parent, women's stories reveal the difficulty they experienced in describing their relationships as "family" (mishpaha). Despite the myriad constellations of "shared parenthood," my objective in this chapter is to explore the contrast that women in shared parenting arrangements draw between their own reproductive routes with known men and those of single women who become mothers on their own through anonymous donor insemination.

Anonymous donor insemination enables single Israeli women to "bring children into the world," yet as Chapters 1 and 2 explored, this reproductive route does not easily create a recognized "family." Women's narratives of shared parenting reveal the enduring salience of men's contribution to making family, as the participation and continuing presence of a known father is central to their accounts. While individual choice and contractual (or transactional) relationships are often associated with the "postmodern" (postmodernit) or "new" (hadasha) family, women in shared parenting arrangements underscored the "family-like" aspects of their family and the close friendship with their children's fathers. ${ }^{58}$ 


\section{THE NEW FAMILY REVOLUTION}

"For each child, there [is] a mother and a father," Hana told an audience of men and women who had come to hear about shared parenthood (horut meshutefet) — an umbrella term for alternative parenting arrangements made between single women and (mostly) gay men. Hana's session was one of the many events at the second annual Rainbow Families Conference, a threeday event in February 2011 that coincided with Family Day, a nationally-celebrated holiday in Israeli daycare centers and schools. The conference organizers aimed to promote awareness, acceptance, and the creation of Israeli families that differ from the imagined norm of "father, mother, and children" (abba, ima, v'yeladim). Bright dots color-coded the sessions, workshops, and presentations according to the myriad configurations that engender what some refer to as the "new family revolution," fusing technological and social innovations: transnational surrogacy, third-party donor insemination, in vitro fertilization, single/later mothering, adoption and shared parenthood.

Having children outside the normative Israeli framework of father, mother and children has become more acceptable and accessible since the mid-90s, when Hana co-founded the organization Horut Aḥeret ("Alternative Parenting Center"). At the time, single women who wanted to receive donor insemination were still subject to social and psychiatric evaluations (Kahn 2000:27-29). Since then single women have gained access through the health system to subsidized reproductive technologies. However, as discussed in Chapters 1 and 2, single mothers who bring children into the world through anonymous donor insemination are perceived of as "alone" and single-mother families are deemed incomplete families. While increasing numbers of single women do take this route to motherhood, it remains stigmatized and is seen as a last option rather than as a "choice." For gay Israeli men, surrogacy abroad was almost unheard ofat most a faint idea on the distant horizon in the mid-90s. ${ }^{59}$ The Israeli surrogacy law (1996) 
restricted gestational surrogacy to married heterosexual couples with a diagnosis of infertility and established a national committee to oversee all contracts between married heterosexual couples and surrogates (Teman 2010). For gay men, surrogacy is only possible abroad for those who can afford the estimated expense of $\$ 80,000-\$ 180,000$ depending on the location of the carrying mother. (As one surrogacy broker joked: "India is coach, the US is first class.") Yet, contracting the services of an Indian surrogate remains prohibitively expensive for most gay men. Further, surrogacy abroad is fraught with medical, legal, religious, and bureaucratic uncertainties, vividly brought to the public's attention in 2010 by the case of Dan Goldberg, a gay Israeli man who fought the right-wing head of the Israeli Ministry of Interior to repatriate his Indian-born twins. ${ }^{60}$ In contrast to the opening of transnational surrogacy routes, it has become increasingly difficult for Israeli gay men to adopt children from abroad, due to the tightening of policies in host countries. Given the enduring stigma on single motherhood through donor insemination, the expense and uncertainty of surrogacy abroad, the restrictions on international adoption, and the desire of Israeli women and men to have children, a partnership between single women and gay men has become an alternative route to parenthood.

Hana told me that she created Horut Aheret because when she looked around at her female friends who were single mothers, she noticed that "There is a lot of aloneness (bedidut) in single parenthood (had horiut)." Hana's use of the word bedidut echoes the way that many single mothers I interviewed described their experience of having a child outside of the conventional boundaries of Israeli family. Yet, Hana proudly claimed that her organization had invented a solution that she deemed preferable to the anonymity of the sperm bank: a gay co-parent. As Hana looked at her gay friends, most of whom did not have children, Hana thought that "they could be great fathers." She imagined that she could bring her unmarried female friends together 
with gay men. Since the mid-90s, her organization has provided a kind of dating service, or in Hana's words, match-making (shiddukh) between gay men and older single women. Although described herself as a leftist, married with three children, Hana joked that this personal pronatalist project had unexpectedly become her life's mission.

When we spoke several weeks after the Rainbow Families Conference, Hana told me "Today it's very trendy to be a gay man with a child (homo im yeled)." Her observation that gay fatherhood is "trendy" is an apt one, at least in the upscale neighborhood of Tel Aviv where Horut Aheret rents an office. Like other parents in this part of the city, gay couples stroll along Rothschild Boulevard — a fashionable street with occasional café-kiosks, divided by a tree-lined pedestrian lane - proudly pushing their infants in name-brand baby carriages, dogs in tow. Beyond Rothschild, the gay community and the wider world of Tel Aviv have become nearly indistinguishable: rainbow flags hang from windows in all neighborhoods, the annual Pride Parade is a city-wide celebration that incorporates three intertwined marches, and the municipally-funded Gay and Lesbian Center, in a renovated international style building for which the city is famous, commands the edge of Gan Ha'ir Park in the heart of old Tel Aviv. Yet, Hana was not only speaking about the openness, at least in Tel Aviv, toward gay men as parents.

In an environment of increasing social acceptance of gay men Hana thought that, in turn, gay men were now open to mainstream Israeli values. Commenting on this social shift, she explained, "[Gays are] not just in their homosexual world without the ability to give [to others], they also care about continuity (hemshekhiut)." In her understanding, gay men wanted to participate in mainstream society by adopting normative social practices, namely getting married and having children. Furthermore, men's procreative contribution or "continuity" is located in 
the realm of the Israeli collective, rather than attributed to an individual (see Chapter 5). Openness is part of a larger Israeli narrative about the "development" and "evolution" of the gay community that is also voiced by some within the community (see Weston 1991). For example, the Minister of Welfare, Isaac Herzog (Labor Party) praised a room of gay men at the Rainbow Families Conference for "the evolution that the [gay] community has undergone." He was referring to gay couple's desires to have children through surrogacy and adoption, peppering his enthusiastic speech with the word "development" (hitpathut). The underlying assumption voiced by alternative family activists like Hana and the Minister of Welfare is that the gay community has "developed" or "evolved" from individualistic (and hedonistic) lifestyles that do not contribute to the benefit of Israeli society and to the gendered continuity of the Jewish “collective." However, while some activists promote surrogacy in Israel for gay men under the banner of "the right to parenthood" (z'khut l'horut) and the making of "new" or "postmodern" families, Horut Aheret seeks to find a place for openly gay men within the normative Israeli family. According to Hana's formulation of shared parenthood, by becoming parents together single mothers and their children could overcome the marginalized social position or "aloneness" associated with the absence of fathers and gay men could contribute their "continuity" to the nation's future.

\section{“A Syringe and a Cup”: Intimate Beginnings}

Pairs of men and women and pairs of men sat in clusters of folding chairs, gathered under a white tent erected in yard adjacent to the Gay and Lesbian Center. They had come to attend Hana's presentation on shared parenthood, one of many events in the Rainbow Families conference. During her presentation, Hana told the audience that making a child should be an 
"intimate" experience. She recommended that couples avoid the interference of the Israeli fertility establishment and instead "use a syringe and a cup," a line she repeated again in our meeting in her Tel Aviv office. This low-tech method would not only avoid a medicalized procedure, it would help to build the couple's relationship as parents-to-be. Hana told me, "There is something more intimate about [a man] saying to a woman 'take my sperm and be the mother of my child." She then retold the same vignette she had used at the Rainbow families conference to illustrate this intimacy:

There was one couple, who went on a trip to Provence. They woke up in the morning, did the insemination (hafriya), and then went to eat breakfast in the hotel-a great daughter (akhla yelda) came from this.

In the version of this story she told to the men and women assembled under the tent, the couple lit candles, creating a romantic ambiance to their procreative French holiday. She contrasted this honeymoon-like escape with an invasive clinic insemination, which takes place under bright lights in an examination room full of people. The message in Hana's parable of the syringe and the cup is that the close intimacy between intending man and woman is what helps to promote a positive parenting outcome. Here, emotional intention and care replace the assumption that two individuals create a contract for the purpose of having a child. Though sexual intercourse is not involved (and Horut Aheret actively discourages it as a procreative means that "can make things complicated"), the conjugal union is approximated through an intentional, private and romantic act between the future parents. In Hana's understanding, medical interventions and clinical encounters turn procreation into a procedure: by moving the private act onto the examination table, the medical establishment renders procreation a sterile, public event —a gloved intrusion that obstructs the enactment of intimacy imagined as constitutive of an Israeli family. 
New Family, a legal organization located in the same Tel Aviv neighborhood as Horut Aheret, also assists women and men to enact shared parenting arrangements. Made visible through controversial court cases and by regular media exposure of their charismatic and outspoken founder, Irit Rosenblum, New Family promotes parenthood for all Israelis as a basic human right. In their statement on shared parenthood, New Family declares:

The desire to be a parent is an independent will of its own, and parenthood is a right granted to every person. The societal openness and the technological capability enable [one] today to become a parent without particular difficulty and without a partner (ben $z u g$ ), it is shared parenthood without cohabitation and without a conjugal or sexual relationship. ${ }^{61}$

Unlike Horut Aheret, New Family explicitly defines shared parenthood as an individual pursuit, one that does not involve a romantic relationship, co-residence, or couplehood. In this organization's understanding, parenthood is conceived of as a basic human right and as an "independent will" that is dislocated from the mutuality, intimacy and sentiment actively encouraged by Hana's organization. Whereas Horut Aheret encourages the "openness" of gay men to partake in Israeli society by having children, New Family celebrates the "openness" of society and the "capability" of technology that turns becoming a parent into a straightforward project without social or medical barriers. Rather than provide emotional and psychological support, New Family is primarily involved with creating contracts between couples and advocating an expansion of their legal rights on the national level.

When I met with Hana, she distinguished the work of Horut Aheret from other organizations (and drew an implicit contrast with New Family) for the level of detail and broad scope encompassed by their contracts. The contract, in her view, was not merely a legal document, but a statement of the couple's desire to make a family that intertwined emotional and psychological aspirations with minute details about the future child's life. Hana rummaged 
through a cabinet and eventually produced a binder full of contracts. She selected an example, handing me a color-coded Excel spreadsheet with neat boxes: the hours of the day on the vertical axis and the child's age on the horizontal axis. The green and purple boxes delineated who would care for the child during the hours of the day, and where the child would spend nights and weekends. Hana emphasized that, beyond the contract and the intention behind it, her organization's approach was unique: Horut Aheret brings couples together to talk about the emotional and psychological aspects of parenting that cannot be accounted for in a spreadsheet or the sprawling clauses of a contract. In the case of conflict, Hana has couples specify a mediator in order to avoid disputes that might lead to family court. To date, Horut Aheret claims to have "made" more than 300 Israeli families through its matchmaking and contract services.

Although both Tel Aviv-based organizations contribute to public awareness of shared parenting and discourses of alternative family arrangements, women's accounts differ from both organizations' formulations of this emergent kinship practice. Even as Horut Aheret emphasized both friendship and contract as the basis of shared parenthood, women did not place these elements on equal footing. At the same time, women emphasized the care and nurturance between them and their parenting partners, but they did not attempt to make conception an intimate event. And in contrast to the rights discourse championed by New Family, the women who shared their stories with me did not claim parenthood as a right, and in fact sought to diminish drawing attention to it as an individual pursuit. Nor did they situate their co-parents' ambitions to become fathers within the larger context of the political struggles waged by the gay community. In fact, this was almost entirely absent from all accounts. Women's stories do not attest to the straightforwardness of technological capability, to the supposed openness of society toward "non-normative" family arrangements, or to the ease of cultivating intimacy through 
shared parenthood. Instead, they reflect the complicated experience of being both a single woman (revaka) and forging families through shared parenting. Women highlighted friendship over intimacy and couplehood without conjugality that makes them into families.

Notably, the central tension in women's narratives of becoming mothers involves the presence of a father, who is neither a male romantic partner (ben zug) nor solely a contracting individual (shutaf). While there is not a romantic relationship or sexual intimacy between the parents, women emphasized the multiple ways that friendship transforms shared parenting into Israeli families. Women's accounts make evident that families are not born, they are made: the cultural labor involved in making shared parents into families extends well beyond the context of the fertility clinic, although anthropologists of reproduction have tended to fixate on the moment of medicalized conception (Carsten 2004:174). At the same time, their accounts reveal that bringing a child into the world may bring a woman and a man together, but it does not in itself engender a recognized family. The remainder of this chapter seeks to explore the question: what practices, processes and rituals make or unmake shared parenting arrangements as families?

\section{Shared Parenting Arrangements}

In this section I focus on three women who became mothers through shared parenting arrangements with gay men: Sara, Tali, and Ilana. I selected these women's stories because they capture the themes that arose in the many accounts of shared parenthood I encountered over the course of fieldwork. These women reflected on the coming-into-being of their families, a process that unfolded over many years. Their accounts highlighted significant milestones in the evolving partnerships between women and men, from the decision to become parents to undergoing fertility treatments, from birth through early childhood. Part of the thread running through each of these accounts is an implied comparison with single motherhood through anonymous donor 
insemination, which becomes explicit at key moments in the narrative. Though the practice of shared parenthood in Israel may encompass more than two individuals, (e.g., it may bring together lesbian and gay couples) and these combinations change as relationships are assembled and sometimes dissolved, I did not have the opportunity to interview single women who partnered from the outset with couples. Further, the prevalent "shared parenting" arrangement appears to be between a single woman and a gay man. In the analysis that follows, I aim to answer following questions: what do these accounts of shared parenthood reveal about single motherhood through donor insemination in Israeli society? What makes a shared parenting arrangement "a family" or "family-like" or not a family at all?

\section{The Terms of Shared Parenthood}

Women's use of the Hebrew terms ben zug and shutaf are integral to their understandings of their relationships with the fathers of their children and to their distinctions between single motherhood and shared parenthood. Ben zug, in contemporary usage among secular Israelis, can refer to a romantic male partner (spouse, mate). Zug means "couple" or "pair" (as in a pair of shoes) and ben means "son." Calling one's partner a ben zug suggests the connection is more serious than a boyfriend (haver), but also implies that one is not married, at least by a religious ceremony. Secular Israelis who cohabitate or have obtained a civil marriage abroad may use ben

$z u g$ instead of husband ( $\left.b a^{\prime} a l\right)$, as the latter connotes ownership. ${ }^{62}$ Gay Israelis may use the term ben zug to refer to their lovers, boyfriends and partners. Israelis, regardless of sexual orientation, will speak of couplehood (zugiut), which is also deemed more politically-correct than marriage (nisuimin $/ \mathrm{m}$ ). Ben zug, however, is occasionally used by married women regardless of whether their marriage was religious or not, rather than husband ( $\left.b a^{\prime} a l\right)$ because it has a more politically- 
correct ring to it, following the fashion of non-conventional, yet heterosexual, conjugal relationships.

Given these nuances of contemporary Hebrew relationship terminology, women in shared parenting arrangements tread in uncharted terrain. Several problems arise for mothers in shared parenting situations with the existing appellation ben zug. First, it suggests a romantic relationship rather than a platonic friendship. Second, the male partner may have his own ben $z u g$ - a boyfriend, partner or lover. Finally, women used ben zug in relation to their desire to achieve heterosexual couplehood, which remained a future goal for many. In addition, for lesbians referring to a co-parent as a ben zug would imply a romantic relationship with a man, rather than a female partner or bat zug. With all of these possible meanings, referring to one's partner in parenting as a ben zug is confusing. Yet using the term shutaf as an alternative to ben $z u g$ is also problematic. In everyday parlance shutaf often refers to a business partner or other transactional relationship, for example a flatmate who shares the rent. Although shutaf may avoid the sexual intimation of ben zug, its business connotations undermine the sentiment, emotion and affect that my interlocutors sought to express. As will become clear below, women take different approaches to this terminological kinship conundrum. It is important to pay close attention to use of these terms in narrative context, as relationships commenced, evolved and sometimes, painfully dissolved. For single women, neither ben zug nor shutaf adequately captured the platonic companionship at the center of their parenting relationships with gay men.

Despite the transformations experienced as two individuals become parents together in shared parenting arrangements, "father of my child" (abba shel hayeled sheli) endured. This description, however, is also ambiguous because it does not locate one's relationship to the "father," and thus implicitly calls attention to the undefined connection between mother and 
father. In fact, divorced women will use this phrase when talking about their ex-husbands as will women who had a child outside of marriage. Abba shel hayeled sheli accentuates the presence of a father who participates in the child's life, yet it is not specific enough because it does not clarify the parenting relationship. In the accounts that follow, women creatively drew on conventional terms to explain their unconventional relationships. Even as they narrated the creation of family, women struggled with the limitations of available terms: whether the terms implied sexual intimacy where there was a platonic connection, single motherhood where there was shared parenthood, or contractual transaction where there was enduring friendship and sometimes absence of a formal contract.

\section{"I Had This Idea in My Head"}

I met Sara after her work one evening at her apartment in Rehovot, a city in central Israel. We sat in her living room, full of toys and objects tidily arranged in duplicates: identical play strollers, scooters leaning against the packed bookshelf, matching Disney backpacks hanging on low pegs near the door. "I always wanted children," Sara explained, "But I didn't find a ben zug. Nothing worked out." She was shy and it was hard to muster the courage to go on blind dates. Nevertheless, Sara remained optimistic that she would eventually meet the "right" man. She pushed herself toward this goal, undergoing intensive therapy over several years to help her confront her tendency to overeat and to strengthen her self-image. At the age of 36, however, Sara reached an unexpected turning point: she began to question her life-long dream of getting married.

When this happened, Sara was attending a conference in Europe on her own. On the trip, she started to take stock of her life and to do what she called "soul accounting" (heshbon nefesh). She had brought along a book titled Seder Nashim by Amia Liebleich, a well-known Israeli 
psychologist and author. She told me, "the book is about single mothers without a ben zug; it's very sympathetic." ${ }^{63}$ As she read, Sara became immersed in the stories of the single women, who had not "given up" on motherhood. "It became my 'bible' (hatanakh sheli) on the trip." Sara had encountered a previously unknown world through reading women's stories, narrated in firstperson, of becoming single mothers. These include women who became mothers through anonymous sperm donation and through various arrangements with known men. Until this point, Sara assumed that she would find a ben zug and have a wedding before having children: she had never considered otherwise. She told me, "I had this idea in my head of family—-that I need to meet somebody, [that I would have] a wedding." But, reconfiguring her idea of family was not the only conceptual challenge. She explained, "I also had an idea in my head about women who raise children alone. They always seemed pitiful to me (miskenot)." Sara was drawn into women's personal accounts, becoming aware of their different routes to bring children into the world. As she read, her presuppositions about single motherhood were supplanted by the voices of single mothers-women with names and stories. Sara recalled, "The book changed my perspective. I needed something to make me brave (la'tet li ometz)."

When she returned from the trip, Sara went to see her gynecologist. Though she had been cautious with him in the past, she felt emboldened. Sara found herself revealing her innermost desires. Soon after he greeted her, she bluntly told him "I want to have a child alone" (ani rotzah l'havi yeled levad). But, she was even more surprised by his response. He said, “'If you want [a child], then I want a child too." Sara was shocked by the doctor's support; she had assumed that he would "object and say it's forbidden [by Jewish law]." This fear, she acknowledged, was in her head, an internal judgment. She had thought "That if I say to [him], 'I want children on my own,' [he'1l] say, 'That's not okay.'” For Sara, it was difficult to overcome her fear of how 
others in her life would respond to her desire to become a single mother. As she put it, "this was a really big obstacle (mahsom) for me." The word mahsom however, also refers to military checkpoints, and thus signifies not only a barrier to pass through, but also a place where one is commanded by others to halt before being inspected and ushered through or else, turned away. Similarly, Sara's trepidation about becoming a mother was not only a personal obstacle to overcome through internal psychological process, but a social checkpoint that once she passed through it, would make her difference permanently visible.

Even as Sara approached becoming a mother with newfound resolve, she found the process of donor insemination daunting. When she got to the sperm bank she felt overwhelmed. “They asked so many questions," she remembered. The sperm bank staff presented Sara with different possibilities for sperm donors: height, eye and hair color, and ethnic background. She felt unsure of how to choose a donor and asked herself "Why does it matter"? In the end, she accepted the donor the clinic staff selected for her: a Jewish tourist from the same country of origin as her late father. With the vials of frozen donor sperm waiting for her at the clinic, Sara began the prescribed hormone protocol, squeezing fertility treatments into her busy schedule. The clinic became a stop on her commute to work and she left early in the morning to allow plenty of extra time. Though she was stressed about getting to the appointments, enduring the long waits at the clinic, and arriving at work on time, she admitted that what really bothered her was the thought that "the child won't know who his father is" (hayeled lo yeda mi ha abba shelo). Sara felt uncomfortable with the absence of a father, but she continued the rigorous protocol of regular hormone injections, blood tests, and ultrasounds.

Several months into treatment, Sara suddenly changed course. She was out with a group of friends when one took her aside and told her, "There is someone I know, who also wants to 
have a child...he's really cute (nehmad)." As Sara put it, it was "a kind of shiddukh," using the word commonly associated with match-making. At first, Sara objected to her friend's suggestion. She was undergoing fertility treatments and felt that this was an insensitive imposition. She had begun to come to terms with becoming a mother on her own, which was not an easy process. Insulted, Sara told her, "Why are you bothering me?" But, her friend insisted, “He's really great." So after several phone calls, Sara agreed, "Fine, I'll meet him, and if it suits me, that's good because there will be a father."

When Sara met Itay, her reservations were immediately allayed. She said, "We spoke the same world (oto olam)." They shared many interests in common, talking late into the night about the same music and books. After meeting with Itay a few times, Sara stopped the fertility treatments altogether. Over the next six months, Sara and Itay spent time getting to know one another. They went on vacations to the resort city of Eilat and on hiking trips in the Galilee, and they shared long conversations. They also met with other women and men involved in shared parenting, to learn about how these arrangements worked in practice. After these meetings, Sara was confident about moving forward: she trusted her early intuition about Itay. Yet, even though Sara was ready to commit, Itay remained cautious. As she put it, 'He didn't want 'just' (stam)— he wanted to be sure it was right."

During this period, Sara and Itay met each other's families. Her older sister, at first, opposed the idea of shared parenting and cautioned Sara that "splitting parenting with someone who isn't a ben zug will be difficult." Sara acknowledged that shared parenting "sounds scary to some people." Itay was a man she had recently met, and her sister was worried about how their parenting would unfold in the absence of a committed, conjugal relationship: would Itay remained committed and involved over time? Fortunately, when her sister met Itay, "She fell in 
love with him." As she got to know Itay, Sara joked that her sister chided her, "Why don't you bring him to visit more often?" Though Sara's sister was skeptical at first about shared parenting, she eventually came around to supporting the idea. In contrast, Itay's parents welcomed Sara and the idea of shared parenting from the beginning. They were in their mid-80s and had no grandchildren. His father had survived the Shoah, but lost most of his family. The continuity of his family was important, but his only son was gay and in his late 40s. Sara told me, "We went to visit his parents at their house, like a couple (zug), and they came to visit us." Sara and Itay were received by his parents because they resembled a heterosexual couple; not only were they eager to have a grandchild, but their son's homosexuality was obscured by the involvement of a woman. For Itay, however, his parents' acceptance of Sara was more complicated:

It was hard that they welcomed me so easily, because [Itay] had a ben zug for many years and they didn't want him to visit them at home. It was sad for him that someone who wasn't his lover received their acceptance.

While Sara's sister had cautioned her against becoming a parent without a ben zug, Itay's parents accepted their couplehood for its semblance of meeting their expectations. For his aging father, it was not only the idea of having a child (imagined as male) and securing the family's continuity into future generations, but that his son would, at last, have a family of his own.

Sara decided to start fertility treatments again, this time with Itay. Before their first appointment together at the IVF clinic, they planned a weekend trip to the Galilee to celebrate their decision to become parents together. However, while on route the couple received upsetting test results: Itay's sperm count was far below average. The doctor told them that they would need IVF for both female and male factor infertility problems. This would require more medical intervention and make getting pregnant even more challenging. Sara found that being on a trip with Itay after hearing this burdensome news was a relief and “relaxing because he wasn't a ben 
zug." Itay's sub-optimal sperm count might have been more problematic had he been a romantic partner, yet somehow it strengthened their friendship, to know that each had a medical condition that impaired fertility. Despite the statistical odds, the next week they embarked on first round of treatment together.

Following her second round of IVF, Sara received the results of the routine blood test two weeks later: the beta level showed "something not here or there." Sara was referring to the test for the production of Human Chorionic Gonadotropin (hCG), a hormone produced by cells in the placenta after an egg implants in the uterine wall. There is a wide range of response to this test, greatly varying from patient to patient. Sara's result was indeterminate: it did not detect the absence of pregnancy (less than $5 \mathrm{mlU} / \mathrm{ml}$ ), but it was in the mid-20s- too borderline to indicate a positive pregnancy. Sara waited and took another test. This time the beta level had returned to normal. She explained, "[The pregnancy] didn't stay in the uterus, it fell (miscarried). It really reflected my confused desires." Although Sara wanted to become a mother with a known man and felt a strong connection with Itay, she believed that her failure to get pregnant was caused by the fact that she had not let go of the idea of a romantic relationship as the basis of motherhood.

After the disappointing news, Sara began to doubt her decision to become a parent with Itay. She told me, "I said [to myself], why am I doing this with a gay guy? I want a ben zug." Sara returned to the idea of getting married and starting a family. In fact, between the first and second rounds of undergoing IVF with Itay, she had started to date a man, hoping for a romantic connection. They met a few times, but Sara felt stressed about her situation. She wanted a baby and did not want to wait any longer. She continued, "I returned to reality, to making a child. It was a decision: okay, enough. What do I need to do so that will happen?" Sara attributed the failures of IVF to her previous indecision about becoming a parent with a gay man, "My body 
accepted the embryos, but that wasn't enough. I wanted, but didn't want [at the same time]." Her dream of finding the "right" man and getting married was not easily cast aside. After the almost pregnancy and dating interlude, Sara returned to fertility treatments. This time was different she explained to me, "Before the third try [of IVF], I felt that things were falling into place." Her friendship with Itay had grown over the past months, before, and during fertility treatment. Returning to the dating scene, however briefly, reminded her that she did not want to wait any longer. As it was, fertility treatment provided her life with enough uncertainty. Now Sara had Itay. Notwithstanding her protests, he came with her to every check-up in the fertility treatment process that he could. After the fourth round of IVF, Sara and Itay received exciting news; she was pregnant, with twins.

Itay and Sara prepared together for the birth of their children. They took a parenting course. After making long lists and hours of debate, they chose names for their children. He drove her to the hospital for her scheduled C-section and waited, nervously, close to the operating room for news. And Itay was the one who phoned Sara's family and friends immediately after the birth. When their children came home from the hospital, Itay regularly slept on the sofa in Sara's living room. Tired of living over thirty minutes away, he bought an apartment on an adjacent street and sold his house so that he could live "almost door to door." Sara reflected on becoming parents together with Itay:

[Ours] is not the story of a couple (zug) that makes a partnership (shutafut) to parenthood together. It's a friendship...but, in practice there is actually couplehood (zugiut). We do a lot of things together. We take care of each other. Not each one in his own world. It's not someone who wants to meet for the purpose, but prefers to do it separately.

Although Itay is not her ben zug, Sara's formulation of their relationship as characterized by couplehood zugiut rather than partnership shutafut is a revealing distinction. The friendship they share is the basis of their family, nourishing it with care and love. It is not "each in his own 
world"- a practical arrangement between two individuals for "the purpose" of making each a parent, who then go about their parenting separately. Even as Sara had parted with her dream of finding a ben zug, she was not raising her children on her own: through their friendship, she and Itay shared the same world.

\section{"We are Family-Like"}

"I brought a child into the world with an abba gay (gay father)" Tali began her account. A few weeks earlier, I had introduced myself to her at the Rainbow Families conference where we both had attended a workshop on shared parenting; she immediately welcomed the idea of an interview. Now, as she began to reflect, she remarked with a smile "our story is cute." When she reached her late 30s, Tali began to think about having a child on her own. "I saw that I'm not finding a suitable ben zug, but in any case I wanted children," she told me. Her first thought was to register at a sperm bank and undergo insemination with anonymous donor sperm. Yet, even though she knew many other women who had taken this route to motherhood, Tali was uncomfortable with the idea and preferred that the child have a known father:

My reasons were personal. I have almost no family and I knew that I wouldn't have a lot of help...when you have a child its desirable that you have a family, a ben zug, and money....For me, I didn't have family or money, so it was better to have a ben zug, a "partner" for this story...but even without [a partner], I was ready to do it alone.

Tali worried about becoming a mother in the absence of familial and financial support. Her parents were no longer alive and she had lost a sister many years earlier in a tragic accident. Her job provided an adequate salary and she owned her one-bedroom apartment, but nevertheless the high cost of living in the center of the country did not leave room for extras. In the absence of this emotional and economic support Tali was eager to find a father. 
Over the years, Tali discussed the different routes she could take to motherhood in long conversations with her therapist and her close friends. She remained uncomfortable with going to the sperm bank, but acknowledged that it was an option if nothing else worked out. Tali also considered adopting a child. "I thought if I'm creating an incomplete family unit...its better that I'll take somebody whose options are even worse. That means, its better [for the child] to be with a single mother than in the orphanage." Tali's idea of an "incomplete family unit" extends to both donor insemination and adoption: to her, both routes are missing fathers and therefore incomplete. Tali liked the idea of adopting a child, which in her view was the more justifiable route as a single woman. She told me, "I felt a need to compensate the world...that I'm doing a good deed." Tali held on to the idea of adoption, in part, because of her reservations about single motherhood. But, more than the absence of a father, Tali felt that becoming a single mother was a failure to contribute to society because having a child on one's own was an individualistic decision. Thus, she believed that she must "compensate" for the act of doing something that went against society and having a child when there were children without families.

When Tali inquired about the adoption process abroad, she learned that it was beyond her means. Tali then looked into adopting an Israeli child, but like many older, single women, she discovered that because of her age and marital status, she could only receive a child with special needs (see Chapter 2). Tali knew that she did not have adequate support to raise a special needs child as a single mother: she had "no family and no 'back' (gav)." Adopting would mean working even longer hours to provide for the child, a situation that would in turn compromise her ability to care for him. On-going discussions with close friends convinced Tali that rather than adopt a child with special needs, she could have a child on her own, "without asking forgiveness from the world." 
Even as Tali gave up the idea of adopting and reconciled her feelings about becoming a single mother, she constructed her available options including donor insemination as a "line of retreat" (kav nesiga). Tali was reluctant to let go of finding a "partner" in parenthood: finding a father $(a b b a)$ for her child was her foremost priority. For some time she had thought about Eldad, a gay colleague at work with whom she was friendly. She began to think about how to delicately broach the possibility of shared parenthood with him. Nervous about how the conversation might go, Tali consoled herself that even if Eldad rejected her proposal, she would follow the line of retreat: "I'll look for another father ( $a b b a)$, and if I don't go with another $a b b a$, I'll go to the sperm bank, and if I don't succeed at becoming pregnant, I'll adopt." Having a child without a known father, through anonymous insemination was the least desirable option. Though Tali had initially favored adoption over insemination, it came to be the most daunting route.

Intent on finding a father for her future child, Tali set about approaching Eldad. She sensed that it might be a good match, but was cautious since they worked for the same company. If the conversation went poorly, she would be jeopardizing a friendship and a collegial relationship. Instead, she appointed a friend to act as the go-between, to ask Eldad as discretely as possible. Although she was nervous, Tali summoned the courage to live with the consequences. Fortunately, she did not have to wait long for his answer. Her intuition about the match proved to be mutual. Soon after, Tali met with Eldad in person to discuss becoming parents together. As they started to share their desires, "It became clear to us that each one of us is looking for a "partner" (English) in parenthood, in the next room (ba'heder hasheni). But we said, why look far, we know we are a good team. ${ }^{, 64}$ Like Tali, Eldad also wanted to become a parent. The two colleagues realized they had been looking "in the next room"- -looking for relationships and connections that might bring them closer to their desires. Yet, this was actually 
interfering with the possibility of a partnership that was right in front of them, but that each one had overlooked. For Tali, the trust and friendship they had developed as colleagues was the basis of their partnership as parents. Though Eldad was not a ben zug, Tali felt that he could provide the support she needed to become a mother: she would not be on her own.

The suitability of their partnership, however, was put to the test early on. Tali was surprised to discover how difficult it was to make a contract with Eldad. They needed a signed agreement before their health fund would agree to cover the medical costs of intrauterine insemination, but disagreements sprang up between them. Eldad was worried about Tali's "spiritual tendencies," and doubted her, "What if you become religious?" (This is a surprisingly common question that arises in contract-making according to Hana.) She was sure that she would remain secular, but she understood his concern. She told me, "I can understand why he was worried, because in this country the law discriminates against homosexuals and so he wanted a [clause in the contract] that if I became religious, he would have full custody." Tali was sympathetic but refused to consent to the clause. Beyond worrisome hypotheticals, other more realistic complications arose while drafting the contract. Both Tali and Eldad worked in professions that had better employment possibilities outside of Israel. They discussed, for example, what would happen should one of them receive a position abroad. The main source of their disagreement, however, turned out to be financial questions.

Writing a contract, Tali told me, "takes out all the fun [out of making a baby]... it brings out all the conflicts and disagreements." Over the years, Tali has met women, whose route toward shared parenting took a detour when they reached the contract phase, triggering the dissolution of many who almost became parents with gay men. She explained the frustration of the contract phase: 
When you get married and it's a normal marriage, there are fears, but [you] don't need to deal with it [for] hours and days. Imagine that you sit down with your future husband and you speak for hours [about] what will be if this and that [happen]... it takes out all the fun, who wants to get married anymore?

Unlike heterosexual couples, who don't make contracts before having children, shared parents attempt to sort out minute details concerning custody, education, finances, and parenting practices for a child they have not yet met (or even conceived). They aim to consider all possible contingencies, while pushing themselves to imagine the worst case scenarios. Tali contrasted the process she went through with Eldad with what she imagined how it might be to conceive a child in a heteronormative relationship. Rather than endure hours of drawn out conversation, Tali explained, "The natural way is of course to deal with life as it happens." She imagined that for heterosexual couples getting married and having a child was not a string of decisions that become clauses in a legal contract, but as she constructed it, a flow of events, a "natural" unfolding of life. Tali and Eldad did their best to foresee the decisions that might be put before them in the future; this process was detrimental, not only because it provoked disagreements, but also because, for her, it emphasized the difference between her route, and normative marriages. Tali knew that, at 40, she didn't have the luxury of time to keep working on the contract. From the beginning of their conversations about parenting, she understood that some of the differences between them would not be easily solved. She said, "If you ask him, to this day [Eldad] thinks that we've finished the contract, but I don't think we have [finished it]." Eventually, Tali and Eldad took their " 90 percent completed contract" to the health fund in order to begin undergoing insemination.

Tali was surprised at how quickly she became pregnant, given that she was over 40 when they began the inseminations and her doctor had been less than optimistic. But, her initial excitement waned when Eldad's response did not meet her expectations. "At the beginning of the 
pregnancy," Tali explained, "I felt that he was really cold, that he didn't support me, there was even a moment when I regretted making a child with him." Flushed with hormones and feeling alone, Tali wondered what had gone wrong. She told me, "I expected to get more support and warmth, even though he's not a ben zug." As Tali's belly swelled over the coming months, the tension between her and Eldad grew. With her due date nearing, Tali was astonished to learn that Eldad wanted to be with her at the birth. For her, Eldad had become "a strange/foreign man" (ben adam zar). Although he was the father of her child, there was no intimate connection between them at this point. Despite Tali's uncomfortable reaction to his request, Eldad was adamant about being present in the room with her during the birth. He told her, "It is one of the biggest moments of my life, and I have to be there...it's the holiest moment [in my life] (harega hakadosh)." Hurt by the months of being pregnant on her own, Tali was not easily convinced. "I felt," she painfully recalled, "a strange man wants to be with me at a very intimate moment, and we're not in a close enough situation for that...we're not intimate enough for that."

Undeterred by Tali's refusal, Eldad became determined to change her mind. She told me, "It [became] his mission to receive my trust" and fondly remembered one milestone that happened as they started to "invest" (l'hashkia) in their relationship together. On one occasion, Eldad invited Tali over for breakfast at his apartment. She laughed, "He's a horrible cook, but I saw that he was really trying." Tali realized that morning that Eldad had been distant and cold because he did not want her to mistake him for a ben zug. Though he cared for her as a friend, he was worried that after the birth Tali would expect him to be more than a parent to their child. She told me, "[Eldad] feared I would leech off him (l'hetalek alav), that I would want too much from him [emotionally]." After that "milestone" day, Eldad made a renewed effort to show his support and Tali tried to prove to him that she was not trying "to turn him into a ben zug." By the 
end of the pregnancy, Tali no longer thought of Eldad as a strange man and he no longer imagined that she was trying to make him into a ben zug. As they spent more time together, Tali revised her birth plans; she now wanted Eldad to be there. In the weeks before her due date, she invited Eldad to attend a birth preparation course with her. She was glad for his company but saw "that it wasn't easy [for him] to be there with all the straight couples." Tali took this as further evidence of his turning around, since he endured the awkwardness of the sessions. By the time her water broke, Eldad had earned her trust; he was there to support her and "was even helpful" when their son was born.

Even though they had brought a child into the world together, Tali did not feel that they were a family. Over the first six months, Eldad frequently slept in her living room and the three of them spent most of their free time together. Eldad's mother came over to Tali's apartment to care for her new grandson. They celebrated the circumcision (brit milah) of their son, an occasion that brought their families, colleagues and friends together in a festive party. It was through these experiences that Tali came to see what she had as a family. In fact, this process of becoming a family made them akin to heterosexual couples. As a new mother, Tali learned from the experiences of married friends with children that "At the beginning, it's a bit difficult, that it takes six months until they are a father, and a mother and a child (abba, v'ima, v'yeled)." She felt that "We are really similar in that respect." Like married, heterosexual couples, Tali and Eldad became a family - they too became a mother, a child, and a father. Yet, they also had to overcome the absence of intimacy that is the assumed basis of married, heterosexual couples and find other means of nourishing their relationship.

Tali joked with a close friend, whose marriage is less than perfect, "We, in our not familial way, are very family-like." Her friend corrected her, "You, in [your] not-familial-way, 
are more family-like than [our] way, which is familial.” Though said in jest, her friend's retort is a reminder that heterosexual marriages, in the absence of love and care do not necessarily constitute a family. Tali perceived the way that she and Eldad had brought a child into the world as not quite family. What she had, in contrast, was "family-like." Yet approximating family, as the joke reveals, still marks shared parenting as different, or lacking the conjugal relationship and the imagined intimacy at the center of family. In this case, a married couple with children on the verge of separating $i s$ conceived of as a family while shared parenting, despite cohabitation and close friendship, is limited to being family-like.

Unlike her married friends, Tali experienced another dimension of creating a family with Eldad. Until the birth of their son, Tali told me that she had thought of herself as a "single woman" (revaka). Now, Eldad's extended family flooded into her cramped apartment, swooning over the baby, bringing meals, and making themselves at home. "That was something," she laughed, "you're a revaka and you are used to your quiet, and your space, and suddenly, a huge family falls on me." Tali was not only a single woman, but she was also the only surviving member of her natal family. Eldad was not only a father to her son, his extended family is what helped make their parenthood "family-like" and in so doing, altered her status as a single woman. She now lived with Eldad and a family that had "fallen" on her-this kinship transformation, however, was temporary.

As the new parents became a family, when their son was six months of age they reached another milestone. Their "family-like" family was now going to separate into two homes. In their agreement, their son would begin to sleep at his father's house two nights a week when he reached six months of age. Since Tali was no longer breastfeeding, she could not see a reason to interfere with this arrangement, although it was heart-wrenching for her to part with her son. At 
the same time, she recognized that "these are the life conditions of the child," and that it was only fair to Eldad that she uphold the terms of their contract. Rather than "giving him up," Tali and Eldad invited their closest friends who supported them throughout the process to a dinner and ceremony at her apartment. Tali did not want to send her son to his father "with bitterness (literally: sour), but with blessings." Yet, despite her resolve to ease the parting as much as possible and even celebrate this change, Tali found this transition to be one of the most difficult moments of her life. On the first night at Eldad's apartment, she slept on the sofa in his living room, cringing when she heard the baby cry in his father's bedroom. Gathering all her strength, Tali forced herself not to intervene; she believed that Eldad had to find his own way as a parent. Since the early months of their son's life, the family-like family—abba, ima, v'yeledthat Tali and Eldad created has become more complicated. First, Eldad met a man, who lived with him for several years as his partner. I asked Tali whether she considered Eldad's partner a part of their family. She answered, "My son doesn't relate to him as a parent." Nevertheless, Tali was curious to see how her son would draw his family on Family Day, a national holiday celebrated in Israeli schools each winter on the 30th day of the Hebrew month Shevet. She told me, "He drew himself with $a b b a$ and ima, and didn't draw the ben zug of his father, not even outside of the house. He totally ignored him." Tali explained the absence of Eldad's ben zug in her son's drawing: "That's not the family." Yet, while the presence of Eldad's partner did not challenge the family-like family, the idea of having another child did.

When she was 42, Tali and Eldad tried to have another child together. This time, however, she did not become pregnant. Because of her age, the doctor recommended that they immediately begin in vitro fertilization rather than try again with intrauterine insemination (IUI). Tali wanted a sibling for her son, but she was ambivalent because of her health. She had gained 
weight after the birth and developed high blood pressure, and her doctor warned her that this condition is known to worsen with pregnancy. After one round of IVF, Tali decided that it was enough. Eldad, however, was determined to have another child. Tali told me, "He's looking to have a child with another woman. I don't like the idea, but I accept it." While she wants another sibling for her son, it is unclear what "another woman" would mean for their family. Though Eldad (at the time of our conversation) had broken up with his partner, Tali was uncertain about the meaning of this change for their co-parenting relationship.

As their son grew up, the family that "fell" on Tali has receded into the background. After the early months, Eldad stopped sleeping at her apartment and they spent less time together with their son. As discussed in Chapter 2, the normative Israeli family is not only a "father, mother and a child" but a "father, mother, and children." Having an "only child" makes a family exceptional. Though they had become a family-like family and celebrated Jewish life-cycle rituals and holidays together, it was the desire to have another child (one Tali couldn't fulfill) that brought the tenuousness of their family-like family to the fore. Tali's ambivalence about Eldad's quest to have another child raises the question of whether a family that spans three houses and includes an abba gay, several children, two mothers (and potentially a gay partner and/or boyfriends/husbands) can count as a family.

\section{“The Most Natural Decision in the World"}

When she first introduced herself, Ilana sarcastically remarked, "I have a little family: I have a child and a dog." We were sitting in the living room of her flat, which she shares with her seven-year-old son and a feisty dog. But within minutes of beginning her story, it became clear that family was a painful topic for Ilana. She explained her "complicated" situation, "All the 
years, it was shared parenting (horut meshutefet) on the basis of friendship. We would do things together, he would stay here, I would go there.” In her understanding, Ilana's close friendship with her son's father "was special." She emphasized that their parenthood was based on this unique friendship, which shaped their life together. Though they lived in separate houses, their homes were permeable to the flow of their life as a family. Her wistful recounting the relationship in past tense prefigured the present difficulties: in recent years, things had "cooled" between Ilana and her son's father.

"I didn't get married. I didn't find a ben zug. The years started to pass and I got to an older age (gil mitkadem)," Ilana told me. She had never considered becoming a mother on her own, though she knew several women who had children through donor insemination. Instead, she turned to her best friend Uri, who she had known for many years. Of this decision, she told me, "It seemed to me the most natural thing in the world, so I asked him." At the time she mentioned becoming parents together, they were driving out of the city on the highway. In her retelling, the spontaneity of the event naturalizes the coming together of two dear friends, who just happen to be a heterosexual woman and a gay man, for the purpose of becoming parents. Ilana's use of the phrase "the most natural thing in the world" foregrounds friendship over sexual orientation and marital status as the relevant factor informing their decision. Ilana explained to me that her situation was different from other women who also partner with gay men to have children. She told me: “It wasn't 'just' (stam) somebody, it wasn't meeting somebody for the purpose of [getting pregnant] (l'tzorekh hainyan). It was the opposite. It was right, it suited us." For Ilana, the fact that the father of her child was already in her life and not "just" somebody made all the difference. It made their joint parenthood purposeful, and not merely a meeting or an encounter, "for the purpose" of having a child. 
Ilana and Uri did not draft a written agreement before deciding to become parents together. In part, this was due to their long-term commitment as friends and the trust they shared. Ilana acknowledged that now, in hindsight, her assumption about their friendship was a mistake. At the time, however, she thought, "If we are good friends, it will work out." Yet, Ilana's decision not to create a contract was also connected to her disdain for the very idea of making a family out of a formal legal document. She was proud that "[Our son] was born out of love between two people, not through a contract." For Ilana, the close friendship between her and Uri made them into an almost couple. During fertility treatments (IUI and IVF) and the pregnancy she felt that what they had "was like a couple." They spent much of their time together and he accompanied her to medical appointments. Although Ilana is close with her sisters, Uri provided "the meaningful support" during pregnancy and at the birth. Until the birth, they were "like a couple," but in her account, they were not yet a family.

For Ilana, it was the brit milah or ritual circumcision of their eight-day-old son that forged them into a family. Though she had met them from time to time over the years of their friendship, his parents were not involved during the fertility treatments or the pregnancy. She exclaimed, "After the birth, they appeared!" Up until that point, Ilana had had little contact with Uri's family. The brit milah at her sister's house was the first time that both families came together, which stood in for the wedding they did not have. For the occasion they even contemplated renting a large event hall where many Israeli weddings take place. Of the brit, Ilana fondly recalled, "His whole family came, for the first time, to meet me. I don't know what they thought, and with my whole family there." As the families celebrated the ritual that connects the newborn boy to the Jewish people, Ilana was treated like a bride on her wedding 
day. In her memory of that day, the members of Uri's family equally swooned over her and over the baby sleeping in her arms.

In her son's early years, Ilana and Uri lived in separate houses in the same neighborhood, but did almost everything together. They celebrated holidays and birthdays in each other's houses, spent Shabbat as a family, and went on trips all over the country. Further, their extended families were intricately involved with raising their son. Uri's mother regularly came to Ilana's house to take care of her grandson and Ilana's sister spent afternoons at Uri's apartment when her nephew was there. During this time, Uri had a serious boyfriend, but in Ilana's account, this external relationship did not interfere with the family they were creating. Ilana explained that she and Uri, "really resembled a couple, at least in an outward projection." This resemblance, Ilana told me, "camouflaged" their unusual situation to the outside world, in a suburb filled with heteronormative families outside of Jerusalem. When Uri picked up their son at preschool, other parents did not see his homosexuality: they saw a father. Similarly, others did not notice Ilana's stigmatized marital status as a single woman (revaka): they saw a mother. This camouflage was created through their shared parenthood—-"there is a father, a mother." People in their suburban community, less than an hour away from Tel Aviv, did not think to look past the external presentation of a couple and a child: they saw a family.

A year after the birth of her son, Ilana became determined to add to their family. She was 42, but had gotten pregnant with her son on the first try of IVF. While Uri had supported her efforts to get pregnant the first time around, this time was different. As she plunged into fertility treatments, Ilana felt that Uri became increasingly unsupportive of her efforts to have another child. Nevertheless, she remained intent on the idea, undergoing cycle after cycle of IVF for three years. She became pregnant once, but miscarried early in the first trimester. Ilana 
remembered these difficult years, which took a physical and emotional toll on her: "I felt the absence of a ben zug. The fantasy ended." Like Tali, Ilana imagined family as including not only a father, but more than one child. Although anthropologists have explored the relationship between cultural meanings of pregnancy loss and normative family (e.g., Layne 2003), as discussed in the previous chapter, failure to have more than "an only child" is interpreted by many Israelis as a kind of reproductive disruption (Inhorn 2008). For Ilana, this disruption had lasting consequences for the family she had created together with Uri.

When Uri's participation waned early on, Ilana decided to go to the sperm bank. Despite her previous reservations about this route, she wanted to have another child, even if it meant that the child would not have a known father. The combination of her eggs and an anonymous donor's sperm in the lab produced many frozen embryos. Yet, Ilana never used any of them. After she completed a cycle of IVF with anonymous donor sperm, Uri reluctantly re-entered the picture. Ilana preferred to try IVF with Uri's sperm, even though this stalled the process by many months. In the end, her decision to try with Uri's contribution came at a price: the embryos created with the donor sperm were made from Ilana's "younger" eggs and thus had more potential than those made from her "older" eggs and Uri's sperm. Even though many embryos were created from the reproductive cells of the two former friends, Ilana told me that by this point—her mid-40s—she had become "a cemetery for embryos." None of the embryos that fused their contributions successfully implanted after transfer. Ilana stopped trying to have another child when she reached 45 and was no longer eligible to receive subsidized fertility treatment with her own eggs. She decided, "Let's be happy with what we have, and not [dwell] on what isn't to be." But, what was to be was not the same after the turbulent years of IVF treatments to 
have a second child. Ilana's quest to have another child and "complete" their family opened cracks in their friendship that could not be repaired.

As they became emotionally distant from one another, Ilana and Uri's parenting relationship dissolved. Their family was no longer a father, mother and a child. Ilana described their current situation, "It's more like a divorce. We divorced, but didn't marry." When they separated, she and her "son's father" (abba shel hayeled sheli) split custody and financial obligations and they drew up a legal contract. Socially and bureaucratically, Ilana became a single mother. At the time of our conversation, Ilana was struggling with the same issues that many divorced Israeli women face as single mothers. She was trying to enroll her son in a better school in a nearby town where his father lived. This would mean, however, giving up her address as her son's “official” place of residence and transferring it to his father's house. This residential transfer could have repercussions for their shared-custody agreement. Instead of filing this relatively straightforward paperwork with the municipality, Ilana was preparing to confront the educational bureaucracy to keep her son's primary residence at her house: this was a fight that she believed she could not afford to lose. More than seven years earlier, Ilana and Uri's desire to become parents together had been "the most natural decision in the world." Now each decision between the two former friends and co-parents was carefully calculated in relation to the damage it might inflict on upholding shared custody of their child.

\section{Single Motherhood, Shared Parenthood}

In their accounts, all three women reflected on anonymous donor insemination and the route to motherhood not (or almost) taken. Sara and Tali initially considered becoming single mothers and both women took active steps in this direction. Sara read the stories of brave single mothers in Seder Nashim, passed through an emotional "checkpoint" (mahsom), and began 
fertility treatments with donor sperm. Tali explored her "line of retreat" (kav nesiga)—the possible routes leading to motherhood—-through conversations with those closest to her. ${ }^{65}$ Even as they took these steps, neither felt entirely comfortable with their decision to undergo insemination with anonymous donor sperm; it would mean having a child, yet creating "an incomplete family unit." As single mothers, they felt the visibility of their family's difference as "incomplete" made it impossible for either to feel "whole/complete" (shleyma) with the decision. This feeling of incompleteness or difference persisted even with the support of family, friends and doctors.

In contrast, Ilana did not think about single motherhood or consider anonymous donation. She was determined to find a "father" for her child and struggled with the idea of anonymous donor insemination only later, when she was determined to have a second child. Despite the possibility of using the frozen embryos made with her "younger" eggs and donor sperm, she never had any of them implanted, remaining committed to the idea of a known father. For Sara, donor insemination was problematic because "the child won't know who his father is"-yet, bringing a known father into the equation did not immediately dispel her discomfort with having a child outside of marriage. The discomfort was so significant that she attributed it to her failure to become pregnant, both from anonymous insemination and later, with Itay. She ascribed conception to a moment in the process when she accepted the idea of becoming parents together. This moment was a turning point, after several months of getting to know one another, they had become close friends who are not a couple (zug) but who shared couplehood (zugiut). What they have is not a pragmatic arrangement "for the purpose of" having a child, but deep friendship between two people who "spoke the same world." Similarly, Tali emphasized the process through which their friendship developed. Though they began as colleagues who made a good 
team, this was not enough to constitute them as family. In fact, during the pregnancy Tali struggled with the absence of a ben zug and felt hurt by the absence of affection and care that Eldad showed her. So intense was this disappointment that Tali felt he was a "strange man" who should not be present during the intimate event of childbirth. It was only when Eldad changed his approach and began to care for her that Tali trusted him to attend the birth. This friendship strengthened over time, and is what made their shared parenthood "family-like."

For Ilana the decision to become parents with a gay man who was already a close friend was a "natural" one. Further, her account emphasizes the spontaneity of the circumstances in which the idea arose, conversations that took place at the beach and on a long drive respectively. Unlike the dating-like process that Sara and Tali went through with their partners, Ilana described going through the process of fertility treatment and birth "like a couple." Whether a processual development or a natural decision, all three accounts emphasized friendship that made them into families (Weston 1991) rather than a partnership (shutafut) based on contract "for the purpose" of having children. None of the women I interviewed considered or attempted becoming pregnant through "the syringe and a cup" method advocated by Hana. To different extents, all underwent medicalized procedures, which has become routine for Israeli women who try to conceive for the first time in their 40 s.

Sara, Tali, and Ilana, like many other women in shared parenting arrangements with whom I spoke, emphasized the day-to-day practices of kinship that made them family. They spoke of the care, friendship and couplehood between them and the father of their child(ren). The birth of a child brought extended families together for religious rituals (e.g., brit milah) and celebrations such as birthday parties and shared holiday meals. Though not formal "in-laws," women's families now encompassed the extended families of their children's fathers, bringing 
benefits and new obligations. Recall Tali's difficultly at adjusting to the many new relatives who flooded into her house, trampling the peace and quiet she had known as a revaka.

With the birth of their child(ren), the new fathers slept on sofas and came and went from women's apartments during all hours of the day and night. As their children grew, fathers began to care for them, first for several hours, then for days at a time. In some cases custody was split evenly, in others it gradually increased over time, becoming equal when the child was several months or years old. In other cases, mothers retained primary custody and fathers had weekends and afternoon visits. While many parents lived in the same city, it was not uncommon for one of the parents to move closer to the other. Itay moved from a nearby town to an apartment on Sara's street. During vacations, these new families traveled together. For example, when Eldad received a position abroad for several months, Sara and the twins joined him, living together in the same apartment.

\section{The "Shared Basis" of Shared Parenthood?}

While New Family and other alternative family advocates promote the possibility of shared parenthood between single women and gay men as part of a "new family revolution," for some Israelis the idea of making family in this way remains problematic. What struck me as I interviewed women over a period of two years was how widespread the idea of shared parenthood had become. At the same time, most women did not ultimately opt for this reproductive route although many had thought about it or had even taken steps to find a gay coparent. In some cases, relationships fell apart early on or while writing a contract. For others, the difficulty in becoming pregnant at "advanced maternal age" became an insurmountable source of tension between intending co-parents, particularly after enduring several cycles of in vitro fertilization or experiencing the pain of pregnancy loss. 
Yet even those who count themselves among the "open" sector of Israeli society conveyed conflicted understandings of shared parenthood. For example, one long-time IVF nurse in a Tel Aviv hospital happily recalled a recent experience with a woman and man who had come for fertility treatments. She admired the man's involvement and his care for the woman undergoing IVF as he tended to her at the bedside and accompanied her to all of the treatments. Although the couple had not admitted to the clinic staff they were becoming co-parents together, it was apparent to the nurse that they were not married. She laughed, "It was obvious that he was gay, even his cologne, you just knew!" Given away by his affect and his scent, this nurse was nevertheless impressed by the couple's emotional commitment to each other. While she grew fond of these patients over the course of several months of treatment, the nurse tempered her enthusiasm for the future family that might result. Following her lighthearted comments, she suddenly turned serious:

Look, it's really problematic to take someone with whom there is no connection (kesher) with him and [there is not] going to be a household (meshek bayit) and after that when the kids are older, what school to send him to, and he goes to his house, and what will be [there] its worse than divorced parents even because divorced parents had a shared basis (basis meshutaf) and [only] after that separated. But here, there is not a shared basis.

Despite the close friendship that women in shared parenting arrangements foregrounded, many Israelis, like this IVF nurse, do not view these relationships as a legitimate connection or basis that creates family. Moreover, some equate shared parenthood with divorce or "worse than" divorce because it is an arrangement that begins with a custody contract or intention to raise the child in more than one household. In their understanding, a family requires a "shared basis" anchored in a romantic relationship and a common household.

While the prospect of two split households based on a contractual agreement resembles divorce, the other underlying problem that bothers some Israelis with shared parenthood is the 
possibility that more than two adults engage in a parenting relationship. For example, a man who turned to surrogacy abroad with his partner of many years explained:

We were in a longstanding couplehood and we thought that something is missing. We began meeting women who were searching [for] shared parenthood, but we quickly understood that this is not "our line" (hakav shelanu). Perhaps this is suitable for single men (gevarim bodedim), we didn't have any desire to introduce a third parent (gorem) into our couplehood. (Lior 2013)

Similarly, the women who shared their experiences of parenting with gay men tended to marginalize their co-parents' romantic relationships, and the potential of having to account for a third parent in the family. Instead they highlighted their connection with the (biological) father of the child and their authentic desire to have a child together which grew out of their mutual intention and friendship. As of 2013, regulatory changes in India prevent gay couples from contracting with Indian surrogates. Given the shifting landscape of transnational surrogacy arrangements, it remains an open question whether shared parenthood between more than two adults will become an acceptable option for both single women and gay men.

Indeed, even activists who promote shared parenthood and "the new family revolution" hesitate when it comes to encouraging parenting constellations that come uncomfortably close to practices of making family associated with "unmodern" others. At the end of Hana's presentation at the Rainbow Families Conference, a woman in the audience asked whether gay couples ever partner with a revaka (single woman), so that each man has a biological child with the same mother. Hana seemed annoyed by the question, and brushed it off as this is counter to the goal of Horut Aheret, which promotes "a father and a mother" for each child. The woman then boldly revealed that she was in a shared parenting arrangement with the two men seated next to her, who were holding hands. In another presentation on shared parenthood that took place under the same tent the next day, a well-known activist lawyer commented that an arrangement between 
more than two adults will never be recognized by Israeli law, because it is analogous to polygamous marriage which is illegal in Israel.

As discussed in the Introduction, the construction of the modern Jewish family in Israel entailed the unmaking of kinship practices — including polygamy — that, while permissible according to Jewish law, are counter to the modernization of the Jewish state and the nationmaking project of separating of Jews from non-Jewish others. Indeed, polygamous marriage was practiced by Mizrahi communities up until it was declared illegal in 1950. (It had been banned in Ashkenazi communities for over a thousand years.) While the proposed arrangement of a single woman and two men reverses the "unmodern" form of polygamy between a man and two women, it nevertheless subverts the evolutionary narrative of the modern family that defines the inclusions and exclusions of citizenship in the modern, Jewish nation-state.

Women's accounts of shared parenting emphasize the love and friendship between two individuals and the everyday doing of kinship that, while not based on heterosexual intimacy, do not seek to challenge the idea of normative family. Care and nurturance between friends make these shared parenting families a viable alternative to anonymous sperm donation and the creation of single-mother families. Yet these shared parenting families encounter two sources of difficulty. On the one hand, if perceived to be based on contract, the family-like nature of these partnerships ceases to be recognized and the arrangement becomes an agreement between two individuals who lack a meaningful "shared basis." In other words, the association with making a contract undermines the friendship and care that those in these relationships claim is central to their experience of making family. On the other hand, if more than two parenting partners are included, the intimacy of the relationship between a man and a woman risks losing its potency and becoming associated with "unmodern" kinship practices. While mostly secular Israelis 
weigh the option of shared parenthood against other possible reproductive routes for single women including donor insemination, the next chapter shifts focus to consider debates about single motherhood and the influence of modernity on the family taking place within the religious Zionist community. 
Part Two: Making Nation 


\section{Chapter Four \\ establishing a loyal House: The "National Problem" of Older Single Women}

[T]he question of women and Judaism is more crucial than all the political problems of the people and its state. Failure to deal with it seriously threatens the viability of the Judaism of the Torah and Mitzvot in the contemporary world. - Yeshayahu Leibowitz 1982, quoted in Ross 2004: xiii

Until today rabbis have avoided permitting egg freezing for women who are religious and single from fears that they would not hurry to marry. The fear was and still is that if a young religious woman knows that she has a chance to have a child at the age of 50, she won't hurry to marry or have children. When she knows that there is no [rabbinical] permission to freeze eggs this calls attention to "the train is leaving" and she is forbidden to be carefree about matchmaking (shiddukh) and having children. - P'sak Halakha, in Schlesinger 2010

Shortly after the Jewish New Year 5772 (2011), a religious woman emailed a rabbi via his Jerusalem-based institute's website, where it was posted a few days later. She began by stating her sincere efforts to find a husband:

Dear Rabbi, I am a single woman, age 37, still looking for my husband, but unfortunately I am at a loss. Of course, I have made every effort and have tried every means at my disposal: internet, matchmaker (shiddukhit), [and] singles events in an attempt to find my heart's chosen, to get married according to Jewish law (l'hinase k'halakha) and to establish a loyal house (bayit ne'aman).

Like many other single women or ravakot in their 30s who consider themselves observant, this woman wanted to marry according to religious law (halakha), and together with a husband establish a house that would uphold Jewish traditions. For these ideals to be met, the desired way of life follows a normative order of milestones. Marriage comes first: only on the grounds of this covenant (brit nisu'in) is it possible "to build a loyal house in the nation of Israel" (l'hakim bayit ne'aman b'am yisrael). This expression draws on a Biblical register of speech that draws attention to religious tradition and piety. A loyal house is one that lives according to the tenants of religious law, including strict observance of dietary and family purity codes. This is only one aspect, however, of establishing a loyal house. For observant Jews, the very idea is synonymous with bringing children into the world. 
Even as she sought to establish a house according to Jewish law, the woman writing to the rabbi was also worried about finding her "heart's chosen." Like other single women (ravakot) in the religious Zionist (dati tzioni) community (also called religious nationalist or dati leumi), her goal was not only to become a wife, but also to enjoy a relationship based on love. Although dati leumi communities have plenty of professional and volunteer match-makers, they do not share the practice of arranged marriage that is common in ultra-orthodox Jewish communities. ${ }^{66}$ Among the dati leumi, choosing a partner is left to individual men and women. At the same time, getting married in this community is not perceived as a choice-it is a given. Religious Zionist or Orthodox communities (as they are interchangeably referred to by Israelis) incorporate a wide spectrum of observance, tradition and political affiliation. One of the difficulties perhaps in defining the boundaries of this community is that while it does not refer to any one group, the boundaries between religious Zionist sub-groups are not rigid and they are increasingly permeable to multiple influences including feminism, New Age and Hassidic rituals, and the arrival of those "returning" to the fold (hozrim b'tshuva) (Rutlinger-Reiner 2011). When attending public events and celebrations, I was often struck by the range of participants' styles of dress; body language and communication with members of the opposite sex; and position on religious and political issues. Further, what is considered "Orthodox" Judaism encompasses a range of historical traditions that emerged in different contexts including neoOrthodoxy ( $19^{\text {th }}$ century Germany), Modern Orthodoxy ( $20^{\text {th }}$ century North America and Western Europe), and another tradition that originated in Lithuania which spans ultra-Orthodoxy and Modern Orthodoxy (Ross 2004:58); these streams and the different shapes they have taken in contemporary Israel make Orthodox Israeli-Jewish communities dynamic, diverse and difficult to classify. However, what religious Zionists in Israel do share in common is the space 
between what is called ultra-Orthodoxy and secularism, a middle path that "demands considerable ability to maneuver, openness and flexibility, along with great diligence in keeping the commandments" (Rutlinger-Reiner 2011:77). With a foot in both worlds-through observance of halakha and commitment to secular national life, including the army-religious Zionists find themselves dealing with complicated social matters, including the related "problems" of unmarried individuals and women who become mothers on their own. In addition to building a loyal house, the writer had another, more pressing concern that is shared by many Orthodox ravakot in their mid-30s and beyond. She continued her email:

Lately, the issue of fertility decline with increasing age is bothering me more and more and I am very concerned that I'm entering a critical age (gil kriti), that if I don't do something soon to preserve fertility, this will prevent me from motherhood.

In the era of reproductive technologies, it is not the absence of a husband that prevents an observant woman, at least conceptually, from becoming a mother in Israel. As I discuss in this chapter, a handful of Orthodox rabbis have declared that donor insemination is acceptable on a case-by-case basis for women in their late 30 s who have not found husbands. At the same time, religious women and their communities are debating the opposition to single motherhood through donor insemination espoused by the majority of Orthodox rabbis; to do so, women are drawing on arguments grounded in Jewish law (halakha) authored by feminist religious scholars such as Dvora Ross (1998), now available online. Given the multiple and differing interpretations of Jewish law that are now formulated as internet cyber-responsa (rabbinical answers to individuals' questions), knowledge and uncertainty are co-configured, and disseminated throughout diverse Israeli publics.

Since the late 1990s there has been a growing awareness of single motherhood as a potential reproductive route for Israeli women (Kahn 2000). It is this awareness that troubles 
rabbis, for it has released women's fertility from the moral order of "marriage with birth" and introduced, through the decisions of secular courts, a discourse of rights into a realm that in Jewish law is framed as an obligation of men alone. Thus for rabbis, the problem with single motherhood extends far beyond "preserving social norms" (Kahn 2000:57). In Orthodox religious thought, the commandment (mitzvah) "to be fruitful and multiply" is an example of a mitzvah that is not restricted to women under the category of positive timebound commandments (from which women are explicitly exempted), yet in practice has applied only to men (Ross 2004:88). As Tamar Ross provocatively contends, "The most incredible example of an exclusionary reading of the biblical text pertains to the highly valued mitzvah of reproduction. For obvious biological reasons one would expect this commandment to be considered the special preserve of women, yet the general consensus of the poskim is that it does not apply to them" (2004:88). Given the implications of extending this commandment to women, this is not a matter of "biological reasons" but rather of preserving a hierarchal relationship that justifies inequality and provides the basis for theological power in Jewish law. In this moral order, procreation is a divinely-ordained obligation that, together with religious study, authorizes men as the sole channel through which the generative and gendered labor of "building the world" is transmitted — these sacred activities are interpreted as an extension of divine creation.

Alongside the emergence of this reproductive route among religious women and the challenge it poses to the gender order of procreation, Orthodox Judaism has been confronted with a challenge from Jewish Orthodox feminists, first in the United States (1980s) and later in Israel to make the tradition more inclusive, to improve the status of women and to increase women's participation in ritual and textual study (El-Or 1997; Ross 2004:27-30). In her ethnography of the textual literacy movement among religious Zionist women, Tamar El-Or 
shows that when female students contested the gendered "mind-womb" dichotomy, their teachers reemphasized that women should not disturb the "boundaries of the role of care giver for men [and] children" (1997:191). Thus even as a quiet revolution is taking place in Jewish women's literacy, an authoritative message is disseminated to female learners that a woman will gain merit in the next world insofar as she enables her husband (and male children) to study Torah and does not usurp the role of "knower" from the father (El-Or 1997:191). In this model, it is women's fulfillment of their roles as wives and mothers that assists, but does not appropriate the male obligation to build the world through procreation and Torah study.

As the statement in the epigraph above by the influential Orthodox philosopher Yeshayahu Leibowitz suggests, matters of women and Judaism are critical to the viability of this authoritative tradition and the continuity of its transmission into present and future generations of Jews. Problems of the contemporary world that potentially divert women's contribution as wives and mothers to men's study and to the gendered, hierarchal channeling of knowledge make this time a critical age for the Jewish people. As religious women experience their own "critical age," their personal predicaments are not confined to matters that concern individual actors, or even the relationship between individual and society. Orthodox rabbis acknowledge that women's routes to motherhood, on their own, may create halakhically Jewish children, yet sever the unique relationship between the Jewish people and God that in their interpretation depends on the subordination of women, the perpetuation of men's procreative obligations over women's reproductive rights, and the preservation of marriage at the expense of individual choice. In this critical age for Orthodox Judaism, rabbis fear the destruction of the gendered authority and generational continuity that carries the divine covenant between God and Abraham's descendants from generation to generation. 
In addition to the challenges to Orthodox Judaism wrought by women's reproductive agency and their access to textual learning, technological innovations are further complicating religious single women's dilemmas. Several months before this woman sent her letter, the Israeli Ministry of Health (MOH) issued a policy that permitted egg freezing for "social purposes" (matarot hevratiot). This is a significant departure from the previous policy, which strictly limited the use of in vitro fertilization (IVF) and related procedures to women diagnosed with medical conditions (MOH 2011). Since 2011, Israeli women without medical conditions may undergo the first steps of IVF in order to donate their eggs to other women and/or to freeze eggs for themselves. Egg freezing requires this phase of IVF, including hormonal stimulation and surgical extraction of ova under full anesthesia. However, rather than fertilizing the eggs in vitro and re-implanting the resulting embryos, the unfertilized eggs are preserved for future use. By offering this technology to healthy women between the ages of 30-41, Israeli policymakers took a proactive, but also paternalistic approach to the problem of "age-related" infertility—meaning the unavoidable decline, over time, of a woman's ovarian reserve, or the quantity and quality of egg cells remaining in her ovaries. Following the policy change, IVF clinics throughout Israel began to advertise egg freezing programs and fertility consultation services. In fact, as of October 2012, 11 Israeli fertility clinics offered fertility preservation for social purposes (MOH 2012) ${ }^{67}$ At the time of writing, several hundred Israeli women had reportedly undergone this procedure in local clinics (Rosenblum 2012). As egg freezing technology becomes available, it entails multiple predicaments, leading ravakot to turn to Israeli fertility doctors and rabbis for guidance. Yet women are also turning to each other, through online forums, e-mail lists, and public gatherings. The writer of this letter had recently attended one such gathering on fertility preservation held in Jerusalem. 
In this chapter, I explore how, in this critical age, egg freezing — an emergent route to motherhood-is envisioned and contested in Israel as a solution to the overlapping medical, social and religious dilemmas experienced by ravakot. Egg freezing is seen by doctors, policymakers and women as an alternative to later motherhood through egg donation and as a possible remedy to the seemingly unavoidable onset of age-related infertility. In the religious Zionist community, it is also being discussed as an alternative to becoming a single mother through donor insemination. Egg freezing is attractive to some because it appears to overcome the medical impasse of reproductive aging and to sidestep the social complications and uncertainties of Jewish law (halakha). Further, a number of vocal rabbis and policymakers are configuring fertility preservation for women as the panacea, perhaps, that will re-encompass women's reproduction within marriage and the Jewish house while preventing the kind of individualistic decision-making that they see as destructive to the collective tenets of the Jewish tradition. Amidst these debates, ravakot in their early 30s and beyond are becoming responsible, in this time of expanding technological possibility and circulation of competing claims to authority, for preserving both their modesty and their fertility.

Departing from technical questions of what is prohibited or permissible by Jewish law (see Kahn 2000), I argue that a discourse of "establishing a house" has emerged among rabbis as a way to exclude unmarried women's reproductive agency and to avoid debates about single motherhood solely anchored in religious law. That is, while rabbis may concede that the children of Jewish single mothers may be Jewish as this essence is transmitted matrilineally, they emphasize that without husbands and fathers, Jewish single mothers and their children cannot "establish a house." Though there are many internal differences within the religious Zionist sector (migzar), community leaders along the spectrum from its moderate to conservative wings 
frame "later singlehood" (revakut meukheret or revakut mitmashekhet) and the resulting practice of motherhood through donor insemination as serious threats to the Jewish family and house, to the community and to the nation's future. The discourse of establishing a house frames individual choice and modernity as destructive agents of family as the foundation of Jewish tradition and its continuity. It is within this context that egg freezing and fertility preservation are being articulated as viable, yet uncertain, alternatives for religious single women.

In what follows, I draw together ethnographic and archival data in order to make sense of the complex web of cultural and religious understandings that inform Israeli fertility preservation. In the first part of this chapter, I outline the social context that informs rabbis' responsa on the related issues of single motherhood and egg freezing technology. In so doing, I seek to situate egg freezing within broader questions in the religious community concerning women, Judaism and the threat of individual choice. In the second part of the chapter, I examine the growing anxiety among rabbis and policymakers about the potential for religious single women to use reproductive technologies for "their own good" as individuals rather than what community leaders determine is the good of the Jewish people. As the ruling (p'sak halakha) from 2010 in the second epigraph reveals, halakhic positions change and sometimes expose uncertainty rather than espouse authority. Nevertheless, a discourse of "establishing the Jewish house" has become prevalent among community leaders as a way to avoid the questions generated by halakhic uncertainty concerning single motherhood. In the third part of this chapter, I explore how egg freezing is presented to observant women by medical and religious experts. Even as egg freezing is hailed by these experts as a solution, it engenders new ideas about fertility and conflicting possibilities of moral action and reproductive agency. Together, all three sections consider the meaning of "establishing a house" in relation to individual choice, 
its association with modernity and secularism, and its relation to a gender hierarchy that encompasses motherhood within marriage.

\section{AUthority in THE ONLine ERA}

Over the past decade, unmarried men and women who identify as dati leumi have become a marginalized, yet nationally visible community. To some extent, it was the popularity of an Israeli television series called Srugim (referring to the knit skullcaps worn by men), that thrust the plight of those on the edges of the dati leumi sector into Israeli primetime with its debut in 2008. Srugim is set in Katamon, a Jerusalem neighborhood also referred to in local slang as "the swamp" (habitza) because it is teeming with unmarried religious singles in their mid-20s and above. These men and women are characterized as educated professionals, who form an alternative community to the family-centric moral order from which they are perceived as social deviants. There are "swamps" beyond Katamon, including other southeastern Jerusalem neighborhoods such as Rehavia and the Moshava, as well as in Givat Shaul adjacent to Bar Ilan University (a religious university), and in pockets of Tel Aviv. The three seasons of Srugim delve into the intimate difficulties of "continuous singlehood" (revakut mitmashekhet) in a community that encourages marriage before one's mid-20s and where a prohibition on touching the opposite sex and codes of modesty shape the encounters between unmarried men and women. The dramatized dilemmas of religious singles in the show captures the paradoxes of belonging to the moderate and conservative streams that flow into religious Zionism, which fathoms itself as the middle ground between intractable tradition of ultra-orthodox Judaism and the depravity of Jewish-Israeli secularism. 
Although there are no exact figures for the number of religious singles who remain unmarried, there is a growing sense among many in the dati leumi sector that this "phenomenon" (tofa' $a h)$, as it is sometimes called, is a problem that requires large scale intervention. As community leaders explained in public forums, it is becoming clear to them that they need to better prepare young men and women for early marriage, despite the ever-increasing cost of living in Israel and the demands of obtaining a higher education in order to enter the Israeli workforce. Education, in their view, has a great deal to do with the problem of religious singles; they worry that the gender-segregated path from youth to adulthood does not prepare men and women to interact with one another in courtships that lead to marriage proposals. In the dati leumi sector, boys and girls attend religious-state (mamlakhti dati) schools (some elementary and most secondary schools are gender separated). Upon completing high school, boys may enlist in a special program that combines army service and yeshiva study, while girls may perform one year of national service and/or continue religious studies in a women's Torah study institution (see El-Or 1997). In the ideal trajectory, young men and women meet one another (not through matchmakers), get married and begin having children in their early 20s. Marriage is not seen as only a ceremony between two individuals, but is an extension of parents' and especially mothers' religious merit.

\section{Ravakot at the Crossroads}

Many in the dati leumi community recognized that religious women, in particular, beyond the average age of marriage experience difficulty in finding suitable partners. This stems, in part, from public speculation about older women's declining fertility, rendering some women unable to assist their future husbands in fulfilling the first commandment "to be fruitful 
and multiply." As feminist scholar Rachel Elior observes of Jewish religious tradition, there is no word in Biblical Hebrew for a single woman "because there is no such status in a society which sees all its females as virgins, engaged, or married women, pregnant and giving birth" (2001:204). Thus, there is no word that identifies a woman who exists independently from subordinate relations to men. In the contemporary context, the Modern Hebrew term for unmarried woman (revaka) has taken on new meanings for dati leumi Israelis.

Single religious women, from their late 20 s on, begin to feel marginalized as their sisters, friends, and colleagues become wives, mothers, and even grandmothers. As the name of one online forum for religious singles proclaims: "no bride our way" (lo kalah darkeinu). This phrase is a play on the word "easy" (kalah), which is a homonym for the word "bride" (kalah), enabling a second meaning: "our way isn't easy." The name of the forum captures the social suffering of older singles — and older single women in particular — in the religious community as the experience of remaining single is difficult and isolating. When others get married, they extend their blessing to unmarried women, "May you be next" (b 'karov etzlekh, literally: soon it will be yours). But for single religious women, soon becomes more and more distant and the plight of remaining a revaka grows with time, as finding a mate becomes more challenging. At a wedding celebration I attended on a balmy June evening in Beit Shemesh, a small city west of Jerusalem, I was seated next to a woman and her daughter, a 34-year-old accountant. I noticed that we appeared to be the only two women our age without covered heads among the vast sea of colorful scarves that mingled and moved throughout the packed room. While music blared over the speaker system, the woman next to me asked, with a mix of curiosity and suspicion, about how it was to be an American student in Israel. When she heard that I lived in Tel Aviv, she expressed concern for my well-being ("Why not live in Jerusalem?”). (Tel Aviv is 
associated with anti-religious attitudes and immoral behavior.) After dinner, we headed over to the far side of the room, separated from men by a cloth screen, where adolescent girls and middle-aged women formed tight circles and took turns dancing in the center with the young bride, glowing in a floor-length white satin gown. Young women sat on the chairs around the edges, their bellies protruding under their festive dresses; despite their heavy makeup, they looked to be in their early 20s. Other women nursed infants under cotton blankets or held fidgeting, overtired toddlers. As we danced, bareheaded, encircled by expectant and veteran mothers, I could not help but feel how this tight-knit world that celebrates "marriage with birth" leaves little room for those who do not conform to conventional life trajectories.

In the age of assisted reproduction, the predicament of being a revaka among the datileumi community accelerates as women reach their mid to late 30s. Although single motherhood through donor insemination is not yet a widespread practice, as women are becoming aware of age-related fertility decline they are contemplating alternatives to the normative "family framework." Indeed in its mission statement printed on a flyer distributed at an Orthodox feminist conference, a new group for religious single mothers summarizes the situation faced by ravakot considering donor insemination:

A woman who reaches the age of thirty-five finds herself at a difficult crossroad. She must decide if she should risk the possibility of never having children due to increasing infertility with each passing year or take the bold step to become a single mother. It is true that the decision to become a single mom for all women is not easy; for Orthodox women it is even more difficult...In these communities, women over thirty-five often feel alienated. They are concerned that becoming a single mom will only increase this sense of alienation. (Kayama Moms 2011)

The difficultly experienced by religious ravakot is openly discussed by rabbis, community leaders and matchmakers, yet the solutions offered do not ease the sense of alienation for women over the age of thirty five. Even as their acknowledgment of the "problem" (baiya) of older 
unmarried women circulates, so does a related conversation about encouraging early marriage as the community's answer. A health care professional and mother of nine children said about single motherhood during a public talk, "The primary prevention is to talk about getting married from the age of zero! It's not just getting a degree. It's getting a family degree." This discourse about getting a "family degree" or "family as career" stems from the anxiety in the religious community that modernity is diverting the attention of Jewish women towards degrees and careers, and away from marriage and childbearing. Yet, the proposed solution of early marriage does not assist those women who, in the present, want children and for whom not having children would only add to their sense of alienation. In other words, no matter which path they take — remaining childless or opting for donor insemination — the "crossroad" that single religious women find themselves at in their 30s does not offer a passage from their otherness.

\section{Halakha in the Twenty-First Century}

In the age of the internet, religious women who reach this crossroad are not alone. Single women are navigating the uncertainties of Jewish law (halakha) on the subject: they are reaching out to one another through online forums, corresponding with rabbis, and a few are bravely using their voices to make these dilemmas (and rabbinical disagreements) audible in public. For example, in a radio interview in September 2011, a talk-show host and his guest, a revaka in her late 30s, discussed single motherhood by donor insemination and the possibility of egg freezing among religious women (Gazit 2011). Part of their heated conversation went as follows:

Woman: I want women to know that there is an alternative to sperm donation or not doing anything. A woman who has decided [not to become a single mother], whether for religious reasons or the good of the child (tovat hayeled).... She wants on the one hand not to be at risk for [birth] defects or she is scared that by the time she marries she'll be barren (akarah) and she won't be able to give birth, that there will be alternatives. Egg freezing isn't a perfect solution... 
Host (cutting her off): But the rabbis, if I'm not mistaken, don't permit alternatives to women in this situation. They want to see a woman give birth in a family framework (misgeret mishpaha), with a father for everything (im av l'khol davar), correct?

Woman: Half correct.

Host: Okay?

Woman: The first thing is that there is no word "rabbis" (ein milah rabbanim). There are those [rabbis] who don't permit [alternatives] and those who do.

Continuing, the interviewee mentioned that although the majority of Orthodox rabbis forbid this alternative, there are several (she named a specific rabbi) who are considered to be more lenient on the issue of single women and alternative routes to motherhood. The talk show host's interjection—“the rabbis...don't permit" — reveals how in everyday parlance, particularly among secular Israelis, the idea of rabbinical authority gets constituted as a solidified system. Thus, beyond highlighting the "alternatives" (donor insemination or egg freezing) that the host assumed are forbidden, the interviewee emphasized that there is no unified position on the question of single women and motherhood: one cannot speak of "the rabbis" — in a word — as a singular authority.

Online, religious women encounter these multiple positions and have access to direct, anonymous communication with their male authors. Before the existence of the internet, religious authorities (poskim) answered personal questions on matters of halakha. Their answers, called responsa, were published in print volumes. As was then customary, women would not approach rabbis in person or in writing. Instead, they would rely on their husbands or other (male) family members to address their rabbi or less often a leading posek. This patriarchal gatekeeping limited women's access to religious authorities and resulted in the marginalization of women's questions, though not of issues pertaining to women, in the responsa literature 
(Pitkowsky 2011). By contrast, at the beginning of the twenty-first century the web is bursting with thousands of cyber-responsa, accessible to Hebrew speakers through free portals such as www.kipa.co.il and www.moreshet.co.il. The letter that opens this chapter provides an example of a relatively new sub-genre of cyber-responsa, of women directly emailing rabbis about intimate matters. Religious women may independently navigate these vast tracts of information and communicate with rabbis through anonymous means, for example through filling out web forms or sending text messages that may be submitted without providing identifying information.

This possibility has led to the online explosion of numerous and sometimes contradictory positions on matters of women's status and halakha. It has also led to an expansion in the subject range of questions, which span from the mundane (proper hand-washing methods) to the immoral (dealing with prohibited sexual relations). Whereas earlier rabbinical responsa would contain detailed references to halakhic sources, the genre of cyber-responsa typically provides shorter answers often without references at all, raising questions not only about the changing nature of religious authority but also its very content and dissemination (Pitkowsky 2011:145, 150). Among the questions asked by religious ravakot include matters concerning the contemporary experience of unmarried women. May single women enter the ritual bath (mikveh)? May they cover their heads with headscarves or wigs? May they undergo donor insemination?

While most Orthodox religious authorities in Israel condemn donor insemination for single women, as the radio interviewee noted, there are a number of dissenting rabbinical voices. Perhaps the best known among the latter is Rabbi Yuval Cherlow, who is an active member of Tzohar, a network of progressive Orthodox rabbis (Tzohar rabbis officiate at weddings for secular Israeli Jews—-provoking dissent among rabbis from more conservative streams). Through 
his work on a national bioethics committee, his writings and public presentations, Rabbi Cherlow has become an address, both on and off the internet, for questions concerning assisted reproduction and related practices, including surrogacy. Cherlow, by his own count, has written over 13,000 internet responsa and has estimated that 5-10\% of the inquiries he receives come from women (Pitkowsky 2011:145). One of Cherlow's responsa provoked condemnation among Orthodox rabbis and helped cement his reputation among ravakot seeking a sympathetic religious figure.

In 2007, Rabbi Cherlow posted his reply to an email he received from a 36-year-old woman, who had tried to get married for many years. In her email she wrote to Cherlow, "I beg you: please write to me the entire subject from the beginning to the end." In particular, she wanted clear answers to two questions. Was single motherhood halakhically acceptable? If so, what was the preferred source to conceive through donor insemination (from a Jewish or nonJewish donor)?

In response to her first question, Cherlow stressed the centrality and holiness of the Jewish family that binds together couplehood, sexuality and procreation. He continued, stating that "the poskim are divided amongst themselves" when it comes to whether single motherhood through donor insemination is permissible (Cherlow n.d.). The rabbi explained the two main positions on this matter. The opponents voiced concerns about "the slippery slope" that might ensue, should women abandon the institution of marriage and family. For this camp, a woman's individual desire should not come before the public good. The second position which includes Cherlow derives from the acknowledgment that "there is no explicit [halakhic] prohibition on a woman to give birth without the family building (binyan mishpaha)." He concluded that for a woman who is at least 37 years old and "who has done everything in her capability to get 
married" this was an acceptable course of action. In his answer, Cherlow asserted than reproduction is a "basic essence of human existence," yet differentiated between motherhood as a human need or desire and the Torah-given commandment of "establishing a house" (l'hakim bayit), which joins the divinely-ordained obligations of marriage and procreation. The rabbi advised single women who become mothers through insemination to endeavor to get married and “establish a house." Thus, even Cherlow's accommodating stance suggests that in his thinking, reproduction, while a "basic essence," is not equivalent to the moral fulfillment of "establishing a house"-a fulfillment that is achieved through marriage alone.

As for the source of the sperm donation, Cherlow was adamant. The primary choice should be a known Jewish man in order to preserve the lineage of Israel (shmirat hayihusin $b^{\prime} y i s r a e l$ ). If that were not possible, then the secondary option was the sperm of an anonymous non-Jewish man. Cherlow insisted that sperm from an anonymous Jewish man was not an acceptable option (most Israeli sperm banks provide this third option since most donors are Jewish-Israeli men). Although the nuances of Jewish law that inform Cherlow's position are beyond the scope of this chapter (see Kahn 2000), what is relevant for this discussion is his transparency and openness in addressing "the entire subject" directly and online.

Cherlow's answer circulated from its page on his yeshiva's website throughout the Hebrew and English internet, in newspaper stories on and offline, and was published in Yediot Ahronot (YNET), the largest Hebrew newspaper (Tana 2007). Although Orthodox rabbis hold divergent positions on the subject of single motherhood through donor insemination, Cherlow's widely disseminated statement was a tipping point: rabbis from across the broad spectrum of Orthodox Judaism denounced his position. In the wake of fiery criticism concerning both the content and public form of his answer, Cherlow went on to post an even more detailed follow up 
that defended both the halakhic grounds of his position and the manner in which he had communicated his controversial responsa. It is relevant that in restating his reasoning, the rabbi emphasized marriage as the sole means to "establishing a house" and fulfilling the commandment to procreate. He contended that along with all of the rabbis of Israel, they agreed about this fundamental point, "The establishment of a house in Israel is the sanctified basis of the nation" (Cherlow n.d.). Of the Jewish family, Cherlow restated, "It is composed of three elements whose source is in the story of the Garden of Eden-couplehood (zugiut), sexual intercourse ([yahasei] eishut) and children — and only when all exist as one are we speaking about the full sanctification of the family" (Cherlow n.d.).

Many of Cherlow's colleagues, including rabbis who are part of the progressive Orthodox movement (Tzohar), were among the vocal objectors to his position. At a conference of Tzohar rabbis the following summer, Yediot Ahronot reported:

Rabbi Nachum Eliezer Rabinovich, head of the Birkat Moshe hesder yeshiva in Ma'ale Adumim, ruled that "bringing an orphan into the world is an unthinkable act. Any woman who plans to give birth to such a baby just to fulfill her desire to be a mother - there is no greater evil and cruelty. Such a woman does not deserve to be a mother to any human creature." Rabbi Yaakov Ariel added that "there is no such thing as a single-parent family, just like no square can be round. A family is a father, mother and children. (Chomsky 2010)

In their vehement rejection of Cherlow's ruling, these rabbis likened the children born to single mothers as "orphans" and the impossibility of fitting a single-parent family_like a round square - into the concept of family. However other members of Tzohar, such as Rabbi David Stav, have taken a more moderate position: for him, the question is not one of halakha, but rather of "policies" (mediniut)—a distinction I explore below. Further, for Rabbi Stav, an unknown father raises concerns about the future marriages of a woman's offspring according to Jewish law, leaving him unable to decide whether donor insemination for single women is permissible 
or not. ${ }^{68}$ As Tzohar's members debated Cherlow's responsa, rabbis in the more conservative wing of the dati leumi community waged their own campaign against single motherhood through donor insemination.

\section{Rabbinical Authority and the Politics of Halakha}

While at the time of writing her path-breaking account, Susan Kahn noted that she found few rabbinical writings on the issue of single motherhood (2000:57), over a decade later articles on the subject - primarily in opposition to this reproductive route-abound in Orthodox journals, online forums and public meetings. Although informed by many individuals, the rabbinical opposition to single motherhood gained prominence through PUAH, a Jerusalem-based Orthodox institute that focuses on matters of fertility and Jewish law. As part of its outreach activities, PUAH organizes an annual conference that attracts hundreds of attendees. Following Cherlow's 2007 responsa, the issue of single motherhood has been addressed by leading Orthodox rabbis at the annual PUAH conferences from 2008-2011. In what follows, I consider an example of rabbinical opposition to single motherhood from a presentation made at a PUAH conference. My intent is not to provide a comprehensive review of the opposition, but rather to point towards the concerns and categories delineated by prominent Orthodox rabbis.

In 2008, at the 9th annual PUAH conference in Jerusalem, Rabbi Shlomo Dichovsky spoke about fertility preservation and single women. A former member of the high religious court (beit din ha'gadol), Dichovsky is considered moderate-leaning when it comes to Jewish law (Lis and Ettinger 2010). His remarks were made three years before the Egg Donation Law passed and the option to freeze eggs became available to Israeli women. Though his lecture was titled "Fertility Preservation for Single Women," Dichovsky began by repeating the question that 
"to our sorrow, more and more [women] are asking." From the viewpoint of halakha, the rabbi wondered, was sperm donation from a Jew or a non-Jew (goy) more permissible? Speaking firmly into the microphone, the rabbi announced:

The answer is a short one. As I have written, this is not a halakhic question, but is a question of the policies of Jewish law (mediniut hahalakha)...the great ones (hag'dolim), from generation to generation, have the authority to amend regulations, to derive edicts, and to institute leadership. And here we enter into questions that are not easy concerning the policies of halakha in the contemporary [era].

By referencing "the great ones," Dichovsky drew attention to the difference between the authority to interpret halakha and Jewish law itself. That is, the subtext he begins with is that not all rabbis can participate in interpreting Jewish law. Given this hierarchal distinction between "the great ones" and other rabbis, Dichovsky explained to the audience what he meant by the key difference between halakha and the policies of halakha through an example:

May a single woman be permitted to dip in the ritual bath (mikveh)? ... What is bad about an [unmarried] woman who enters the mikveh? Of course, the intention is that in the event that something happens [sexual relations], and that the same women decides for many reasons to deviate from the framework (misgeret), at least she won't traverse the most severe prohibition... She will be pure (tahora).

If the act of entering the mikveh isn't explicitly forbidden to unmarried women by Jewish law, what is the problem with them undertaking this monthly ritual? In other words, in pure halakhic categories, one cannot make the case that it is forbidden, and by default, what is not forbidden by Jewish law is "permissible" (mutar). Dichovsky poses the moral quandary: given the woman's intention (sexual relations with a man), wouldn't it be better to make an exception to sociallyaccepted practice of limiting the mikveh to married women?

Situating this contentious issue beyond matters of strict legal interpretation, Dichovksy appealed to the public good, "Who knows what breach we are opening in this direction?" The direction he referred to is the result that, by using the mikveh, single women may go on to 
conceive through sexual relations with men, but that their offspring, though outside the framework of Jewish family, will at least be "pure" (tahora) (not conceived during the days a woman is considered impure or niddah). For Dikovksy, only the "great ones" (gdolim) have the authority to issue halakhic rulings and to discern when a moral breach might damage the public good. ${ }^{69}$ Other rabbis lack the knowledge and authority to determine the public good and may even damage it. Thus Dichovsky rhetorically acknowledged, "There is no halakhic prohibition (ein kan eisur hilkhati). If donor insemination, like dipping in the ritual bath cannot be outright prohibited...then what is the problem?" This is where Dichovsky returned to his distinction between halakha and public policies in the contemporary moment:

From the view of halakhic policies, at the head of the ladder of the decisors (poskim) of the great ones of the generation (gdolei hador) who are responsible for the passage of the tradition from generation to generation, stands the issue of the Jewish family. The Jewish family is built from two parents and [from] honoring your father and your mother...the model of a single parent family, not a posteriori ( $b$ 'diavad) following divorce or G-d forbid (halila) death, but from the beginning (mil'khthila), for the children there is a problem, not only in the absence of a father figure (d'mut av) but in the situation that there is no father at all...the father's family (mishpahat av) will disappear... It will be not only a single-parent family, but a child of single parent and the term "father" will not exist with him (lo kyam etzlo).

Dichovsky differentiated between halakha as a revealed system of law and "halakhic policies" as the interface between the bounded legal system and the rabbinical politics of interpretation and authority. In his understanding, when it comes to policies, "the great ones of the generation" should assume more responsibility for preserving the moral order of the Jewish family. This is not a matter of interpretation, but of who can claim the authority to make decisions on behalf of the public good. In this case, the continuity of the Jewish family should be in the hands of "the great ones" alone.

For Dichovsky, the creation of the single parent family "from the beginning," meaning based on human intention, analogous to entering the ritual bath with the objective of entering 
into illicit relations, undermines the primary purpose of adjudicating situations that arise in the contemporary world. Through the distinction between a posteriori and from the beginning, Rabbi Dichovsky locates having a child on one's own as an act of self-interest. Through this reasoning, single women's reproductive agency is located outside the realm of halakha, and further it becomes an individual act opposed not only to maintaining the public good (the absence of a father figure), but of channeling divine purpose (the passage of the Jewish family). For Dichovsky, those rabbis who enable women to have children "from the beginning" are going beyond their proper authority and issuing "policies" that reflect misplaced judgment rather than revealed wisdom.

In her study of Orthodoxy and feminism, Tamar Ross delineates rabbinical traditions of halakhic interpretation which include formalist and non-formalist approaches. This methodology is understood to produce irrefutable rulings of either "permissible" (mutar) or "forbidden" (asur). She writes:

By contrast, questions of public policy - those involving educational, communal, or political considerations - even when relating to the law, belong to a discretionary gray area not governed by formal criteria. Here the individual posek is free to supplement the law by exercise of personal discretion. (Ross 2004:68)

Accordingly, the category of a "policy" recognizes that a rabbinical ruling may have an effect on the Jewish public, and therefore both the formalist and non-formalist approaches to rulings made by Orthodox rabbis are not adequate to address the social complexities that face the community in the contemporary world. Instead, "policies" offer rabbinical authorities a way to offer guidance beyond the formal domain of Jewish law and the explicit textual record on which it is based. Yet at the same time the domain of "policies" also circumscribes rabbis' authority, leaving open "a discretionary gray area" to contestation. 
It is within this gray area that the rabbinical opposition seeks to denounce the possibility of single motherhood through donor insemination. Whether appealing to higher authority (the great ones of the generation) or stating that "there is no posek of significance" Orthodox rabbis are, in the end, limited by formalist principles of interpretation. They are reminded of this by Orthodox feminists, who are not standing on the sidelines as the "discretionary grey area" is defined and contested by men. For example, Kolech-Religious Women's Forum, the first Orthodox feminist organization in Israel, has critiqued the information the PUAH Institute has provided to women seeking information about single motherhood through donor insemination. In an online article on Kolech's website, titled "PUAH Institute - Transparent or Biased Information?" its author argues:

The truth is that I doubt...the halakhic approach that led to this ruling, or perhaps [it is] natural conservatism worded as if it were halakha. And perhaps the revered Rabbi is afraid to put his social view to the test and is hiding behind "halakha" and "moral considerations." If it comes to moral considerations, I am not sure that he is indeed an authority in this field and I'm not sure that he has even a relative advantage in this field. (Safrai n.d.)

In this striking passage the halakhic and moral authority of the head rabbi of PUAH is questioned. Further, the accusation is made that halakha is being used as something "to hide behind"- or, put differently, for political purposes. In fact, the author criticizes the institute for falsely telling women that there is no rabbinical ruling that permits single motherhood through donor insemination, thereby implying that all rabbis have explicitly forbidden this route. She concludes, "Concealing information (dis-information - disinformatzia) is one of the indicators of a militant and patronizing approach."

The debate about Jewish law and single motherhood has become an arena of contested positions. Yet, in the online era, it has also expanded the possibilities for women's voices to be heard and prompted them to raise questions about the source of rabbinical authority and the 
political motivations informing both halakhic rulings and policies. As the next section explores, the uncertainty about assisted reproduction, single motherhood and the promotion of "individualistic" behavior and women's reproductive agency is not limited to a debate among Orthodox rabbis.

\section{For Her OWn Good: The Problem Of Individual Choice}

Like rabbis, policymakers are deeply aware of the widespread practice of single motherhood through donor insemination, which lenient health care policies have helped to facilitate. I asked Dr. Rachel Adato, a parliament member from a centrist party who also happens to be an ob-gyn, what she thought about egg freezing. "I'm for it," she told me, "because there are a lot of young women, who at age 35 become pregnant from sperm donation to preserve their fertility." She explained, "They give up, already at 35." The politician was referring to women who decide to become mothers on their own. Adato continued, "So they find a donor from the sperm bank and become pregnant as single mothers. If there were other possibilities...maybe they would continue to look for a husband. This might relieve the pressure on young women to become pregnant alone." In this doctor-turned-politician's opinion, single motherhood is an unfortunate result of the intense pressure, particularly on unmarried secular women, to have children even without a husband. Egg freezing, she thought, would motivate women — religious and secular — to keep looking for a partner, rather than succumbing to pressure, "giving up," and acting on their fertility, alone.

Other policymakers claimed that promoting egg freezing might "do something" about what they understood to be a social problem. The legal counsel to the Ministry of Health, Mira Huebner-Harel, an active figure in shaping the policy and an observant Jew told a journalist, "Many women who still have not realized 'couplehood' (zugiut) fear that a time will come when 
they don't have eggs, or that [the eggs] won't be good enough. This creates pressure [on the Ministry of Health] to allow women to freeze [unfertilized] eggs and to preserve them for a later stage" (Gal 2010). As the legal counsel envisioned it, the "later stage" would be after a woman got married. In her narrative, Israeli women had not abandoned the goal of getting married; egg freezing, she reasoned, might be a way to help women realize options besides single motherhood. Huebner-Harel saw herself as sympathetic to women's plight: in her thinking the women should wait, but their eggs couldn't. While the possibility of fertility preservation through egg freezing might encourage women to delay having children until marriage, some policymakers worried that a lenient policy might send the wrong message. They feared that with the option of egg freezing, women could attend to their own goals: they might prioritize finishing degrees and establishing careers, and thus delay childbearing. These concerns about fertility preservation were not new, but had in fact surfaced a decade earlier.

Over the course of 2000, an advisory committee met to make recommendations on an egg donation law. One of the issues discussed in the committee's hearings was the possibility of egg freezing — which at the time was being explored in veterinary science (in human models, it was still only a theoretical possibility). Nevertheless, the committee assumed that egg freezing was an inevitable technological development, and therefore one that required serious forethought. Israel is a small country, and many of the leading figures on the committee-physicians, rabbis, policymakers and fertility activists - interact with one another in a number of forums, including medical conferences, bioethics study days and government committees. Mira Huebner-Harel, the legal counsel to the Ministry of Health, was one of the policymakers involved in the committee. She explained to fellow committee members, "In order to freeze eggs, I need very clear criteria, so that a situation isn't created where a woman will come and say, 'Now I want to 
have a career, when I'm 50 take my eggs out of the freezer"' (MOH 14). The legal counsel did not want women to use egg freezing to postpone childbearing in order to advance their careers. She insisted that the national provision of fertility preservation be carefully protected from the socially undesirable consequences that might result from women's individualistic demands.

Rabbi Burstein, an Orthodox rabbi from the PUAH Institute who participated in the committee meetings, echoed the legal counsel's concern about women's individualistic demands. He supported the use of egg freezing technology, but anticipated the radical import of its widespread use, particularly among secular women. The rabbi told the committee:

In giving our permission to use technologies like this, we are helping to destroy the institution of family in part of the population. We are actually increasing the chance that she will be tempted to delay the establishment of family...we are in fact helping her come to a decision that isn't to her own good. (MOH 14)

The rabbi sought to subordinate women's own good to what he deems good for Israeli society. While the rabbi was referring to "part of the population," he was acutely aware of the influence of that part—secular Jews — on the practices of observant communities. The rabbi, like other policymakers, feared that egg freezing might promote individualistic decision-making among secular women, which would in turn spread to religious women, and thus destroy the "institution of family" among the Jewish people as a whole.

The legal counsel and the rabbi, along with other policymakers, struggled with the problem: how to sync "her own good" with what, according to them, is good for the nation. During the committee sessions, policymakers could not predict the magnitude of "the problem" of single women, yet they fully grasped the significance of normative family as a national institution. They understood that fertility preservation traverses an uncertain border: it may solve the shortage of donor eggs and the practice of non-Jewish egg donation, and it may deter women from single motherhood, but at the same time it may engender women's reproductive autonomy 
and an ethos of individualism and choice, as the advent of assisted reproduction has done in Euro-American contexts (see Dolgin 1997). Perhaps for this reason, the egg freezing policy limited the procedure to women between the ages of $31-40$, an age range that reveals social calculations rather than the available scientific data, which suggest that the younger the eggs are frozen the more likely a live birth is to result. As one female physician angrily remarked of the specified age range, this was a "paternalistic policy" reflecting social unease rather than medical knowledge.

In their statements to national media outlets following the new regulations on egg freezing (2011), policymakers explained that the pressure to include the option of fertility preservation in the egg donation law came from religious women themselves. For example, when Huebner-Harel announced the new egg freezing policy, she described how the idea of freezing eggs arose years earlier, when she began to receive entreaties from women. In January 2011, the legal counsel explained the new policy at a closed-door conference of fertility doctors during a weekend conference at a Herzliya resort. She told the audience of physicians, "Women, ages 35, 38 turned to me, who aren't married and who knew that the time is running out, [and] the condition of their eggs [was deteriorating] and they asked, 'Let me freeze eggs, so that when the right man comes I can fertilize them"' (Bashen 2011). In this narrative, women who desired egg freezing were complying with socially-expected norms rather than replacing them with individualistic values. The legal counsel justified the policy, which had been labeled "revolutionary" by some media outlets: women wanted to freeze their eggs because they had not found a partner, yet. As she explained the "official" rationale behind the policy, Huebner-Harel simultaneously represented women's desire to get married and establish normative families to an audience full of Israel's fertility experts - the future healthcare providers of the women who 
would soon become the first Israeli egg freezing patients. By imagining the reproductive agency of older ravakot as embedded in their longing for "the right man," the representative of the Ministry of Health endeavored to undermine the narrative, promoted by Israeli media accounts, about egg freezing as a "revolutionary" technology. Appropriating the voices and desires of ravakot has become a way of making authoritative religious and medical claims about fertility preservation.

\section{A Life Float to Save the Nation}

"What is the place of family?" Rabbi Foirstein asked a packed room of doctors and nurses, during a boisterous discussion on fertility preservation. Though the primary aim of the two-day annual meeting of the Israeli Fertility Association (AYALA) held each May at a luxury hotel on Tel Aviv's beachfront is the presentation of new research findings, there is also a program on the "psychosocial" dimensions of assisted reproduction, including matters of Jewish law. This rabbi, a member of Tzohar (the progressive coalition of Orthodox rabbis discussed above) was a part of an afternoon panel on the ethics of egg freezing. After he posed his question, he took a rhetorical detour, plunging into the subject of rising divorce rates in Israel and then to the ways the "good of the child" (tovat hayeled) was being damaged by the destruction of families.

It was difficult, at first, to see where Foirstein was going, as the subject of the roundtable was egg freezing technology for single women. But rabbis have a way of making a point by taking circuitous paths. Foirstein released a powerful torrent of words that flowed into a forceful sermon. He lamented: 
Israeli society is more and more egocentric, more "selfish" (he used the English word), more independent. The house and the family are broken; they are less built. There is no life. There is no building of family.

The rabbi's understanding of "building" is central to his point. According to Foirstein, children in divorced families and Jewish women not having children are equivalent problems in contemporary Israeli society. In his view, neither contribute to building the Jewish house and creating the world - to carry forward the life of the collective Jewish nation. He then addressed the subject of the roundtable:

Thus, I welcomed [egg freezing] because I meet with older singles, religious men and women, and they are miserable. They tell me [switching to first person feminine], "I didn't find [a husband]. I want a ben zug, normative couplehood. I don't want sperm donation, but I need to preserve my biology."

Foirstein, like the policymakers in the previous section, sought to situate women's desire to "preserve their biology" within the moral boundaries of Jewish family and marriage. Like Huebner-Harel, Foirstein appropriated the voices of women — even speaking in first person feminine - rhetorically encompassing their choices within the appropriate framework in the dati leumi community.

The rabbi did not criticize this novel reproductive technology for its radical potential to alter Israeli family, but instead hailed its soteriological properties. Here, Foirstein's impromptu sermon arrived at its point. He declared, "The [egg freezing] technology isn't carrying us forward; the technology is the life float (galgal hatzala) that will save us from much deeper crisis." Egg freezing technology, in the rabbi's reasoning, was not going to save the nation by bringing progress as science, medicine and technology are understood to do in the Israeli nationalist ethos (Efron 2007; Wahrman 2002), but by restoring the value of marriage and the place of family - the divinely-ordained Jewish house — as the anchoring source of life and of the basic unit of building the nation. Like many Orthodox rabbis, Foirstein was concerned about the 
undermining of the Jewish values of marriage and family by the western concept of the individual. Israeli society, in their thinking, has put the "I" before the "collective." Yet, the rabbi, speaking in the feminine voice, was optimistic that Israeli women (and even secular women or "anti-religious" as he called them) desire the social norm and will return, through the help of this God-given technology, to the wisdom of Jewish values of family and community. For the rabbi, egg freezing engenders a solution to this egocentric riptide; it may save single women and society as a whole from drowning in the absent values of the "modern" western world.

The rabbi not only endorsed the idea of egg freezing for single women, he constructed this invention as prior to the problems of modernity. In this formulation, technology is something that already exists as part of God's creation, waiting for Jews to put it to use to heal the nation. In the rabbi's view, "God built the world" (hu bana olam) and therefore all of creation, including new technologies, has been preordained for human use and for the purpose of building the world. Here, it is not the technology itself which is kosher (or not), but the way humans use the technology (Ivry 2010b). In this case, technology, given by God, is the life float to save the Jewish nation from selfishness and egocentrism — or in Foirstein's reading, the absence of building the family. The appropriate use of the technology, rather than the technology itself, is what is at stake. The rabbi explained, "Fertility preservation is a huge Jewish value, the subject of fertility and bringing children into the world is one of the basic premises of [Jewish law] halakha and Jewish thought....The human race is developing, not only existing, continuing... without 'be fruitful and multiply' none of the other commandments (mitzvot) can happen." In this teleological argument, fertility preservation — as an extension of a foundational Jewish commandment — preceded the modern technology. 
Foirstein claimed that having children is the way Jews, since creation, have contributed to the ongoing work of "he built [the] world" (hu bana olam). Indeed, Rachel Elior (2001) makes the perceptive observation that "son" (ben) and the verb "to build" (bana) are from the same Hebrew root. The rabbi's underlying message about women's participation in "building the world" is twofold. First, he emphasized that having children without a husband/father does not contribute to the sanctified task of building, but is rather outside the accepted moral order. This argument has been made by many Orthodox religious authorities who oppose single motherhood through anonymous insemination, including the former Sephardi Chief Rabbi of Israel, Eliyahu Bakshi-Doron who wrote against single motherhood, "There is no permission to give birth in the single motherhood framework (misgeret)...to give birth to an orphaned child without a father, without a family, without sanctification and without the divine presence (Bakshi-Doron 2002:4). The work of building the world through the Jewish family requires not only a father "to educate the (male) child and teach him Torah" but the contribution of the divine presence in procreation as "the basis of the family and its success in the Jewish house" (Bakshi-Doron 2002:3-4). Through the ideology of "building the world" and "establishing the house," Orthodox rabbis endeavor to differentiate between the gender hierarchy within procreation (of a couple assisted by the divine presence) and reproduction (of a single mother).

Second, Foirstein made clear that delaying childbirth also undermines the work of creation, for it allows individualistic intention to subvert divine commandment and collective contribution to building the world through bringing children/sons into being. The cosmology of building the world is based on a central premise: individuals (single women) cannot build the world alone. Delaying one's fertility whether by intention or not is therefore interpreted as a destructive element. Foirstein told the audience, "We have to permit fertility and cope with the 
subtext. We have to return to family from a Jewish perspective. We have 'to establish family as a career' (l'hakim mishpaha k'kariera)." Foirstein was directly addressing the remarks of a previous speaker, a female psychologist, who had commented on the challenges of balancing career and childbearing experienced by Israeli women. While aware of this tension faced by many religious women (who in some cases are the primary source of household income), the rabbi maintained that Jewish law cannot be manipulated in order to solve what he termed "cultural or educational problems." Rather than encourage women to pursue education and careers as individuals, in Foirstein's revision the family should be treated as women's career.

At the end of a roundtable on fertility preservation an audience member asked Rabbi Foirstein whether a woman who freezes her eggs may use them later-even if she is single. "I'm not sure we should discuss that [issue] here," the rabbi answered. Irritated, he returned to his point about encouraging women to find husbands. He told the audience, "The solution isn't [the technology], rather it is about how to make decisions toward establishing a house (l'hakim bayit)." Foirstein concluded that increasing women's reproductive options through egg freezing was permissible according to Jewish law, but only if fertility remained within the Jewish moral order of marriage and establishing a house. To rabbis like him and to policymakers, individual decisions to use this technology in ways that promote individual choice and autonomy and that delay fertility have destructive implications for the Jewish nation and its future.

One of the main assumptions that Orthodox rabbis make is that single women are too choosy. For them, acceptable choices lead to marriage and family and to compromisetechnology should assist this social value. Foirstein concluded, "As we get older, our ability to decide on a partner (ben zug) is more complicated, [but] that I think is the solution and not running after technology." A physician on the panel interjected, "You rabbis criticize us for 
running ahead with the technology, but I will help my patient make the best possible choice.” Although the doctor endeavored to reframe the issue in terms of individual choice and medical decision-making, in this time of technological innovation, the "best choice" is not self-evident. Furthermore, expanding women's reproductive options - far from creating “best” choicescreates new uncertainties that complicate both religious and medical authority.

\section{THE FUTURe IS (AlREADY) HeRE}

During a break at a fertility awareness conference, I spotted a flyer posted near the entrance to the auditorium. It was an announcement for an event the next evening at a Jerusalem synagogue, entitled: "Preserving Fertility: Halakha and Practice for women only." A handdrawn arrow pointed to an adjacent flyer, where the words "a national problem of single women" had been circled in thick black ink. The second flyer contained a recent statement issued by the PUAH Institute (mentioned above) on the "hardship of single women" (metzukat haravakot). The issue of older single women had been receiving a lot of attention, both in the medical and religious communities.

During the previous months, I had discussed fertility preservation and egg freezing with physicians and watched numerous presentations on the subject at medical conferences, including Rabbi Foirstein's. In these spaces, there was a lot of anticipation concerning this technological breakthrough. Professionals presented new discoveries and engaged in lively discussions concerning the technical intricacies of the procedure, but the potential beneficiaries of this breakthrough were largely absent. This notice marked the first public event on egg freezing that was organized for religious women, by religious women. What medical information would be presented on the new technology? What religious perspective would be offered? And what 
differences of opinion would be expressed by the forum's two experts on women's fertility—a secular doctor and an Orthodox rabbi?

As I made my way up the street toward a synagogue in Jerusalem's Old Katamon, I wondered whether women would attend the forum. The dark alley adjacent to the synagogue was empty. But as I got closer to the entrance of the sanctuary, I heard a clambering of voices. Inside, it was completely packed, wall to wall, with women greeting one another with hugs and double-cheek kisses, chatting away, pushing folding chairs closer together to make room for more. There were women wearing bandanas and colorful head scarves (some showing a bit of hair, others showing none), in knit caps, or neat wigs, but mostly there were women without these varied markers of marriage. There were women in skirts reaching the floor, mid-calf, and even showing some knees; in wide-legged pants; in skirts over pants; and others still in skinny jeans. All of these fashion statements spoke to the diverse interpretations of female modesty abided by the Orthodox community. The chatter increased and the room filled beyond capacity. As the invited speakers took their seats in front of the arc holding the sacred Torah scrolls, women made hushing sounds and a collective sense of anticipation took hold.

The organizer, a religious social worker in her late 30s, began the forum by asking the audience to focus on egg freezing and "not to turn the subject of the evening into another subject (noseh aher)." That silenced subject was single motherhood. The organizer explained that focusing only on egg freezing would allow each attendee to fully understand the technology and to show respect to the rabbi. But this reminder to remain on modest ground was challenged as the urgent, though unspeakable subject of single motherhood through insemination smoldered on throughout the night, fanned by women's questions and flaring up in the doctor's problematic advice. The atmosphere in the crowded sanctuary contrasted with all of the conferences and 
symposiums I had attended in medical centers, convention halls, and university auditoriums.

Rather than the sober "scientific" tone or agitated exchanges between professional egos characterizing these other spaces, the feeling here was one of shared urgency. The social worker set this tone as she concluded her remarks with a moving prayer, "Everything that [G-d] blessed women, he didn't bless [them with] a single thing to be wasted. These breasts that you bestowed us with—Why?....Not to nurse with them? Blessed are you, who hears [our] prayer." The audience resounded with a strong and heartfelt "Amen."

"It's really exciting. There is tremendous energy here, more than what we expected," the fertility expert said as he began his presentation. As he spoke, women pulled their chairs even closer, clutched pens, and balanced notebooks on their laps, craning forward to see the doctor's PowerPoint presentation. Slides of magnified eggs and embryos were projected onto the synagogue wall, which served as a makeshift screen. The doctor pointed out the difference between a young ovary, packed with follicles and the few lone follicles_- "one here, one over there"-still lingering in a 40-year-old woman's ovary. "Women are born with all their eggs...millions," he explained, "but by age fifty about one thousand eggs remain in each ovary and gradually, the woman stops ovulating." He got right to the point, "After age 40 the chance of success goes down, there is decline in ovarian reserve and in the quality of the eggs." The doctor pressed on, listing additional concerns that women "may not be aware of": gynecological diseases (endometriosis), surgical procedures (laparoscopic cyst removal), medical treatments (chemotherapy) and genetic conditions (carriers of fragile X). All could hasten fertility decline and cause premature menopause.

"What could be done to counter fertility decline," the doctor asked rhetorically. "Hormones can be profiled with blood tests," he answered his own query, "levels of FSH, LH, 
estrogen and sometimes additional factors." There were still more possibilities: an ultrasound exam immediately after a period finished, an antra-follicle count performed, and now, a new test called Anti Mullerian Hormone (AMH). "AMH is very reliable, but it is not enough," the doctor told the women without explaining what AMH was. He paused for a moment, and then called out "next slide." Using scientific charts, graphs and statistics, the doctor rushed through the "biological facts" of age-related fertility decline. I had heard much of this data presented in medical conferences and seen many of the same charts and graphs. But, here, in this Jerusalem synagogue, the clinical neatness of this information grew muddled with each slide. As women's questions would later attest, this volley of authoritative facts, predictive tests and strange English acronyms was alarming news for many in the audience.

When the doctor came to the evening's main subject — oocyte vitrification — he tried to sound encouraging. The doctor told the audience, "There is no need for a partner, no need for the sperm bank." His pointer produced a quivering red dot that darted around a slide containing two eggs side-by-side: one frozen with conventional slow-cooling, the other vitrified (Hebrew: zigug), turned into a bluish glass-like bead in a few minutes. Of the difference between the conventional and the new method, he explained, "The fast-freezing doesn't produce ice, and that is what protects the eggs." Without more detail, the doctor rushed through the first steps of the procedure, which resemble in vitro fertilization: two weeks of hormones—“injections, not pills"- to stimulate follicle ripening and suppress ovulation from happening too soon; blood tests to check the hormone levels; follow-up to prevent ovarian hyper-stimulation (OHSS); and the ultrasound, he hesitated for a moment, before adding, "vaginal ultrasound is required."

Women in the audience immediately interrupted him; they wanted to know, was this invasive ultrasound necessary? Might there be some other way instead? The room was awash 
with wave of murmuring voices. "The subject of virginity is important," the doctor sympathized with the audience, "but [vaginal ultrasound] is the only precise way." This procedural detail is no simple matter: for observant, single women who strive to live according to a strict code of modesty, vaginal ultrasound in the absence of medical indication uncomfortably penetrates halakhic concerns. Yet, the doctor had no alternative to offer. There was still more information to cover and variables to consider: eggs could be harvested ripe or taken too soon; eggs might require ripening in a Petri dish before freezing (in-vitro maturation or IVM); the hormone stimulation protocol might need tinkering; women might not react well to initial hormone protocols; different clinics used either short or long protocols; some women might get 20 eggs on the first try, but other women might require two or three cycles to get to this number. Still others might get very few eggs, or none, at all. While the doctor had presented seemingly straightforward steps, he now entered the territory of unknowns, for which there were no straightforward answers. There is a significant difference between IVF and egg freezing. In the latter, the eggs are not transferred back into the woman's uterus. Instead, they are dehydrated with cryopreservants and stored at $-196 \mathrm{C}$, as her reproductive future unfolds. The fate of the vitrified eggs becomes part of this uncertain future.

As the night went on, the barrage of questions about fertility preservation grew even more complicated and unanswerable. A woman in the front row asked the doctor, "Which eggs are better: the ones frozen at 35 or the fresh ones at 43 ? Before the doctor could finish his answer, a woman sitting close by asked, "What if a woman wants more than one child?" Women's questions kept coming, but the doctor's answers were lacking. The technology was new - too new for answers. As the number and complexity of questions attested, the potential benefit, yet unknown efficacy, of egg freezing sparked an urgent feeling for many women in the 
audience. Many of these women were approaching or had already reached the policy's cut-off age of 41 .

Eventually the doctor interrupted the women's questions. He seemed frustrated and told the women, "The time has come to say this: we are talking about fertility preservation. The term, maybe, is not correct. We are talking about an attempt (nisaiyon) to preserve fertility." He tried to explain what he meant by an attempt, "I'm not promising everyone who freezes eggs that tomorrow she'll have two children. This is an attempt, but the numbers are based on medical data." The mixed message of cautious hope and clinical frankness, woven throughout the doctor's presentation, reached its apex. Even as the doctor buffered his optimism with clinical reserve, he nevertheless reasserted his medical authority in the face of uncertainty and inefficacy, with objective scientific data (Good 1993). The doctor's message of optimism - that something could be done (tests, monitoring, procedures), resonated with the audience of religious women, who sought to protect their modesty and avoid becoming single mothers. All the information that lent to possible action was met with troublesome caveats: there are more tests available, but the information they provide is not always helpful; monitoring is a way to check the rate of fertility decline, but it may not be a justifiable intervention; egg freezing procedures are getting promising results, but not for all woman.

As anthropologists of reproduction have observed, assisted conception is often figured as a "narrative of hope" for both children and technological progress (Franklin 1992; see also Becker 2000; Thompson 2005). Yet, for women struggling with infertility this narrative is one "that foregrounds the ambiguity and contingency of conception, rather than its certainty" (Franklin 1992:90). More recent scholarship on egg freezing or oocyte preservation as it is called in medical literature differentiates between women with diagnosed fertility problems in 
the present and "anticipated infertility" in the future, which concerns all women (Martin 2010). The key difference for women who face anticipated infertility but do not currently have medical conditions is that, for them, the hope acquired through egg freezing merges with discourses about choice, entrepreneurial spirit, investment and individual risk analysis (Martin 2010). As Tiffany Romain argues, for professional women in the United States who freeze their eggs, the uncertainty of technological possibility enabled them to "creat[e] for themselves futures that were open and unknown, ones that retained the possibility of 'having it all'” (2012:190). These accounts of egg freezing in North America suggest that the "narrative of hope," while fused with anxiety (Romain 2012:199), has become a marketplace commodity that enables the cultivationin the present —of a rational, individual agent who is responsibly managing future risk and reproductive uncertainty. Yet, for religious ravakot motherhood is not a goal to be planned for and managed by savvy 30 -something female consumers hoping to "have it all"; instead, it is a social milestone that was expected to have already occurred in the past.

At the end of his presentation, the doctor's scientific tone and his oscillating message of hope and caution came to a unexpected halt. He blurted out, "If you are over 40, you need to think about another framework (misgeret)." The "framework" he was referring to, as explained in Chapter 1, is a linguistic code in this context for single motherhood: in this case, the implied framework was a deviation from the family framework. The doctor, a secular fertility expert, clarified what he meant, "If you are 40, I'd like to see you get pregnant right now." Despite the audience of observant women and the Orthodox rabbi sitting nearby, the doctor reiterated his advice. Rather than speaking as a male expert, he now spoke from the perspective of a revaka in first-person feminine, “I'm (bat) 40, 41 years old, I don't have a partner (ben zug), what can I do?" He answered "her" hypothetical inquiry as the authoritative, yet sympathetic, male 
specialist, "I think that while it depends on tests, as we get older..." Then he suddenly changed course and blatantly declared, "Leave the story of fertility preservation." He directed his comments, now in plural, to all the women in the audience, "Get pregnant now, because otherwise that [too] won't be achieved." With this startling directive, the doctor's rapport shattered. There was nothing that he, an expert, could do to convince this synagogue full of religious women to become mothers by chosing "another framework."

This was an awkward moment for everyone in the synagogue. The optimistic title of the doctor's presentation - "the future is (already) here"- took on another meaning for women who had reached a critical age. Egg freezing was not an option for women in their 40s, but neither was single motherhood. As discussed above, for women in the Orthodox community, getting pregnant without a husband is difficult to imagine and for many, it is simply inconceivable. For some women in the audience already experiencing this social difficulty, nothing could be postponed, frozen for the future. Egg freezing was a breakthrough technology, but for them it was a route that had come too late.

The rabbi, who had been sitting quietly and listening until now, immediately broke the almost tangible sense of discomfort. He joked, "I hope each one of you gets married now," mocking the doctor's imperative to "get pregnant now." Although the rabbi said this in a low voice, the women in the audience heard it and broke into laughter. Their response signaled a moment of shared relief after absorbing the doctor's provocative, but problematic advice. The rabbi would spend his presentation refuting this recommendation, late into the night.

\section{Fertility Preservation through Marriage}

"It is the duty of rabbis to help with later singledom (ravakut me 'uheret)," Rabbi Burstein began his presentation. Throughout his remarks on fertility preservation, the rabbi reframed the 
problem: it was not fertility that required preservation, but rather the preserving of fertility within the conjugal couple. The duty of rabbis, according to Burstein, was to "help with the possibility of marriage, even at a slightly older age." Although the forum was organized to provide women with information about "halakhic perspectives" on egg freezing technology, the rabbi focused almost entirely on the importance of marriage, as a kinship-making technology.

While the doctor had exposed the medical facts of age-related infertility, bolstering these truths with statistics, probabilities and visualized truths (PowerPoint charts and images), the rabbi appealed to another kind of knowledge. The doctor's presentation endeavored to translate science for a lay audience. In fact, many Israeli health care providers I interviewed who work in the field of fertility believe that the demonstration of these biological truths, which they claim are unknown to most women, will precipitate responsible action. Accordingly, the fertility doctor had presented egg freezing as a reasonable option for individual patients, single women in their 30s. However, for women of a critical age, the doctor prescribed "getting pregnant now," which he presented as the only logical (that is medically-sound) action after becoming aware of the biological facts. The rabbi, conversely, appealed to another order in the world-to God's creation. His presentation sought to transmit a higher knowledge, one that cannot be translated but rather a revelation that must be abided.

For the rabbi, the biological facts of fertility defy human understanding precisely because they are not man-made. Nevertheless, the God-given order of the world - though defiant of human reason - must be respected. He explained to the women:

There are things that have an order. There are things that I don't quite understand... [Why] is the [preferred] age of marriage ' 18 [years old] and the marriage canopy' (shmonah esrei l'huppah)? I think it would be more fitting if we could enjoy life a little bit, have a little bit of career, of building a house (li'vnot), and then get married. 
In the rabbi's words there appears to be apparent contradiction: early marriage is encouraged by the ancient sages, as captured by the expression " 18 and the marriage canopy (huppah)" and his acknowledged concession that in the modern world, humans reach maturity later in life. In this moral order, men are expected to marry and build a house at precisely a point in their lives when they lack secure livelihoods and the wisdom of experience.

Even as the rabbi was well aware of the western narrative of individual self-fulfillment before marital partnership, his duty was to make sense of this seeming incongruity. Accordingly, the rabbi first tried to reason with his human faculties against the given order in the world. In doing so, he sympathized with the audience and demonstrated his awareness of the "modern" narrative of individual self-fulfillment. He told the women:

G-d gives the age of fertility, but if I were in his place, I would extend [it] to at least 50 or 60. It seems that G-d has other thoughts and that he created the world a bit differently. We have to fit ourselves to the existing technologies and conditions.

Even as the rabbi sought to empathize, he quickly returned to affirming his role as authoritative transmitter. Rather than try to deny the order of the world or reason through western categories, Burstein emphasized that ravakot must accept the way of life in the religious community. What he meant by "fit ourselves to the existing technologies" however, was not immediately evident.

In presentations like this one and in his writings, Burstein cautiously supported egg freezing for single women in their 30s, provided that it was done under strict rabbinical supervision. At the same time, he advised that ravakot continue praying to find a husband and to carry out acts of "charity" (hesed) to hasten marriage. Thus, the rabbi's lenient position on egg freezing technology was coupled with an underlying message about making appropriate decisions that "fit" God's order and the Orthodox community's norms of marrying and establishing a legitimate Jewish family—as soon as possible. 
During his presentation, the rabbi passed out copies of a thin pamphlet, prepared specially for the event, entitled: "Fertility Preservation: Medical and Halakhic Perspectives." He jokingly encouraged women to read it, as "homework." But like his remarks on egg freezing, women who looked inside would have found very little information specially related to egg freezing technology. Instead, after a few pages on the importance of pre-marital genetic testing and a chart of recommended hormone level tests that can diagnosis fertility decline, there were articles written by rabbis on the importance of marriage and examples of prayers for single women. An article by Burstein titled "Why Isn't This Working" was addressed to single women and men "age 25 and above." Like his presentation, the rabbi began his article with a sympathetic tone. He recognized that the religious community should not blame older singles for their situation - a situation as the rabbi understood it that was created by the problem of too much choice, which he contended creates indecision. According to Burstein, as singles get older their individual desires strengthen, to the detriment of their ability to make compromises.

Burstein argued that older singles who "truly want to marry must give up (l'vater)"they must give up the [western] idea of choice that has permeated Orthodox communities, engendering modern ideals of marriage. While religious Jews could "choose" their partner, marriage itself was not a choice, but a requirement:

You must get married! There is no concept [in Judaism] that a man doesn't marry and establish a house. In western culture, there indeed exists a concept like that, but it is important that such a terrible thing doesn't enter [our culture]... it is important that we take other thoughts out of [their] head[s]. (Burstein 2011:10)

The rabbi was referring to men and women, whose marital status as "single" (revak/revaka) suggests the incursion of a non-Jewish concept - the individual. For the rabbi, the presence of the unmarried individual in the Jewish community is "a terrible thing" that must be eliminated: the value of family and establishing a house must be preserved, even at the expense of "choice." 
Burstein's fervent position is unapologetic. In fact, he attempted to console singles with his insight: "most humans can marry and get along with almost anyone and build a nice life" (Burstein 2010:12).

Although Burstein promoted marriage as the solution to what he calls "the national problem of older single women," he simultaneously supported the use of new medical tests and fertility preservation technologies like egg freezing. Indeed, this influential rabbi advised women in their early 30 s to undergo hormonal tests to determine ovarian reserve and if possible, to freeze their eggs - just in case. Yet as discussed above, Burstein as well as other rabbis and conservative policymakers were deeply concerned about the potential misuse of egg freezing to delay fertility, or even worse, to help older women become pregnant — on their own. Thus, while his guidance on marriage ("get married now") and egg freezing ("just in case") appeared somewhat contradictory, these two courses of action are connected to an idea about the individual in relation to Jewish values of marriage, family and nation. Of these values, another rabbi at the PUAH Institute explained to me, "Marriage is a stabilizing factor in the Jewish collective. We should promote it earlier rather than later. And there is a fear, if you can inseminate or freeze eggs, then the motivation [for women] to get married is going to be less." While Orthodox rabbis recognize religious single women's dilemmas, they want to encourage having children within marriage. Reproductive routes like egg freezing, if done in the wrong way, will damage the Jewish family on which the future of the Jewish nation depends (Ariel 2001). The fear that western, individual desires will replace Jewish values underscores rabbis' thinking about egg freezing technology. Yet even as they are wary of egg freezing, most rabbis understand that unmarried women may turn to "another framework" - single motherhood through donor insemination. 
Even as rabbis are beginning to endorse egg freezing as a way to avoid single motherhood, a new uncertainty is created: what if a revaka freezes her eggs and then uses them, later, to have a child on her own? In public arenas, I observed how rabbis deflect this question, instead channeling the conversation back to the issue of marriage and Jewish values. For them, fertility preservation has to do with the safeguarding of Jewish reproduction within the family and with the privileging of men's religious obligation (mitzvah) to procreate over women's reproductive "rights" and the expansion of individual choice. Rabbis' understanding of fertility decline does not focus on the "biological" limits experienced by women but rather on making clear the limits of the divinely ordained moral order and rejecting the possibility that women $—$ on their own - may establish a house.

This tendency to avert the question that concerns many women facing age-related infertility has not gone unobserved. For example, a newspaper column on single later motherhood among religious women quoted a revaka who is also an activist for increasing women's choices:

The phenomenon of older single women in the religious world is increasing. Medicine is extending our life expectancy, but [medicine] hasn't succeeded at extending the [freshness] of the eggs, so that at 36 there is a very dramatic decline. Therefore, whoever doesn't want to give up (le 'vater) on motherhood needs, at a certain age, to make a decision. Our problem is that [rabbis] fear coping with the issue of single women's fertility and prefer to close the door on us. (Rothschild 2011)

By closing the door on women like this one, the contested idea of "giving up" is paramount. Orthodox rabbis like Burstein want older women to "give up" individual choice and to marry according to Jewish law. However, single women in the Orthodox community are becoming aware of a new possibility, one that has received approval by a minority of rabbis: even if they do not marry, they may not need to "give up" having a child. 


\section{“Block Upon Block"}

At a meeting on single motherhood that took place in November 2011 in Jerusalem, one of the organizers introduced the evening. Like the night several months earlier in July, rabbis and physicians were scheduled to present their perspectives on the dilemmas faced by religious ravakot. In contrast to the previous event, two rabbis with more lenient views on single motherhood were present, including Rabbi Yuval Cherlow. While the July night had silenced discussion of single motherhood as "the other issue," this evening put it at the very heart of the matter. The organizer told the audience of mostly women how excited she was about the event:

I'm 41 years old, not married and I want to bring children into the world. Like everyone, I dreamt from a young age of marriage and establishing a family (l'hakim mishpaha). This dream, to get married, still exists, and I don't intend to give it up (l'vater alav) just like I don't intend to give up on the religious values (arekhim datim) that I was raised with and on the halakhic framework in which I was educated. But, like many women I also, of course, am not prepared to give up on the right ( $\left.z^{\prime} h u t\right)$ and maybe also on the obligation to give birth (hahova sheli le'ledet).

In her introduction, the organizer defines her desire to have children as a normative aspiration "like everyone" and is careful to situate her yearning within the moral code of marriage with birth. Further, she orients her desire to have children in accordance with "religious values" and Jewish law. After she establishes her validity within this moral code, this revaka makes a striking statement. Though she is not "giving up" on the lifeworld of Orthodox Judaism, she frames motherhood as a right and as an obligation. With this proclamation, the organizer aligns motherhood with a republican discourse about citizen's rights established by the secular courts (Shelav and Gooldin 2006) and with an emergent Orthodox feminist discourse about procreation as a male as well as female obligation.

Beyond reconfiguring motherhood as an individual right and a woman's obligation, the organizer turned to textual interpretation of the week's Torah portion. Not only did the organizer 
summarize the rabbinical discourse of building the Jewish house that is deployed to counter single motherhood, but in so doing, she issued an authoritative statement on the issue at hand:

In our upcoming Torah portion (parsha) we learn that the need for children (hatzorekh b'yeladim) is an existential need. Sarah was prepared to bring another woman to Abraham provided that there would be a child. Presumably, it was very simple emotionally to do this [we learn from the words] "to be born from her" says Rashi... "One who doesn't have sons is not built," the Rabbi Shimon Raphael Hirsch writes of these words. I will build on the word "sons" block upon block...G-d (hakadosh barukh $h u$ ) is the builder (banai) and every person and every generation they are the building blocks (evnei habinyan) [literally: the stones of the building]. [Those] who don't have children are not adding to the building (ein mosifim li'vnot al gavam). Later in the parsha...Rachel declares the desire [to have children] that is so deep until she says, "Give me sons, or I shall die" (Gen 30:1)...I, together with my friends, established [the organization] in order to help to fulfill (l'hagshim) the longing of thousands of women in Israel and in the world [to have] children. Sometimes, it's easier...to hold onto the thought that, with the help of G-d, the groom will arrive.

Interestingly, in her interpretation of "building" the organizer leaves out the final part of the well-known statement made by the father of neo-orthodox Judaism, Rabbi Hirsch (1808-1888): one who doesn't have sons is not built; he is destroyed (in the sense of a destroyed structure). While this procreative cosmology of building the nation, block by block, son by son, in the rabbinical discourse is reserved for men alone, this speaker weds it to an accepted discourse on women's "longing" for children. She cautions the single women in the audience not to hold on to optimistic thoughts or to hope for divine intervention (as in Rachel's story). Instead, through her textual interpretation that juxtaposes these central ideas-men's obligation to build and women's yearning to have children — this woman's subversive message becomes clear: single women can fulfill their desire for motherhood and by doing so they fulfill not only a "existential" need, but participate in the sanctified work of building the world, one block at a time.

In the internet era, women's access to multiple and contested rabbinical interpretations of single motherhood reconfigures the meaning of the "crossroad" of later singlehood and the hegemony of religious authority. At this crossroad, egg freezing among the dati leumi in Israel is 
far more than a technical procedure or a matter of women's expanding choices in a consumeroriented paradigm of assisted reproduction (Martin 2010; Romain 2012). Given the magnitude of the perceived threat that comes from increasing choice and autonomy, Orthodox rabbis' and policymakers' discourses about egg freezing acknowledge that fertility preservation is crucially engaged with the future of the Jewish people, rather than individual women's reproductive routes. Some prominent rabbis have sought to reassert their authority and to foreclose women's reproductive agency by side-stepping technical discussions of religious law and by leveraging an exclusionary discourse of "establishing the Jewish house." This rabbinical discourse encompasses women within family: as wives and mothers they assist men to achieve their procreative obligation to procreate and they enable their husbands and sons to dedicate themselves to the sanctified practice of textual study. Yet this gendered cosmology relies on childbearing within marriage to reproduce the hierarchal distinction within the Jewish house between "minds" and "wombs" (El-Or 1997). It is the preservation of this distinction that enables men to fulfill the divinely-ordained obligation to study and procreate - to engage in the sanctified work of building the world. In this critical age for religious Zionism and for observant women as they weigh their options, a growing cadre of ravakot stands at the threshold of the Jewish house and the building of future generations. As the next and final chapter explores, religious discourses about familial and national continuity proliferate among the broader Israeli public in unexpected ways. 


\section{Chapter Five \\ "LET ISRAEL REMEMBER": NATIONAL SACRIFICE AND THE LOGIC OF MALE CONTINUITY}

Let Israel remember, be blessed by his seed and mourn the splendor of his youth. - IDF prayer for fallen soldiers

No ram was caught in the thicket

For me.

I bound

And slaughtered.

God had no respect unto me -

He laughed. "Isaac" by Shin Shifra (Feldman 2010:11)

In 2002, a young soldier named Kevin Cohen was killed by Palestinian sniper fire while on patrol in Gaza. In the immediate hours following his death, Kevin's parents filed a court order to surgically extract and freeze his sperm through post-mortem sperm retrieval (PMSR), a medical procedure that enables harvesting of reproductive cells from a brain dead or deceased male. ${ }^{70}$ Kevin's parents claimed that their 22 -year-old son, though single, had spoken often of his desire to marry and have children during his army service.

Soon after enlisting in the Israeli Defense Forces (IDF) in 2005, Aidan Snir was diagnosed with cancer. Like many Israeli cancer patients, the young man banked sperm samples because chemotherapy is known to impair fertility. ${ }^{71}$ After his death, Aidan's parents declared that he had spoken to them about the posthumous use of his sperm - he had even written about this possibility on social media, "A liter of security, before they start to drip all kinds of disgusting substances into my body, I asked (also was asked) to drip the future generation into a cup that would stay in the sperm bank... and when we finished the business, I offered my parents their grandchildren inside a little plastic cup." ${ }^{, 72}$

Upon his return from a post-army backpacking trip in India, a young man named Baruch Pozniansky was diagnosed with cancer. Like Aidan, before he started chemotherapy, Baruch froze samples of his sperm. Shortly before his death in 2008, the 25-year-old man signed a 
"biological will." On the basis of that document, Baruch's parents fought to obtain the rights to their son's frozen sperm. Although, in each of these cases, the forms of consent, personal backgrounds and the circumstances of death differ, Kevin's, Aidan's and Baruch's parents shared the same desire: they sought to bring their sons' descendants into the world through posthumous sperm donation.

The tragic and untimely deaths of young men, particularly of those who fell in combat or who served the nation, provoke public identification with their stories, with the suffering of their families, and with futures that should have been. These futures, however, are not imagined as those of individual men, but of participants in the making of families, as husbands and fathers. Though, at first mention, posthumous conception may sound more like science fiction than the object of anthropological inquiry, as I explore in this chapter this unusual reproductive possibility affords insight into cultural understandings about the differences between male and female contributions to procreation and the making of family in Israel. In this context of violence and loss, these differences are both central to ideas about creating life and to narratives about kinship, sacrifice and memory.

This chapter examines continuity (hemshekhiut) as a gendered logic through which Israelis make meaning of tragic deaths of soldier-sons in an era when the ethos of national sacrifice is increasingly questioned. Continuity, as I will show, is not solely a biological or genetic substance (physical sperm cells), but is rather enmeshed in kinship ideologies informed by religious and nationalist cosmologies. Recent studies of male infertility in Israel have focused on the salience of men's genetic fatherhood and on ideas of kinship and lineage stemming from Jewish law (Carmeli and Birenbaum-Carmeli 2000; Goldberg 2010; Kahn 2000). While this scholarship demonstrates the stigma surrounding male infertility, it does not attend to questions 
about the meanings of male contributions to procreation or to the ways that the differential valuation of male and female procreative contributions shapes the logic of continuity and the relationship between family and nation. In contrast, I approach posthumous conception as a powerful narrative through which to investigate the tension between life/death underlying reproduction and the generation of family and nation in contemporary Israel. Even as women are inextricable from reproduction and "bringing children into the world" (reproducing Jews), my reading of posthumous conception suggests that men, alone, are the procreative agents of Jewish continuity in the family and the nation. My focus is not on the specific technologies and procedures that make possible posthumous sperm retrieval and subsequent reproduction, but rather on the multiple ways that this possibility brings together conceptual categories that shape the ground of the conceivable, and even the desirable.

My analysis of posthumous sperm donation builds on feminist anthropological scholarship concerning the production of power, value and difference in scientific and religious theories of procreation. Feminist anthropologists have attended to the ways that authoritative discourses about conception are shaped by cultural ideas of masculinity and femininity, while naturalizing difference and gender inequality. Emily Martin (1991) demonstrates the ways that stereotypes about sex roles in romantic relationships inform Euro-American understandings of biological processes in conception that are assumed to be natural and therefore separate from cultural influence. As it turns out, much more is at stake in the meeting of the egg and the sperm than an egalitarian romance of reproductive cells (and persons) ending in the birth of a baby. Calling into question the "facts" of biology, Martin argues that the construction of male sperm as active, individual, and heroic and the female egg as passive and wasteful reproduces a hierarchy 
of value between male and female reproductive processes and between male and female contributions to the nation-state.

The differential valuation of female and male contributions to reproduction in scientific discourses is also central to Western religious cosmologies. Carol Delaney (1991) contends that Judaism, Christianity and Islam share what she calls a "monogenetic theory of procreation." In this model, the male seed is the active, unique and divinely-ordained agent of conception while the female is constituted as a nurturing, passive and generalized field or vessel:

Paternity has not meant merely the recognition of a physiological link between a man and a child analogous to that held to exist between a woman and the child she bears.

Paternity has meant begetting; paternity has meant the primary, creative, engendering role, and it means the same thing whether the male is a human or God the father. If there is any difference between the two, that difference has to do with the difference between the human and divine realms, not the meaning of paternity. (Delaney 1991:11)

Whereas man, like God, is the author of life, women are figured as "secondary and supportive" - paternity and maternity are hardly equivalent in Western religious cosmologies (Delaney 1991:12). The monogenetic theory of procreation is not only central to monotheistic religious traditions but also to nationalist ideologies and the ways that the birth of the nation is conceived through gendered categories of fatherland and motherland, for example as "Father State" and "Motherland" in Turkey under Ataturk (Delaney 1995). In Turkish nationalism, it is the motherland that fosters attachment to the land and provides the shared substance of belonging (the womb), although not the essence of citizenship—in fact, Turkish citizenship is transmitted from father to children (Delaney 1995:186). Further, Delaney argues that, beyond the Turkish case, nationalist discourses deploy discourses of procreation and imagery of heterosexual intercourse and forced assault (including rape), "Because of their symbolic association with land, women are, in a sense, the ground over which national identity is played out" (Delaney 1995:191). Drawing upon Martin's and Delaney's insights, I demonstrate that in contemporary 
Israeli accounts of posthumous conception, male procreative agency is constructed through distinct language and symbolism that elevates male contributions while it encompasses and diminishes female contributions. This differential valuation is evident in the conjugal and generational dimensions central to the gendered logic of continuity, which expose a kinship ideology that locates family rather than individual as the basis of citizenship and the building of nation.

In the first part of the chapter, I explore the conjugal and generational dimensions of familial and national continuity. I consider the assumptions about male continuity, conjugal unions and generational ties that came to the fore in regulatory debates about posthumous sperm donation, leading up to the issuing of guidelines by the Israeli Attorney General in 2003. These guidelines permit posthumous sperm donation for heterosexual couples whether married or not; the existence of an intimate relationship between a man and a woman is understood as an "indication" of the deceased's intent and therefore overrides the absence of his explicit consent. However, the guidelines do not sanction posthumous sperm donation by men who are single at the time of their deaths. Put differently, the "right to parenthood" by the surviving female partner is recognized, while the "right to grandparenthood" by the surviving parents is not. Given the policies limiting posthumous sperm donation to heterosexual couples regardless of marital status, parents of young men without female partners have to make the case for these unlikely procreative unions between their deceased young sons and older single women, whom they had never met in life. By analyzing media representations of these cases, I show how these Israeli parents drew upon the symbolism of Jewish marriage rituals to reconfigure the dead and the living into an appropriate conjugal couple and to fashion an appropriate generational tie between grandparents and grandchild. I suggest that, through this symbolism, parents and other 
actors diminished the reproductive agency (and individuality) of the mothers-to-be while emphasizing the procreative continuity and uniqueness of the deceased young men.

In the second part of the chapter, I explore how the nationalization of male sacrifice is a key element in Israeli ideas about continuity and in the differential valuation of male and female contributions to procreation and making family. This differential valuation has gendered and generational dimensions made evident in the foundational Jewish-Israeli narrative of sacrifice (akedah), in proposals to establish a national sperm bank for enlisted soldiers, and in the association made between levirate marriage and posthumous conception. Drawing together Jewish and nationalist ideologies of continuity, these discourses demonstrate that "raising up" and "establishing" the sperm of the deceased is about much more than the bringing into being of one's descendants. I argue that in these discourses, the transmission of continuity privileges the exclusive procreative power of deceased, known men ("the living-dead") while encompassing single women within conjugal and generational relations. I conclude by suggesting that these assisted conceptions - at the threshold of life and death - illuminate the seed of gender inequality critical to the kinship ideologies that conceive the nation through family.

\section{THE Gendered Logic OF CONTINUITy}

Beginning in the mid-90s, medical centers throughout Israel began to receive requests made by family members to use the sperm of married and single young men whose lives had been cut short. ${ }^{73}$ Some of these requests, like the one made by Kevin Cohen's parents for postmortem sperm retrieval (PMSR), were made with little time for prolonged deliberations since this procedure is most successful when performed with 24 hours of death. Others sought to use sperm samples previously frozen by men undergoing fertility treatment or other medical 
treatments, including chemotherapy. Yet there was no law, regulation or directive on posthumous sperm retrieval or donation in existence. A Ministry of Health circular (34/92) instructed sperm banks to destroy banked samples of deceased men, unless a written request was made by his wife within a year of his death (MOH 1992:5.28). Another Ministry of Health circular (135/89) permitted men to bank sperm for purposes of fertility preservation for an extended period (e.g., before receiving radiation), but similarly directed sperm banks to destroy the samples of deceased men (MOH 1989:5).

In September 2002, a parliamentary committee on scientific and technological research and development held a hearing to address the issue of using sperm for artificial insemination after death. Spanning across disciplinary boundaries, the presentations of medical, legal, bioethics and religious experts raised complicated questions on a range of topics: individual autonomy, the meaning of consent, the right to parenthood, the right of the child, and the creation of single-mother families. While all of these issues are inextricable from one another, the guiding assumption that emerged during the hearing was that, even in the event of death, a manespecially one in a relationship with a female partner-would desire continuity and descendants.

One of the main quandaries that participants addressed was whether other surviving relatives, namely the deceased's parents, should be able to request posthumous sperm donation for men without female partners. As philosopher Asa Kasher (himself a bereaved father) explained to the committee, "I cannot describe to myself a way that there is more respect for man (k'vod ha'adam) than to establish his sperm in his life and in his death" (l'hakim lo zera b'hayaiv ve bmoto) (Knesset Committee 2002:6). Of the relationship between the deceased father and the living child, Kasher reasoned:

He will think of [his father], he will do his desire (ratzon), he will [carry out] his will, he will be part of his genes, he will go by his features, he will live according to his values. I 
cannot think of a more meaningful way, richer, fuller to honor a man in his death than to establish his sperm when it is possible to do [so]. (Knesset Committee 2002:6)

This statement reveals that "the establishing of sperm," a phrase which is widely used in discourses about continuity, encompasses moral, emotional and spiritual dimensions that link a future (male) child to his father. Thus even though a genetic or biological connection with the future descendent is an important aspect of continuity for many Israelis, it is not the sole essence. As I discuss in the second part of this chapter, continuity also conscripts the collective obligation to "honor a man"- particularly a man who has fallen for the nation.

Kasher declared that, whether a man had a partner or not, deference to the value of his continuity, even in the absence of explicit consent, trumps concerns about interfering with the individual choice and autonomy of the deceased. In fact, when asked by a politician and ordained rabbi from the Shas Party about whether in the absence of written documentation, a wife has the authority to decide whether her deceased husband would have consented or not, Kasher objected, "Is that how it is with the matter of levirate marriage (yibum)? Levirate marriage is [done] without documents" (Knesset Committee 2002:7). This provocative mention of yibum demonstrates the interdisciplinary reaches of these testimonies and the ways that domains of knowledge (religious/secular) are porous in Israeli public discourses. Here, a university-based philosopher steeped in liberal traditions draws upon legal codes from the Torah to bolster his argument about the morality of enabling continuity over concerns about individualistic autonomy. Levirate marriage in Jewish tradition is not a choice nor does it require the consent of the deceased: it is rather the collective obligation of a childless man's surviving kin (his wife and brother) to fulfill on his behalf. By referencing levirate marriage, Kasher locates the contemporary desire for continuity in a Jewish practice of posthumous conception originating thousands of years ago - a tradition in which the nation's destiny eclipses the autonomy, consent 
and choice of individual, childless men and their surviving female partners. Furthermore, it suggests that in the case of the tragic death of a young, single man the socially-sanctioned use of assisted conception to create his descendants, despite the obsolescence of levirate in contemporary Israeli life, justifiably reanimates the ancient rationality behind a kinship practice that emphasizes collective obligation over individual autonomy. ${ }^{74}$

While levirate marriage may provide proponents of posthumous sperm donation with a practice rooted in an ancient Jewish tradition, for others encouraging single motherhood is a source of discomfort. A social worker objected to the philosopher's position, raising concerns about the potential harm to the future child who would be raised by a single mother. However Kasher countered that many married couples get divorced, yet this is not grounds to limit them from having children. He suggested that any difficulties encountered might be overcome with proper psychological treatment. Following this exchange of opposing opinions between the philosopher and the social worker, the head of the committee posed a question, "What is the difference between sperm donation from a living man and sperm donation from a deceased man? The phenomenon of single mothers (tofa' at hahad horiot) is already a phenomenon that is socially anchored" (Knesset Committee 2003:7). As she understood it, whatever the source of the donation, a single mother would result. A woman who undergoes posthumous conception with her deceased partner's sperm would become a single mother. This is equivalent, in the committee head's formulation, to a single woman who undergoes anonymous donor insemination with a living man's sperm. Whereas the committee head equated these two possibilities, for other participants at the hearing the existence of a conjugal tie (or a cohabitating relationship) and the presence of a known, albeit deceased, father mobilized different 
understandings of these resulting single-parent families, articulated through discourses about continuity (hemshekhiut).

In the absence of a conjugal bond, some participants objected to the idea of selecting a mother for their son's child - a woman whom he had never met. In their opinion, this parental incursion infringed upon their son's autonomy and individual choice. One bereaved mother who opposed the use of posthumous conception to create grandchildren cautioned:

The decision of parents to bring a child into the world from a woman who the[ir] son did not know and did not choose seems to me to violate his autonomy. Perpetuating the memory of the son (hantzahat zakhar ben) who is no longer [alive] is one of the activities that is almost an obsession for parents...I don't believe that if this possibility is created there will be one family of bereaved parents that will let itself not make use of this opportunity. (Knesset Committee 2002:9, emphasis added)

Though she personally disagreed with the idea of choosing a woman to bear her son's child, this mother acknowledged the incredible difficulty that parents would face should posthumous sperm donation become an option. Bereaved parents are expected to embrace the cultural work of commemorating the nation's fallen - the option of posthumous sperm donation would only add to that "obsession."

Even as some questioned whether partnering with a single woman to participate in the project of “continuing his sperm” infringed upon a man's autonomy, the entangled logics of bereavement and male continuity came into tension with the stigma of single motherhood. For example, a lawyer from the Ministry of Justice summarized her institution's position:

We accept the assumption that the basic desire of most of the individuals in society is for continuity (hemshekhiut) and for existence after death. We know that the subject of procreation (hulada) and raising up offspring (heamdat tzeatzaim) is...valued in Israeli society....We see it also in the subject of in vitro fertilization, and in methods of artificial insemination, of which their use is widespread in society and also the issue of single mother families (mishpahot had horiot) that exist, which are not exactly the model of family that we recognize/know. (Knesset Committee 2002:12) 
Like other participants, the lawyer's statement employed expressions such as "raising up of offspring" (heamdat tzeatzaim) that are not commonly used in everyday speech. Instead, by drawing upon an alternative linguistic register these expressions evoke a formal, archaic sound. Further, this expression is suggestive of a sentiment of pathos when it comes to assisting the continuity of a man who cannot "bring children into the world" due to tragic circumstances. While the lawyer drew on lofty sounding language to affirm the "basic desire" for continuity, at the same time she grappled with what she understood to be an unwanted side effect of this assisted reproduction: the creation of a less desirable "model of family" headed by single mothers.

Other committee members recognized that the uncertainty of young men's lives made the Israeli situation unique, justifying the subordination of other ethical concerns. A representative from the Ministry of Health noted that Israeli society would support the desire of a surviving female partner to conceive in this way, "because this was the fruit of love (pri ahava) that was not realized and not a fruit of a test-tube (pri mavhana)" (Knesset Committee 2002:18). In her understanding, the intent to have a child born from a relationship of love is what makes this posthumous conception bearable. Similarly, she accepted the legitimate desire of bereaved parents to create grandchildren and rejected the notion that this course of action produced a "testtube" in contrast to the "the fruit of love" between a couple (as the bereaved mother suggested in her testimony). The representative argued that the desire of bereaved parents to have a child in this way was no less than the desire of a surviving female partner "because the dreadful phenomenon of parents burying their children is not the fruit of inheritance (pri nahaltan) of other countries" (Knesset Committee 2002:18). It was precisely the ever-growing number of bereaved parents in Israel that, for her, justified the need "to relate to these issues while 
exercising caution to see the whole picture." The September hearing took place in the midst of the Second Intifada (2000-2005), in the wake of deadly spring that witnessed a surge in suicide bombings and other terrorist attacks. For this participant, seeing the "whole picture" meant recognizing the uniqueness of Israeli suffering and the bitterness of loss.

\section{Conjugality as Consent}

The year following the Knesset hearing, the Israeli Attorney General issued guidelines permitting women to use the sperm of their deceased male partners (whether officially married or "known-in-public" - yedua b'tzibur), with or without their explicit consent. Throughout the document the female partner is referred to as a bat zug rather than a wife (isha), suggesting that it is not a formal marital tie that constitutes future procreative intent, but a romantic heterosexual relationship, broadly defined. ${ }^{75}$ The relationship between a married man and a woman (or cohabitation between unmarried heterosexual couples) served as evidence of the deceased's desire to have children. Only explicit disagreement of the deceased would provide grounds for prohibiting the posthumous use of his sperm by surviving female partners. ${ }^{76}$

Like the statements made by many of the participants in the parliamentary hearing, the Attorney General presumed that a man would eventually want to have a family — that is, "to bring children into the world."77 The introductory section of the guidelines relates posthumous conception to Jewish tradition, to its values of preserving the memory of the dead and providing for descendants and heirs, and to its emphasis on continuity and procreation:

The desire for continuity and for existence after death through descendants is a basic desire of the majority of individuals in society. A concrete expression of this desire can be discovered in the Jewish tradition and in Jewish law (halakha). The stories of the patriarchs in the book of Genesis, generation after generation-Abraham and Sarah, Isaac and Rebecca, Jacob and Rachel—revolve around their yearning for sperm (kmikhatam l'zera) and the fruit of the belly (pri habeten). In another sense, the establishment of the 
deceased's sperm is the basis for the levirate laws (yibum). It should be noted that the commandment to 'be fruitful and multiply' is the first commandment in the Torah. (Israel Attorney General 2003:2 section A.6)

In this striking statement, the Attorney General connects the desire of the majority of individuals in contemporary Israeli society to ancient Jewish traditions and Torah law. The yearning of the patriarchs represents the seed of this desire, which has been transmitted through the generations up until the present. In Jewish tradition, "seed" (also sperm) is synonymous with the idea of male continuity as a genealogical trajectory, generation after generation, while "fruit of the belly" is used in relation to women's personal desire for children as an essentialized desire of all Jewish women, but one that is not constructed as a genealogical transfer. In the Torah, levirate marriage is the obligation of a surviving brother and the deceased man's widow to establish continuity_ “that his name may not be blotted out in Israel" (Deut. 25): the deceased is considered the father of the child (see Weisberg 2009 for later rabbinical interpretations of levirate). ${ }^{78}$ The Attorney General's reference to both the divinely-ordained laws of levirate marriage (yibum) (Deut. 25) and to the commandment "be fruitful and multiply" relate the sanctified nature of this yearning to a textual precedent that associates paternity with continuity.

The parliamentary committee discussion and the Attorney General guidelines suggest that the liberal ideal of individual autonomy during life (and afterwards) does not always accord with the desire for continuity. Whereas autonomy is connected to control over one's body, the right to consent to medical procedures, and the choice of a spouse, continuity is associated with the collective perpetuation of life particularly in the event of untimely death. While discourses about autonomy, continuity and the deeper ideological traditions that inform them may sometimes overlap, they are also in creative tension with one another. As such, the "right to parenthood" as an established individual right in Israeli law (Shalev and Gooldin 2006) is not identical to the 
cultural logic of continuity and the notion of "raising up/erecting descendants," which is constructed as a shared familial and national obligation with deep roots in the Jewish tradition.

The guidelines for posthumous sperm donation, however, limit the collective enactment of continuity to the surviving female partner. Specifically, the Attorney General repeatedly denied the possibility that the deceased's sperm might make grandchildren for his bereaved parents. The guidelines are sympathetic to the desire of the deceased's parents, "Granted, the desire of parents to see the continuity of their sons is a human, natural and understandable desire, but parents do not have any legal status in questions of the fertility of their children" (2003:6.21). The Attorney General reasoned that parents legally did not have any say in the reproductive decisions of their children, either in life or in death: this would be an intrusion into the "private and intimate sphere" of conjugal life that should be prevented (2003:6.21). Despite identifying with their loss, the deceased's parents were barred in the guidelines from objecting to a surviving female partner's desire for posthumous conception and they were denied "the right to grandchildren." In this formulation, the relational autonomy of the couple is privileged while parental involvement in supporting (or preventing) continuity is prohibited. By limiting posthumous fatherhood to deceased men in intimate heterosexual relationships, the Israeli Attorney General discounted the tremendous salience of the generational dimension of male continuity, particularly in the context of war-related suffering and loss. Nevertheless, the guidelines suggest some degree of flexibility toward determining presumed desire on a case-bycase basis and by naturalizing continuity as a desire of all men (and their parents). Furthermore, by focusing on the actions, sayings and expressions or "indications" of the young man, the Attorney General left room for creative contestation. 


\section{Making a Match}

Given the Attorney General's guidelines restricting the use of posthumous sperm donation to surviving female partners, Kevin's, ${ }^{79}$ Baruch's and Aidan's parents faced a challenge: they had to make the case for their son's continuity through the creation of unlikely procreative unions between the deceased young men and older single women whom the men had never met in life. As discussed in the parliamentary hearing above, some of the participants had a strong reaction to the idea that parents would interfere with their son's intimate decision of a partner and with his autonomy. To make their case, parents reconfigured their sons' desire to have children within the normative Jewish framework of marriage, family, and generational relationships. By drawing upon the symbolism of Jewish marriage rituals, parents constituted their sons as desiring men and the older single women as desirable daughters-in-law. Through these rituals, the parents of the deceased fashioned a conjugal bond between the deceased and the living. At the same time, they established their proper generational relationship as grandparents, to the future child. As grandparents of the child (rather than parents of the deceased), they would impart a semblance of normalcy and "family," thereby sparing the creation of another singlemother family. Thus, what appears at the outset as an improbable relation between the living and the dead is rendered appropriate and even preferable: the single-mother family is unmade through the existence of a known father and a generational tie to his family.

Perhaps the most outspoken of activists when it comes to posthumous sperm donation is Irit Rosenblum, founder of the Tel Aviv based organization called New Family (also discussed in Chapter 3). Rosenblum has represented the families of Kevin, Baruch, and Aidan among many others. In a small country like Israel, individuals like this charismatic, boldly bespectacled lawyer play a central role in shaping public discourses on controversial topics. Through frequent 
appearances on television and radio programs and in professional conferences, Rosenblum's ideas and arguments, whether accepted or not, have become inseparable from the way the Israeli public has come to think about this emergent possibility. In what follows, I explore how the parents of the deceased together with Rosenblum, the lawyer who represented them, drew upon Jewish kinship rituals and Israeli ideals of family to constitute this exceptional reproductive route as acceptable and morally preferable to single motherhood.

Through print and television media coverage, parents shared their struggles against the state with the Israeli public. This largely sympathetic coverage helped these young men's parents naturalize their mission to bring into being their son's descendants through posthumous sperm donation to single women. The layering of linguistic and visual cues presented in media accounts restored vitality to the deceased. Television segments interspersed photographs, home movies, and voice recordings to portray young Israeli men enjoying typical activities, surrounded by "the guys" (hahevre) and hanging out with young women. For example, in a Channel Two television news segment (Mizrachi 2009), a still photograph shows Aidan posing on a pool ladder, barechested in swim trunks and sunglasses; in another photograph, he is seated cross-legged in a circle of male friends, playing a harmonica; in silent excerpts from home movies, Aidan goofily dances with a friend in front of a laptop; in another he sits with a stern face in his army uniform, a long-haired girl(friend?) drapes her arm around him and then rests her head on his shoulder. Together, these images of a young man immersed in usual preoccupations of his peers reanimate him while simultaneously giving viewers the feeling of a life cut tragically short.

Narrative voice-overs and reporters' synopses bolster this imagery, using colorful language that invigorates the deceased. For example, in a television segment about the legal battle waged by Baruch's parents, the newsroom host introduces the young man, "Baruch 
Pozniansky, just (rak) 25 [years old] when he passed away from a difficult disease, a guy (bahur), young (tzair), and tall (gavoa) and a smiler (hiykhan) surrounded by love and friends" (Glick 2009). In this introduction, Baruch, like Aidan, is represented in the images that follow as a popular and attractive young man. He is shown in uniform playing video games with fellow soldiers, at an outdoor picnic with friends before his departure to India, and on the six month trip standing alone in nature, with outstretched hands, the mountains rising behind him in the distance. ${ }^{80}$ These accounts help to produce empathy amongst the public for the families of the young men, while constructing the physical and emotional qualities that would have made them attractive romantic partners.

More than promoting compassion, these media accounts constituted the deceased young man and older single woman, who had never met, as appropriate matches for one another. In television appearances and newspaper interviews, parents drew on the trope of matchmaking (shiddukh), as they constructed (older) single women into desiring and desired young girls. Three elements of creating an appropriate match are discernible in these accounts. I separate them here for analysis, though in these accounts they intersect. First, a pool of female contenders is evoked, always in the plural. By creating the many women attracted to this opportunity to have a child from a known source, parents naturalized posthumous sperm donation by highlighting the attractiveness of the young man and the demand for this otherwise exceptional reproductive route. For example, Rachel Cohen, Kevin's mother, recounted receiving “a wave of inquiries from women" after a newspaper ran a story about her mission to preserve her son's continuity (David 2006). When interviewed on Channel 10 news, Kevin's mother told a reporter, “There were many girls (banot), it wasn't just one young woman (bahura), at the time there were about 
200 women (bahurot) who called me, [who] knocked on my door" (Lior 2007). Similarly, Yulia Pozniansky, Baruch's mother, explained to a reporter:

We approached the single mothers' forum, and many women (bahurot) contacted us through the internet. Women (bahurot) who thought to make a child and they saw the opportunity to make a child from a known family from a known man (mi'mishpaha yeduah m'ben adam ydua). (Glick 2009)

These mothers emphasized the many women who showed interest in this arrangement and contacted the family: the use of the word "many" naturalizes women's desire to become mothers in this way and generalizes their desire. The quantity of inquiries and the direction of inquiry ("they contacted us") bolster the young men's desirability, transferring agency from the parents to the contenders.

Second, the female contenders receive a linguistic anti-aging treatment, shifting emphasis away from a woman's biological age and marital status to her symbolic position as a bride. The mothers' choice of words such as "girls" (banot) and "young women" (bahurot) to describe women conspicuously older than their young sons is significant: most Israeli women trying to becoming single mothers are in their late 30 s and above. ${ }^{81}$ Normative heterosexual relationships in Israel are commonly imagined to involve two individuals of the same age range, or else a younger woman and an older man. Thus the resulting age difference between the deceased and the living reverses the expected age-gender nexus, generating a potential source of uneasiness. By constructing the many desiring women as young women, they are remade into appropriate matches. The use of these synonyms also directs attention away from the possibility that the chosen woman was closer in age to the man's parents than to him (e.g., if she is 40 and the parents are in their late 40s/50s). Thus, by replacing "single women" (ravakot) with "young women" (bahurot), stigmatized associations about gender, age, and marital status are weakened. 
Third, only one woman is selected as "the right woman" from among the many desiring and appropriate young women. The chosen contender has the personal qualities that make her a suitable match for the deceased and future mother to his child. After focusing on Baruch's vitality, a Channel Two segment turns to a meeting between Baruch's parents and the chosen woman, her face digitally obscured. An apartment door opens and an upbeat piano melody replaces the more contemplative music in the background soundtrack. The parents enter as though they were in-laws coming to visit for a meal, carrying a dish of homemade food as they warmly greet the future mother. In the next cut, the parents sit together on a sofa in the living room; empty plates containing remains of the meal rest on the coffee table, separating the couple from the intended mother. Baruch's mother says to the woman (and to the reporter), "When I saw her, I thought to myself, Baruch would have chosen a [young] woman (bahura) like [her]. He loved petite [women] and strong, like you, and pretty" (Glick 2009). Baruch's father adds, "I didn't even dream of a fit (ha'atama) like this" (Glick 2009). Even as this woman is the "right" one, Baruch's parents emphasized that he would have chosen her: it is his choice that makes her the right one.

In creating the suitable match, parents carefully avoided overstepping their deceased sons' autonomy. After receiving the praises of Baruch's parents, the intended mother responds to them, "Your dream is your dream, I really hope that he there (sham), also agrees with the choice" (Glick 2009). Objecting to the woman's mention of Baruch in the present tense ("he agrees"), Baruch's mother says quietly, "Why should we speak of him, I don't know what he thinks" (Lior 2007). It is one thing to speak of the deceased's preferences in the hypothetical "would have," but quite another to speak of him in the present tense. On the other hand, Kevin's mother explained the match not as her son's choice, but as one of divine will. Of the chosen woman she 
says, "[She is] a very charming young woman (bahura), I think that G-d (hakadosh barukh hu) sent her to me. That's an inner feeling" (Lior 2007). As she speaks, the camera zooms in on a gold star-shaped pendant around her neck, a portrait of Kevin etched in the center, visually reminding viewers that the match is between the young man and the intended mother (and not between his parents and the woman). While parents sought to naturalize the match as a suitable one, they diminished their agency in "choosing" the right one.

Part of constructing a suitable match between the living and the dead requires demonstrating a meaningful connection between the intended mother and the deceased man's parents (and especially the future grandmother). In fact, as part of the lawsuit against the Attorney General, the deceased's parents and the intended mother would be observed together by Israeli social services. As such, the warmth and closeness of the in-law relationship is a vital component in demonstrating the mutuality of the participants and naturalizing the intentions of all parties. ${ }^{82}$ For example, Kevin's mother said, "I saw in her eyes, I felt that she is brave and wise and she knows what she wants [desires]. There is special chemistry between us...she says she even wants me in the delivery room, so I can hold her hand" (David 2006). Part of her suitability is her bond with the mother-in-law, who will take the place of the absent father (or of her close kin as happens often in single mother's birth plans). Similarly, Baruch's mother explained, "There was chemistry between us, already from the first moment" (Magnazi 2011). Of this bond, Baruch's mother said, "She fits us like glove to a hand. She is suitable to be the mother of our grandson...We know her parents. We talk all the time" (Linor and Adelson 2009). Here speculation about what the son's preferences might have been fades as these mothers-inlaw produce the woman's suitability to become "the mother of our grandson." Both mothers mention chemistry and an immediate sense of embodied connection through hands and physical 
touch to explain and naturalize the distinctiveness of the bond. These representations also align the future kinship relationship between the mother and grandparents, who through their participation in the doing of family_attending the birth, sharing meals, and remembering the dead-will become her in-laws.

Once the match is made between the families and alignment of desires is in place, a conjugal bond is made between the deceased parents and the mother-to-be. The announcement of a favorable decision four years after Kevin's death marked the first time an Israeli court permitted posthumous sperm donation from a known, unmarried donor to a woman who was not his partner. The press conference held on this occasion, at the offices of New Family (the legal organization founded by Rosenblum that represented the Cohen family), called upon wedding symbolism. In fact, the television reporter began the segment, "at this celebration, the joyous groom will not [attend] (hahatan hasameh lo yihiyeh)" (Lior 2007). By referring to Kevin as a "groom," the viewer infers that there is a bride (kalah). Inside the office, we see a woman (the bride?) alongside Kevin's mother, who opens a bottle of red wine. The two of them stand above a large framed portrait of Kevin resting on a table. The cork pops, and the voice-over continues, "He died four years ago from Palestinian sniper fire" (Lior 2007). Kevin's mother and the unnamed woman, wearing white blouse and vest, clink their glasses of wine together with their lawyer as Kevin's mother says, "that we'll hold the baby, with the help of G-d (b'ezrat hashem)" (Lior 2007). This celebration, despite the groom's absence, with the toast of wine glasses recalls the blessing over the wine, which is recited in a traditional wedding ceremony (see Goldberg 2003). Later in the segment, Kevin's mother sits in a small office with Rosenblum, who reads the court ruling out loud. The cadences of lawyer's voice are suggestive of a rabbi chanting a marriage contract (ketubah), which is done as part of a typical Jewish wedding. 


\section{“A Family Envelope”: Encompassing Women's Reproductive Agency}

In June 2013, another first for assisted reproduction made headlines: a baby girl was born to a father through posthumous sperm donation to an unmarried Israeli woman. In this case, the parents of a young man, who had frozen his sperm before dying at age 30, did not have written consent from their son. Nevertheless, they obtained court permission to donate his sperm to a single woman. In a newspaper story about the unusual circumstances of this assisted conception, elements of the symbolic tropes involved in making a suitable a match converge. Of the special connection between the parents of the deceased and the mother (referred to by the initial "A"), their lawyer, Irit Rosenblum, commented, "The connection between them and A was from the beginning special, exceptional. From their conversations, Nitai's (not his real name) mother told me that according to them, if Nitai would have brought a woman home, she would have been very similar to A" (Avramov 2013). A is rendered a proper match: she has the characteristics and personality that Nitai himself would have chosen. This statement affirms the deceased's autonomy within this procreative union as it diminishes the role of his parents in making the match. The relationship created between the intended mother and the grandparents becomes akin to that between a daughter-in-law and her in-laws; it is this "special" and "exceptional" connection that becomes the basis for the family that $\mathrm{A}$ is joining.

Even as the intended mother's suitability is highlighted, this report of the "first" posthumous conception between a deceased man and a single woman designates the young man and his parents as the locus of reproductive agency. Concomitantly, A's involvement is limited. For example, "the parents who lost their son decided to choose a woman who would carry his daughter in her womb (tisa b'rhemah)" (Avramov 2013). It is the parents who "choose" and "decide"; the son is constructed as the sole parent of the child ("his daughter"); the woman will 
"carry" the man's child in her womb. The emphasized purpose of this conception is not so that the woman can fulfill her desire to become a mother. Rather, it is to enable the parents to have "a grandchild (nekhed) who will continue Nitai's way (ymshikh et darko shel nitai)" (Avramov 2013). In return for "carrying" their grandchild, the parents "intend to give her a warm and supportive family envelope (ma'atefa mishpahtit - also a cover or wrapper)" (Avramov 2013). Here, the assumption is that, on her own, the woman and her child are not a family; it is only when enveloped by Nitai's parents that they become a family. Although a mother is needed for the future grandchild, producing "his" descendant involves enclosure within his family and the foreclosure of her reproductive agency. In this "first" case of posthumous conception with a single mother, the deceased's continuity is secured by elevating his procreative contribution and by emphasizing the generational relationship of his parents to the descendent.

At the same time, encompassing Nitai's child and A within a family naturalizes the intentions of the deceased's parents to bring a child into the world through posthumous sperm donation. Irit Rosenblum, their lawyer, comments on this model arrangement:

A is a regular, natural mother. And that's the beauty [of it]. When I called her before arriving, Nitai's mother was just [then] babysitting. Maybe Nitai is not there, but his presence is there in photographs in the living room and in the presence of his family members. That is as close to something complete. A. said to me, "this is as close to the real thing." (Avramov 2013)

According to Rosenblum, not only do the deceased's kin appear to have the sole authority to make a family, in doing so they render the woman's motherhood "natural" and "regular"-as opposed to the adjective "artificial" that is often used to characterize assisted reproduction. In the absence of a conjugal tie, it is the presence of the deceased man through enduring artifacts, his surviving kin and their intergenerational relationships that make A. - a single mother-part of a family that is as close to something "complete" and "real." 
Supporters of posthumous conception tend to focus not on the absence of the deceased father in the future child's life, but rather on the difference between conceiving from the sperm of a known man and taking sperm from an anonymous donor. Through this distinction, they foreground what they understand to be the moral benefit of these unions. In her interviews and her writing, Rosenblum has emphasized the ways that posthumous conception from a known man offers single women a better option than going to the sperm bank. For example, in a television news interview following a court ruling in favor of Baruch's parents, Rosenblum told Geula Even, the interviewer:

Irit Rosenblum: Now, it must be understood that in effect, the big thing that we did here, it's that we opened a new option for young women (nashim tzairot) who want to conceive (l'herot) and the only option they have, for those single women (ravakot) is taking anonymous sperm (netilat zera anonimi) here we... are giving an incredible option (optzia madhima).

Geula Even (interjecting): What, there is a family to the deposit of sperm?

Irit Rosenblum: To the deposit of sperm there is a family. There is an identity (zehut). It's not anonymous; the child who is born will have a grandfather and grandmother. He will have uncles [and aunts]. He will have a family, spiritual and emotional support. He will have a biological record. (G. Even 2011)

Rosenblum focuses on what the child will have by knowing the identity of the donor: grandparents, uncles, and a family. The underlying presumption about single motherhood through anonymous donor insemination is that women "take anonymous sperm" because they have no other option to become mothers (see for example Rosenblum 2010:23). Posthumous sperm donation from a known donor overcomes the negative reproductive agency of "taking" sperm, by "giving" women a better option. The interviewer's comment suggests that, like her, Israeli viewers might deduce from the coded language of "taking" sperm that, in the context of posthumous conception, a better alternative to anonymous insemination is the connection between "a deposit" and a family to which it belongs. Rosenblum's answer implies that without 
an "identity," the much more typical option (taking from anonymous donor) is a transaction that is not productive of "family" and of the "spiritual and emotional support" it provides. Although Rosenblum advocates the right to know one's "biological record," her many statements on posthumous conception reveal that, in her thinking, access to this knowledge is not the sole benefit of this "incredible option."

Besides Irit Rosenblum, other supporters of posthumous sperm donation have made similar statements about this option as an alternative to the anonymity of the sperm bank. For example, when asked by a reporter about "the good of the child" the father of a young man whose family received court-ordered post-mortem sperm retrieval (PMSR) with the assistance of New Family replied:

The child (son) who is born will [have] a wide and more supportive family than a child who is born to a woman who received a sperm donation from an anonymous father from the sperm bank...there is no doubt that this is a better alternative for the child. (Zarhin 2011)

Again the sperm bank is figured as a less desirable option. Similarly, a journalist asked another bereaved father and advocate of posthumous conception, "Is it not a little egotistical...to bring an orphan (yitum) into the world to preserve the memory of a fallen [soldier]? The father answered:

We can imagine that among such a large group of single mothers, there will be enough women (bahurot) who want to have a child through the sperm bank, but not [from] an anonymous father, rather [from] a man [through whom] she receives a warm and loving family, [she] knows who he is and from where he comes. (Torres 2009)

By referring to the resulting child as an "orphan," the reporter implies that neither the mother nor the grandparents are relevant to the construction of the child's status as parentless. However the father counters by extending the goal of posthumous sperm donation from the bereaved parents' goal of preserving an individual's memory to the larger social purpose: these assisted conceptions will provide a group of single women with "a warm and loving family" and alleviate 
the creation of more single-mother families. Together these comments in support of posthumous conception demonstrate that a known father, even in his absence, makes a family. On the other hand, an unknown source lacks both an identity and a family and is therefore not productive of relations.

This understanding of posthumous sperm donation as generative of family has received institutional recognition in Israeli courts. In the case of Aidan Snir, the court ruled in favor of the plaintiff, a 39-year-old woman who wanted to become a mother by using the young man's frozen sperm. Of the unique circumstances in the case, Judge Alon recognized that "there exists a fear that the child will serve as a monument (gilad) to his father" (New Family v. Rambam Medical Center 2009:5). In her written statement the judge weighed the considerations for and against posthumous conception from a range of perspectives including legal, psychological, philosophical and Jewish law. However, she ultimately concluded that the various interests of the involved parties - the deceased, his parents, the intended mother and future child — all overlap in favor of this option. She wrote first, of Aidan's interest "the victory of life bubbling inside him and in a continuing generation that will carry his name"; second, of the intended mother's interest "to realize her parenthood in a close family [that] as much as possible [will] give a traditional family structure"; third, of Aidan's parents' interest "to realize their grandparenthood and to complete what they understand as their son's will"; and finally, of the interest of the future descendant to "identity, belonging to a family, a loving mother who awaits his arrival, and grandparents who wish for him” (New Family v. Rambam Medical Center 2009:24). In this precedent-setting decision, "the victory of life" originating in a young man and transmitted by the future generations that will "carry his name" engenders the making of a "traditional family structure." By drawing upon this powerful logic of male continuity, the case ended in a victory 
for Aidan's parents, overcoming the Attorney General's guidelines (2003) that limit posthumous conception to surviving female partners.

\section{Elevating Men's Procreative Contribution}

In Israeli accounts of posthumous conception, male procreative agency is produced through distinct language and symbolism that diminish female contributions to reproduction. This language significantly differs from commonly used expressions about conception and pregnancy. In everyday speech, the expression "to bring a child into the world" or "to become (literally: to enter) into pregnancy" are two of the most ordinary ways of talking about conception and pregnancy. The first expression is used by men and women in a wide variety of contexts. While "child" is always masculine (yeled) and thus the result of conception is gendered, male and female procreative agency both men and women may "bring" a child into being. The second expression, "to enter into pregnancy" is used when talking about women and, in more recent discourses, about couples. In contrast, discourses about posthumous conception employ ways of speaking about procreation that are uncommon in everyday Hebrew.

Women's contributions to conception are diminished by the expression "to conceive from his sperm" (l'herot mizero), used widely in the accounts of posthumous sperm donation. Unlike the commonplace expressions mentioned above, here reproductive agency is derived entirely from the male contribution (his sperm/seed). For example, after a court decided in precedentsetting ruling in favor of Aidan Snir's parents in 2009, one newspaper headline declared “A Woman Will Give Birth From the Sperm of a Soldier whom She Didn't Know and who Died from Cancer" (Ettinger and Aiadat 2009). In the article, the woman's identity and motivations were summarized, “Eight months after [Aidan's] death, a single woman (isha revaka), a 39-yearold accountant, approached his parents, and offered to conceive from his sperm (l'herot mi zero) 
and to raise their grandchild." ${ }^{83}$ Together, the absence of the woman's details and the use of this expression undermine the little agency she is accorded (she "approached" and "offered"). In stories of posthumous conception variations of this expression such as "to conceive from his sperm" and "will give birth from his sperm" ricochet throughout the Israeli media. Without names, identities and life stories, women are not figured as co-creators. Instead, their bodies are discursively reduced to vessels that anonymously conceive from life-giving sperm. This example extends Delaney's argument about the "monogenetic theory of procreation" through death: in his absence, a deceased man is still regarded as the singular creator of life, and male seed remains potent even after its originator's physical demise. In fact, of his desire to become a father posthumously, the judge who ruled in favor of Aidan Snir's family wrote, "[he really 'created' (bara) his children through his writings even before they came into the world" (New Family v. Rambam Medical Center 2009:4). Aidan's statement in the introduction to this chapter is an excerpt of his writing on an internet forum and a website for cancer patients that Judge Alon cited in her decision. As the judge's statement about Aidan's online writing makes explicit, here the exclusivity of authorship and generative power converge as Aidan's creation (see Rose 1993).

In addition to the use of uncommon expressions, discourses of posthumous conception in Israel employ a range of representational means to elevate the procreative agency of the deceased young man, while negating the living woman's role in the process. In the accounts above, the young man is named and his life — made vivid through the layering of visual and audio clips — is the center of the story. His voice and photographs enable a glimpse of him in the world of the living. In contrast, the living woman becomes the anonymous recipient of the known father's sperm: she is unnamed (or sometimes assigned a first initial) and when shown, her face may be 
digitally blurred and parts of her body receive the camera's focus (e.g., hands, back of her head). Her age and employment may be mentioned, but these are generalized (e.g., an accountant). Although anonymity and the blurring of identifying details may be a means to protect the woman and future child, the stark contrast between what is known and even celebrated about the father's life and the absence of any personalized information about the intended mother lessens the significance of her participation. In these representations of posthumous conception the differential valuation of the father and mother and their gendered contributions to procreation is critical to activating the cultural logic of continuity. Women's bodies are figured as passive, generalized (and unnamed) vessels that nurture the sperm, producing "his descendants" and "their grandchildren." While the future mother is chosen from many contenders, her maternityhowever morally-commendable - is never equated with the paternity of the deceased and his unique generativity.

These slights of language serve not only to diminish women's procreative contributions and reproductive agency, but also to unmake "single" mothers. In media accounts, the young man's parents, and their mothers in particular, are central actors; like their sons, they too are named and their participation in memorializing the deceased is central to the transmission of his continuity and memory. In contrast, the woman's family is entirely absent from the story; it is rarely mentioned whether she has any kin—a silence which serves to constitute her as alone. By constructing the unnamed woman as without kin, the happy ending can be readily imagined: by becoming a mother through posthumous sperm donation she and the future child will receive a family and the young man's sperm will be the source of life, identity and continuity. 


\section{Posthumous Motherhood and Continuity?}

"The victory of life" channeled through male continuity raises the question: is there an analogous cultural logic of female continuity? A month after Baruch's family received permission to use his sperm, another story made headlines in Israel. This case involved a married couple who had struggled with infertility for many years, undergoing in vitro fertilization and other treatments until a tumor was discovered in Karen, the wife. Prior to her death from cancer at the age of 35, Karen signed a will that granted her husband, Nisim, the right to use their frozen embryos to have a child. After she died, her husband fought the Ministry of Health to use their frozen embryos. Nisim won the case, and eventually contracted with a surrogate mother in the United States to carry the embryos. (The Israeli law limits the use of surrogacy to married couples, but both spouses must be alive.) In June 2011, for the first time in Israel, a woman became a mother two years after her death through a gestational surrogate (Regev 2011). Nisim travelled to New York for the ritual circumcision (brit milah) of their son and returned with him to Israel.

Even as the media celebrated Nisim's determination to bring about Karen's lifelong wish to become a mother, media accounts did not categorize this instance of posthumous procreation as one that enabled her continuity. Instead they attributed this conception to "fulfilling her dream of bringing a child into the world" and described her husband's mission "to fulfill Karen's dream" (Channel Two, June 13). In an interview Nisim said, "I am happy that I succeeded to fulfill (l'hagshim) her last wish" (Regev 2011). As his lawyer, Irit Rosenblum, put it, "it wasn't only fulfilling Karen's dream, but also Nisim deserves to be a father (magia lo li'hiot av)" (Channel Two, June 13). As discussed in Chapter One, motherhood is considered "fulfillment" (hagshama) - rather than individual choice — when it is encompassed within collective purpose. 
Although the idea of motherhood as fulfillment shares the dimension of collective purpose with continuity, this case suggests that the term "continuity" applies primarily to male procreative contributions, namely to the continuity of sperm/seed (zera) rather than maternal contributions. Rosenblum said of the newborn boy, "He was born within a complete and full framework (misgeret) of life (Channel Two, June 13)." By "framework," the lawyer was referring to the family—his father, grandparents and extended kin from both parents' families—who welcomed the child into the world. ${ }^{84}$ In this case, by becoming a father by using the embryo made with his sperm and his deceased wife's egg, Nisim helped fulfill Karen's motherhood and create a "complete and full" family. The resulting family was not described as a single-parent family nor was Nisim referred to as a single father.

Rosenblum (who had also represented Baruch's family) compared the two cases of posthumous parenthood. Of the young man's case, she remarked, "[Baruch] wrote a biological will in which he requested to continue his sperm (lehamshikh et zero)...it was impossible [for the court] to oppose the written desire...that a man wants continuity" (sh'adam rotzeh et hemshekhiut) (Channel Two, June 13). Earlier in the television interview, the lawyer had emphasized Karen's posthumous fulfillment as a mother, while of Baruch, she celebrated the posthumous continuity of his sperm/seed. While fulfillment, like continuity, is connected to the deceased's desire it does not appear to have unique, generative essence that is productive of relations. Given the connection between male "seed" and "continuity," is there a difference between a couple's embryos, as in the case with Nisim and Karen, and an unmarried woman's oocytes?

In 2011, a seventeen-year-old girl named Chen was hit by a car while crossing the road in Kfar Saba (Channel 10 News, August 7). ${ }^{85}$ After several days, doctors declared her brain dead 
and her parents agreed to donate Chen's organs. However, her parents also filed a precedentsetting court order to extract and freeze their daughter's eggs with the hope of donating these to an infertile woman. ${ }^{86}$ Her parents also asked that some of the eggs be fertilized with donor sperm as frozen embryos are more likely than frozen eggs to result in pregnancy, although the court did not grant them this request (D. Even 2011). Of the donation to another woman, Chen's mother said, "If I will see that her eggs are fertilized in someone else - that is my daughter. That is my daughter. That is the only miracle that can happen to me" (Channel 10 News, August 7). Later in the segment, a reporter asked her, "The question is whether you also see yourself at some point raising your grandchild?" Chen's mother replied, "Why not? Why not? I will only live another 100 years" (Channel 10 News, August 7). While having a grandchild through assisted reproduction might create life after devastating loss (as discussed in Chapter 2), Chen's mother did not claim that her daughter's eggs would enable her daughter's continuity. Her words imply a kind of spiritual continuation of Chen's life through the lives around her as her daughter's eggs may create a "miracle." Yet it is unclear whether deceased women's eggs contain the same generative power that is explicitly ascribed to deceased men's sperm. Can a woman's eggs when not part of an embryo made with her partner's sperm produce family and continuity? The answer to this question may have to wait: Radio Galgalatz reported that Chen's parents eventually decided to destroy their daughter's frozen eggs.

Questions aside, these two cases of women's posthumous motherhood provide two important observations about the differential valuation of male and female procreative contributions. First, a married woman may "fulfill" motherhood after her death. Second, eggs from a deceased, single woman may be productive of a kind of double miracle when donated to a childless woman. Yet, these cases do not indicate whether female contributions, while productive 
of fulfillment and miracles, are generative of continuity and of family on their own. ${ }^{87}$ In the next section, I examine the logic of continuity in relation to Israeli ideas about family and nation. Specifically, I ask: how are national sacrifice and memorialization enlisted in the hierarchal valuation of male and female contributions of procreation? What does this hierarchal valuation reveal about cultural understandings of family that are critical to the idea of the nation?

\section{“LET ISRAEL REMEMBER": NATIONALIZING CONTINUITY}

In many militarized societies, nationalist cosmologies hold that men give their lives so that the nation may live. George Mosse (1990) traces the rise of the "cult of the fallen" and the intertwined Christian and nationalist imageries of masculinity, youth and sacrifice in European nations from the eighteenth century through the Second World War. The power of this imagery eventually converged in building of tombs for "the unknown soldier" throughout Europe, which became "a convenient and central place for the cult of the fallen" (Mosse 1990:96; see also Anderson 2006[1983]:9-11). Yet, even as the cult of the fallen increasingly privileged the contribution of the individual soldier (Mosse 1990), it was the very absence of the deceased and the symbolic power of the unknown soldier that came to stand for the nation and generalized sacrifice: the individual (male) citizen dying on behalf of the nation — the giving of a part in place of the whole (Handelman and Shamgar-Handelman 1997).

In Israel, war-related loss is a key dimension of civil religion to an extent that "memorialization of the dead is such a central leitmotif in Israeli political culture that it has evolved into a national cult (Aronoff 1999:43). Commemoration of the dead punctuates the national holiday cycle; memory books, songs and poems memorialize the fallen; and official monuments and private memorials to the dead are found across the natural and urban landscape (Ben-Amos 2003; Bilu and Witzum 2000; Handelman and Shamgar-Handelman 1997). Yet, in 
contrast to the European ideal of national sacrifice represented in the tomb of the unknown soldier, this form of anonymous memorialization is entirely absent in Israel "because Israelis claim that all soldiers are known and that each is known by his name" (Handelman and ShamgarHandelman 1997:118, endnote 8). Not only is each Israeli soldier known by his name, but in his

death he is also tied to parents' names, which are inscribed on his gravestone. ${ }^{88}$ The significance of being known, of having a name and of being connected to the preceding generation is central to Israeli practices of commemorating the fallen and to the cultural logic of continuity.

\section{A Silver Platter and National Sacrifice}

In Israeli foundational narratives, the possibility of rebirth and collective continuity is established through acts of national sacrifice. Among the first generation of Zionist pioneers (halutzim), the shame of passive death in the Diaspora as victims was replaced by an ideal of active sacrifice for the Land of Israel; this entailed a gradual shift from the tradition of religious martyrdom in the name of God (k'dosh hashem) to a secular formulation of national heroic sacrifice through death for the motherland (moledet) (Feldman 2010). These heroic sacrifices brought about life for "in dying on the soil of the Land, the halutzim did not die, because a 'beautiful death' replaced mortal life with immortality” (Neumann 2011:93). This collectivized immortality had material and spiritual dimensions: the blood of the fallen pioneers watered the earth, turning infertile land into productive soil and consecrating Jewish territory (Neumann 2011:93). In these decades, sacrifice for the collective engendered the immortality of the Jewish people in the Land of Israel (eretz yisrael).

The ideology of a noble death became nationalized after the War of Independence and the establishment of the State of Israel through the "1948 generation" (the children of the pioneers). For example, Natan Alterman's famous poem, “The Silver Platter” (magash hakesef) (1947) was 
written as a response to a statement made by the first president of Israel that the nation would not be handed to the Jewish people on a silver platter. In Alterman's poem, when the nation (ha'uma) asks a young couple (a boy and a girl) existing between life and death "Who are you?" they answer, "We are the silver platter on which the State of Jewish was given to you" before falling to their deaths at the nation's feet. "The Silver Platter" became iconic through its recitation at official memorial ceremonies. Although the givers of life in Alterman's poem are a boy and a girl, representing the entirety of Jewish youth, the nation's fallen soldiers are almost entirely men and the very idea of a "fallen soldier" is always represented as a young man, whose "death in combat ...[was] exalted as the apotheosis of life" (Bilu and Weitzum 2003:4). In fact, the culture halls found throughout the country which serve as memorials to the nation's fallen are called "Memorial to the Sons" (yad l'banim), symbolizing the soldiers' gender (male) and also his familial relationship (a son).

The loss of young Jewish men has occupied a central place in Israeli understandings of the relationship between family and nation. Scholars of Israeli history and society make a connection between family and bereavement: as young men die in battle, surviving parents (and other kin) join an ever-growing "family of bereavement" (mishpahat ha'shkhol); deceased or missing soldiers are referred to as "sons" whose tragic deaths are figured as parental sacrifice; bereaved parents become "living memorials" who carry on the memory of their soldier-sons (Bilu and Weitzum 2003:5; Zerubavel 2006:75). Of the link between the nation's fallen soldiers and family in Israel, Yael Zerubavel observes, "the sacrifice rhetoric also employed the family trope to convey intimacy in the new relationship between the fallen soldiers, their families, and the nation-state (2006:75). Yet the sacrifice of the soldier-son is conceived of not only through 
familial and generational relationships between parents and children, but in particular, in the relationship between fathers and sons.

The meaning of the silver platter and the patriotic ethos of sacrifice that developed in Israel from 1948 through the late 1990s is inextricable from the Sacrifice of Isaac (known in Hebrew as akedah - meaning "binding") (Ben-Amos 2003; Zerubavel 2006). The akedah is not only the foundational myth of Judaism (Abraham's promise with God, linking seed, patrimony and descendants) but is also considered "the deepest symbol of modern Israeli existence" and is also one of the most contentious (Sagi 1998:45), finding expression and contestation in Israeli art forms, including literature, poetry and theater (Berg 2006; Feldman 2010; Sagi 1998). Whereas in Genesis 22, Isaac is spared at the last moment, substituted by a ram as a test of Abraham's faith in God, in the classic Israeli akedah, Isaac the soldier-son willingly sacrifices himself on the nation's alter-there is no redemption through substitution. Despite key differences between the Biblical and Jewish-Israeli versions of akedah (see Feldman 2010; Sagi 1998), they overlap to fashion a master narrative about national sacrifice that binds together fathers and sons, while placing them in generative tension: first, as sons of one generation become the fathers/sacrificers of the next generation and second, as the goals of family continuity and national destiny are seemingly placed at odds.

In its total focus on generations of men, the binding power of akedah combines male sacrifice (fathers/sons) and continuity as it begets the complete exclusion of women as active participants. In Genesis 22, God commands Abraham alone to take his only son, Isaac, to Mt. Moriah: yet where was Sarah ${ }^{89}$ This absence from the definitive foundational story of faith has become a central theme in Israeli women's poetry and literature (e.g., Aharony 2007; Berg 2006; 
Feldman 2010; Hever 1999). ${ }^{90}$ For example, in the poem entitled "Isaac" written in 1962 by Shin Shifra in this chapter's epigraph:

No ram was caught in the thicket

For me.

I bound

And slaughtered.

God had no respect unto me -

He laughed. "Isaac" by Shin Shifra (quoted in Feldman 2010:11)

In this female poet's version of akedah, Sarah's sacrifice is not accepted by God-there is no substitution, only indifference and stolen laughter. Recall that in the biblical telling Sarah laughed when she heard God was going to bless her with Isaac. ${ }^{91}$

One of the most powerful examples of this gendered exclusion through akedah is found in David Grossman's highly-acclaimed novel To the End of the Land (Hebrew: Isha Borachat Me'besurah 2008). In this inversion of akedah, a mother named Ora acknowledges driving Ofer, her youngest son, to the frontlines: "I left him there. I left him for them. With my own hands, I did" (Grossman 2010:124). Though Ora willingly carried out this act, upon return to her house in Jerusalem she decides to escape from:

The deal that the army and the war and the state may try to impose upon her very soon, maybe even tonight. The arbitrary deal that she, Ora, agrees to receive notification of her son's death, thereby helping them bring the complicated and burdensome process of his death to its orderly, normative conclusion... Of course, the notice will be dispatched again immediately - she has no illusions. They won't give up, they cannot lose this battle, because their surrender, even just to one woman, would mean the collapse of the entire system. Because where would we be if other families adopted the idea and also refused to receive notice (besurot) of their loved ones' deaths? (Grossman 2010:105-6)

Ora flees Jerusalem and her expected maternal role (to wait at home for her son's phone call), instead forcing her former lover and Ofer's biological father, Avram, to travel with her to the northern border between Israel and Lebanon. From there, Ora and Avram hike the Israel trail southward toward Jerusalem. This trip is a classic symbol of territorial conquest in modern 
Israel. It is on this journey that the gendered inversion of akedah becomes the central problem of the novel: the transmission of continuity through memory. Ora is convinced that although Avram (the Hebrew version of Abraham) has never met his only son, ${ }^{92}$ he alone is capable of remembering Ofer's life, while she is becoming empty and forgetting. Indeed, throughout various scenes and turning points in To the End, Grossman plays with the Hebrew words zakhar - meaning both male and memory and nekva - meaning both female and empty orifice. ${ }^{93}$ As the novel unfolds, Ora narrates the story of their son Ofer to his father Avram, reversing the generational flow of memory. The fact that Ofer did not know his father threatens the transmission of male continuity through memory. However, Ora is wrongly convinced that through this inverted gender and generational transmission, she can keep Ofer alive (or at least) the memory of him. Even as Avram has never met his son, on the day Ofer enlists in the army, Avram makes a pact with God to spare his only son from death. Yet in this female-usurped akedah, there is no possibility of substitution nor can Ora escape her female role as mother/mourner.

Since the 1980s, Israeli society has experienced a growing ambivalence about the meaning and purpose of national sacrifice. This sentiment has intensified in the wake of the Second Intifada (2000-2005) and the Lebanon War (2006), as the loss of young lives enlisted in a protracted struggle with no end in sight is increasingly questioned by the Israeli public — an uncertainty captured by Ora's dilemma to stay in her house (and thus remain a mother/remain complacent) or to escape from this “nationalization” of her family, as Grossman' character bitterly pronounces this intrusion (2010:600). As their hike across the land ends, Ora and Avram realize the futility of their flight: just as they cannot give up their homeland for another, they cannot escape being hailed together as Ofer's parents into the national family of bereavement. ${ }^{94}$ 


\section{A National Family-in-Arms}

As the meaning of national sacrifice is changing, Israeli society has experienced an expansion of "personal commemoration" and "private models of bereavement and memorialization" (Bilu and Weitzum 2000:11). According to Bilu and Weitzum (2000) this shift in practices of memorialization represents the rise of an individualistic ethos in place of collectivist principles. Within this framework, posthumous conception might be viewed as an extension of this change in memorialization practices. As such, it fits the scholarly propensity to identify all changes as a confirmation of an overall process of "individualization" taking place in Israeli society, including the Israeli family (see Introduction). Although posthumous sperm donation valorizes the contribution of a known man and, particularly in the case of PMSR, goes to heroic lengths to retrieve his sperm for future use, I want to offer an alternative interpretation that takes into account the connection between family and nation evident in the cultural logic of continuity. My reading seeks to overcome the inclination in studies of nationalism to view discourses that relate kinship to the nation as metaphor (Delaney 1995). As Susan McKinnon and Fenella Cannell argue, "What is at issue here is not simply a 'metaphorical' relation (the nation is 'like' a family) but rather how particular cultural understandings about kinship, marriage, family, and relatedness organize, inform, and naturalize what will count as the nation and citizenship, and how these intersect (2013:24). In Israel, cultural understandings about family that inform the gendered construction of nation and citizenship span the threshold between life and death.

Studies of Israeli nationalism posit the idea that family is a "metaphor" for the nation particularly during war. By positing the metaphorical aspect of this relationship, the EuroAmerican assumption about the nation as a collection of individuals rather than families is 
reproduced. For example, in his study of Israeli nationalism Don Handelman (2004) suggests that during times of crisis, such as the Second Intifada, the rhetoric of "no choice" (ein breira) prioritizes concerns about collective security and survival above all else. During these periods, "the state is turned unequivocally into the Jewish State, the State for its Jewish citizens, and they become its nation-in-arms, its family-in-arms, its bereaved family uniting the living and the dead" (Handelman 2004:13). Perhaps because of his focus on bureaucratic events including official state ceremonies of memorialization, Handelman identifies the relationship between "the nation-in-arms" and the "family-in-arms" as temporarily mobilized for the occasion. This relationship between nation and family is rhetorically called into being through "the intimacy of metaphors of nation-in-arms, family-in-arms, bereaved family, [that] are crucial to the State's monopoly of physical violence" (2004:13). Even as Handelman recognizes that the relationship (albeit metaphorical in his analysis) between family and nation that underwrites state-sanctioned (and sanctified) death, he privileges the unit of the individual as the part that sacrifices for the nation:

The imagery of the homogenous nation-in-arms, taking shape in crisis, is also that of the sacrificing nation. In this self-enclosing nation, wrapped into and enrapt within itself, every member shares essential qualities of being a Jew with all others. This is more than a matter of persons identifying themselves with one another, for they are made the equivalents of one another. In this imaginary each person is in the virtual position of 'soldier,' synecdochal with the nation-in-arms. The part, the 'soldier,' embodies the whole, the nation-in-arms. (Handelman 2004:15)

The theory of the nation as a "homogeneous" entity with each part (the soldier) that can stand in for the whole (the nation) presumes a bounded political domain that is genderless. In Israel, this political domain is imagined to be constituted by the army and security concerns- - the domestic domain ("the homefront") is passive, in need of protection although it is occasionally summoned to support the army in times of crisis (Herzog 1999). Women are doubly excluded: among 
Jewish citizens not "every member" is equivalent or in the "virtual position of soldier"-women cannot be fighters and thus their deaths are not national sacrifices. Furthermore, the trope of akedah not only excludes women, but channels continuity, sacrifice and memory through generational relationships between fathers and sons.

Though synecdoche implies levels of inclusion (the part for the whole and vice versa), by resorting to the individual/nation model of Euro-American nationalism, Handelman's analysis ignores the gendered and generational dimensions of Israeli nationalism that become evident when the family, and not the individual, is taken as the basic unit of the nation. To sideline the analysis of kinship to metaphor is to ignore the relations of power and gender hierarchies reproduced through the work of memorializing the fallen sons through the ever-growing national "family of bereavement." What difference does it make to consider the sacrifice of the "soldierson" in place of the individual soldier? How is this difference foregrounded through the logic of continuity in Israeli accounts of posthumous sperm donation?

\section{Soldier/Son and Continuity}

Perhaps more than any other element of the deceased's life, media accounts of posthumous sperm donation emphasize the young man's contribution to the nation as a soldier. In fact, Kevin Cohen's case became known as “The Case of the Soldier's Sperm." Media accounts connected his death in combat and to his bereaved parents' quest to have a grandchild. A television segment on Kevin shows and names the place where he was killed by sniper fire in Gaza (Lior 2007). Newspaper headlines about Kevin featured his status as a fallen soldier, for example, "The Parents of the Killed Soldier Will Receive a Grandson" (David 2006). These images and phrases remind the public that Kevin's death was not accidental. He was killed 
fighting for the country during active service-following this sacrifice, the nation is indebted to him and to his family. This contribution, however, is highlighted whether or not the man died during active service (as was the case with Kevin Cohen) or from unrelated illness (as was the case with both Aidan Snir and Baruch Pozniansky). Regardless of the cause and timing of death, national service as a soldier (often in a combat unit) reconfigures the loss as one that ranks highly in the hierarchy of Israeli death from heroic death (in combat), to death from natural causes, and at the bottom, accidental death (Ben-David 2006).

The focus on military service elevates the status of the father; his willingness to sacrifice his life to the nation, whether actualized or hypothetical, becomes a central part of the narrative about the stakes of his continuity. In television segments on Baruch, many of the videos and stills highlighted his participation as a "fighter" in a combat unit. This detail about his service is important because it reminds the public of Baruch's sacrifice to the nation (not all men serve in combat units, which have more prestige in the military hierarchy). Volunteering for a combat unit signifies the "ultimate consummation of self-realization" in the hierarchy of army service (Helman 1999:200). One segment shows in close-up a black and white photograph of Baruch clad in a helmet, his glasses hung over the picture frame. In another shot, he is walking outdoors wearing full combat gear including a helmet, vest, and backpack. Aidan's service is also mentioned in media accounts, making clear that he was enlisted at the time the cancer was discovered. Even in headlines, such as the one mentioned above, "A Woman Will Give Birth from the Sperm of a Soldier Whom She Didn't Know and Who Died from Cancer," 95 the emphasized source of the sperm is a soldier rather than a young man or a cancer patient. ${ }^{96}$ In drawing this connection between the deceased and his national service, these accounts impart a sense of the viewing public's indebtedness both to the young man and to his parents. 
Indeed, parents of the young men are referred to in these accounts as "parents of the soldier" (horei ha'hayal) and are often pictured with memorabilia from their son's army service (e.g., portraits of him in uniform). Through these representations, the deceased is constituted as a soldier/son whose loss is experienced by his family and whose sacrifice obligates the collective nation. It is not his sacrifice as a nameless individual, but a family's sacrifice of their son that creates a synecdochal relationship between the soldier's family and the nation (the part for the whole) and between his parents and the "family of bereavement." When married soldiers are killed, their wives become war widows, who alongside his parents, tend to the work of preserving his memory. How then does the intended mother who will conceive from the soldier/son's sperm fit into this relationship between the family and nation?

The procreative union formed between the living and the dead is not only an unlikely one, it is an unequal one. The soldier/son is known, belongs to a family, and has sacrificed, whether in actuality or hypothetically by enlisting and/or serving in a combat unit, his life to the nation, now collectively indebted to him and to his parents for their sacrifice in place of his/their continuity. The intended mother is unknown and is portrayed as alone: her family is almost entirely absent from media accounts of posthumous sperm donation. Her status as a daughter and the details of her military service are entirely ignored. Not only is her reproductive agency diminished (as discussed in the first part of this chapter), but relative to the deceased and his family, her locatedness within a family and her contribution to the nation is doubly negated. It is by "conceiving from his sperm" of the soldier/son and becoming enveloped by his kin that single women who become mothers in this way gain entrance into family and into the national family of bereavement. Thus, these procreative unions reproduce a gender hierarchy: the heroic "victory of life" generates male continuity of the nation's fallen through, but not by, women's bodies. In 
these accounts, posthumous sperm donation and the enclosure of single mothers within men's families hardly appear to reflect an "individualizing" process of memorialization. In fact, it suggests the opposite: through the channeling of deceased men's sperm in the name of his continuity, single mothers (as individuals) are unmade. These procreative unions bring together the dead and the living, enjoining continuity and fulfillment while reproducing the differential valuation of men's and women's contributions to making family. In the final section below, I consider how these gender inequalities that relate family to nation are nationalized in proposals to create sperm banks for enlisted men and to encourage "modern levirate" marriages.

\section{A Modern Levirate?}

Over the last decade, the idea of banking the sperm of young men enlisted in the Israeli Defense Forces (IDF) has surfaced in a variety of public contexts. One of these proposals was made by Irit Rosenblum, the charismatic lawyer who founded New Family (the organization discussed above). In fact, in 2003, the Knesset discussed New Family's petition to create a national sperm bank for soldiers, to be entirely subsidized by the State of Israel. A background paper issued by the Knesset Center for Research and Information, points to the key ideas motivating this proposal for male fertility preservation on a national scale. Given the recent requests made by surviving kin for "continuity of the generations" (hemshekhiut hadorot) (Center for Research and Information 2003:1), the proposal for sperm bank aimed to raise awareness of this possibility for men whose fertility might be damaged during military service or who might lose their lives and to record explicit directives. New Family sought to expand the meaning and scope of the state's responsibility to enlisted soldiers, who are entrusted in its care and its burden to provide for damages should they lose any ability to function. This covers the 
period between enlisting in mandatory service at age 18 until completion of reserve duty at age 45 (though many men do not continue to serve for this extended period). In the event of a soldier's or reservist's death, New Family proposed that either surviving female partners could use the banked sperm or, if the man did not have a female partner at the time of death, then his parents could request to use the banked sperm after finding "a suitable woman who would agree in writing to conceive from his sperm (l'herot mi'zero)" (Center for Research and Information 2003:3). By incorporating explicit written consent (in the form of a "biological will") New Family aimed to wed the liberal value of autonomy to the Jewish-Israeli logic of continuity: "to bestow a man with the possibility to erect/stand for himself descendants" (Center for Research and Information 2003:5, my emphasis).

This proposal resonated with politicians and with enlisted men and their families. In 2004, two Knesset members proposed a law to make a national sperm bank for enlisted men, though it did not advance in the legislative process. ${ }^{97}$ Nevertheless, according to New Family, over one hundred soldiers signed biological wills before their service in the Second Lebanon War (Solomon 2006). The idea also found support among bereaved families. Ma'ariv newspaper covered the story of a couple who became supporters of creating a national sperm bank after they lost their son, Zev, who was an officer in a combat unit. After Zev suffered permanent injury to the brain stem in a traffic accident on the way home from an army operation, his parents donated his organs. Yet even before his death, his parents imagined the possibility of posthumous conception, as their son had served in dangerous situations in which others had lost their lives. The couple was pictured in their home, a picture of their son in uniform resting behind them. While other families found ways to "perpetuate" (l'hantziah) their loved ones, these bereaved parents wished for "living and breathing perpetuity" (hantzaha haya ve'noshemet tzoheket 
ve'mishtollet) — that is, they would have preferred a grandchild, if it had been an option (Torres 2009).

The logic of continuity that finds expression in the proposals for a sperm bank for enlisted men draws upon the Jewish tradition of levirate marriage. In making this connection to levirate, the generational and conjugal dimensions of transmitting continuity through family are combined as are the religious and nationalist kinship ideologies of lineage and national sacrifice that inform Jewish-Israeli ideas about male contributions to procreation. When asked about religious objections to their campaign to support the option of a sperm bank for enlisted men, Zev's father answered:

I don't know if the religious establishment supports this idea or not, but I can say that it has not voiced sweeping opposition on its part. Jewish halakha actually supports levirate marriage (yibum). In this case, a woman should be required [to conceive] by the brother of the deceased in order to preserve the generation (l'shamer et hador), but science can enable it much more simply. The religious establishment disapproves of anonymous sperm donation through the sperm bank that could lead to a person born who in the future will marry with a close relative. In this case, the donation is not anonymous and such a thing cannot happen. (Torres 2009)

This father's comment exemplifies the ways levirate marriage is appealed to as a precedent for continuity when it comes to posthumous conception, by both religious thinkers and by the Israeli public, including Israelis who identify as secular. In this reconfiguring of the Biblical commandment, science in the form of assisted reproduction replaces the physical act of sexual intercourse between the surviving brother and the deceased's wife. ${ }^{98}$ In Israel scientific and technological innovation stand for the prowess and modernity of the Jewish people (Efron 2007). Here science/nation "enables" continuity and replaces the brother's obligation to the deceased. In this formulation ${ }_{2}$ the moral debt between brothers is generalized to all soldier-sons who have sacrificed their lives to the State of Israel and the project of "raising up" the seed of the deceased is nationalized as a shared responsibility of the living (the collective). Yet, the father's comment 
also reveals that science has enabled single women to conceive on their own from the sperm bank. However, when constructed as a conjugal union or "levirate" marriage, posthumous conception from a known man alleviates the social qualms surrounding the science-enabled and state-subsidized creation of single-mother families through anonymous donation. Through a state-supported sperm bank for enlisted men, science replaces the religious obligation of the brother, technologizing and nationalizing continuity while it reconfigures single women as war widows; they are joined through conjugal and generational ties to the soldier's family and encompassed within the family of bereavement (the nation). In this way, the logic of continuity resolves the problems single motherhood through anonymous donation poses to both religious and nationalist understandings of family that build the nation through generations of known men.

The conceptual association between levirate marriage, posthumous conception and single motherhood through donor insemination was made explicit in an Op-Ed piece in Ha'aretz by Einat Ramon, the first female head of the Masorti (Conservative) stream of Judaism in Israel. Provocatively entitled "Modern Levirate" (yibum moderni), Ramon proposes that in order to "solve the plight of older single women in the Jewish nation who suffer from the lack of Jewish men (in Israel because of the wars...)" a sperm bank of the Jewish people [should] be established that will allow:

Sperm donation from young Jewish men who died or were killed while creating a 'match' (shiddukh) between the family of the deceased and the mother who will raise the descendant. This process is preferable from the perspective of religious law to anonymous donor insemination. It avoids the creation of mamzerim as a result of marriage between siblings without their knowledge and [it] grants the child a mother and the father's family identity and continuity. (Ramon 2011)

Of this "match" Ramon suggests that it might be thought of as a "modern levirate." Ramon's oped reflects the shared concern among many religious Israelis surrounding paternity, lineage (yihus) and the practice of anonymous donor insemination to single women. ${ }^{99}$ As I explored in 
Chapter 4 , it is not only the question of future marriageability among those considered mamzerim and the fear of future incest between genetically-related brothers and sisters that informs these uncertainties. Beyond formal problems of Jewish law (halakha), however, rabbis and other community leaders are concerned about single women's reproductive agency and the dissolution of the Jewish family. In their understanding, the religious cosmology of "building" the Jewish nation is dependent upon a gendered transmission of continuity and tradition that encompasses and subordinates women's reproductive agency through conjugal ties to men.

The idea of posthumous sperm donation as a "modern levirate" fuses together the religious cosmology of building the nation through family and the nationalist ideology of male sacrifice. In the Biblical version of levirate, it is not the physical presence of a living/individual man that generates continuity, but the collective obligation of his kin to "raise up" his seed, his name and his memory. In the contemporary proposals for "modern levirate" and a sperm bank for enlisted men, it is the collective obligation of the nation to help the deceased's kin "raise up" the soldier-son's seed in exchange for his sacrifice and his family's sacrifice. In both the biblical and modern versions of levirate the purpose of these procreative unions is not motherhood as fulfillment but rather the continuity of divine blessing and national patrimony through male seed, identity and memory. In these assisted conceptions, the collective obligation to remember the soldier-son and to erect his descendants is made possible through the bodies of single women, who on their own can reproduce Jews but whose families, in the absence of known men, cannot build the nation. The cultural logics of male continuity and sacrifice, and the generative tension between them, remain ever-salient as they enlist Jewish-Israeli women — at a critical age — in the making of family and nation. 


\section{The Single Mother FAMily and Male Continuity}

One of the challenges that anthropologists experience is to design a research project and a set of related questions, and then, to let go and watch these plans evolve and transform over the course of fieldwork. I was fortunate that, from the very outset, my Israeli interlocutors eagerly probed and debated my initial project and questions. From them I quickly learned that my idea to research "technologically-assisted later motherhood" was problematic — that, to paraphrase Dorit's objection, I was trying to study two different situations entirely. While nearly everyone I met proclaimed that single motherhood was "accepted" nowadays, why then did the singlemother family somehow count less than the normative family? Answering why later, single motherhood and the resulting single-mother family is a "different situation entirely" has taken me beyond assisted reproduction, individual bodies and the bounded world of the clinic. This departure led me to investigate how multiple and contested meanings of family — as a historical formation and cultural construction — contribute to Israeli understandings of gender, citizenship and nation. In turn, my focus expanded from motherhood and reproduction to kinship, continuity and sacrifice.

$* \quad * \quad *$

For nearly two decades, single women in Israel have had unparalleled access to assisted reproductive technologies. During this time, they have given birth to thousands of children and to thousands of "single-mother families." While the offspring of Jewish mothers who are conceived through anonymous sperm donation are considered Jewish by most Israelis, contemporary discourses about single motherhood suggest that much more is at stake than making more Jewish citizens: the reproductive routes and kinship practices of Jewish-Israeli women in their late 30s and beyond unsettle cultural assumptions about "the family." 
A Critical Age contends that in Israel, family is a nation-making technology of vital import. Yet as the chapters in this dissertation have demonstrated, the idea of family in this context is not informed by a single, hegemonic understanding; rather, it is shaped by historical formations, social and demographic changes, geo-political circumstances, technological possibilities and Jewish kinship cosmologies. Against this backdrop, family comes to have multiple, and sometimes contested, meanings across various domains of social life. It is in relation to these numerous and overlapping ideas about family that the possibilities and limitations of later, single motherhood take shape. As they endeavor to bring children into the world and create families, single mothers of all backgrounds encounter Jewish-Israeli family ideologies, which define the boundaries of inclusion in the nation ("the collective"). In so doing, single-mother families make visible the differential valuation of families in Israel and the gendered coordinates that underlie this valuation.

Women's accounts reveal that becoming a single mother through assisted reproduction is "accepted" when the flow of life does not contradict appropriate constructions of the relationship between self and nation. In their narratives, motherhood is configured as a kind of selffulfillment that contributes to national purpose and continuity, while having children is conceptualized as an obligation or duty. However, not all single women are equally in the position to construct their motherhood as "accepted"-here the stratification of reproduction comes to the fore as mothers without recognized family frameworks are perceived to be alone, on the margins of society. These women risk being subjected to social censure and discrimination; their motherhood may be interpreted by others as a kind of contagion or even as a pathological act. Yet the distinction between the categories of "accepted" and "alone" is tenuous for all women who become mothers on their own. 
These categories inform the social and medical dilemmas that arise when Israeli single mothers attempt to have more than one child through assisted reproduction. In the past and present, the "only child" has been negatively associated with individualism, failed socialization, and weakened contribution to the nation. Further, the only child is problematic given the uncertain future and risk of losing a child as the Israeli-Palestinian conflict shows no sign of resolution and as the Middle East faces increased unrest and instability. As such, women's efforts to conceive for a second time or their perseverance in carrying a multi-fetal pregnancy may receive a kind of socially-recognized merit. At the same time, anxiety about losing kin and being left alone can further add to the stigma of the single-mother family. Whether they had one child or several, single mothers actively cultivated ties with extended kin networks and with male relatives in particular, in order to situate their children within recognized families.

Even as reproductive technologies enable single motherhood, other routes are becoming viable alternatives to anonymous donor insemination. One such arrangement is the practice of "shared parenting" between single women and gay men. By highlighting the participation of known fathers in the child's life, women differentiated their experience from that of single mothers who went to the sperm bank. Yet kinship relations are not a self-evident outcome of these arrangements: women who became mothers through shared parenting emphasized the doing of kinship — the practices and processes that engender families over time. In so doing, women foregrounded the care, love and nurturance that contributed to making their families while downplaying the contractual basis of the relationship. As a "new" or "postmodern" family, shared parenting occupies a liminal position within the broader Israeli construction of the modern, Jewish family. Insofar as the basis for these arrangements is a contract between two adults who lack an intimate sexual relationship, these families are perceived by some Israelis to 
be akin to divorced hetero-normative couples and thus signify the strengthening of individualism. However, when shared parenting occurs between more than two individuals (e.g., a woman and a gay couple), this kinship practice approaches the boundaries that differentiate between the modern Jewish family and the "unmodern" families of non-Jewish others.

Creative uses of assisted reproduction and family-making are not limited to secular Jewish women alone. Unmarried women in the religious Zionist sector-a community between the secular and ultra-orthodox worlds - are weighing the possibilities of anonymous donor insemination and emergent technological routes, including egg freezing. In an era when women are participating in textual study and engaging with rabbinical rulings on single motherhood, the gendered authority of Orthodox Judaism and the moral order of Jewish family are challenged. While the children of single mothers may be considered Jewish according to halakha, a discourse about "establishing a house" has developed as a way for those who oppose single motherhood to encompass unmarried women's reproductive agency. That is, Jewish women may give birth to Jewish children, but without conjugal ties to known men they cannot assist the divinely-ordained male obligations of procreation and study that are understood to build the world, from generation to generation. Amidst these debates, egg freezing has emerged as a new, yet unproven, reproductive route — one that may enable unmarried religious women to preserve their modesty and fertility.

As the Israeli public struggles with the toll of protracted military engagements, the relationship between male sacrifice and continuity is being reworked. Men's sacrifice for the nation, once an unshakable foundational narrative, is no longer an unquestioned tenet. Concomitantly, posthumous sperm donation, a new chapter in the Israeli IVF story, has become a way to make sense of the tragic deaths of soldier-sons by conscripting religious and nationalist 
tropes about the preservation of male continuity. Accounts of the unlikely unions made between young men and single women who never met in life show how male continuity is produced through distinct language and symbolism that fashions conjugal and generational ties to known men and their families. This fashioning of kin relations between the living and the dead reproduces the differential valuation of male and female procreative contributions. In this case, the soldier-son's life-giving sacrifice (and that of his family) is exchanged for life-generating continuity. In assisting this continuity, the single mother is enveloped within the soldier-son's family and fulfills her motherhood as a national purpose: by participating in the collective work of "raising up" the seed of the soldier-son, she carries, but does not create, familial and national continuity across the threshold between life and death.

\section{Significance of the Research}

By placing the family rather than the individual at the center of analysis, A Critical Age contributes to several areas of disciplinary conversation while opening new avenues for topical and areal research. First, it offers an ethnographic account of assisted reproduction that moves beyond Euro-American categories of choice, autonomy and the individual body, which remain the theoretical mainstay of anthropological studies of reproduction and biomedicine. This shift in emphasis enables the study of reproduction and risk in relation to the contingencies of losing kin in a context of violence and uncertainty. Second, this project situates emergent kinship practices within a particular nationalist configuration of the modern family. In so doing, it encourages anthropologists to investigate how kinship practices labeled new or alternative are conversant with historical formations and cultural conceptions and contestations of family. Finally, this study attends to the production of gender difference, hierarchy and inequality by examining 
differently-valued male and female procreative contributions in nationalist and religious kinship cosmologies. In so doing, A Critical Age invites scholars to investigate the relational dimensions that are central to political and religious constructions of nation and to nationalist conflicts in Israel, the Middle East and beyond.

Beyond Individual Choice: A Critical Age provides a comparative perspective on technologically-assisted single motherhood that challenges our presuppositions about individual choice and assisted conception, while indicating directions for future study. In Euro-American contexts, the cultural category of individual choice endures as the key framework from which to theorize assisted reproductive technologies and "single motherhood by choice." The assumption is that women make choices as rational actors; appropriate decision-making is presumed to lead to respectable motherhood, even as marginalized women are denied this possibility. The expansion of choice is perceived to be a signifier of modernity and progress, yet this prospect is created through the differential valuation of families across the fault lines of race and class. In the contemporary formulation of this narrative, the middle-class, educated woman who freezes her eggs epitomizes individual choice, intentionality, and self-control. The ideal is the preservation of this cultural ideology, but not necessarily the enactment of temporally-suspended conception: in fact, the Euro-American woman who waits too long have a child is perceived of as "selfish" because she has violated the limits of individual choice. When it comes to technologically-assisted later motherhood and single motherhood in particular, the ideology of "choice" and its underlying coordinates of race, class, gender and age await further investigation.

By attending to the relational dimensions of assisted conception, this study questions the ways we tend to theorize risk, and more specifically, reproductive risk. Insofar as risk is not necessarily constructed at the site of the individual body, how does anxiety about the potential 
loss of kin relations inform reproductive practices and the conceptualization of "risk"? Beyond the microscopic focus on the moment of conception and the creation of life (itself a EuroAmerican preoccupation), anthropologists might broaden the scope of analysis to consider reproductive trajectories within larger contexts of uncertainty and violence, while attending to the creative work undertaken to forge kin relations and to cultural understandings about the urgency of these endeavors.

Family, Nation and Modernity: In the west, popular and social scientific discourses have constructed an evolutionary narrative that presumes a shift from "primitive societies" in which kinship is the idiom of social relations to modern states in which the individual is basic unit of economic and political interaction: in the modern state, the (nuclear) family, is imagined to be distinct and separate from other spheres of social life (McKinnon and Cannell 2013). In Vital Relations: Modernity and the Persistent Life of Kinship, Susan McKinnon and Fenella Cannell contend that "models of social evolution, development, and modernity have been overdrawn in such a way that it is nearly impossible to access or even consider, the ways in which kinship actually operates beyond the domestic domain in so-called modern societies" (2013:8). This has been the case with mainstream social scientific analysis of nationalism, which has privileged the individual (male) citizen as the basic unit of belonging. A Critical Age draws upon McKinnon and Cannell's observation that "the avoidance of the term "kinship"...is one of the ways in which all sorts of implicit claims are made about Western modernity" including the relationship between family and nation (2013:11).

In the Israeli case, however, it is through the differential valuation of family that "all sorts of implicit claims" are made about Jewish-Israeli modernity. The "avoidance" of family in 
Israeli historiography as well as the strategic deployment of kinship and "familism" in Israeli social science must be situated in relation to a family as a nation-making technology and to its gender and ethnic coordinates. As such, debates about the single-mother family in Israel engage critical questions about the meaning of family, citizenship and nation.

This orientation has implications for social scientific studies of "new families" including those created by single parents and by gays and lesbians. Rather than assume that these families are signifiers of increased individualism and choice, what kind of claims do cultural discourses about these families make about "modernity" and how are these claims about family situated within larger social and political formations, including nationalist conflicts? Furthermore, the practice of shared parenting might push anthropologists to consider the ways we might inadvertently contribute to the production of typologies, namely "gay kinship" and "heterosexual kinship" and the connection between this binary typology and cultural narratives of modernity.

Male Contributions and Procreative Cosmologies: By focusing on Jewish-Israeli tropes of continuity in religious and nationalist discourses of assisted conception, A Critical Age examines the differential valuation of male and female procreative contributions. Bringing together Carol Delaney's work on gender, kinship and procreative cosmologies in monotheistic traditions $(1991 ; 1995 ; 2000)$ with scholarship on the foundational myth of sacrifice in Israel (akedah) (Feldman 2010; Zerubavel 2006), this dissertation explores the multiple meanings of male continuity at a particular juncture in contemporary Israeli history. Delaney proposes that anthropologists investigate the sacrifice of Abraham (Genesis 22) as "the predominant origin story of their own culture, to explore the notions of gender, procreation, family and kinship embedded in it" (2000:446). Yet even as it is the foundational origin story of patriarchal kinship, it is also an origin story about the anxiety surrounding male continuity. Delaney (2000) argues 
that a "theory of monogenetic procreation" operates in the Abrahamic traditions, channeling divinely-ordained power and generative agency through generations of fathers and sons; in this model, it is Abraham's act of complete faith, his willingness to sacrifice his son that is exchanged for authority and patrimony. It is through the subordination of women and their procreative contribution (they are the "soil") that the channeling of "seed" through men accumulates its power and reinforces the hierarchal distinctions that engender patriarchy.

In the contemporary Israeli model there is no substitution - the claim to territory is made through the preservation of the memory of the sacrifices made by many Isaacs. The original tension between sacrifice and continuity is played out in each generation of fathers and sons. Like the biblical model, the exclusion of women's reproductive agency and their encompassment through conjugal and generational ties to known men is critical to the transmission of male continuity. In Israel, the making of single-mother families from an unknown source (an anonymous donor) and the absence of conjugal and generational ties to known men is tantamount to a collapse of the gendered hierarchy that underwrites this kinship ideology. A Critical Age proposes that, beyond the confines of the domestic domain, anthropological investigation of the ways gender, family and kinship operate in our own foundational myths of origin and their changing and contested meanings may provide more nuanced understandings of political and religious conflicts in the present and the future.

As I prepared leave the field, a strange news item flickered across Israeli headlines: a group of unmarried women placed a notice in a weekly pamphlet that is distributed in religious Zionist communities throughout the country. It stated, "There is a solution for Judaism: (1) to the many single women (2) to the demographic struggle (3) to the prevention of forbidden relations 
[according to halakha]." Underneath, there was an excerpt from a ruling issued by the former Sephardi Chief Rabbi of Israel, Ovadia Yosef, permitting marriage between a man and two women for Mizrahi Jews. At the bottom, the notice added, "For additional information and decisions that also permit [marriage to two women] for Ashkenazim, please find us online" and a web address for an organization called "the complete Jewish house." In national media outlets, word of this notice was met with outrage. A television news guest angrily assessed the situation, “This will send us back 1000 years!” Orthodox rabbis denounced the ruling. In reactions to this possibility, the various elements of Jewish-Israeli ideologies of family collided: kinship as a nation-making technology and signifier of modernity, predicaments of Jewish law, demographic changes, questions of ethnicity and religious authority (Mizrahi versus Ashkenazi), gender and the limits of reproductive agency (although, a women's group placed the notice!).

As secular and religious Jewish-Israeli single women from different communities approach a critical age, they encounter multiple routes—some "accepted" and others controversial — to motherhood. The resulting single-mother families are not only lived social formations; they are rendered intelligible through existing kinship ideologies even as they engender novel and contested possibilities for conceptualizing "the family." In Israel, ideas about the family and nation are co-configured. Amidst significant shifts in demographic composition and ever-uncertain geo-political circumstances, the power to preserve the differential valuation of families and the authority to determine which families constitute the complete Jewish house will make all the difference, at this critical age for the Jewish-Israeli nation. 


\section{ACKNOWLEDGMENTS}

A community of friends, colleagues, advisors and family members supported me at every phase in the process, from start to finish. I would like to thank Susan McKinnon, my advisor, for her unwavering encouragement. Richard Handler, Dan Lefkowitz and Vanessa Ochs provided insightful suggestions and attentive readings. Colleagues in the Department of Anthropology contributed greatly to my framing and re-framing of this project. Conversations with Claire Snell-Rood, Na'amah Razon and Sibylle Lustenberger helped push me to articulate my ideas. I am grateful to all the women and health care professionals in Israel who generously participated in this study. Support for the research was made possible through grants from the National Science Foundation, the Wenner-Gren Foundation and the University of Virginia. Finally, special thanks to my family and to Nadav, Naomi and Eli. 


\section{NOTES}

\section{INTRODUCTION}

${ }^{1}$ In 2011, 4.8 percent of all births were to unmarried single mothers (CBS 2013).

2 The ever-growing literature on assisted conception in anthropology and other disciplines as well as in the popular media attests to the provocative and unsettling potential of reproductive technologies in the $21^{\text {st }}$ century, in particular when it comes to creating new persons and family constellations (e.g., through surrogacy or prenatal genetic diagnosis). Bridging critical medical anthropology and feminist perspectives, cross-cultural studies of assisted reproductive technologies and in vitro fertilization have focused on changing ideas about personhood (e.g.,Konrad 2005); disruptions to the normative life-course (Becker 2000; Freise et al. 2006; Friese et al. 2008); medicalization and commodification of the body (and its parts) (e.g., Konrad 2005; Nahman 2013); the formation of family (e.g., Mamo 2007; Thompson 2000); and the lived experience of infertility, social suffering and involuntary childlessness (e.g., Inhorn 2003; Inhorn and Van Balen 2002).

${ }^{3}$ Beyond anthropological research, feminist scholars have debated the meaning of post-menopausal pregnancy as an extension of reproductive choice (e.g., Parks 1999; Watkins 2007). Other scholars have considered the historical construction of later motherhood (Berryman 1991) and the emergence of the "biological clock" in American medical discourses (Amir 2006).

${ }^{4}$ Although multiple embryo transfer, "advanced maternal age" and high-risk pregnancies are occasionally mentioned in ethnographic vignettes (e.g., Teman 2010; Thompson 2005) these issues have not been at the center of analysis.

${ }^{5}$ Recently, popular discourses about egg freezing have cast the spotlight on the intersection of female reproductive aging, assisted conception, the meaning of marriage and family, and the work/life balance (e.g., Inhorn 2013; Klein 2013; Morgan and Taylor 2013; Richards 2013; Urist 2013).

${ }^{6}$ For example, the report authored by Daniel Moynihan entitled "The Negro Family: The Case for National Action" (1965) accused black matrifocal families of perpetuating a "tangle of pathology." Moynihan's report attributed the absence of fathers to low IQ, to high rates of unemployment, to delinquency and crime, and to failure to pass the armed services mental test, and to drug addiction and social alienation. http://www.dol.gov/oasam/programs/history/moynchapter5.htm

${ }^{7}$ In contrast to accounts that focus on the production of normativity and middle class values of family, Linda Layne (2013) suggests that the focus on the "normalization" and "naturalization" of kinship through assisted reproduction is a limited view. Instead, she proposes that the uncanny is a better framework to view donor insemination, enabling the traffic between normalization and the "strange" feeling that both straight and lesbian women talk about in connection to insemination from an unknown donor. The source of the discomfort in buying sperm, Layne argues, is the mixing of marketplace and family-creation it engenders: rather than a father-figure or identity, the practice of purchasing sperm from a sperm bank fosters an "interchangeability of men" (2013:146). Layne concludes that the emerging option of non-anonymous donation (open donation) is changing how women think about donation: "sperm donors are now seen as an asset single mothers by choice (SMCs) and lesbian couples can provide their children as evidenced in the increasingly popular practice of selecting 'yes' donors" (Layne 2013:155). It remains an open question whether this seminal asset will become another permutation of an "essential luxury" (Hertz 2006). ${ }^{8}$ See also Linda Layne (2013) on the shift towards open sperm donation and the known donor as a form of social capital.

9 According to Kinneret Lahad, the "overly selective" single woman "puts to the test the assumption that individualized choice and self-determination are valued above all else" (2013:24). Lahad's observation about the construction of the "selective" woman is important; however her analysis blends together the American and Israeli contexts rather than considering salient cultural differences when it comes to constructions of individual choice.

${ }^{10}$ Freud identified the causes of degeneracy in historical displacements rather than biology-Zionists adopted the idea that by returning to their homeland, the degeneracy produced through exilic experience would be overcome (see Gilman 1994 for a detailed study of Freud, Judaism and psychoanalysis).

${ }^{11}$ A by-product of its social scientific fame, the kibbutz family became mistakenly represented beyond the country as the normative Israeli family, when in fact a very small percentage of the overall population has lived in these settlements (never more than seven to eight percent at the peak, and only three percent by the late 1960s when Spiro conducted fieldwork) (Shamgar-Handelman 1996:398; Spiro 2004). 
${ }^{12}$ In the kibbutz, the family as an autonomous unit was supplanted by the collective group (e.g., sibling relationship replaced by the age-set of all children) (Talmon-Gerber 1954).

${ }^{13}$ Although much attention has been placed on the ways family law courts in Israel, based on the Ottoman millet system, preserve the distinction between Jews and other citizens (e.g., there is only religious marriage between members of the same group), this alone does not explain the evolutionary logic that is used to temporally other Palestinians and incorporate the mizrahi family as part of the modern, Jewish nation.

14 "Familism" is a Hebracized version of the Euro-American sociological term that is used by sociologists to describe the value of family as a cultural feature.

${ }^{15}$ Or what some gay family activists claim is a practice of "pinkwashing" to detract from the Israeli/Palestinian conflict.

${ }^{16}$ Among the group of single mothers, two women were divorced.

${ }^{17}$ Ethnicity is a thorny problem in Israeli anthropology, but women self-identified according to their parents' backgrounds. Rather than quantifying "ethnic" backgrounds (particularly since many interviewees had mixed backgrounds, for example a Romanian mother and a Syrian father), I have decided to incorporate this information into women's narratives.

${ }^{18}$ Interestingly, the community that I did come to see in action was the elite group of fertility medicine specialists, who meet throughout the year at conferences and other events.

${ }^{19}$ Aliyah is the Hebrew term used to refer to the return of Jewish individuals from the Diaspora to Israel. It literally means "going up" or "ascent." A new immigrant is refered to as an oleh/ah (from the same Hebrew root as aliyah).

${ }^{20}$ For recent scholarship that explores the political implications of family and kinship and thus moves beyond the predominant focus on relatedness in kinship studies see McKinnon and Cannell 2013.

\section{CHAPTER 1}

${ }^{21}$ Tsipy Ivry's 2009 study is an exception to the scholarly focus on assisted reproductive technologies.

${ }^{22}$ Throughout my years in Israel, I have never heard of anyone who didn't have a baby for financial reasons connected to healthcare expenses. In fact, Israeli women unfamiliar with insurance policies in the United States were often shocked by the very idea that one would consider the cost of health care as a factor in family planning.

${ }^{23}$ For in-depth explorations of Zionism as a project of remasculinizing the effeminate Diaspora Jew, see Biale 1997, Boyarin 1997.

${ }^{24}$ In scholarly references to hagshama the element of physical labor and eroticized land is far more prevalent than references to procreation and male sexuality. In a sense, this reproduces early Zionist ideology of "erotic liberation," which as Biale (1997) and others have argued ironically produced an ascetic nationalism of sexual abstinence.

${ }^{25}$ Freudian psychoanalysis was an important intellectual infleunce on early Zionist ideology (see for example Biale 1997; Neumann 2011).

${ }^{26}$ As discussed in the Introduction, this narrative of individualism is not identical to the North American evolutionary narrative which replaces the family with the individual.

${ }^{27}$ On the concept of hagshama atzmit, Melford Spiro observed that "By the 1970s, this notion that the collective welfare (whether that of the nation, the working class, or the kibbutz) was coincident with one's personal welfare had been rejected by the Sabras. Instead of 'self-realization' [hagshama atzmit], they took as their leitmotif the very different notion of self-actualization (mimush atzmit), that is, personal growth through the development of one's talents and abilities whether or not they were useful to the collective welfare" (Spiro 1996 [1979] xxxiii).

${ }^{28}$ It may also imply that Berman is aware of the deeper history of hagshama atzmit, which emphasizes material over spiritual redemption.

${ }^{29}$ Other less frequent terms such as hore yehid also exist, though these are less often used in everyday speech.

${ }^{30}$ However, em yehidanit (solo mother) appears to be used by women in online forums without this concern.

${ }^{31}$ Although the term has become associated with foreign workers and refugees, it can be used to speak of any person who is not Jewish.

${ }^{32}$ In fact, the Interior Ministry's effort, led by right-wing politician Eli Yeshai of the Shas party, to deport illegal workers and their Israeli-born children demonstrates their unequivocal foreignness (and the ease with which the government can dispose of them). Throughout the two years of my fieldwork there was an on-going debate in the more politically progressive center about the morality of these deportations, particularly of young children who had been born and raised in Israel, but were not Jewish. 
${ }^{33}$ The Center for Single Parent Families, Haifa municipality:

http://civilsociety.haifa.ac.il/orgDetPrint.asp?lang=heb\&orgid=364, accessed August 22, 2012.

${ }^{34}$ Since the 1990s, over 200,000 Jews have immigrated to Israel from Ethiopia.

${ }^{35}$ Indeed, the film Yana's Friends (1999), about a pregnant Russian immigrant represents the precarious position of these women. When Yana's Russian husband abandons her, she turns to a compassionate neighbor, and it is through her relationship with him that she navigates Israeli bureaucratic and social interactions. The theme of "inter-ethic" romantic coupling (see also Loshitsky 2001) as a means to cultural assimilation, between Russian women and Israeli men is a recognized cinematic theme. Russian women are rendered sexualized and helpless, their "inassimilable foreignness can be overcome only in romantic involvement with an Israeli man" (Gersonson 2011:166). In contrast, Russian men are portrayed as offensive and sexually repugnant to Israeli women (Gersonson and Hudson 2007; Gersonson 2011:165-166).

36 "Since 1970 the right to immigrate under this Law has been extended to include the child and the grandchild of a Jew, the spouse of a Jew, the spouse of a child of a Jew and the spouse of a grandchild of a Jew. The purpose of this amendment is to ensure the unity of families where intermarriage had occurred; it does not apply to persons who had been Jews and had voluntarily changed their religion" (Israeli Ministry of Foreign Affairs). http://www.mfa.gov.il/mfa/aboutisrael/state/pages/acquisition\%20of\%20israeli\%20nationality.aspx, accessed August 12, 2013. The irony of the Law of Return is that while it aimed to unify families through the extension of citizenship, it creates families who can never fully belong as Jews.

${ }^{37}$ Thanks to Inna Leykin for pointing out this linguistic difference.

${ }^{38}$ Although I rarely heard this expression in relation to pregnancy, the notion of "a bug in the head" explained pregnancies judged as deviant by health care providers. For example, a labor and delivery nurse told me that unmarried women who receive both egg and sperm donation must have "a bug in the head" since the child will not be "hers."

${ }^{39}$ Interestingly, I interviewed several secular single women who lived in shared apartments during the time they underwent fertility treatments. Their housing situation never came up with medical professionals.

${ }^{40}$ Based on Rivka's account, it seems that she had heard about the documentary from others, but had not seen itmany ultra-orthodox Israelis do not watch secular television programs.

${ }^{41}$ At the hospital where I did fieldwork, among women age 45 and above the caesarian rate was over $70 \%$ (personal communication with head nurse).

\section{CHAPTER 2}

${ }^{42}$ Literally: "You'll get shikkunim with an entrance and a kitchen."

${ }^{43}$ After the snack food called bourekas, made from layers of filo dough eaten throughout former Ottoman Empire. This genre encompasses comedies about ethnic tensions between mizrahim and ashkenazim in Israel.

${ }^{44}$ It is worth noting that Mizrahi music has not been incorporated into official Memorial Day programs, despite its ubiquitous presence in the Israeli soundspace.

${ }^{45}$ Perhaps the most memorable and haunting example is the character of Momik, the only child of two Holocaust survivors, in David Grossman's novel See Under: Love (1986).

46 "Most people do not hesitate to ask women of childbearing age in Israel if they have children or when they are going to have their next child, in a blunt direct style known as 'dugri speech'; this is not interpreted as rudeness, but as an accepted cultural form of relating to others" (Teman 2010:108).

${ }^{47}$ In practice, parents can sign an agreement overriding this policy. Nevertheless, periodically in the press parents and others object to this option. See for example, a letter published in the opinion section of Haaretz in 2009 urging legislation that would prevent this option: http://www.haaretz.co.il/opinions/letters/1.1278141, accessed August 30, 2009. Unlike enlisted soldiers, reservists do not need parental permission to override this policy; they can volunteer for combat units but will not be placed in them automatically: http://www.aka.idf.il/kamlar/klali/?catid=43334\&docid=46143\&list=1, accessed February 72013.

${ }^{48}$ In her ethnography of Israeli security practices, Juliana Ochs provides a moving account of a pregnant woman who describes how she drove past an ultrasound clinic where another pregnant woman carrying twins was killed in a terrorist attack; this memory of another woman's lost life becomes a key experience in the informant's own pregnancy (2011:105).

${ }^{49}$ For an analysis of gendered speech and the use of masculine forms by women in Hebrew, see Sa'ar 2007. 
${ }^{50}$ A recent Israeli study of all patients in the Maccabi health fund demonstrates that the rate of success (live birth) from IVF for women ages 40-45 is 6.4 percent per cycle, compared to the rate among women age 30-35 (23.1 percent per cycle). Further, there is a significant drop in outcomes between the ages of 40-45, from 12 percent at age 40 to 1.7 percent at age 45 (Even 2013).

${ }^{51}$ Several studies feature ethnographic vignettes of twin pregnancies, including Franklin 1997 and Teman 2010. However, cultural understandings of multi-fetal pregnancies are not central to the analysis.

${ }^{52}$ Egg donation accounts for the higher rate of twin pregnancies among women in this age bracket, since it is done in offshore clinics where doctors seek to maximize their patient's chances by transferring multiple embryos.

${ }^{53}$ The expression "instant family" is also widespread in Euro-American discourses of IVF and twin pregnancies.

${ }^{54}$ Most of the hospital staff believed that Miri had gone through egg donation. Like many other patients, she never revealed this to me. Her reluctance to share this information despite being open about many other personal circumstances highlights the enduring stigma of egg donation in Israel.

${ }^{55}$ In contrast to anthropological analysis of the construction of fetal personhood in the United States (Layne 2003; Morgan and Michaels 1999; Taylor 2008), Ivry (2010) demonstrates that Israeli women do not conceive of the fetus as a baby nor do they accord it with personhood. Similarly, my interviewees almost exclusively used the term "fetus" (ubar) in place of "baby" (tinoket) when referring to the unborn. Further, because "fetus" and "embryo" are not lexically distinguished from one another, in Hebrew the idea of reducing a fetus/embryo is less defined. In interviews women referred to fetal reduction as "reduction" (dilul, literally means diluting) alone, eliding the fetus/embryo entirely. Another overlaps occurs with the word most commonly used by women to refer to pregnancy loss (hapala), which is used for both spontaneous miscarriage and for induced abortion.

\section{CHAPTER 3}

${ }^{56}$ Similarly, ethnographic accounts of infertility and assisted reproduction among heterosexual couples reveal that, beyond blood and biology, everyday practices of care and even the experience of undergoing medical treatment are generative of family (e.g., Becker 2000; Thompson 2005).

${ }_{57}$ As it does with heterosexual married couples who separate or divorce.

${ }^{58}$ In the United States, researchers refer to shared parenting as "transactional families" (e.g., Hertz 2006). For example, Rosanna Hertz writes "these contracts function to allow autonomous individuals to make their own bargains outside the normative organization of the culture. These are transactional families, where the adults agree that they want to share a child together" (Hertz 2006:147). In Israel, researchers have referred to these arrangements as "hetero-gay families" (Segal-Engelchin et al. 2005).

${ }^{59}$ Circle Surrogacy, one of the first American agencies to promote surrogacy for gay men, was founded in the mid1990s. Israeli brokers began to offer surrogacy services to gay men in the past decade.

${ }^{60} \mathrm{http} / / / \mathrm{www}$.haaretz.com/print-edition/news/gay-father-of-twins-born-to-indian-surrogate-denied-permission-tobring-his-sons-home-1.289128, last accessed June 1, 2010.

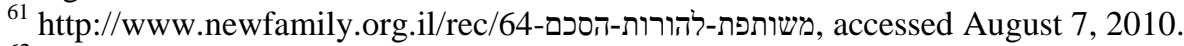

${ }^{62}$ In fact, $b a$ 'al literally means owner (for example: landlord is ba'al bayit, literally owner of the house). Husband and wife are literally "owner" and "woman."

${ }^{63}$ Seder Nashim is a collection of first-person accounts compiled by Amia Liebiech, a well-known Israeli psychologist from Hebrew University who has published numerous works on contemporary Israeli life. The title is a play on the classical text in the Mishnah, by the same name, which addresses religious issues related to women: family law, marriage contracts, adultery, divorce, betrothal, and lineage.

${ }^{64}$ This use of the English word "partner" is another way out of the terminological muddle described above.

${ }^{65}$ See Omi Morgenstern-Lassiter (2006) on the use of militarized imagery in Israeli hospital births.

\section{CHAPTER 4}

${ }^{66}$ Perhaps the most well-known is the Jerusalem-based organization Yashfe (www.yashfe.org), which sponsors singles events and provides counseling services.

${ }^{67}$ Prior to 2011 Israeli medical centers offered fertility preservation for medical conditions such as cancer. After 2011, Israeli health funds now subsidize fertility preservation for medical conditions, although at this time agerelated infertility is not considered a medical condition.

${ }^{68} \mathrm{http}: / /$ www.ynet.co.il/articles/0,7340,L-3582009,00.html, accessed April 26, 2013. 
${ }^{69}$ For an extended survey on Orthodox approaches to interpreting Jewish law, see Tamar Ross 2004.

\section{CHAPTER 5}

${ }^{70}$ The first medical case of PMSR was described over thirty years ago (see Rothman 1980). Sperm harvesting techniques used in PMSR include: electro-ejaculation (in the case of a brain dead patient), extraction with a syringe (immediately following death), testicular harvesting with micro-surgical extraction in the lab (up to 24 hours following death). A study conducted jointly between an Israeli and American researchers found that sperm could be successfully harvested up to 36 hours following death (Shefi et al. 2006).

${ }^{71}$ This kind of fertility preservation is a practice becoming more common among young Israeli men and women undergoing chemotherapy, and as of 2010, paid for by national health insurance.

${ }^{72}$ New Family Organization v. Rambam Medical Center and the Attorney General, 13530/08 (2009:4).

${ }^{73}$ By 2002, it was estimated that there had been 20 cases of this kind nationwide (Knesset Committee 2002).

${ }^{74}$ The ceremony of halitza is still performed by Orthodox Jews in order to release the widow from the obligation to conceive with the deceased's brother.

${ }^{75}$ It has become typical for secular Israelis to cohabitate for an extended period before getting married.

${ }^{76}$ These guidelines were challenged, but not overturned, in a Supreme Court case on the grounds that they infringed upon autonomy and respect for the deceased's body and inheritance (The Citizen's Coalition v. Israeli Attorney General 03/10224).

${ }^{77}$ The Attorney General cited the Nahmani case as a precedent for the connection between presumed consent and conjugal relations (PMSR Guidelines 2003:5.18).

78 "When brothers dwell together and one of them dies and leaves no son, the wife of the deceased shall not be married to a stranger, outside the family. Her husband's brother shall unite with her: he shall take her as his wife and perform the levir's duty. The first son that she bears shall be accounted to the dead brother; that his name may not be blotted out in Israel" (Deut. 25:5, quoted in Weisberg 2009: xxvii).

${ }^{79}$ Kevin Cohen was killed before the Attorney General's guidelines were issued. Nevertheless, his parents' struggle to bring about his descendants took place after the guidelines. While not legally bound to them, they still undertook a symbolic struggle to justify their efforts (which departed from what the guidelines deemed acceptable).

${ }^{80}$ Lengthy trips abroad, sometimes called "the big trip" (hatiyul hagadol), have become a typical experience for Israeli men and women after they finish mandatory army service (see Noy and Cohen 2005).

${ }^{81}$ In other contexts, for example at a nursing conference I attended with an entirely female audience, the women referred to the audience members collectively as banot with a kind of chuckle, since few were "girls" but rather established professionals.

${ }^{82}$ This demonstration of mutuality and care between the single woman and young man's family is reminiscent of the kinship work done in shared parenting relationships.

${ }^{83} \mathrm{http}: / / \mathrm{www}$. haaretz.co.il/misc/1.1293624, accessed December 6, 2009.

${ }_{85}^{84}$ See Chapter 1 for an extended discussion of the Hebrew terms "fulfillment" and "framework."

${ }^{85} \mathrm{http}: / /$ news.nana10.co.il/Article/?ArticleID=820578, accessed April 26, 2012.

${ }^{86}$ The Egg Donation Law (2010) does not state whether a deceased or brain-dead woman may donate eggs.

${ }^{87}$ The possibility of a "groom" for the woman's unfertilized eggs would require finding a surrogate mother. At this time, surrogacy is only legal in Israel for married, heterosexual couples. Creating a procreative union would therefore require contracting the services of a surrogate abroad.

${ }^{88}$ Another example of the centrality of memorialization and names is Yad VaShem, the official memorial to the Shoah in Jerusalem: "And to them will I give in my house and within my walls a memorial and a name (yad vashem)... that shall not be cut off" (Isaiah 56:5).

${ }^{89}$ For the meaning of Sarah's absence in the three monotheistic traditions, see Delaney 2000.

${ }^{90}$ Of women's exclusion from the Hebrew cannon Hannan Hever contends, "Not only are they excluded from the act of representing the living-dead, since they are not granted the position of serving as witnesses to war, they are also excluded from the very representation itself, as the figure of the living-dead does not include their agency. Additionally, the very metaphor functions further as an act of exclusion since in the new birthing of the dead into life, men appropriate the power of giving birth from women, investing it in themselves" (1999:235).

${ }^{91}$ Susan Kahn (2000) and other feminist anthropologists of Israel have noted the pervasive trope of barrenness and motherhood in Israeli poetry, but have not focused to the same extent on family and bereavement. 
${ }^{92}$ Avram is fatherless in the novel. He was also an unwilling Isaac during his service in the Sinai campaign. Throughout the book, Avram occupies the position of the dead-living due to his mental illness caused by the war (as opposed to the sacrificed living-dead).

${ }^{93}$ For example, Ora mentions "coffins" and being buried in the earth (literally: her orifices filling with dirt) while Avram pushes himself "to remember" his past, even as it traumatizes him.

${ }^{94}$ To the End of the Land was completed after Grossman's youngest son died while serving in a tank unit in the Second Lebanon War.

${ }_{95} \mathrm{http}: / / \mathrm{www}$. haaretz.co.il/misc/1.1293624, December 6, 2009.

${ }^{96}$ Not all men serve in the military, although service especially in a combat unit is associated with positive characteristics and personal qualities. In fact, Cyrobank, a large private sperm bank in central Israel, only accepts sperm donations from men who served in the army (Even 2012), suggesting that military service has come to index the "quality" of the donor.

${ }^{97} \mathrm{http}: / /$ news.nana10.co.il/Article/?ArticleID=124301, accessed July 7, 2013.

${ }^{98}$ Although the State of Israel proscribed the practice of levirate marriage in 1950, Jewish religious courts continue to require widows of childless men to undergo a ceremony called halitza to release them from the Torah-mandated obligation to marry a surviving brother in order to "raise up" the sperm of the deceased. Even as levirate marriage has not been practiced by Ashkenazi Jewish communities since 1000 C.E. following Rabbi Gershom's ban, it endures as a contemporary practice through halitza and surfaces as a cultural prototype for theorizing and male continuity and the "raising up" of deceased men's seed/sperm.

${ }^{99}$ For scholarship on posthumous conception and halakhic considerations, see for example: Ariel et al. 2000; Green 2002; Halperin 2001. 


\section{BIBLIOGRAPHY}

Agassi, Judith Buber

1980[2005] The Status of Women in Kibbutz Society. In Israeli Women's Studies: A Reader. Esther Fuchs, ed. Pp.171-180. New Brunswick: Rutgers University Press.

Aharony, Irit

2007 The Outcry, the Question and the Silence: Sarah and the Aqedah in the Midrash and Contemporary Israeli Literature. In Unbinding the Binding of Isaac. Mishael M.Caspi and John T. Greene, eds. Pp. 151-186. Lanham, MD: University Press of America.

Almog, $\mathrm{Oz}$

2000 The Sabra: The Creation of the New Jew. Berkeley: University of California Press.

Anderson, Benedict

1983[2006] Imagined Communities: Reflections on the Origin and Spread of Nationalism. London: Verso.

Ariel, Yaacov

2001 The Structure of the Modern Family: Halakhic Perspectives. Tehumin 11(2):129-147.

Aronoff, Myron J.

1999 Wars as Catalysts of Political and Cultural Change. In The Military and Militarism in Israeli Society. Edna Lomsky-Feder and Eyal Ben Ari, eds. Pp.37-53. Albany: State University of New York Press.

Avramov, Etti

2013 The First in Israel: A Child from Frozen Sperm of a Deceased Man. Yediot Ahronot, June 10.

Bakshi-Doron, Eliyahu

2002 Single Mother Family. PUAH $11^{\text {th }}$ Annual Conference Program. Jerusalem: PUAH Institute.

Bashen, Tal

2011 Fertility Revolution: Four Women Who Froze Their Eggs Speak for the First Time. Ma'ariv, January 14.

Becker, Gay

2000 The Elusive Embryo: How Women and Men Approach New Reproductive Technologies.

Berkeley: University of California Press.

Ben-Amos, Avner

2003 War Commemoration and the Formation of Israeli National Identity. Journal of Political and Military Sociology 31(2):171-195.

Ben-David, Orit

2006 Ranking Deaths in Israeli Society: Premature Deaths and Organ Donation. Mortality 11(1):79-98.

Berg, Nancy E.

2006 The Politics of Paternity and Patrimony. Shofar: An Interdisciplinary Journal of Jewish Studies 24(3):100-114.

Berkovitch, Nitza

1999 “Women of Valor": Women and Citizenship in Israel. Israeli Sociology 21(1):277-317. 
Bernstein, Deborah

1992 Pioneers and Homemakers: Jewish Women in Pre-State Israel. Albany: State University of New York.

Biale, David

1992 Eros and the Jews: From Biblical Israel to Contemporary America. New York: Basic Books.

Bilu, Yoram, and Eliezer Witzrum

2000 War-Related Loss and Suffering in Israeli Society: An Historical Perspective. Israel Studies $5(2): 1-31$.

Birenbaum-Carmeli, Daphna, and Yoram Carmeli

2002 Physiognomy, Familism and Consumerism: Preferences among Jewish Israeli Recipients of Donor Insemination. Social Science and Medicine 54(3):363-376.

2010 Kin, Gene, Community: Reproductive Technologies among Jewish-Israelis. New York: Berghahn Books.

Bock, Jane D.

2000 Doing the Right Thing? Single Mothers by Choice and the Struggle for Legitimacy. Gender and Society 14(1):62-86.

Boyarin, Daniel

1997 Unheroic Conduct: The Rise of Heterosexuality and the Invention of the Jewish Man. Berkeley:

University of California Press.

Burstein, Menachem

2011 Fertility Preservation: Halakhic Perspectives, PUAH Institute, Jerusalem.

Campbell, Patricia

2011 Boundaries and Risk: Media Framing of Assisted Reproductive Technologies and Older Mothers.

Social Science and Medicine 72(2):265-272.

Carsten, Janet

2004 After Kinship. Cambridge: Cambridge University Press.

2007 Ghosts of Memory: Essays on Remembrance and Relatedness. Oxford: Blackwell

Publishing.

Central Bureau of Statistics

2009 Newborns in Single and Multiple Births by Mother's Population Group, Religion

and Age. Table 3. http://www.cbs.gov.il/shnaton63/st03_18.pdf

2011 Statistical Abstract of Israel 63, Table 3.17.

2013 Family Day: Families and Households in Israel, 6 February.

Cherlow, Yuval

N.d. Birth Without Marriage

http://www.ypt.co.il/show.asp?id=22400

N.d. Birth Without Marriage - Part B

http://www.ypt.co.il/show.asp?id=22451

Chomsky, Gilit

2010 Being a Religious Single Mother, Jewish World, Yediot Ahronot, August 25.

Cohen, Abner

1965 Arab Border-Villages in Israel: A Study of Continuity and Change in Social Organization.

Manchester: Manchester University Press. 
Colen, Shellee

1995 "Like a Mother to Them": Stratified Reproduction and West Indian Childcare Workers and Employers in New York. In Conceiving the New World Order: The Global Politics of Reproduction. Faye D. Ginsburg and Rayna Rapp, eds. Pp. 78-102. Berkeley: University of California Press.

Collier, Jane, Michelle Z. Rosaldo, and Sylvia J. Yanagisako

1997 Is there a family? New Anthropological Views. In The Gender/Sexuality Reader: Cultural, History, Political Economy. Roger N. Lancaster and Micaela di Leonardo, eds. Pp. 71-81. New York: Routledge.

Committee for Matters of Scientific and Technological Research and Development 2002 Protocol 97 (Fourth Session), $15^{\text {th }}$ Knesset, Jerusalem, September 30.

Coontz, Stephanie

1992 The Way We Never Were: American Families and the Nostalgia Trap. New York: Basic Books.

Cussins, Charis

1998 Producing Reproduction: Techniques of Normalization and Naturalization in Infertility Clinics. In Reproducing Reproduction: Kinship, Power, and Technological Innovation. Sarah Franklin and Helena Ragone, eds. Pp. 102-117. Philadelphia: University of Pennsylvania Press.

Darr, Yael

2011 Discontent from Within: Hidden Dissent against Communal Upbringing in Kibbutz Children's Literature of the 1940s \& 1950s. Israel Studies 16(2):127-150.

David, Meirav

2006 Parents of the Murdered Soldier Will Receive a Grandson. Ma'ariv, January 27.

Delaney, Carol

1991 The Seed and the Soil: Gender and Cosmology in Turkish Village Society. Berkeley: University of California Press.

1995 Father State, Motherland and the Birth of Modern Turkey. In Naturalizing Power: Essays in Feminist Cultural Analysis. Sylvia J. Yanagisako and Carol Delaney, eds. Pp. 177-195. New York: Routledge.

2000 Cutting the Ties That Bind: The Sacrifice of Abraham and Patriarchal Kinship. In Relative Values: Reconfiguring Kinship Studies. Sarah Franklin and Susan McKinnon, eds. Pp. 445-467. Durham: Duke University Press.

de Tocqueville, Alexis

1990[1840] Democracy in America. Volume II. New York: Vintage Books.

Dolgin, Janet

1997 Defining the Family: Law, Technology, and Reproduction in an Uneasy Age. New York: New York University Press.

Dominguez, Virginia R,

1989 People as Subject, People as Object: Selfhood and Peoplehood in Contemporary Israel. Madison: University of Wisconsin Press.

Druckman, Yaron

$201231 \%$ of Israelis at Risk of Poverty. Yediot Ahronot, October 17. 
Edwards, Jeanette, Sarah Franklin, Eric Hirsh, Frances Price, and Marilyn Strathern

1993 Technologies of Procreation: Kinship in the Age of Assisted Conception. Manchester: Manchester University Press.

Efron, Noah

2007 Judaism and Science: A Historical Introduction. Westport: Greenwood Press.

Eglash, Ruth

2012 Rise in Single Mothers Giving Birth. Jerusalem Post, February 23.

Eisenstadt, S.N.

1985 The Transformation of Israeli Society: An Essay in Interpretation. Boulder: Westview Press.

Elior, Rachel

2001 "Present but Absent," "Still Life," and "A Pretty Maiden Who Has No Eyes": On the Presence and Absence of Women in the Hebrew Language in Jewish Culture and in Israeli life. In Streams into the Sea: Studies in Jewish Culture and it Context, Dedicated to Felix Posen. E. Reiner and R.

Livneh-Freudenthal, eds. Pp.191-211. Tel Aviv: Alma.

Ellison, Marcia A.

2003 Authoritative Knowledge and Single Women's Unintentional Pregnancies, Abortions, Adoption and Single Motherhood: Social Stigma and Structural Violence. Medical Anthropology Quarterly 17(3):322-347.

El-Or, Tamar

1997 Next Year I Will Know More: Literacy and Identity among Young Orthodox Women in Israel.

Detroit: Wayne State University Press.

Ettinger, Yair, and Fadi Aiadat

2009 A Woman will give Birth from the Sperm of a Soldier She Didn't Know who Died from Cancer.

Ha'aretz, December 6.

Even, Dan

2011 The First: Oocytes Retrieved from a 17 Year Old who Died. Ha'aretz, August 7.

2012 Israeli Sperm Bank Only Taking Donations from IDF Veterans. Ha'aretz [English edition], February 9.

2013a Despite the Increase in IVF Treatments, Fewer Women Succeed in Giving Birth.

Ha'aretz, January 30.

2013b In a Year: An Increase of 11 Percent in the Number of IVF Treatments. Ha'aretz, April 30.

Even, Geula

2011 Fatherhood after Death. Tonight with Geula Even. Channel One, April 11.

Fabian, Johannes

1983 Time and the Other: How Anthropology Makes Its Object. New York: Columbia University Press.

Feldman, Yael

2010 The Glory and the Agony: Isaac's Sacrifice and National Narrative. Stanford: Stanford University Press.

Fogiel-Bijaoui, Silvie

2002 Familism, Postmodernity and the State: The Case of Israel. Journal of Israeli History: Politics, Society and Culture 21(1-2):38-62.

Franklin, Sarah

1997 Embodied Progress: A Cultural Account of Assisted Conception. London: Routledge. 
Franklin, Sarah, and Susan McKinnon

2000 Relative Values: Reconfiguring Kinship Studies. Durham: Duke University Press.

Gal, Etti

2010 The Ministry of Health Approves Egg Freezing for All Women. Yediot Ahronot, September 6.

Gazit, Gaby

2011 Fertility Preservation also for Religious Women: We Want to Create Awareness in the Religious Community, Radio 103FM, September 15 (10:00AM).

Ginsburg, Faye D., and Rayna Rapp

1995 Conceiving the New World Order: The Global Politics of Reproduction. Berkeley: University of California Press.

Glick, Yifat

2009 After My Death. Ulpan Shishi. Channel Two News, June 26

Goldberg, Helene

2010 The Man in the Sperm: Kinship and Fatherhood in Light of Male Infertility in Israel. In Kin, Gene, Community: Reproductive Technologies among Jewish-Israelis. Daphna Birenbaum-Carmeli and Yoram S. Carmeli, eds. Pp. New York: Berghahn Books.

Golden, Deborah

2003 A National Cautionary Tale: Russian Women Newcomers to Israel Portrayed. Nations and Nationalism 9(1):83-104.

Good, Byron J.

1993 Medicine, Rationality and Experience: An Anthropological Perspective. Cambridge: Cambridge University Press.

Goodman, Yehuda, and Joseph Loss

2009 The Other as Brother: Nation Building and Ethnic Ambivalence in Early Jewish-Israeli Anthropology. Anthropological Quarterly 82(2):477-508.

Grossberg, Michael

1985 Governing the Hearth: Law and the Family in Nineteenth-Century America. Chapel Hill:

University of North Carolina Press.

Hacker, Daphna

2005 Transfer to "Aging Virgins" and "Sex in the City": Singlehood as an Important Option and the Relationship of Israeli law to It. Inyanei Mishpat 3:903-950.

Halperin-Kaddari, Ruth

2004 Women in Israel: A State of Their Own. Philadelphia: University of Pennsylvania Press.

Handler, Richard

1988 Nationalism and the Politics of Culture in Quebec. Madison: University of Wisconsin Press.

Harwood, K.

2009 Egg Freezing: A Breakthrough for Reproductive Autonomy? Bioethics 23:39-46.

Hashash, Yaeli

2010 Medicine and the State: The Medicalization of Reproduction in Israel. In Kin, Gene, Community: Reproductive Technologies among Jewish-Israelis. Daphna Birenbaum-Carmeli and Yoram S.

Carmeli, eds. Pp. 271-295. New York: Berghahn Books. 
Handelman, Don

2004 Nationalism and the Israeli State: Bureaucratic Logic in Public Events. Oxford: Berg.

Handelman, Don, and Lea Shamgar-Handelman

1997 The Presence of Absence: The Memorialism of National Death in Israel. In Grasping Land: Space and Place in Contemporary Israeli Discourse and Experience. Eyal Ben-Ari and Yoram Bilu, eds. Pp. 85-128. Albany: State University of New York Press.

Hazan, Chaim

2001 Simulated Dreams: Israeli Youth and Virtual Zionism. New York: Berghahn Books.

Herbst, Anat, and Orly Benjamin

2012 "It was a Zionist Act": Feminist Politics of Single-Mother Policy Votes in Israel. Women's Studies International Forum 35(1):29-37.

Hertz, Rosanna

2006 Single by Chance, Mothers by Choice: How Women are Choosing Parenthood without Marriage and Creating the New American Family. New York: Oxford University Press.

Herzog, Hannah

1998 Homefront and Battlefront: The Status of Jewish and Palestinian Women in Israel. Israel Studies 3(1):61-84.

Inhorn, Marcia, and Daphna Birenbaum-Carmeli

2008 Assisted Reproductive Technologies and Cultural Change. Annual Review of Anthropology 37:177-196.

Israel Attorney General

2003 Guidelines for Sperm Extraction and Its Use after Death (1.2202), October 27.

Israel Ministry of Health

1989 Director's Circular 135/89: Sperm Bank Management.

1992 Director's Circular 34/92: Management of Sperm Banks and Artificial Insemination.

2011 Egg Freezing for the Purpose of Preserving Women's Fertility. Circular 1/2011, Unit for Health Affairs

2012 Egg Freezing Procedure for Non-Medical Reasons, Unit for Health Affairs

Israel Ministry of Welfare

2008 Information for Single Parent Families. Ministry of Welfare and Social Services: Jerusalem.

Ivry, Tsipy

2009 The Ultrasonic Picture Show and the Politics of Threatened Life. Medical Anthropology Quarterly 23(3):189-211.

2010a Embodying Culture: Pregnancy in Japan and Israel. New Brunswick: Rutgers University Press.

2010b Kosher Medicine and Medicalized Halacha: An Exploration of Triadic Relations among Israel

Rabbis, Doctors and Infertility Patients. American Ethnologist 27(4):662-680.

Kahn, Susan Martha.

2000 Reproducing Jews: A Cultural Account of Assisted Conception. Durham: Duke University Press.

Kanaaneh, Rhoda

2002 Birthing the Nation: Strategies of Palestinian Women in Israel. Berkeley: University of California Press. 
Katriel, Tamar

1991 Communal Webs: Communication and Culture in Contemporary Israel. Albany: State University of New York Press.

Katz, Ruth, and Yochanan Peres

1986 The Sociology of the Family in Israel: An Outline of its Development from the 1950s to the1980s. European Sociological Review 2(2):148-159.

Kraft, Dina

2011 Where Families are Prized, Help is Free. New York Times, July 17.

Laskov, I., N. Michaan, A. Cohen, Z. Tsafrir, S. Maslovitz, M. Kupferminc, JB Lessing, and A. Many

2012 Outcome of Twin Pregnancy in Women 45 years old: A Retrospective Cohort Study. The Journal of Maternal-Fetal and Neonatal Medicine 26(7):669-672.

Layne, Linda

2003 Motherhood Lost: A Feminist Account of Pregnancy Loss in America. New York: Routledge.

Lemish, Dafna

2000 The Whore and the Other: Israeli Images of Female Immigrants from the Former USSR. Gender and Society 14(2):333-349.

Levine, Nancy E.

2008 Alternative Kinship, Marriage, and Reproduction. Annual Review of Anthropology 37:375-89.

Lewin, Ellen

2009 Gay Fatherhood: Narratives of Family and Citizenship in America. Chicago: University of Chicago Press.

Lieblich, Amia

2003 Seder nashim: sipurei nashim b'mispaha hahadasha b'yisrael

[Women's Order: Women in the New Family in Israel]. Schoken Publishing: Tel Aviv.

Lior, Ilan

2013 Despite the Financial Cost and the Difficulties: A Surge of Appeal in Surrogacy

Abroad. Ha'aretz, June 26.

Lior, Ron

2007 The First in Israel: A Biological Will by Court Approval. Channel 10 News, January 16.

Lis, Yonatan, and Yair Ettinger

2010 Rabbi Shlomo Dichovsky Chosen as Temporary Head of the Religious Courts: The Ashkenazi Haredim Angrily Left the Discussion. Ha'aretz, August 15.

Lomsky-Feder, Edna, and Eyal Ben-Ari

1999 The Military and Militarism in Israeli Society. Albany: State University of New York Press.

Ludtke, Melissa

1997 On Our Own: Unmarried Motherhood in America. New York: Random House.

Luz, Ehud

2003 Wrestling with an Angel: Power, Morality and Jewish Identity. (trans. Michael Swirsky) New Haven: Yale University Press. 
Mamo, Laura

2007 Queering Reproduction: Achieving Pregnancy in the Age of Technoscience. Durham: Duke University Press.

Mannis, Valerie S.

1999 Single Mothers by Choice. Family Relations 48(2):121-128.

Martin, Emily

1991 The Egg and the Sperm: How Science Has Constructed a Romance Based on Stereotypical MaleFemale Roles. Signs 16(3):485-501.

Martin, Lauren Jade

2010 Anticipating Infertility: Egg Freezing, Genetic Preservation, and Risk. Gender and Society 24(4):526-545.

McClintock, Anne

1993 Family Feuds: Gender, Nationalism and the Family. Feminist Review 44:61-80.

McKinnon, Susan

2013 Kinship in and beyond the "Movement of Progressive Societies." In Vital Relations: Modernity and the Persistent Life of Kinship. Susan McKinnon and Fenella Cannell, eds. Pp.39-62. Santa Fe: SAR Press.

McKinnon, Susan, and Fenella Cannell

2013 The Difference Kinship Makes. In Vital Relations: Modernity and the Persistent Life of Kinship. Susan McKinnon and Fenella Cannell, eds. Pp. 3-38. Santa Fe: SAR Press.

Mizrachi, Yossi

2009 Father after Death. First Edition. Channel Two News, December 6.

Morgan, Lynn M., and Meredith W. Michaels

1999 Fetal Subjects, Feminist Positions. Philadelphia: University of Pennsylvania Press.

Mosse, George

1990 Fallen Soldiers: Reshaping the Memory of the World Wars. Oxford: Oxford University Press.

Neumann, Boaz

2011 Land and Desire in Early Zionism. Lebanon, NH: Brandeis University Press.

Ochs, Juliana

2011 Security and Suspicion: An Ethnography of Everyday Life in Israel. Philadelphia: University of Pennsylvania Press.

Peleg, Yaron

2008 From Black to White: Changing Images of Mizrachi Men in Israeli Cinema. Israel Studies 13(2):122-145.

Pfefferman, Talia

2013 Separate Spheres, Intertwined Spheres: Home, Work, and Family among Jewish Women Business Owners in the Yishuv. The Journal of Israeli History 32(1):7-28.

Pitkowsky, Michael

2011 "Dear Rabbi, I Am a Woman Who...": Women Asking Rabbis Questions, from Rabbi Moshe Feinstein to the Internet. Nashim 21: 134-159. 
Portugese, Jacqueline

1998 Fertility Policy in Israel: The Politics of Religion, Gender, and Nation. Westport, CT: Praeger.

Rabinowitz, Dan

2002 Oriental Othering and National Identity: A Review of Early Israeli Anthropological Studies of Palestinians. Identities: Global Studies in Culture and Power 9:305-324.

Ramon, Einat

2011 Modern Levirate. Ha'aretz, May 31.

Razi, Tammy

2010 The Family Is Worthy of Being Rebuilt: Perceptions of the Jewish Family in Mandate Palestine, 1918-1948. Journal of Family History 35(4): 395-415.

Regev, Dor

2011 Thanks to Egg Freezing: Keren Became a Mother after Her Death. Yediot Ahronot, June 13.

Remennick, Larissa I.

1999 Women with a Russian Accent in Israel: On the Gender Aspects of Immigration. European Journal of Women's Studies 6:441-61.

2004 Providers, Caregivers, and Sluts: Women with a Russian Accent in Israel. Nashim 8:87-114.

2006 The Quest for a Perfect Baby: Why Do Israeli Women Seek Prenatal Genetic Testing? Sociology of Health and Illness 28(1): 21-53.

Robertson, John A.

2003 Children of Choice: Freedom and the New Reproductive Technologies. Princeton:

Princeton University Press.

Romain, Tiffany

2012 "Fertility. Freedom. Finally": Cultivating Hope in the Face of Uncertain Futures among Egg Freezing Women. In The Anthropology of Ignorance, Casey High, Ann H. Kelly and Jonathan Mair, eds. Pp. 189-215. New York: Palgrave Macmillan.

Rosenblum, Irit

2010 Biological Will. With Open Doors -Israel Bar Association, February/March: 22-23.

Rosenblum, Sarit

2012 The Fertility Revolution: Hundreds of Women in Israel Freeze Eggs. Yediot Ahronot, May 1.

Ross, Dvora

1998 Artificial Insemination in Single Women. In Jewish Legal Writings by Women, Micah D.

Halperin and Chana Safrai, eds. Jerusalem: Urim.

Ross, Tamar

2004 Expanding the Palace of Torah: Orthodoxy and Feminism. Waltham: Brandeis University Press.

Rothman, Barbara Katz

1986 The Tentative Pregnancy: Prenatal Diagnosis and the Future of Motherhood. NewYork: Viking Penguin.

Rothschild, Sophia

2011 Is There a Solution for a Religious Single Woman who wants a Child? Yediot

Ahronot, November 7. 
Rutlinger-Reiner, Reina

2011 "Drowning in the Marsh": Israeli Orthodox Theatrical Representations of the Singles Scene. Israel Studies 16(3):73-96.

Sa'ar, Amalia

2007 Masculine Talk: On the Use of Masculine Linguistic Forms among Hebrew- and Arabic-speaking Women in Israel. Signs 32(2): 405-430.

2009 Low-Income "Single Moms" in Israel: Redefining the Gender Contract. Sociological Quarterly 50:450-473.

Safrai, Dina

N.d. PUAH Institute - Transparent or Biased Information?

http://www.kolech.com/show.asp?id=34294

Santorum, Rick

2005 It Takes a Family: Conservatism and the Common Good. Wilmington: Intercollegiate Studies Institute.

Schlesinger, Yehuda

2010 A New Halakhic Ruling: Single Women are Permitted to Freeze their Eggs. Israel Ha'Yom, December 19.

Schneider, David M.

1980[1968] American Kinship: A Cultural Account. Second Edition. Chicago: University of Chicago Press.

Second Israeli Broadcasting Authority

2011 Interview with Irit Rosenblum from New Family. Channel Two News, June 13 (11:15am).

Shafir, Gershon

2002 Being Israeli: The Multiple Dynamics of Citizenship. Port Chester, NY: Cambridge University Press.

Shai Shefi et al.

2006 Posthumous Sperm Retrieval: Analysis of Time Interval to Harvest Sperm. Human Reproduction 21(11): 2890-2893.

Shalev, Carmel, and Sigal Gooldin

2006 The Uses and Misuses of In Vitro Fertilization in Israel: Some Sociological and Ethical

Considerations. Nashim 12:151-176.

Shamgar-Handelman, Lea

1996 Family Sociology in a Small Academic Community: Family Research and Theory in Israel.

Marriage and Family Review 23(1-2):377-416.

Shkedi-Rafid, Shira, and Yael Hashiloni Dolev

2012 Egg Freezing for Non-Medical Uses: The Lack of a Relational Approach to Autonomy in the New Israeli Policy and Academic Discussion. Journal of Medical Ethics 38(3):154-157.

Shorter, Edward

1975 The Making of the Modern Family. New York: Basic Books.

Shututland, Ilana, and Shiri Melamed

2009 Revaka + 2, Ma'ariv, April 19. 
Simchen, Michal J., Adrian Shulman, Amir Wiser, Eran Zilberberg, and Eyal Schiff

2009 The Aged Uterus: Multifetal Pregnancy Outcome after Ovum Donation in Older Women. Human Reproduction 24(10):2500-2503.

Smith, Anthony D.

2010 Nationalism: Theory, Ideology, History. Second Edition. Cambridge: Polity Press.

Solomon, Gil

2006 Service for the Soldier: Sperm Inheritance. Ma'ariv, September 15.

Spiro, Melford E.

1996 [1979] Gender and Culture: Kibbutz Women Revisited. New Brunswick, NJ:

2004 Utopia and Its Discontents: The Kibbutz and Its Historical Vicissitudes. American Anthropologist 106(3):556-568.

Strathern, Marilyn

1992 Reproducing the Future: Essays on Anthropology, Kinship, and the New Reproductive

Technologies. New York: Routledge.

Stoller-Liss, Sachlav

2003 "Mothers Birth the Nation": The Social Construction of Zionist Motherhood in Wartime in Israeli Parents' Manuals. Nashim 6:104-118.

Talmon-Garber, Yonina

1954 The Family in Israel. Marriage and Family Living 16(4):343-349.

Tana, Elad

2007 The Rav Cherlow: Birth without Marriage? In Certain Circumstances. Yediot Ahronot, August 20

Taylor, Janelle

2008 The Public Life of the Fetal Sonogram: Technology, Consumption, and the Politics of Reproduction. New Brunswick, NJ: Rutgers University Press.

Teman, Elly

2010 Birthing a Mother: The Surrogate Body and the Pregnant Self. Berkeley: University of California Press.

Thompson, Charis

2005 Making Parents: The Ontological Choreography of Reproductive Technologies. Cambridge: MIT Press.

Tololyan, Khachig

1991 The Nation-State and Its Others: In Lieu of a Preface. Diaspora: A Journal of Transnational Studies 1(1):3-7.

Torres, Einat

2009 To Remember Him Alive: The Berger Couple Leads the Fight to Establish a Repository of Soldiers' Sperm. Ma'ariv, February 12.

Wahrman, Miriam Z.

2002 Brave New Judaism: When Science and Scripture Collide. Hanover: University Press of New England.

Weissenberg, Ruth, and Ruth Landau

2012 Are Two a Family? Older Single Mothers Assisted by Sperm Donation and Their Children Revisited. American Journal of Orthopsychiatry 82(4):523-528. 
Weston, Kath

1991 Families We Choose: Lesbians, Gays, Kinship. New York: Columbia University Press.

1998 Long Slow Burn: Sexuality and Social Science. New York: Routledge.

Willen, Sarah S.

2007 Transnational Migration to Israel in Global Comparative Context. Lanham: Lexington Books.

Yanigisako, Sylvia J., and Carol Delaney

1995 Naturalizing Power. In Naturalizing Power: Essays in Feminist Cultural Analysis. Sylvia J.

Yanagisako and Carol Delaney, eds. Pp. 1-22. New York: Routledge.

Yarkoni, Yoram

2011 In Pain You Shall Give Birth. Yediot Ahronot, March 27.

Yehoshua, A.B.

[1977]1993 The Lover. New York: Harvest.

Yuval-Davis, Nira

1997 Gender and Nation. London: Sage Publications.

Zarhin, Tomer

2011 Parents who Donated Their Son's Organs Request Ownership of His Sperm that was

Frozen after His Death. Ha'aretz, February 7.

Zerubavel, Yael

2006 Patriotic Sacrifice and the Burden of Memory in Israeli Secular National Hebrew Culture. In Memory and Violence in the Middle East and North Africa. Ussama Samir Makdisi and Paul A. Silverstein, eds. Pp. 73-102. Bloomington: Indiana University Press.

Zoll, Miriam

2013 Pregnant at 60. Atlantic Monthly. May 22. 